Redes empresariales marítimo-portuarias en el Pacífico sudamericano

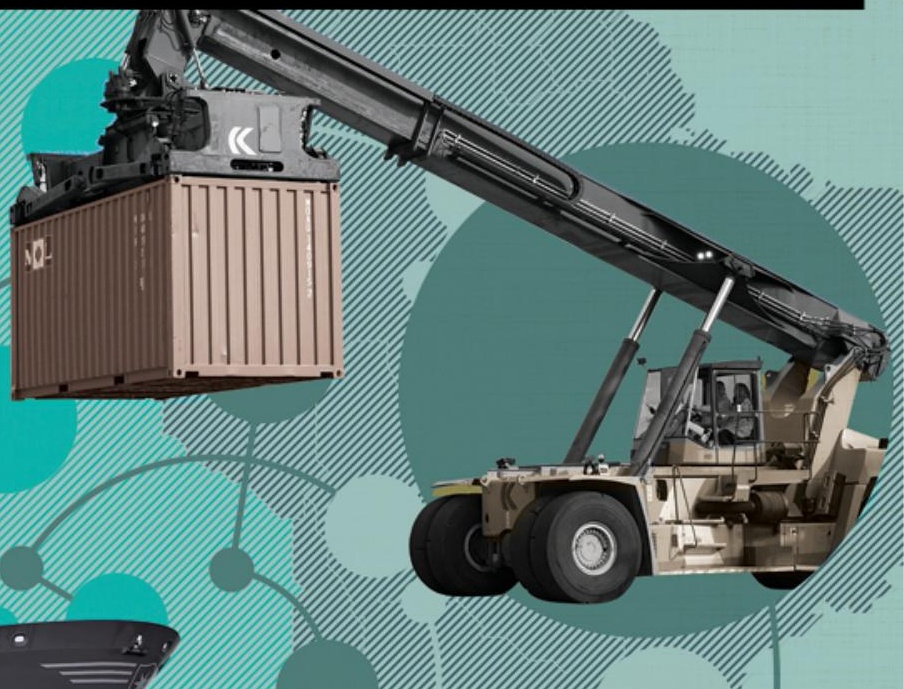





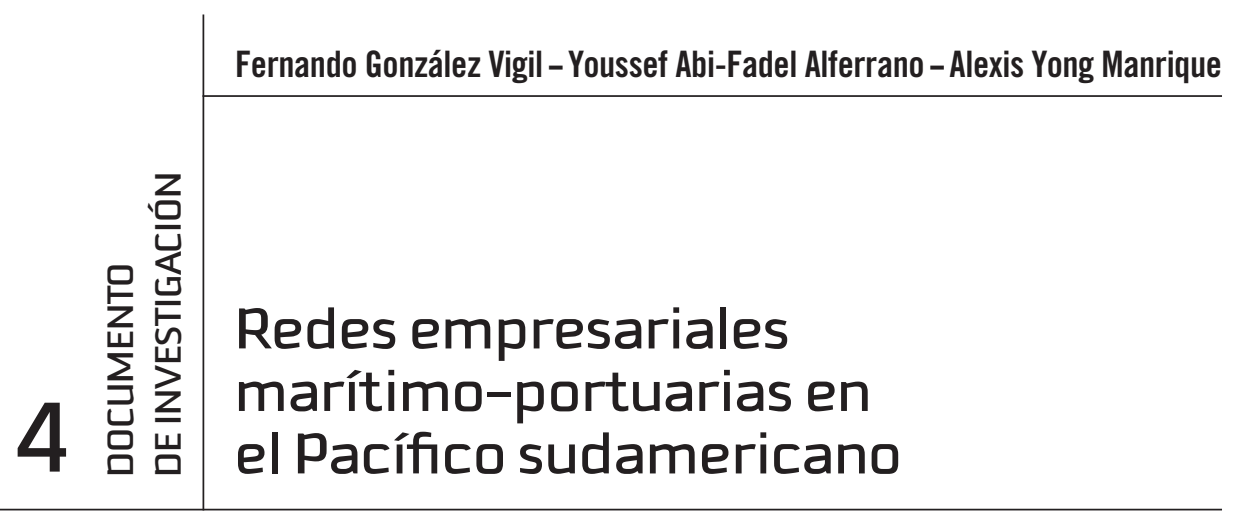


(C) Universidad del Pacífico

Avenida Salaverry 2020

Lima 11, Perú

www.up.edu.pe

\section{Redes empresariales marítimo-portuarias en el Pacífico sudamericano}

Fernando González Vigil

Youssef Abi-Fadel Alferrano

Alexis Yong Manrique

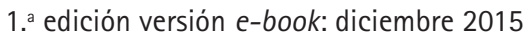

Diseño gráfico: İ́cono Comunicadores

ISBN: 978-9972-57-347-7

doi: http://dx.doi.org/10.21678/978-9972-57-347-7

BUP

\section{González Vigil, Fernando.}

Redes empresariales marítimo-portuarias en el Pacífico sudamericano / Fernando González Vigil, Youssef Abi-Fadel Alferrano, Alexis Yong Manrique. -- 1a edición versión e-book. -- Lima : Universidad del Pacífico, 2015.

209 p. -- (Documento de investigación ; 4)

1. Transporte marítimo -- América del Sur

2. Tráfico marítimo -- América del Sur

3. Puertos -- América del Sur -- Administración

4. Conglomerados (Economía)

5. Redes de empresas

I. Abi-Fadel Alferrano, Youssef.

II. Yong Manrique, Alexis Siwaig.

III. Universidad del Pacífico (Lima)

387 (SCDD)

Miembro de la Asociación Peruana de Editoriales Universitarias y de Escuelas Superiores (Apesu) y miembro de la Asociación de Editoriales Universitarias de América Latina y el Caribe (Eulac).

La Universidad del Pacífico no se solidariza necesariamente con el contenido de los trabajos que publica. Prohibida la reproducción total o parcial de este texto por cualquier medio sin permiso de la Universidad del Pacífico.

Derechos reservados conforme a Ley. 


\section{Índice}

Introducción

I. Marco analítico ...........................................................................................19

1.1 Conceptos básicos para el análisis económico del sector maritimo-portuario 19

Economías de escala y economías de diversificación ...................23

Economías de aglomeración..............................................................26

Economías de fragmentación...............................................................29

Cadenas de valor, redes económicas y economías de densidad....31 Ventaja competitiva: a nivel de la empresa, de la industria y del país o región

1.2 Expansión internacional de redes empresariales maritimo-portuarias .40

Expansión internacional de líneas navieras. 44

Internacionalización portuaria: de operadores portuarios y con líneas navieras 50

Conglomerados, holdings y redes empresariales 54

Concentración de mercado y costos en la cadena maritimo-portuaria

1.3 Estrategias empresariales: tendencias globales y espacios regionales. .66

Competencia por la carga para liderar cadenas de valor 0 cadenas de suministro internacionales

Patrones de transporte hub \& spoke y jerarquías de puertos.....71

Desarrollo portuario: estrategias de regionalización .79

1.4 Hipótesis de investigación .85 
II. Operadores portuarios y proveedores logísticos . .87

2.1 Puerto de San Antonio, Chile

2.1.1 Terminal Sur: San Antonio Terminal Internacional (STI) ...88 Sudamericana Agencias Aéreas y Marítimas S. A. (SAAM) .88

SSA Holdings International Chile Ltd...................................93

2.1.2 Puerto Panul .............................................................................93

Graneles de Chile.......................................................................95

Inversiones Portuarias Ltda. (familia Skalweit

Wachsmann) ................................................................................

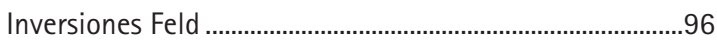

Maritima Valparaiso Chile ....................................................96

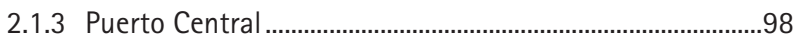

Puerto de Lirquén S. A. ........................................................98

2.1.4 Policarpo Toro (Muelle 9) ......................................................99

Empresa Portuaria San Antonio (EPSA)...............................99

2.1.5 Proveedores logisticos............................................................99

Agencias Universales S. A. (Agunsa Chile) ........................101

Agencias Maritimas Broom S. A.......................................... 102

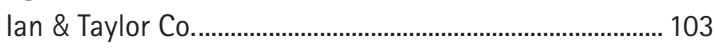

Sudamericana Agencias Aéreas y Marítimas S. A.

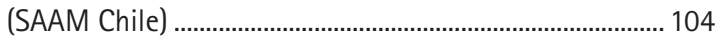

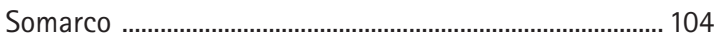

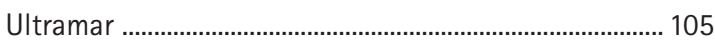

2.2 Puerto del Callao, Perú ............................................................... 106

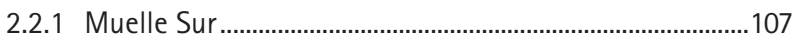

DP World Callao......................................................................107

2.2.2 Muelle Norte............................................................................ 109

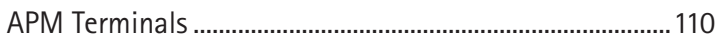

2.2.3 Muelle Centro....................................................................... 111

Cormin Callao S. A. C. .......................................................112

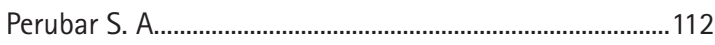

Minera Chinalco Perú S. A....................................................112

Sociedad Minera El Brocal S. A. A. ....................................113

Santa Sofia Puertos S. A.......................................................113

2.2.4 Proveedores logísticos......................................................113

Agencias Universales Perú S.A (Agunsa Perú) ...................116

Inversiones Maritimas Universales Perú S. A. (Imupesa) ... 116 
Petrotankers S. A. C.

Sudamericana Agencias Aéreas y Marítimas S. A.

(SAAM Perú) - Trabajos Marítimos S. A. (Tramarsa) .......117

Andino Investment Holding ..............................................118

Cosmos Agencia Maritima S. A. C.................................... 120

Nautilius S. A ..................................................................... 120

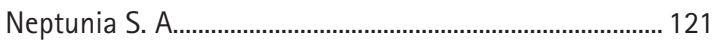

Svitzer Andino S. A. C. ......................................................... 121

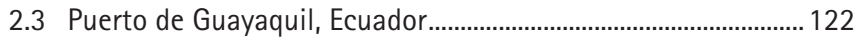

2.3.1 Muelle de contenedores y multipropósito ........................ 122

Contecon Guayaquil S. A. (CGSA) ....................................... 122

2.3.2 Muelle de granos y multipropósito ................................... 124

Andipuerto S. A.............................................................. 124

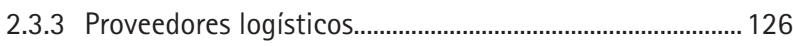

Agencias Universales S. A. (Agunsa Ecuador) ................ 128

Aretina S. A. ...................................................................... 128

Coestibas S. A. .................................................................. 129

Sudamericana Agencias Aéreas y Marítimas S. A.

(SAAM Ecuador) ............................................................. 129

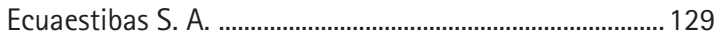

Terminal Portuario de Guayaquil (Inarpi) ......................... 130

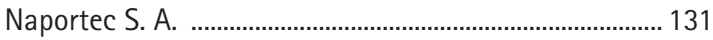

Pozo Servicios Portuarios Cía. Ltda. .................................. 131

2.4 Puerto de Buenaventura, Colombia............................................ 131

2.4.1 Sociedad Portuaria Regional de Buenaventura S. A.

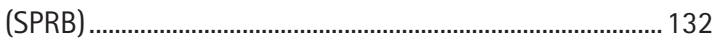

Harinera del Valle S. A. ....................................................... 133

NWS Holdings ..................................................................... 134

Comercializadora Internacional de Azúcares y

Mieles S. A............................................................................. 135

Corporación Brisas del Pacífico S. A. ................................ 135

2.4.2 Proveedores logísticos............................................................. 137

Asistencia Integrada y Cía. Ltda. OP ............................... 139

BGP Container and Logistics S. A.................................... 139

Data Control Portuario S. A................................................ 139

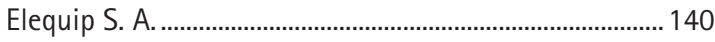

Galotrans Ltd. ........................................................................ 140

Granportuaria Buenaventura S. A..................................... 141 
Nautiservicios S. A. 141

Serteport - Servicios Técnicos Portuarios S. A

Terminal Especializado de Contenedores de

Buenaventura S. A. (Tecsa)

III. Conglomerados empresariales en la COAS ............................................ 143

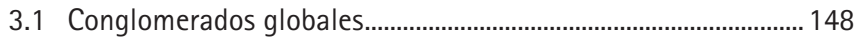

3.1.1 A.P. Møller-Maersk............................................................... 148

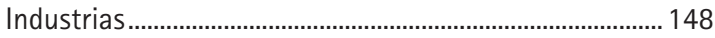

Accionariado ........................................................................ 150

Perspectivas a futuro en el rubro marítimo...................... 150

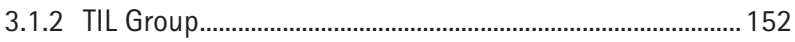

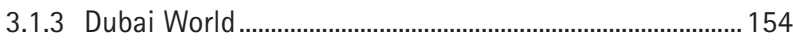

Industrias ........................................................................... 154

Dubai Ports World ................................................................ 156

3.2 Conglomerados regionales................................................................ 158

3.2.1 Compañía Sudamericana de Vapores ............................... 158

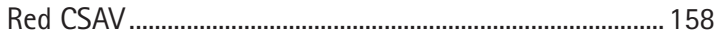

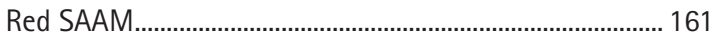

Red Quiñenco ...................................................................... 163

3.2.2 Compañia Chilena de Navegación Interoceánica ........... 165

Red CCNI.............................................................................. 166

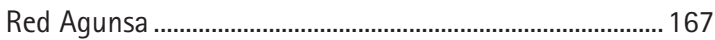

Red Grupo Empresas Navieras......................................... 169

3.2.3 Ultramar Agencia Marítima ..............................................171

Ultragas .............................................................................171

Transmares ............................................................................. 172

Ultratug ........................................................................... 173

Neltume ........................................................................... 173

Ultraterra ............................................................................ 174

Ultramar Network ........................................................... 174

Conclusiones preliminares.................................................................. 175

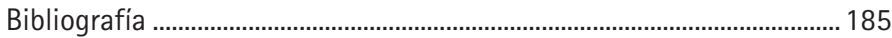

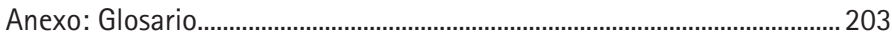




\section{Introducción*}

Este documento versa sobre uno de los temas -referido a redes empresariales marítimo-portuarias- de una investigación más amplia sobre comercio y transporte marítimo. Esta es motivada por el contexto internacional contemporáneo, donde la importancia de los costos de transporte, además de seguir siendo grande en la dinámica de generación y acumulación de «economías de aglomeración» (Krugman 1991: 11, Fujita y Thisse 1996: 365), se ha acrecentado como factor determinante no solo de los costos del comercio, en vista de la considerable reducción de aranceles y otros costos en frontera, sino también de las posibilidades que empresas y países tienen de aprovechar las "economías de fragmentación" ${ }^{1}$ propagadas por cadenas de valor o de suministro internacionales, que interconectan múltiples lugares de producción competitiva a través del planeta y que por ello son intensivas en transporte y muy sensibles a los tiempos de envío (Banco Mundial 2007: 37; Mesquita Moreira, Volpe y Blyde 2008: 1-2).

Puesto que por vía marítima se canaliza alrededor de un 80\% del comercio mundial en volumen y un 70\% en valor (Lugo 2013: 5), nuestra investigación solo aborda el transporte marítimo y está enfocada en su parte más dinámica que es la de carga en contenedores. De hecho, durante el período 1985-2011, el transporte marítimo de contenedores creció a nivel mundial a una tasa promedio

\footnotetext{
* Los autores agradecen a Juan Manuel Hurtado por su valioso apoyo en la primera etapa de recopilación y sistematización de información para los capítulos II y III del presente documento.

1. En la sección 1.1 (capitulo I) del presente documento se definen los conceptos económicos básicos que sustentan el análisis desarrollado a lo largo del mismo, como son los conceptos de economías de aglomeración, economías de fragmentación y otros que en esta introducción se mencionan entre comillas para facilitar su identificación como tales.
} 
anual $(8,8 \%)$ que fue más del doble que la del total de cargas transportadas por vía marítima $(3,6 \%)$, de modo que la participación de los contenedores en dicho total casi se cuadruplicó, al pasar de 4\% en 1985 a un 15\% en los años 2010-2011 (Sánchez 2012: 11, gráfico 8). También es más dinámico el movimiento portuario de contenedores, incluso en América Latina y el Caribe, donde creció durante el período de expansión económica 2002-2007 a una tasa $(14,3 \%)$ que prácticamente duplicó la del movimiento portuario total $(7,3 \%)$ en la región (Cepal 2008, cuadros 1 y 2).

Con lo anterior en mente, nuestra investigación se concentra en los terminales para contenedores de los principales puertos en la Costa Oeste de América del Sur (San Antonio, Callao, Guayaquil y Buenaventura), debido a que la COAS es la zona donde actúan las fuerzas de gravedad económica propias del sector marítimo-portuario que son más directamente relevantes para el Perú. Fuerzas que en gran medida son determinadas por las estrategias de redes empresariales marítimo-portuarias, según enseña la literatura especializada (que se analiza en el capitulo I de este documento) y según se pudo colegir a la luz de nuestros primeros resultados de investigación publicados en 2012.

De hecho, un muy revelador hallazgo inicial provino de la observación de los diferentes trazos de las rutas marítimas utilizadas por líneas navieras y sus efectos distintos en la conectividad marítima de los puertos en la COAS, con un probable impacto desigual sobre la competitividad del comercio exterior de los países involucrados. Con base en data al año 2010, se halló que la conectividad vía el Atlántico de la carga exportadora en contenedores desde los principales puertos de la COAS era facilitada por el uso, por parte de líneas navieras globales, de rutas marítimas con una dirección norte (northbound), congruente con la ubicación en el hemisferio norte de los grandes mercados de destino para dicha carga. Pero la carga similar destinada al noreste de Asia sufría un curioso desvío que perjudicaba la conectividad transpacífica de puertos no chilenos en la COAS, al ser dirigida primero en dirección sur (southbound) hacia puertos chilenos por algunas navieras que en aquel entonces dominaban la carga transpacífica de la COAS. Especialmente por las dos navieras regionales originarias de Chile, la Compañía Suramericana de Vapores (CSAV) y la Compañía Chilena de Navegación Interoceánica (CCNI), con el evidente propósito de aglomerar tal carga en el home port (o "puerto matriz") de cada una (el puerto de San Antonio y el puerto de Valparaíso, respectivamente) y su así manifiesto compromiso con la aspiración de Chile 
de convertirse en el $h u b$ transpacífico de la COAS (González Vigil, Yong y Hurtado 2012: 66-76).

Ese resultado ratificaba lo que había detectado Nathan Associates Inc. en un notable informe técnico enfocado en el puerto del Callao. A saber, la predominancia de recaladas en el Callao con dirección southbound en las rutas de mayor tráfico: durante el período enero-noviembre de 2004, fueron en dicha dirección 219 de las 352 recaladas vía rutas transpacíficas y 187 de las 344 vía rutas que atravesaban el canal de Panamá (Nathan 2005: 47-48). Pero con esa misma data se detectaba una diferencia clave: mientras que un $62 \%$ de la carga exportadora del Callao transportada por líneas navieras globales salía del puerto peruano en dirección northbound, con la transportada por CSAV y CCNI sucedía lo opuesto. Estas navieras chilenas desviaban en dirección southbound el 62\% de dicha carga cuando estaba destinada al noreste de Asia y un 54\% cuando estaba dirigida hacia otros destinos (Nathan 2005: 28-31, 45-51). Un desvío muy significativo, habida cuenta de que por esos años CSAV y CCNI transportaban un 59\% de la carga transpacífica del Callao (22\% en travesías propias y $37 \%$ con alianzas navieras) y un $46 \%$ de la ruteada por el canal de Panamá (19\% en travesías propias y $27 \%$ con alianzas navieras), lo que sin duda perjudicaba al comercio exportador peruano, encareciendo su costo de transporte y demorando su arribo a los mercados de destino.

Otro resultado revelador emergió al contrastar las mejoras en infraestructura portuaria (instalaciones y equipos) con la reducción de costos portuarios, que estaban ocurriendo a raíz del ingreso de operadores portuarios globales a algunos de los principales terminales para contenedores en la COAS. De aquellos solo se pudo dar cuenta con data para el año 2009 en el citado documento inicial de nuestra investigación, porque al elaborarlo no se contaba con data oficial más reciente sobre todos los cuatro puertos de la COAS en estudio. Pero esa data ya permitía observar las primeras mejoras luego de dos concesiones importantes: la habida en 2006, que adjudicó el Muelle Sur del Callao a DPW (Dubai Ports World), por esos años el cuarto operador portuario del mundo según el reconocido ranking que Drewry Maritime Research publica periódicamente; así como la habida en 2007, que adjudicó el Terminal Bolívar de Guayaquil a una subsidiaria de ICTSI (International Container Terminal Services, Inc.), operador filipino que no está entre los top 10 del mencionado ranking pero cuya división de negocios internacionales fue adquirida en 2001 por Hutchison Port Holdings (HPH), por esos años ubicado en dicho ranking 
como el primer operador portuario mundial en términos de movimiento de carga en contenedores ${ }^{2}$.

Dicho resumidamente, se pudo constatar que, pese a los pocos años transcurridos desde aquellas concesiones, en 2009 ya era perceptible su impacto significativo sobre la infraestructura para contenedores en esos dos terminales, especialmente en el Muelle Sur del Callao respecto a calado, longitud de muelle $\mathrm{y}$, sobre todo, a dotación de grúas pórtico y grúas $\mathrm{RTG}^{3}$ (González Vigil et al. 2012: 44-48 [cuadros 14 al 17]). Los puertos del Callao y de Guayaquil estaban así acortando las brechas en materia de infraestructura para contenedores que tenían respecto al puerto de San Antonio, el mejor de la COAS en tal materia hasta el año 2005 según el índice de infraestructura portuaria creado por Belaúnde y Bryce (2006: 26 [cuadro 6]). Esta investigación, que fue asesorada por uno de los autores del presente documento y que incluyó la construcción de otros cinco índices (de costos portuarios, de conectividad, de distancia, de apertura comercial y de tamaño de mercado) más un índice agregado a partir de los seis índices individuales, corroboró las percepciones acerca del liderazgo que San Antonio y otro puerto principal de Chile (Valparaíso) tuvieron durante el primer quinquenio de aquella década, según lo encuestado y sistematizado para el exhaustivo estudio conducido por un equipo de la Universidad Politécnica de Valencia, que encargó la Corporación Andina de Fomento en apoyo a la Iniciativa para la Integración de la Infraestructura Regional en Sudamérica (UPV/CAF/Iirsa 2003: 665-666).

Sin embargo, en lo concerniente a costos portuarios, si bien las tarifas (reguladas) que cobraba DPW por muellaje y embarque/descarga ya estaban nivelando en estos conceptos al Muelle Sur del Callao respecto a sus pares de la COAS, las tarifas en este muelle por reestiba y almacenaje todavía eran caras en comparación con las aplicadas en el terminal para contenedores de San Antonio

2. Posteriormente hubo otros dos ingresos de operadores portuarios globales en la COAS, de cuyos efectos iniciales no se pudo dar cuenta en nuestra publicación de 2012 con data al año 2009. El de APMT (A. P. Møller-Maersk Terminals), segundo en el citado ranking mundial de Drewry, al Muelle Norte del Callao, cuya concesión obtuvo en el año 2011; y el de DPW al puerto de Buenaventura en 2013, cuando adquirió el $25 \%$ de las acciones de la Sociedad Portuaria Regional de Buenaventura y se convirtió así en su principal accionista. En el presente documento ya se da cuenta de ambas presencias, cuyos efectos, junto con los de DPW en el Callao y de ICTSI/HPH en Guayaquil, en infraestructura y costos portuarios, rutas marítimas y en el comercio, serán analizados en posteriores publicaciones.

3. Véanse las definiciones de términos especializados en el glosario anexo a este documento. 
(González Vigil et al. 2012, cuadros 16 y 18). El elevado costo de la reestiba reflejaba el bajo nivel de aglomeración de carga en contenedores que aún tenía el Callao en 2009, probablemente explicado en parte por la alta incidencia que por ese entonces seguían teniendo las rutas marítimas southbound, desviadoras de dicha aglomeración hacia puertos chilenos. Mientras que el elevado costo de almacenaje al año 2009 reflejaba tanto la aún insuficiente dotación de áreas para almacenamiento en el interior del puerto del Callao, como la mayoritaria proporción de carga que aún era almacenada en instalaciones ubicadas fuera del perímetro portuario y en manos de proveedores logísticos empresarialmente ligados a los conglomerados de las navieras chilenas CSAV y CCNI. Al respecto, un notable estudio previo había detectado, con base en data al año 2004, que las tarifas (no reguladas) cobradas por servicios a la carga y a la nave provistos por esos y otros proveedores logísticos tierra adentro, explicaban el $71 \%$ del costo total en que incurrían los dueños de la carga (exportadores e importadores) por el uso del puerto del Callao (Sgut 2005: 33).

Surgieron así interesantes indicios de que lo hallado, sobre trazos de rutas marítimas y sobre calidad portuaria en términos de infraestructura y costos, no estaría detectando hechos inconexos sino relacionados entre sí. Estos de por sí mostraban que la conectividad marítima y la competitividad del puerto del Callao, que, por un lado, eran perjudicadas por las rutas southbound de líneas navieras regionales originarias de un país vecino (Chile) cuyos puertos compiten directamente con el Callao porque están ubicados en la misma costa (COAS) así como por las costosas tarifas de proveedores logísticos en tierra ligados a esas navieras; por otro lado, estaban siendo beneficiadas por las rutas northbound de navieras globales y por las significativas mejoras en calidad de infraestructura aportadas por operadores portuarios globales. Dado que estas diferencias, además de ser muy reveladoras en materia marítimo-portuaria, comportaban diferentes efectos en el comercio de los países de la COAS y del Perú en particular, se justificaba el investigarlas en profundidad. Con miras a ello, las orientaciones conceptuales y metodológicas provistas por el saber especializado resultaron de suma utilidad para enfocar correctamente la investigación.

En efecto, tal como se sustenta en el capítulo I con base en los influyentes especialistas allí citados, el enfoque analítico dominante aprehende al sector marítimo-portuario como un "network secton», donde las respectivas redes empresariales articulan los segmentos mar (líneas navieras), puerto (opera- 
dores portuarios) y tierra (proveedores logísticos tierra adentro) de la cadena marítimo-portuaria. Estas redes compiten entre sí por el control de la carga asociada al comercio marítimo, con el propósito de liderar el soporte logístico requerido por cadenas de producción y distribución internacionales. Para ello, implementan estrategias competitivas cuyas principales diferencias entre sí son reveladas por la configuración de rutas marítimas y la asociada jerarquía de puertos que cada red define en función de su tamaño y alcance geográfico. Ocurre que a menor alcance geográfico de una red, mayor es la probabilidad de que la configuración de su jerarquía marítimo-portuaria favorezca el desarrollo de la capacidad de aglomeración de carga del respectivo "puerto matriz»; es decir, mayor es la probabilidad de simbiosis entre la estrategia de la red empresarial y las estrategias marítimo-portuaria y comercial del país originario de la red. Todo ello con las imaginables consecuencias distintas para el desarrollo marítimo-portuario y comercial de los países vecinos, dependiendo del alcance geográfico y del tamaño de la red que controla sus puertos.

Por ende, el enfoque analítico de redes económicas permite entender las interrelaciones subyacentes en los hechos observados para el caso de la COAS. Estas serían explicadas por diferentes estrategias empresariales a nivel de red marítimo-portuaria, más específicamente por diferencias entre estrategias de redes globales y estrategias de redes regionales. La detección en detalle de tales diferencias y de sus consecuencias sobre el desarrollo marítimo-portuario y del comercio de los países en la COAS, se erigió así como un componente central de nuestra investigación. Esta, teniendo en cuenta que hay consenso entre los especialistas (como se verá en el capítulo I) acerca de que la estrategia de una red empresarial marítimo-portuaria se diseña e implementa en función de los intereses que representa la línea naviera o el operador portuario insignia de la red, adopta con sentido práctico las siguientes definiciones que simplifican esta labor investigativa.

Una red marítimo-portuaria es aquí definida como "global» cuando su empresa insignia es o una de las top 10 líneas navieras del mundo según el ranking de Alphaliner o uno de los top 10 operadores portuarios del mundo según el ranking de Drewry, en razón de que tal ubicación implica una vasta cobertura geográfica a través del planeta y una muy diversificada orientación regional en cuanto a orígenes y destinos de la carga manejada. Por otro lado, una red marítimo-portuaria es aquí definida como "regional» cuando su empresa insignia es una línea naviera o un operador portuario con muy alta concentración en su 
región de origen como base de los orígenes y destinos de la carga que maneja. Además, para poder dar cuenta de algunas situaciones intermedias, se califica como "emergente» a la línea naviera u operador portuario que muestra estar en camino de convertirse de regional en global, desplegando un proceso de diversificación de la orientación regional de la carga que maneja y apuntalando tal proceso mediante una internacionalización de la cobertura geográfica de su presencia directa con naves propias $\mathrm{u}$ operaciones portuarias a su cargo, según corresponda. Todo ello al año 2013 para el presente documento, por ser el año en que se recolectó la información que le sirve de base ${ }^{4}$.

Cabe reiterar que estas definiciones están motivadas por el propósito práctico de facilitar la investigación empírica, clasificando las redes en pocas categorias (globales, regionales, emergentes) que ordenen el análisis, a sabiendas de que la realidad es siempre más compleja y rica en casos concretos donde son difusos los linderos entre una categoría y otra. Pero también cabe precisar que esas definiciones cumplen tal propósito sin dejar de apoyarse en aportes del saber especializado sobre criterios clasificadores, los cuales son combinados por dichas definiciones de un modo que tiene muy en cuenta lo que se aprende de los especialistas (citados en el capítulo I) sobre el rol clave del control de la carga en las estrategias competitivas de las redes marítimo-portuarias ${ }^{5}$. Esta competencia por la carga en contenedores proporciona a su vez un buen hilo conductor para estimar los efectos de las diferentes estrategias de redes en el comercio de los países donde operan.

Las inclusiones, en el plan de nuestra investigación, de los temas referidos a estrategias de redes empresariales y a trazos de rutas maritimas, representan ambas importantes variantes respecto a algunos de los factores determinantes

4. En la sección 1.2 (capitulo I) se mencionan ejemplos de líneas navieras y de operadores portuarios considerados por esta investigación como globales o regionales o emergentes según dichas definiciones, y su aplicación al caso de los operadores portuarios en la COAS es mostrada en el cuadro 7 (capítulo III).

5. Los criterios de cobertura geográfica y de orientación regional, por ejemplo, que Rodrigue y Notteboom (2011: 12-14) utilizan al indagar acerca de cuán globales son efectivamente los distintos operadores portuarios entre los top 10 del ranking de Drewry, pero que también son útiles para indagaciones análogas acerca de líneas navieras y, por tanto, acerca de redes empresariales marítimo-portuarias aprehendidas como tales. Ambos criterios están presentes en las definiciones que hemos formulado: la cobertura geográfica como criterio de partida subyacente (en la elección de los top 10) para distinguir las redes globales de las otras; y la orientación regional -de la base de carga-como criterio definitorio para caracterizar a una red como regional, así como para observar su eventual salto a la condición de emergente en la medida en que vaya diversificando el portafolio regional de la carga que maneja. 
del costo de transporte -y del costo del comercio, por ende- relievados por Mesquita et al. (2008: 10-11), quienes al respecto se refieren a la competencia entre transportistas (solamente) y no profundizan sobre los trazos de las rutas del comercio internacional. Sin embargo, nuestro plan de investigación sí incluye los otros factores considerados por esos autores. A saber: la composición del comercio, aproximada por ellos vía el coeficiente peso/valor de la carga transportada y por nosotros al enfocar la carga en contenedores; la eficiencia portuaria; y la calidad de la regulación (del sector marítimo-portuario) y de las políticas públicas relevantes, de la comercial en particular. Este factor de políticas y regulaciones es de hecho muy gravitante en todo lo concerniente a un sector como el marítimo-portuario, cuyas características de ser intensivo en regulación y receptor del trato de sector estratégico por parte de la mayoría de países, son reconocidas por los especialistas citados en el capítulo I.

Se ha tenido que realizar la investigación gradualmente, debido a dificultades de acceso a la data necesaria así como a restricciones presupuestarias y de otras índoles. Luego de obtenidos los primeros resultados que se publicaron en 2012, la investigación en detalle de los factores que los explicarían empezó por el análisis de las redes empresariales marítimo-portuarias con presencia importante en terminales para contenedores de los principales puertos de la COAS, cuyos resultados se ofrecen en el presente documento. Estos, conforme fueron encontrados, han ido sirviendo de guía para actualizar el análisis de los cambios en la eficiencia de tales terminales y en los trazos de las rutas marítimas que los conectan, que están ocurriendo a resultas de la acrecentada presencia de redes globales en la COAS. Paralelamente, se ha ido profundizando en el análisis del régimen regulatorio que enmarca el funcionamiento de cada uno de esos puertos. Es así que finalmente se podrá realizar un análisis del impacto combinado de los mencionados factores en el comercio exterior del Perú por vía marítima. Los resultados sobre los factores no abordados en el presente documento serán divulgados en próximos documentos, para después integrarlos todos en un solo texto que será publicado como libro.

Sin duda, esta investigación adolece de varias limitaciones. Las tres principales se derivan de la delimitación del ámbito de estudio y son las siguientes: no se analizan todas las cargas marítimas sino solo la canalizada en contenedores; tampoco se analiza todo el sistema portuario de los países en la COAS sino solo los terminales para contenedores de los respectivos puertos principales; $y$, en lo que específicamente concierne al presente documento, la descripción de 
los proveedores logísticos en tierra no es exhaustiva pues solo cubre a los más importantes de entre los que directamente interactúan con el puerto estudiado y no abarca al resto de la cadena logística tierra adentro. La focalización en la carga contenedorizada, que produce la primera limitación, se explica por lo antes dicho acerca del mayor dinamismo de tal carga así como sobre lo que ello refleja en cuanto a cambios en la composición del comercio exterior y en el asociado coeficiente peso/valor de la carga transportada; mientras que la segunda y la tercera limitaciones se deben sobre todo a que no se pudo contar con el financiamiento que hiciera factible esas extensiones del ámbito de estudio a nivel empírico. A nivel analítico, sin embargo, nuestra investigación sí ha elaborado un marco conceptual (desarrollado en el capítulo I de este documento) que permite aprehender tanto las interrelaciones puerto principal - sistema portuario nacional/regional, como las articulaciones entre los tres segmentos (mar, puerto, tierra adentro) de la cadena logística marítimo-portuaria.

No obstante esas limitaciones, nuestra investigación puede contribuir a que se conozca mejor un tema importante de por sí y para la formulación de políticas, pero poco estudiado académicamente en varios países de la COAS, especialmente en el Perú. Esta subregión marítimo-portuaria tampoco ha sido muy estudiada por connotados expertos de otras regiones, aunque recientemente sí ha empezado a recibir más atención a raíz del creciente ingreso de empresas globales. Además, la mayoría de los informes detallados que periódicamente producen las consultoras y otras entidades privadas del sector, o no están disponibles o, si lo están, no son accesibles para investigaciones con poco presupuesto.

En tales circunstancias, hemos tenido que recurrir a una intensa y perseverante búsqueda de información en la web y a los contados textos impresos accesibles. De estos últimos, los precedentes más relevantes para el caso de la COAS han sido citados en esta introducción. Se ha podido apreciar así lo siguiente: que desde el estudio de UPV/CAF/Iirsa (2003) no se ha hecho, o no está disponible, algo similar para años más recientes; que lo mismo vale a propósito del estudio de Belaúnde y Bryce (2006); y que los estudios de Martín Sgut (2005) y Nathan Associates Inc. (2005) están enfocados en el puerto del Callao. A ellos cabe agregar ahora un par de estudios sobre el caso peruano que son citados más adelante: Fairlie y Queija (2007) y García Marengo (2013).

El presente documento está estructurado de la siguiente manera: en el capítulo I, se desarrolla el marco analítico que orienta a toda la investigación y sustenta 
tanto la hipótesis sobre estrategias de redes empresariales marítimo-portuarias en materia de desarrollo portuario que se formula al final del capítulo, como el detallado mapeo que contiene el resto del documento. En el capítulo II, se identifica a los operadores portuarios y a los principales proveedores logísticos en tierra presentes (al año 2013) en todos o algunos de los cuatro puertos de la COAS aquí estudiados. Los conglomerados globales o regionales de los que esas empresas forman parte son luego reseñados en el capítulo III. Con base en todo lo anterior, las conclusiones preliminares que cierran el documento esbozan, con miras a la verificación de la hipótesis de investigación, las posibles estrategias de que se pueden valer las redes empresariales identificadas, según sean globales o regionales, para aumentar o preservar su control de la carga en contenedores a través del desarrollo de los terminales portuarios a su cargo. 


\section{Marco analítico}

En este primer capitulo, se exponen los enfoques analíticos que sustentan la hipótesis de investigación planteada al final del mismo, así como la necesidad del mapeo detallado de las principales redes empresariales marítimo-portuarias presentes en la COAS que se realiza en los otros dos capítulos de este documento. Con tal doble propósito, se empieza explicando los conceptos más apropiados para un correcto análisis económico del sector marítimo-portuario en su conjunto (sección 1.1) y, en particular, del proceso de expansión experimentado por las empresas más destacadas del sector con la resultante conformación de redes internacionales (sección 1.2), así como de las tendencias contemporáneas que contextualizan las distintas estrategias competitivas de esas redes empresariales según tengan alcance global o regional (sección 1.3). Todo ello con base en valiosos aportes de notables especialistas en esos temas, los cuales son recogidos e interpretados en función de los mencionados propósitos de este capítulo. Por esta razón, corresponde explicitar el descargo de rigor, precisando que los autores del presente documento son los únicos responsables de la interpretación que aquí hacen de tales aportes.

\subsection{Conceptos básicos para el análisis económico del sector marítimo-portuario}

Los especialistas más reconocidos coinciden en que el transporte es un servicio de carácter medular (core service), debido al impacto transversal que tiene sobre la productividad y competitividad de una economía y sobre el bienestar de su población (Mattoo y Stern 2008: 9-10, Findlay 2008: 356357). A lo que se suma la existencia de fallas de mercado, porque el buen funcionamiento de servicios de infraestructura básica requiere de "facilidades (en el sentido de instalaciones o activos económicos) esenciales» (o essential 
facilities $^{6}$, como la nave, el puerto y algunas instalaciones logísticas tierra adentro, en el caso del sector marítimo-portuario), cuya posesión puede conferir un dominio de mercado cualquiera sea la propiedad (pública o privada, nacional o extranjera) de la empresa a cargo. Ambas características explican que esos sectores suelan ser altamente regulados (Mattoo y Sauvé 2003: 2) y que los beneficios de liberalizarlos (en sus distintos modos de suministro contemplados en el GATS ${ }^{7}$ de la OMC) no sean automáticos sino que dependan de la calidad regulatoria y de reformas en políticas complementarias para promover la competencia (Copeland y Mattoo 2008: 84; Mattoo y Stern 2008: 3). Por lo mismo, los costos de transporte son determinados no solo por la geografía y factores económicos, sino también por parámetros de políticas (Findlay 2008: 358-359).

Lo anterior refleja la pugna por cuota de mercado que caracteriza a la competencia imperfecta (cualquiera sea el nivel de concurrencia -o número de empresas- en el mercado), especialmente en mercados donde prima la lógica de acumulación de economías de escala y más aún en aquellos que se estructuran en red (network markets) con el propósito de potenciar esa lógica (Shy 2001: 1, 5), como es el caso del sector marítimo-portuario (Bergantino y Veenstra 2002: 233). En esos mercados, la reducción del costo medio, que certifica la acumulación de economías de escala, depende crucialmente de que la empresa reduzca su costo fijo medio. Para que esta reducción sea mayor que la de los competidores y sostenible en el tiempo, la empresa debe llevarla a cabo no solo a su nivel sino también ganando mercado en el sector donde opera, ya que una vez que la empresa ha incurrido en los costos para dotarse de los activos o capacidades necesarios para reducir su

6. Una essential facility es una instalación o activo no reproducible (en una misma localización) por razones físicas o económicas y que constituye un input clave para un proceso de producción (de bienes y/o servicios), en el sentido de que las empresas no pueden operar en el mercado relacionado si no tienen acceso al mismo. La empresa que lo posee podría asi negar o limitar el acceso a competidores, sin justificación objetiva y con el propósito de dominar el mercado o de reservarlo para si (Eilts y Oxley 2011: 48).

7. El Acuerdo General sobre Comercio de Servicios (o GATS, por sus siglas en inglés) comprende cuatro modos de suministro internacional de servicios: Modo 1, de suministro transfronterizo, cuando la provisión se realiza sin que el proveedor esté presente en el pais donde se recibe el servicio; Modo 2, de consumo en el extranjero, cuando el consumidor se desplaza a otro país para recibir el servicio; Modo 3, de inversión o presencia comercial, cuando el proveedor de un país se establece en otro país para allí prestar sus servicios in situ; Modo 4, de movilidad temporal de personas naturales con fines de negocios, profesionales o técnicos (Adlung y Mattoo 2008: 49). 
costo fijo medio, el costo de expandirse se limita al asociado a los activos o instalaciones adicionales (nuevas naves o terminales portuarios, por ejemplo) que aumenten el mercado a su disposición (Copeland y Mattoo 2008: 95-96). Resultando así que menores serán el nuevo costo fijo medio y el nuevo costo medio agregado de la empresa expandida, no obstante el incremento de sus costos totales (en montos absolutos) que la expansión le acarrea.

Esa retroalimentación -entre los niveles empresa y sector (industrial o de servicios) del proceso de reducción del costo medio- estimula la expansión sectorial y/o geográfica de la empresa, bajo modalidades de «integración» horizontal (cuando la empresa reproduce su negocio inicial en otros lugares; es decir, se expande dentro del mismo segmento del sector) y/o de «integración» vertical (cuando la empresa ingresa a segmentos eslabonados con su negocio inicial «hacia atrás» o "hacia adelante»; es decir, se expande articulando varios segmentos del sector). Ambas pueden llevarse a cabo combinando distintas formas de toma de propiedad o control ${ }^{8}$, como también de acceso a más mercados mediante alianzas estratégicas o acuerdos ad hoc y diversas relaciones colaborativas con otras empresas, aunque sin dejar de competir vía costos o diferenciación de servicios (Vanelslander 2005: 23 y ss.), tal como se verá en la sección 1.2 respecto al sector marítimo-portuario (SMP en adelante, para abreviar).

El mercado se va así concentrando, por mayor tamaño de la empresa y/o del mercado al que puede acceder merced a las redes establecidas con otras empresas, ya que lo uno y lo otro conllevan menores costos fijos y también menores costos operativos (Vanelslander 2006: 17). Ello significa, en el caso del SMP, que si bien la expansión (sectorial y geográfica) -y su concomitante concentración de mercado- es perentoria para las empresas que están en los segmentos del sector más intensivos en capital, como son las navieras y los operadores portuarios (Notteboom 2004: 88), también es necesaria para los proveedores logísticos que están en los segmentos menos intensivos en capital a cargo del manejo y almacenaje de la carga tierra adentro, porque la estructuración en red del sector hace que la lógica de acumulación de economías de escala exista en cada etapa de la cadena de distribución (Gottinger 2003: 6).

8. Entendiéndose por "control» a la capacidad de influir en decisiones, sistemas, métodos o procedimientos; el cual, para una empresa, es mayor cuanto mayor sea su cuota de mercado y/o los beneficios que su influencia reporta a las empresas involucradas (Vanelslander 2005: 39, 44). 
A primera vista, podría parecer ilógica esa dinámica de expansión de empresas y concentración de mercados, en la medida en que produzca sobrecapacidad (en flotas navieras y/o instalaciones portuarias, por ejemplo), aparentemente sin tener en cuenta la existencia tanto del ciclo económico general que repercute en la demanda de transporte marítimo como del ciclo particular al SMP que influye en sus condiciones de oferta, con las eventuales caídas de fletes y rentabilidades en períodos recesivos (Sánchez 2012: 45). Sin embargo, dada la inherencia de lo cíclico en la vida económica y de la competencia imperfecta en los mercados reales, la racionalidad de aquella dinámica consiste en sobresalir en la carrera por reducir costos medios con el propósito de no solo aprovechar mejor los períodos expansivos sino también de no perder cuota de mercado en períodos recesivos.

Asimismo, la racionalidad de la dinámica que no se circunscribe a incrementar el tamaño de la empresa sino también el alcance geográfico de su red para acceder a más mercados, sintoniza bien con tendencias cuyo importante impacto sobre el SMP es resaltado por el Banco Mundial. En particular, con la multiplicación de orígenes y destinos del comercio y su creciente inserción en cadenas de valor globales o regionales, expresiones ambas de la globalización (y regionalización) de la producción. En tal contexto, conforme más países participan como exportadores e importadores de productos (bienes o servicios) con valor agregado, al mismo tiempo que los procesos de producción se descomponen y distribuyen en varios lugares según sus respectivas ventajas de especialización, no solo crecen el comercio intrasectorial (en bienes y servicios) y el comercio de productos intermedios y la densidad de dichas cadenas de valor, sino que también se hacen más intensivos en transporte los sistemas de producción y más dependiente de los costos logísticos su distribución geográfica (Banco Mundial 2007: 3637). De ahí que una red maritimo-portuaria de mayor alcance permita lograr una mayor participación en el transporte y la logística que dan soporte a cadenas de valor o suministro internacionales, además de operar con menores costos medios.

En el sucinto análisis de la economía del SMP que se acaba de realizar, subyacen unos conceptos básicos muy enraizados en las nuevas teorías del comercio internacional y de la organización de mercados y empresas, como son las economías de escala y las economías de scope (o de diversificación o 
de ámbito) respectivamente. Las concreciones en el espacio económico o geográficas de esos conceptos se manifiestan como economías de aglomeración y/o de fragmentación, las cuales dan lugar a complejos sistemas de cadenas de valor y redes económicas que delinean las dimensiones contemporáneas de la ventaja competitiva. Dada la gran importancia de todos estos conceptos para la investigación de la que forma parte este documento, a continuación son brevemente presentados y explicados en los aspectos más relevantes para el análisis del SMP y sus redes empresariales.

\section{Economías de escala y economías de diversificación}

A nivel abstracto se distinguen dos tipos de economías de escala (EE en adelante, para abreviar), definidas como las ganancias de eficiencia expresadas en la reducción del costo medio lograda cuando la producción aumenta en mayor proporción que los recursos utilizados para producir. Los dos tipos son las EE internas y las EE externas, según la reducción del costo medio dependa del tamaño de la empresa o del tamaño de la industria, respectivamente (Krugman y Obstfeld 1995: 140, 142).

La teoría elemental aborda cada tipo de EE por separado (o en equilibrio parcial). Bajo EE internas, la competencia monopolística se da entre un número limitado de empresas con alta cuota de mercado, que buscan incrementarla diferenciando sus productos con el propósito de que las resultantes variedades tengan calidades o presentaciones distintivas. De modo que, cuando el tamaño del mercado crece debido al comercio, se entabla un patrón de comercio intraindustrial que beneficia a productores, consumidores y países involucrados. A los productores, porque ganan EE al producir a menor costo medio la(s) variedad(es) en que se especializan. A los consumidores, porque obtienen a menor precio una gama más amplia de variedades. A los países, en la medida en que logren ser partícipes de aquel dinámico patrón de comercio, lo cual depende de que cuenten con empresas capaces de liderar especializaciones eficientes propulsoras de las mencionadas ganancias en productividad y bienestar (Krugman y Obstfeld 1995: 147, 162).

Mientras que bajo EE externas, de las que también son protagonistas empresas pequeñas, la acumulación de EE ocurre al nivel de la industria, conformada por empresas de variado tamaño que están lo suficientemente 
próximas entre sí para que puedan realizar en conjunto la reducción del costo medio. Así concebidas, las industrias de distintos países difieren entre sí en cuanto a su tamaño (medido por la acumulación de EE lograda) y, por ende, en cuanto al tamaño del mercado donde pueden operar rentablemente. De modo que, cuando el comercio amplía el mercado y aumenta la competencia, los principales exportadores serán de países dotados de industrias con altos niveles de acumulación de EE externas y no de países rezagados al respecto, pese a que entre estos últimos haya países con menores costos de factores. Por ello, muchos países implementan diversas políticas gubernamentales -e incluso políticas industriales activas- para capear fallas de mercado que ralentizan el desarrollo de EE. Los países rezagados en la materia lo hacen con el propósito de sumar ventajas de EE a sus ventajas de costos factoriales. Los países avanzados, para reforzar su liderazgo con tecnologías y conocimientos sofisticados. Se trata de políticas que, sin duda, arrojan experiencias mixtas de éxitos y fracasos porque son susceptibles de fallar al igual que los mercados de competencia imperfecta (Krugman y Obstfeld 1995: 171-174, 312, 343).

Para una mejor comprensión sobre la aplicabilidad de las teorías sintetizadas en los dos párrafos anteriores (y de las otras por mencionar en esta sección) al análisis del SMP y sus redes empresariales, vale precisar ahora lo siguiente: (1) que la noción abstracta de industria incluye a sectores de servicios transables y a sus respectivas empresas embarcadas en procesos de acumulación de EE externas e internas y, por ende, la competencia diferenciando productos también alude a servicios diferenciados; (2) que la asimilación de (tamaño de) mercado con país no es limitativa, pues se debe a que las teorías del comercio internacional buscan explicar el patrón del comercio entre países, pero el (tamaño de) mercado relevante bien puede ser el de una región o al que tiene acceso una red empresarial (como se verá más adelante); (3) que, por tanto, una alta cuota de mercado es un privilegio no exclusivo de empresas grandes, pues algunas empresas medianas pueden tenerlo en mercados específicos, como es el caso de algunos proveedores logísticos extraportuarios en ciertos mercados regionales o nacionales; y (4) que en materia de intervención estatal, así como en la academia, hay consenso para el rechazo al proteccionismo y a la selección caprichosa de empresas e industrias presumiblemente ganadoras, y también hay consenso a favor de políticas transversales de competitividad (que incluyen el desarrollo 
de EE) así como de la necesidad de regular y fomentar sectores medulares como es el SMP.

Otro concepto aplicable es un legado de las modernas teorías de organización de mercados y empresas: las economías de diversificación o ámbito -más conocidas como economías de scope (ES en adelante, para abreviar)- expresadas en el costo ahorrado por la empresa que produce dos o más líneas de productos combinadamente en vez de por separado (Panzar y Willig 1981: 268-269). Para ello, la empresa debe disponer de "inputs compartibles o comunes» (o sharable inputs) en el sentido de útiles para producir varios productos, los cuales son activos especiales e indivisibles, físicos (instalaciones, equipos) e intangibles (conocimientos y habilidades empresariales) (Teece 1980: 223). Nótese, respecto a los activos físicos, la similitud con la ya mencionada noción de "facilidades esenciales». Por ello, en el caso del SMP, ejemplos importantes de "inputs compartibles» son las naves y terminales portuarios y almacenes en tierra, en tanto que permiten que sea más eficiente proveer los respectivos servicios a varios productos y clientes en vez de solo a unos (Crampes 1999: 11, 13). Esta ejemplificación es válida con mayor motivo al tener en cuenta que el concepto de ES se extiende a la diversificación de mercados para un tipo de productos y que también es aplicable al análisis de redes económicas (que se verá más adelante), en cuyo caso las ES se definen como las ganancias en eficiencia resultantes de la operación conjunta de los componentes complementarios de la red (Economides 1996: 677).

Los modelos teóricos elementales cumplen su cometido analizando los temas por separado para poder estilizar sus aspectos fundamentales. Pero en la realidad los fenómenos suelen ocurrir simultáneamente, observándose así múltiples combinaciones de EE -externas e internas- con ES que dan lugar a economías de aglomeración y/o economías de fragmentación, así como a complejos sistemas de empresas organizadas en cadenas de valor y sistemas de mercados organizados en red. La gravitación y heterogeneidad de estos fenómenos ha estimulado el desarrollo de nuevas áreas de especialidad, en particular de la economía geográfica o del espacio, cuya interrogante de origen es: ¿dónde ocurre la actividad económica y por qué? (Fujita, Krugman y Venables 1999: 1). A continuación, se presentan brevemente los conceptos explicativos de esos fenómenos concretos, tan importantes para el análisis económico del SMP y sus redes empresariales. 


\section{Economías de aglomeración}

Las economías de aglomeración (EA en adelante, para abreviar) son esenciales para entender la racionalidad económica de las configuraciones $h u b$ \& spoke propias del transporte marítimo y las jerarquías de puertos que conllevan (tal como se verá en la sección 1.3). Las EA son generadas por la concentración de actividades y factores o recursos económicos en una localización geográfica (Krugman y Obstfeld 1995: 226). El pionero en su comprensión fue Alfred Marshall, quien al analizar las razones económicas explicativas de los "distritos industriales» que afloraron con la revolución industrial y la asociada urbanización, planteó que las empresas aglomeradas pueden lograr un desempeño mejor que estando aisladas, debido a que el mercado ampliado consolidado con la aglomeración facilita la disponibilidad de factores productivos y de proveedores y clientes especializados, así como la propagación de conocimientos (Marshall 1890: 225 y ss., Krugman 1991: 36-38). A estos beneficios aglutinantes se les conoce como "externalidades marshallianas".

Paul Krugman profundiza notablemente al respecto, mediante un análisis con dimensión espacial que bien podría interpretarse como una aplicación del fenómeno de la gravedad a la economía. En efecto, según dicho autor, el espacio económico se desarrolla desigualmente, siguiendo un patrón centro-periferia ( $h u b \&$ spoke), resultante de un proceso de causación acumulativa determinado principalmente por la interacción entre variables como las siguientes: tamaño (y dinamismo) del mercado, tipos de EE, costos de transacción a distancia (costos de transporte y comunicaciones, sobre todo), movilidad de factores de producción y proporción de industrias -de bienes y/o servicios- trasladables (porque son intensivas en factores móviles). Si esa movilidad y esa proporción son altas, la producción tenderá a concentrarse en un número limitado de localizaciones para acumular EE y, debido a los costos de transacción a distancia, las localizaciones preferidas serán aquellas donde el mercado (de factores e insumos para producir y de consumidores) es mayor o más dinámico (Krugman 1991: 11, 98). Nótese que esa interacción acumulativa -o retroalimentación- se da entre variables que evocan a las nociones de masa y distancia, cuyos efectos centro-periferia ocurren en el ámbito de un determinado espacio de gravedad económica, específico y relevante para el tema que se investiga. Por ejemplo, la COAS es el espacio de gravedad económica relevante para los fines de nuestra investigación, 
a juzgar por sus hallazgos iniciales (González Vigil et al. 2012) que hemos comentado en la introducción del presente documento.

Ahora bien, la retroalimentación gravitacional alberga tanto fuerzas centrípetas como fuerzas centrífugas. El incentivo que empresas y trabajadores tienen para congregarse donde hay más recursos para producir y consumir (el centro), convive tensamente con el reto de extender los confines del mercado para continuar ganando EE y posibilidades de consumo. De ahí que la retroalimentación concentradora no ocurre en la misma dirección siempre. Dependiendo de cómo cambien las mencionadas variables, en el ámbito del espacio gravitacional relevante, el centro existente puede perdurar o ser complementado por centros menores o ser reemplazado por un nuevo centro principal. Por ejemplo, una reducción de los costos de transporte puede (según su intensidad y combinación con eventuales cambios en las otras variables de la interacción) contribuir al surgimiento de una estructura multipolar o a la permanencia de una estructura unipolar (Krugman 1991: 26, 86, 98, 105), pero a lo mejor con otro centro principal emergido en alguna localización competidora dentro del espacio gravitacional relevante. Las políticas gubernamentales pueden inclinar la balanza a favor de uno u otro centro o de una estructura multipolar, dado que regulan la infraestructura básica de transporte y comunicaciones, al mismo tiempo que definen el régimen para inversiones así como los parámetros en materia de movilidad de factores y de liberalización del comercio de bienes y (especialmente de) de servicios (Krugman 1991: 71-72, 90).

La comprensión de la dialéctica económica entre fuerzas centrípetas y fuerzas centrífugas mejora aún más cuando se tiene en cuenta que, si bien el tamaño del centro puede alcanzar un umbral tope a partir del cual los consiguientes costos de congestión y deseconomías de escala pueden inducir a algunas empresas a congregarse en otra localidad, la alta concentración (en el centro) ejerce fuerzas contrapuestas. Ello porque al mismo tiempo que agudiza la competencia-precio y por esta vía genera una tendencia centrífuga para empresas que ven su supervivencia amenazada por ese tipo de competencia, también retroalimenta la tendencia centrípeta al incentivar la competencia por diferenciación (de productos, procesos y gestión) y por esta vía hace a las empresas más dependientes de las externalidades ("marshallianas») propias de la aglomeración (Fujita y Thisse 1996: 363, 369, 371). Cabe precisar que estos autores arriban a esos resultados, tan 
útiles para entender la coexistencia de competencia-precio y competencia-diferenciación en el SMP (que se verá más adelante), analizando un escenario de reducción de costos de transporte.

Bajo un escenario similar, cuando se distingue entre productos (bienes o servicios) diferenciados y productos homogéneos (en el sentido de intensivos en factores relativamente inmóviles), se encuentra que las fuerzas centrífugas predominan si el costo de transporte se reduce más rápidamente para los primeros, mientras que las fuerzas centrípetas predominan si se reduce más rápidamente para los segundos (Fujita y Mori 2005: 3, 20). De ahí que, si bien la disponibilidad de infraestructura moderna y un gran nodo de transporte (es decir, de importantes "facilidades esenciales" e "inputs compartibles») refuerza las fuerzas de aglomeración (Fujita y Thisse 1996: 368) y por ello las ciudades o regiones con buenos puertos tienen ventaja inicial para convertirse en centros, conforme estas se van desarrollando y crece así la proporción de productos diferenciados que ofertan y demandan, también crecerá el peso relativo de otras fuentes de aglomeración distintas al puerto, por lo que llegará a contar más el acceso a un buen sistema integral de transporte y logística que el disponer del puerto como tal (Fujita y Mori 1996: 96).

Asimismo, cuando la reducción del costo transporte va unida al desarrollo de un sistema integral de transporte y logística, el consiguiente crecimiento de la demanda por redistribución de carga puede estimular el surgimiento de nodos (o hubs) para transbordo de carga en localizaciones intermedias entre los centros (Ducruet, Notteboom y Langen 2009: 5). En el caso del SMP, esos hubs de transbordo pueden ubicarse en el foreland y en el hinterland ${ }^{9}$ de una región. Todo lo cual, además de corroborar la posibilidad de equilibrios múltiples planteada por Krugman, tiene mucha relevancia para el cabal entendimiento de los requerimientos e implicancias de las estrategias de desarrollo marítimo-portuario basado en el foreland o basado en el hinterland que se examinan en la sección 1.3.

9. El foreland de un puerto es el conjunto de puertos con los que está conectado vía rutas o servicios marítimos regulares y que están ubicados en los mercados de destino final u origen primario o en lugares para transbordo de la carga operada por el puerto. Mientras que el hinterland de un puerto es el conjunto de mercados, ubicados en el pais donde está el puerto y eventualmente también en países vecinos, cuyo comercio marítimo es operado por el puerto en cuestión (Rodrigue y Notteboom 2010a: 2-3). 


\section{Economías de fragmentación}

Las economías de fragmentación (EF en adelante, para abreviar) son las resultantes de la partición de un proceso de producción previamente integrado, en dos o más partes, componentes o procesos intermedios (Jones y Kierzkowski 2001: 3), para que estos "fragmentos» sean producidos en otros lugares donde pueden hacerlos con los mismos estándares pero a menor costo (Kuroiwa y Heng 2008: 14). Cuando las empresas practican la fragmentación contratando a empresas independientes (outsourcing) en otros países (offshoring), además de la motivación de aprovechar las diferencias en costos de factores y ventajas de especialización que existen entre paises, se suman otras motivaciones como el beneficiarse del mejor conocimiento que los proveedores extranjeros tienen de sus respectivos mercados locales, así como del menor riesgo de interrupciones en la cadena de aprovisionamiento que resulta de contar con una amplia cartera de proveedores (actuales y potenciales) compitiendo entre sí por lograr o mantener los contratos (Jones y Kierzkowski 2005: 10). Ello también se aplica al SMP, donde son muy frecuentes los contratos operacionales entre empresas internacionales y locales (como se verá en la sección 1.2).

Pero esas motivaciones no hubiesen podido concretarse, ni estaría sucediendo el generalizado y creciente recurso a la fragmentación que se observa a nivel internacional, de no haber ocurrido las significativas reducciones en costos de transporte y de comunicaciones que facilitan la coordinación a distancia (Jones y Kierzkowski 2001: 1). Este abaratamiento de costos ha sido posibilitado por los grandes avances tecnológicos habidos en esos sectores de servicios y que dan fluidez a la cadena de distribución internacional (como la contenedorización en lo que atañe al transporte marítimo en particular, y la informática en general), así como por las fuertes EE que predominan en esos sectores y los impulsan a seguir reduciendo costos medios llevando a cabo sus propios procesos internacionales de expansión y fragmentación de los servicios que proveen (Jones y Kierzkowski 2001: 11, 17; Kimura 2008: 39). Es decir, las principales condiciones habilitadoras de las EF son las mismas que hacen posibles las EA: EE y progreso tecnológico, especialmente en servicios.

Otras semejanzas importantes entre EF y EA son la combinación de tipos de competencia que generan y el rol clave de las políticas gubernamentales en el fomento de cada una. Respecto a lo primero, a lo antes examinado sobre 
la interrelación entre competencia-precio y competencia-diferenciación en el marco de EA, cabe agregar ahora que, bajo EF y sin menoscabo de la fuerte competencia-precio inherente a la pugna por lograr los mejores contratos de outsourcing u offshoring, tanto las empresas contratantes como las contratistas se ven incentivadas a competir también por diferenciación, con el propósito de ampliar sus bases de clientes o consumidores, ofreciéndoles productos (bienes y/o servicios) a la medida. Ello con los resultantes niveles superiores de especialización fina y división del trabajo interdependiente entre empresas y países (Jones y Kierzkowski 2001: 9, 18).

Respecto a las políticas gubernamentales, las ya mencionadas razones endógenas que les confieren un rol clave en pro del desarrollo de EA también se aplican para el fomento del desarrollo de EF. Dado que las empresas barajan varias opciones para decidir cómo fragmentan sus procesos de producción y dónde localizan la producción de los "fragmentos" mediante contratos o por cuenta propia, resulta necesario que las políticas transversales de mejora del entorno o clima para la inversión y los negocios en general, sean complementadas por políticas activas orientadas a aprovechar adecuadamente las crecientes oportunidades de especialización fina que brinda la fragmentación. Para ello, se requiere de políticas igualmente finas de atracción de inversión extranjera y de apoyo a empresas locales, dirigidas a fortalecer tanto ventajas especificas de dotaciones factoriales para ciertos "fragmentos» de producción, como también ventajas específicas de localización para que las EF y EA se combinen en determinadas regiones del país (Kimura 2008: 43, 48).

De hecho, aunque a nivel abstracto pueda parecer que las EA y EF apuntan en direcciones opuestas, hacia la concentración las primeras y hacia la dispersión las segundas, en la práctica son complementarias: la fragmentación a nivel de la empresa procede junto con la aglomeración a nivel de la industria en una localización geográfica (Kimura 2008: 42). También se retroalimentan entre sí. Por ejemplo, la fragmentación de procesos intensivos en mano de obra (sean o no de industrias basadas en recursos naturales) y el asociado desarrollo de los necesarios servicios de transporte y comunicaciones, traen consigo una diseminación productiva al mismo tiempo que estimulan aglomeraciones en nuevas localidades (Jones y Kierzkowski 2005: 9). En el otro sentido, si bien las EA incentivan inicialmente la concentración de empresas en el centro, conforme bajan los costos de transporte y crece el comercio, las diferencias en costos factoriales comienzan a predominar y así se va 
haciendo atractiva la relocalización de plantas o procesos hacia la periferia, mientras que en el centro van quedando las funciones propias de la matriz (Fujita y Thisse 2004: 5, 26).

\section{Cadenas de valor, redes económicas y economías de densidad}

Por añadidura, no solo las EA sino también las EF tienen enormes implicancias de economía geográfica, puesto que ambas dan lugar a complejas estructuraciones del espacio económico en la forma de sistemas de cadenas de valor y de redes económicas, de singular relevancia para el análisis del SMP y sus redes empresariales. En efecto, las EF acortan la distancia económica e impulsan por ende la extensión del comercio intraindustrial, permitiendo que abarque también a los productos intermedios y no solo a los productos finales (Jones y Kierzkowski 2001: 10-11), así como la expansión internacional de cadenas de valor y redes de producción y distribución.

Michael Porter definió la cadena de valor (CV en adelante, para abreviar) como el conjunto de actividades interrelacionadas que se desempeñan para diseñar, producir, distribuir, vender y afianzar (con servicios de postventa) un producto en el mercado ${ }^{10}$, y señaló que la CV de una empresa refleja su historia y estrategia (Porter 1987: 53-54); estrategia que, con el propósito de reducir costos medios (EE) y lograr ventajas de diversificación (ES), conduce a la conformación de sistemas de valor (o CV industriales), que son los entrelazamientos entre la CV de cada empresa y las respectivas CV de sus proveedores y clientes (Porter 1987: 52-53), los cuales pueden estar localizados en distintos países en virtud de las EF. Así, el concepto de CV, inicialmente referido a una secuencia lineal de actividades, ha dado paso al concepto de redes de producción y distribución.

En términos generales, las redes económicas comprenden las complejas combinaciones de interconexiones empresariales en varias direcciones (horizontales, verticales, diagonales) que atraviesan fronteras nacionales y articulan a sus miembros en estructuras estratificadas y flexiblemente jerarquizadas (Kuroiwa y Heng 2008: 11, 13). La profundización del análisis

10. La inclusión de las importantes etapas de diseño y producción diferencia al concepto de CV del concepto de cadena de suministro (supply chain). Sin embargo, varios de los especialistas en el SMP suelen referirse a ambos conceptos indistintamente o al de supply chain con mayor frecuencia. 
al respecto ha gestado la "economía de redes" (o network economics, para ser más precisos), cuyos conceptos básicos son de singular relevancia para entender la dinámica económica del SMP y sus redes empresariales.

Una red económica es, en su definición más simple, un conjunto de nodos interconectados por vínculos (links) con el propósito de transmitir flujos de productos, personas e información (Crampes 1999: 3). Este tipo de organización económica es necesaria cuando para dicho propósito se requiere de varios componentes sistemáticamente articulados (Economides 1996: 674). Entre ellos son esenciales los componentes o activos físicos e intangibles (incluyendo los organizacionales) que constituyen la infraestructura -hard y soft- indispensable para la transmisión de aquellos flujos (Crampes 1999: 10, 15). Haciendo la conexión con conceptos antes explicados, en esa infraestructura física están las "facilidades esenciales» y, junto con parte de la infraestructura intangible, los «inputs compartibles».

De ahí que cuando a sectores de transporte en general y al SMP en particular, que son consensualmente considerados como organizados en red (Gottinger 2003: xvii, 2), se les denomina como servicios infraestructurales, por infraestructura debe entenderse no solo a la física o técnica sino también a los activos organizacionales propios de las empresas o entidades a cargo de las instalaciones esenciales. Por ejemplo, viendo al SMP por el lado del transporte marítimo, los puertos son asimilables a nodos y los links son las navieras y sus rutas marítimas (Bergantino y Veenstra 2002: 233); mientras que viendo al SMP en su conjunto, a esos vínculos por el lado del foreland se deben agregar los links del puerto con su base de carga por el lado del hinterland. En cuyo caso, los activos esenciales son, respecto a los físicos o técnicos, los contenedores, naves e instalaciones del puerto así como los almacenes y zonas logísticas tierra adentro; y, en términos institucionales, son los activos organizacionales de las empresas navieras que recalan en el puerto, del operador del puerto (y/o de la respectiva autoridad portuaria) y de los principales proveedores logísticos que almacenan, manejan y distribuyen la carga en tierra fuera del puerto. En este ejemplo, la CV marítimo-portuaria es la secuencia lineal de los distintos servicios a la nave, a la carga y a los contenedores a lo largo del flujo en el tríptico mar-puerto-tierra.

Esa ejemplificación corresponde a una red empresarial marítimo-portuaria (REMP en adelante, para abreviar) colectiva, conformada por varias empresas 
que han adoptado un sistema operativo como estándar común para organizar la articulación de los componentes que cada una produce o provee. Sin embargo, dado que esa adopción conjunta, por parte de empresas que compiten, supone coincidencias o convergencias difíciles de lograr, especialmente en materia de alineamiento organizacional y estratégico, hay varios casos en que la REMP relevante es la establecida por una sola empresa o conglomerado empresarial. Estas redes individuales son a veces consideradas como sub-redes (Bergantino y Veenstra 2002: 233-234), en razón del frecuente uso de alianzas, consorcios y acuerdos operativos ad hoc entre empresas del SMP (como se verá en la sección 1.2). Además, se verá en el resto de este capítulo que las REMP -sean individuales o colectivas- suelen ser lideradas por navieras o por operadores portuarios y, por tanto, corresponde considerar a una REMP como global o regional a la luz de si la naviera $u$ operador portuario que la lidera es global o regional (según lo definido en la introducción de este trabajo).

Hecha la ejemplificación pertinente, cabe subrayar que los mercados organizados como redes (o network markets, para mayor precisión) son aquellos que proveen bienes y servicios que deben ser usados o utilizados junto con otros productos tangibles e intangibles (Shy 2001: 2); es decir, son mercados que proveen productos -bienes y/o servicios- compuestos (o composite products). Para lo cual, si bien los componentes deben ser técnicamente complementarios para poderlos articular, la complementariedad técnica es un atributo potencial nomás. La complementariedad efectiva solo puede lograrse mediante la adhesión -por parte de las empresas que deciden conformar la red- a estándares compatibles en tanto que mutuamente adoptados. Es decir, la compatibilidad hace efectiva la complementariedad e implica una decisión estratégica (Economides 1996: 676-677, 686), pues trasciende el plano técnico, adentrándose en los sistemas organizacionales y operacionales propios de la empresa (Shy 2001: 2).

De ahí que la mayor dificultad para lograr la compatibilidad no es de orden técnico (especialmente en sectores como el SMP, debido a la generalización del contenedor y la asociada estandarización de las especificaciones técnicas para instalaciones y equipos portuarios), sino que reside en la alineación de los incentivos para compatibilizar y de los costos que ello involucra. Los incentivos están en relación directa con la cuota de mercado y las utilidades que la compatibilidad redituaría a cada empresa, mientras que los costos dependen 
de la parte que cada empresa tendría que asumir del costo de la adopción del estándar común (Katz y Shapiro 1985: 439) y del costo de coordinación que exige la mantención de la red (Bergantino y Veenstra 2002: 246).

Fácilmente pueden diferir las respectivas evaluaciones de costo-beneficio por parte de las distintas empresas, especialmente porque estas difieren en cuanto a su alcance geográfico (global, regional, local), y por ello les impactan diferentemente los distintos efectos concretos en cuotas de mercado según ámbito geográfico (global, regional, local) que tiene la estandarización para compatibilizar, por ejemplo, trazos de rutas marítimas y las asociadas jerarquías de puertos (Bergantino y Veenstra 2002: 236). Como resultado, habrá empresas a las que les convendrá la compatibilidad y otras a las que les convendrá la incompatibilidad, y entre ambos extremos estarán las que optarán por alguna mezcla de compatibilidad/incompatibilidad parcial (Katz y Shapiro 1985: 425, 432; Economides 1996: 686-690), con la consiguiente posibilidad de equilibrios múltiples en cuanto al número de miembros de la red y su evolución en el tiempo (Crampes 1999: 24-26).

Esa opción mixta supone el recurso a interfaces que, a la manera de adaptadores o convertidores, permiten la interoperabilidad en ausencia de compatibilidad completa (Katz y Shapiro 1985: 424, 426; Economides 1996: 686-687). Por esta razón, es una opción frecuentemente adoptada en el SMP, donde la función de interfaz es cumplida por nodos intermedios (Crampes 1999: 4), es decir, por puertos que se desempeñan como hubs de transbordo y/o como centros de carga regionales (o gateway ports), haciendo así posible la coexistencia y competencia entre distintas REMP con diferentes alcances geográficos (global, regional, local) y diferentes configuraciones de rutas marítimas y jerarquías interportuarias.

De lo anterior se deduce que los network markets se caracterizan por la existencia de fuertes relaciones de complementariedad entre los miembros de la red (Economides 1996: 673), regidas mediante acuerdos institucionales entre los miembros plenos que establecen los más avanzados niveles de compatibilidad entre sí y por acuerdos puntuales u ocasionales con los participantes parciales (Birke 2009: 6). También se caracterizan por el carácter específico de su estructuración en el espacio económico (Gottinger 2003: 4). Ello significa que tienen coordenadas geográficas precisas, tanto las complementariedades y decisiones de compatibilidad que les dan forma, 
como sus otras características: a saber, las significativas EE que impulsan las externalidades que generan para cada componente interconectado, así como las diversas prácticas de que se valen para retener (lock in) a miembros y clientes fidelizándolos y/o encareciéndoles los switching costs o "costos de cambiar", de red en este caso (Shy 2001: 1, 4).

De entre esas características, dos han sido las más abordadas por los especialistas: las externalidades y los relacionados efectos económicos, en los análisis teóricos; y las complejas estructuraciones espaciales, en los estudios empíricos. Ambos tipos de aportes serán rescatados y citados durante el análisis aplicado al SMP y sus redes empresariales que se desarrolla en las secciones 1.2 y 1.3; en tanto que en la presente sección, dedicada a los conceptos básicos, a lo ya explicado hasta el momento cabe agregar ahora algo importante sobre las externalidades económicas de las redes.

Respecto a esas externalidades, si bien los teóricos de corte neoclásico, tan fieles a su proverbial sesgo hacia el consumo, empiezan definiéndolas como si consistiesen en que la utilidad que un usuario obtiene del consumo de un bien aumenta con el número de otros agentes que consumen el mismo bien (Katz y Shapiro 1985: 424), estos mismos autores reconocen que cuando se trata de productos durables provistos por redes de servicios (como son las de transportes y del SMP en particular), aquella utilidad depende del tamaño y la experiencia de la red (Katz y Shapiro 1985: 424). La ambigüedad desaparece en el enfoque de Economides, quien plantea que las redes exhiben externalidades tanto de producción como de consumo y precisa que la razón clave de su aparición es la compatibilización de los componentes complementarios que da forma al producto compuesto de la red (Economides 1996: 678-679).

Así, ya que la articulación compatibilizada de los componentes es adoptada por los productores que establecen la red, estos son los principales generadores de las externalidades resultantes del servicio que ofrecen (de transporte y manejo de carga en contenedores, en lo atinente al SMP) y de cuyo desempeño y crecimiento sostenidos están a cargo; mientras que los consumidores (los dueños de la carga, en el caso del SMP) solo hacen uso del servicio existente en el momento en que lo necesitan (Bergantino y Veenstra 2002: 238). Ello implica que los productores de la red son los que hacen posible las respectivas economías de densidad (ED en adelante, para abreviar), entendidas como las resultantes de la cantidad de agentes 
interconectados por la red y la asociada cantidad de flujos que esta transmite (Crampes 1999: 17). Por tanto, los productores (de la red) son los gestores de los beneficios que tanto ellos como los consumidores obtienen debido a las EE y ES resultantes de la operación más eficiente -porque compatibilizada y conjunta- de los componentes complementarios de la red, así como debido a las economías derivadas del tamaño y/o densidad de la red (Economides 1996: 677, 679).

Todo lo anterior explica a su vez el importante rol que tienen las políticas gubernamentales -transversales y selectivas- en materia de redes económicas, especialmente en sectores medulares como es el SMP. La misión esencial propia de las políticas públicas, de velar por una sostenida mejora del bienestar general concertando intereses de consumidores y productores, emerge endógenamente de la naturaleza misma de las redes económicas, en tanto son creaciones institucionales (según lo antes examinado). Los párrafos precedentes han enfatizado el papel de las empresas debido a que este documento está enfocado en redes empresariales, pero lo real es que las redes económicas son conjuntos organizados de funciones y operaciones interconectadas, desempeñadas algunas por empresas (apoyadas por sus respectivos gremios y otras asociaciones privadas) y otras por entidades públicas (como las autoridades portuarias, por ejemplo). Así como también es real que las estructuras de las redes suelen atravesar límites empresariales (mediante diversas relaciones accionariales y no accionariales) y fronteras nacionales (Henderson et al. 2002: 445-446; Coe et al. 2004: 471-473). De ahí el generalizado despliegue de políticas y regulaciones para convocar a empresas líderes de redes globales e incentivar la inserción de empresas locales en esas redes, con el propósito de mejorar la competitividad y conectividad de la economía nacional en su conjunto y, particularmente, para diversificar su comercio y su atractivo como lugar de inversión.

\section{Ventaja competitiva: a nivel de la empresa, de la industria y del país o región}

El carácter endógeno de los dos elementos - privado y público- de la economía de mercado también se detecta en la forma como la literatura especializada concibe a la ventaja competitiva (VC en adelante, para abreviar), especialmente en el marco de mercados estructurados en red, donde se conjugan EA y EF propulsadas por EE -externas e internas- y ES. Es el caso del enfoque de Michael Porter, quien define la VC a nivel de la empresa, pero luego precisa 
que esa VC solo es comprensible a nivel de la industria, e incluso la articula con la VC a nivel del país que sirve de base doméstica a la empresa (se debe aclarar que, para el nivel país, Porter define la VC del mismo modo que el concepto clásico de ventaja comparativa formulado por David Ricardo), como se verá en este acápite.

En efecto, para dicho autor, la VC nace del valor superior que una empresa es capaz de crear para sus compradores, ofreciéndoles beneficios únicos, o bien beneficios equivalentes a los ofrecidos por los competidores pero a precios menores que los de estos. Pero luego afirma que la herramienta básica para analizar esa VC es la cadena de valor (CV) de la empresa (concepto ya mencionado antes) y su incrustación en un sistema de valor (concepto también mencionado antes). Es a este nivel industrial que se observan las diferencias de desempeño entre la empresa y sus competidores, especialmente en sus respectivas estrategias respecto a los segmentos de la industria y/o a los mercados geográficos que cubren y a los respectivos grados de concentración logrados, mediante procesos de expansión en un segmento de la industria (o «integración» horizontal de la empresa) o entre dos o más segmentos de la industria (o «integración" vertical de la empresa) y/o mediante acuerdos con otras empresas para coordinar o compartir CV (Porter 1987: 20, 51-52). Es decir, el desempeño de la empresa solo es comprensible y evaluable cuando se entiende la estructura de cadenas de valor en que está inserta (Cox 1997: 232, Robinson 2005: 250). Tal estructura de CV entrelazadas también caracteriza a sectores organizados en red, como es el SMP.

Según otro enfoque, los beneficios únicos que plasman el valor superior ofrecido por una empresa emanan de su posesión de recursos o activos especiales, no solo tangibles (equipos, instalaciones) sino intangibles también (knowhow técnico y organizacional, estándares y reputación de calidad, red de contactos y canales de influencia), que en conjunto constituyen las capacidades distintivas con base en las cuales la empresa logra un posicionamiento privilegiado, de liderazgo a nivel de toda la industria o de dominio en un segmento de la misma, dependiendo de su tamaño y alcance geográfico (Wernerfelt 1984: 172-174). Este enfoque, conocido como «basado en recursos" (o resource-based approach), complementa bien al de Porter aportando una importante razón explicativa del posicionamiento privilegiado de una empresa: su posesión de recursos o activos especiales, difíciles de replicar o imitar por los competidores (Panayides y Cullinane 2002: 192). 
Muy reveladoramente, ambos enfoques coinciden en que la VC es un asunto de estrategia, que la empresa implementa para aumentar o mantener las diferencias que la distinguen de sus competidores (Porter 1987: 20, 54), valiéndose de las destacadas capacidades acumuladas en su singular dotación propia de recursos o activos tangibles e intangibles (Wernerfelt 1984: 179, Robinson 2005: 248). Cuando lo anterior se aplica al SMP, los ejemplos clave de activos especiales coinciden, en cuanto a los tangibles, con lo que la literatura especializada antes examinada denomina como "facilidades esenciales» e "inputs compartibles" y son: en el caso de las navieras, el tamaño y gama de capacidades de carga de su flota de naves y el alcance geográfico de sus rutas marítimas regulares; en el caso de los operadores portuarios, el tamaño y alcance geográfico de la red de puertos compatibles (en términos de instalaciones y roles interportuarios) a los que tienen acceso privilegiado; $\mathrm{y}$, en el caso de los proveedores logísticos en tierra, el tamaño y grado de penetración en el hinterland de la cadena de traslado y almacenaje de carga que controlan. En tanto que los recursos intangibles serían el cúmulo de knowhow y otras habilidades específicas (ver arriba) que les han permitido obtener esas posesiones especiales.

Es oportuno recalcar que el desarrollo de esas capacidades sobresalientes no es una proeza solamente empresarial (para el desarrollo del capital humano e institucional, por ejemplo) ni los activos especiales pueden siempre obtenerse sin intervención pública. En sectores de servicios medulares como el SMP, el Estado cumple un rol decisivo, facultando y regulando la posesión de activos esenciales como son las libertades de carga (marítimas y por otros modos de transporte), las concesiones portuarias y las habilitaciones para instalaciones logísticas en el hinterland.

Pero la conjunción público-privada no se limita a esos sectores medulares sino que se extiende reflejando el carácter sistémico de la VC vista en su totalidad. En tal sentido, Porter esclarece el vínculo entre la VC a nivel empresa/industria y la VC a nivel país, cuando afirma que esta última es la productividad de la economía nacional (rescatando así la definición seminal de la ventaja comparativa de un país, legada por David Ricardo) y, puesto que ningún país puede ser competitivo en todo, la mejora sostenida de su productividad promedio es fruto de un proceso dinamizado por empresas e industrias con VC a esos niveles, localizadas en algunas ciudades o regiones del país (Porter 1990: 6-7, 9-10). Específicamente, en aquellas localidades 
con mejor "diamante» de determinantes o condiciones propicias, en términos de factores de producción, demanda, actividades de apoyo o relacionadas, estrategias empresariales y rivalidad entre empresas. De ahí la importancia de la concentración geográfica de empresas/industrias y de las políticas públicas, incluyendo las de los gobiernos regionales y locales (Porter 1990: 29, 71 y ss.).

Si bien Porter se refiere al país de origen de las empresas e industrias que analiza, el "diamante» de competitividad-país que formula también es aplicable (con los ajustes del caso) a un país receptor de inversión extranjera directa, ya que tanto su enfoque como el «basado en recursos» son fácilmente conectables con el paradigma planteado por John Dunning para explicar los determinantes de la inversión directa en distintos países por parte de empresas multinacionales. Según ese paradigma, la empresa multinacional confronta las ventajas de propiedad y de internalización que posee frente a empresas competidoras en determinados mercados, con las ventajas de localización que ofrece un país en comparación con otros a la luz del motivo para invertir que tiene la empresa multinacional.

Las ventajas de propiedad en cuestión son definidas por Dunning en términos muy al estilo del enfoque "basado en recursos», como emanadas de la posesión privilegiada de activos especiales y del control de actividades transfronterizas con valor agregado; mientras que las ventajas de internalización son las resultantes de realizar por cuenta propia actividades (de producción y comercialización) interrelacionadas o eslabonadas entre sí, en vez de mediante transacciones con empresas independientes, para obtener rentas cuasimonopólicas aprovechando fallas de mercado. Con base en ambas ventajas, la empresa multinacional compara las ventajas de localización que ofrecen distintos países en función de lo que motiva su inversión (Dunning 1992: 79-80).

Dunning clasifica dicha motivación en cuatro tipos: buscadora de recursos $(\mathrm{BR})$, de mercado (BM), de eficiencia (BE) y de activos estratégicos (BAE). La BR puede serlo de recursos naturales, mano de obra o activos especiales locales. La BM puede serlo para bienes y/o servicios $\mathrm{y}$, además, ya no se limita al mercado doméstico del país receptor sino que busca mercados ampliados conformados por acuerdos de libre comercio o de integración económica entablados por dicho país, por lo que se trata de una inversión 
muy influenciable por EA. Ambas cosas (bienes y/o servicios, mercados ampliados) también valen para la BE, la cual busca aprovechar diferencias entre países en cuanto a costos de factores y/o EE o especialización fina, por lo que se trata de una inversión guiada por EF. En tanto que la BAE es una variante de la BE muy presente en las actividades de alta tecnología y servicios sofisticados, donde la creación de activos originales es vital para el sostenimiento de la VC (Dunning 1992: 56-61). Cada una de estas motivaciones implica ventajas de localización específicas distintas, pero combinables porque dichas motivaciones no son excluyentes entre sí, y es la responsabilidad de cada país el desarrollar su "diamante» guardando congruencia con la evolución de su dotación de factores y empresas y de su productividad promedio.

Con la ayuda de los conceptos básicos explicados en esta sección, en la siguiente sección se examina la expansión internacional de las redes empresariales marítimo-portuarias, y en la subsiguiente, las tendencias actuales que contextualizan las distintas estrategias competitivas de esas redes según sean globales o regionales.

\subsection{Expansión internacional de redes empresariales marítimo-portuarias}

En la sección anterior, se explicó que una red marítimo-portuaria incluye, en su noción más amplia, a las entidades públicas que definen las políticas o regulaciones del sector y a las que desempeñan funciones operativas en el puerto y sus zonas de acceso por mar y tierra. Estas funciones son de verificación de los procedimientos aplicados a la carga en frontera y para su circulación en el territorio nacional, así como de seguridad y control de naves y contenedores. Sin embargo, también se ha explicado que en este documento el énfasis está puesto en los actores empresariales de la red; es decir, en la red empresarial marítimo-portuaria (REMP en adelante, para abreviar).

Una REMP es completa cuando está conformada por los tres tipos de proveedores de servicios propios de cada uno de los tres segmentos del SMP: mar, puerto y la relacionada logística en tierra. Para carga en contenedores, esos tres tipos son: las líneas navieras (LN, en adelante) que realizan el transporte marítimo de dicha carga mediante servicios regulares que recalan en el puerto; el operador portuario (OP), que es la empresa (privada o pública) 
a cargo de la gestión de al menos uno de los terminales para contenedores del puerto; y los proveedores logísticos (PL) instalados fuera del puerto, pero que lo utilizan brindando servicios a naves, contenedores y/o de almacenaje, traslado y manejo de la respectiva carga en tierra, en calidad de intermediarios entre los dueños de la misma (exportadores/importadores) y su embarque o desembarque en el puerto ${ }^{11}$ (Frémont 2009: 6-8 y figura 1). Pero, en la práctica, las REMP difieren entre sí en la cobertura de los segmentos del sector, respecto tanto a la principal modalidad con que los cubren (vía "integración» vertical de la empresa líder de la red o mediante vínculos entre empresas), como al grado en que los tienen articulados en cada costa o región donde operan.

En esta sección, se verá que esas diferencias reflejan el desigual nivel de internacionalización de los distintos segmentos del SMP resultante de la desigual expansión internacional de las respectivas empresas líderes, con la consiguiente variedad en matices de compatibilidad/incompatibilidad parcial entre REMP según región portuaria. Se verá que las REMP son lideradas por LN u OP y que las principales de estas empresas son las más globalizadas, mientras que la gran mayoría de PL tiene un alcance local o a lo sumo regional $^{12}$. Ello hace posible que, en una determinada costa o región portuaria, las REMP regionales nativas cuenten con bases de PL más completas o densas que las REMP globales ${ }^{13}$ y las sendas estrategias competitivas reflejen esos distintos niveles de internacionalización y de cobertura de los segmentos del SMP, como se verá en la sección 1.3.

11. Como ya se explicó en la introducción de este documento, solo los OP y los PL son incluidos en el mapeo de las más importantes empresas presentes en los principales puertos con terminales para contenedores de la COAS, que se ofrece en el capítulo II. Esto debido a que tal mapeo sirve para el análisis (que será materia de otro documento de la investigación) de los efectos de esa presencia en la infraestructura de los respectivos terminales y en los costos que enfrenta el comercio exterior que los utiliza. Sin embargo, las principales $L N$ que recalan en dichos terminales y las rutas marítimas que trazan para ello, serán analizadas en otra parte de la investigación dedicada al tema de conectividad marítima.

12. La situación actual en los principales terminales portuarios para contenedores de la COAS constituye una buena muestra del contraste entre la gran presencia de PL regionales o locales y la creciente presencia de OP globales. Este contraste se observa fácilmente al comparar los cuadros 3 al 6, donde se sintetiza el muestreo de los principales $P L$, con el cuadro 7, en el cual se sintetiza la información sobre los $O P$.

13. Tal como se precisó en el acápite sobre cadenas de valor y redes económicas de la sección 1.1, las REMP pueden ser clasificadas como globales o regionales según sean lideradas por una LN o por un OP global o regional; esto último definido a su vez en los términos que fueron precisados en la introducción de este documento de trabajo. 
Esta sección enseña así a no subestimar la importancia de los PL, sin mengua de reconocer el rol protagónico que tienen las LN y los OP en las REMP (Olivier et al. 2007: 5) en razón del peso decisivo de la calidad del transporte marítimo y de la eficiencia portuaria en los costos del comercio exterior (Mesquita Moreyra et al. 2008: 7-10). De hecho, los PL inciden grandemente en los costos marítimo-portuarios, ya que participan, alineados con el OP o compitiendo con este, en la provisión de una amplia gama de servicios a la nave y/o a la carga así como a los contenedores que la portan. Ejemplos de servicios a la nave son el practicaje, el remolque, el bunkering ${ }^{14}$, el avituallamiento (a la tripulación, de víveres y artículos básicos), la reparación y el suministro de partes, entre otros; y son ejemplos de servicios a la carga su embarque o desembarque, almacenamiento y traslado local, consolidación, entre otros (Meersman, Van de Voorde y Vanelslander 2010: 212-214). No obstante la heterogeneidad de tales servicios, su interrelación en cadena es un incentivo para que los principales PL tiendan a no confinarse a un solo servicio y traten de abarcar varios o todos de ser posible, tal como se detalla en el capítulo II y sus respectivos cuadros 3 al 6.

Es menester contextualizar los procesos de internacionalización de REMP que serán examinados en los párrafos siguientes, señalando que han sido posibilitados por una conjunción de propicios cambios técnicos, económicos y organizacionales. En lo técnico, el factor decisivo fue la innovación del contenedor, cual herramienta intermodal idónea para el manejo y traslado de varias cargas como si fuesen una sola a lo largo de los segmentos mar-puerto-tierra (Frémont 2009: 5, 8), facilitando así la interoperabilidad física entre los mismos y los respectivos actores empresariales. El gran incremento en el uso del contenedor (ya mencionado en la introducción) ha sido a su vez impulsado por el creciente proceso de globalización (y de regionalización) económica, que no solo expande el comercio sino que también multiplica sus coordenadas geográficas. Ello con la consiguiente necesidad de soportes logísticos más vastos y densos así como de cambios organizacionales del SMP en su conjunto (Banco Mundial 2007: 36-37), especialmente por parte de las respectivas empresas líderes para aumentar la escala y extender el

14. En el glosario anexo a este documento de trabajo se definen los términos mencionados en este párrafo, la mayoría de los cuales volverán a ser mencionados varias veces en el resto del documento y particularmente en el capitulo II. 
alcance geográfico de sus operaciones (Notteboom 2004: 90); esto último aprovechando las amplias oportunidades de coordinación organizacional a distancia abiertas por otro progreso tecnológico aún más clave y de impacto universal: la informática (Banco Mundial 2007: 42).

Como se verá a continuación, la internacionalización de las REMP está procediendo hasta ahora a través de dos procesos mayores -en el sentido de que ya tienen un alcance global-y que se han superpuesto en el tiempo. El proceso cronológicamente primero tiene como eje al transporte marítimo y es liderado por las principales LN globales. El eje del segundo proceso es la operación portuaria, donde entre los OP líderes globales ya hay algunos pertenecientes a conglomerados empresariales que cuentan con LN globales. De cada proceso son partícipes LN u OP emergentes, en el sentido de que están en vías de trascender sus ámbitos regionales de origen. Mientras que, por comparación con esos dos procesos globales, aún está en ciernes la expansión internacional de PL del SMP, ya que por lo general este tercer proceso sigue estando confinado a los ámbitos regionales de origen y liderado por PL empresarialmente dependientes de los respectivos OP o LN regionales. Pero, por ello mismo, es un proceso que ayuda a entender las posibles diferencias entre REMP regionales y REMP globales en cuanto a estrategia competitiva (véase la sección 1.3).

Lo común a los dos procesos principales es que las empresas se expanden combinando modalidades de «integración» horizontal y vertical, complementadas por cooperaciones estratégicas o tácticas con otras empresas en la forma de alianzas y/o acuerdos operacionales o relacionales de diversa índole; todo ello contando con el apoyo de sus respectivos grupos o conglomerados empresariales e incluso de sus Estados de origen. Va de suyo que tales procesos registran avances desiguales. No solo porque desiguales son los desempeños empresariales y las capacidades gubernamentales para apuntalarlos, sino también porque los conceptos básicos (sección 1.1) enseñan que a lo largo de la cadena no son parejos los incentivos para internacionalizarse. Estos, ceteris paribus, son fuertes para las LN porque en el segmento mar el foreland pesa relativamente más que el hinterland; también son grandes para los OP interesados en tener a su cargo varios puertos que sean nodos importantes; mientras que son ambiguos en el segmento tierra dado el peso decisivo que tiene para los PL el disponer de un hinterland cautivo. 


\section{Expansión internacional de líneas navieras}

El primer proceso involucra al segmento más internacional por naturaleza: el transporte marítimo. Su evolución muestra dos etapas: una desde finales de la década de 1960 hasta mediados de la de 1990, y la otra a partir de entonces. Ambas etapas han sido facilitadas por el uso creciente de naves para contenedores ${ }^{15}$, y responden a la pugna por ganar cuota de mercado ante las exigentes presiones competitivas provenientes tanto del negocio marítimo como de políticas públicas (policy). En efecto, no solo la expansión del comercio manufacturero generador de carga para contenedores y la asociada expansión del comercio de servicios, sino especialmente la globalización de dicho comercio manifiesta en el aumento del número de países que participan del mismo, han desencadenado una creciente competencia entre más LN originarias de los respectivos países. Esta mayor competencia, entre empresas fuertemente apoyadas por sus países de origen que las consideran piezas clave de un sector estratégico (Olivier et al. 2007: 16), fue oportunamente acicateada cuando, a las tradicionales libertades de navegación y carga (excepto para el cabotaje nacional), se sumó la liberalización de fletes marítimos que, al romper carteles tarifarios, sinceró la competencia y convino a gobiernos interesados en que los costos del comercio exterior bajen ${ }^{16}$.

La primera etapa tuvo en la mira la carga contenedorizada del comercio en el hemisferio norte (o comercio Norte-Norte), pues fue dinamizada inicialmente por la recuperación (post Segunda Guerra Mundial) de las economías

\footnotetext{
15. Si bien en 1957 empezó el uso de naves para contenedores por parte de la naviera Sealand (entonces Ilamada Pan Atlantic Steamship), fue en 1966 que esta LN pionera (posteriormente adquirida por Maersk en 1999) se convirtió en la primera en ofrecer un servicio regular (semanal) de transporte internacional con esas naves, en sus rutas entre la costa este de los Estados Unidos y Europa. En aquellos años, se trataba de naves construidas inicialmente para transportar carga a granel, luego convertidas para contenedores y dotadas de grúas a bordo. Fue en 1969 que se construyó la primera nave diseñada especificamente para contenedores y para ser atendida por grúas desde el muelle, pues con la eliminación de las grúas a bordo se ganaba espacio para acomodar contenedores en la nave (Banco Mundial 2007: 38-39). Así, el año 2013 las naves para contenedores han llegado a transportar el $52 \%$ del comercio marítimo mundial en términos de valory a incrementar en casi ocho veces su participación en la flota mundial de naves de carga (Unctad 2013: 38). 16. La antigua práctica de las "Conferencias Navieras" (dominadas por las principales LN de países desarrollados), de fijar fletes maritimos uniformes y manejar fondos comunes de ingresos distribuibles a sus miembros, fue desapareciendo a mitad de la década de 1980, cuando Evergreen (una en aquel entonces emergente LN con sede en Taiwán) fijó fletes individualmente y acto seguido otras $L N$ hicieron lo propio, ya sin reacción contraria por parte de las instancias intergubernamentales que supervisan asuntos del transporte marítimo internacional (Notteboom 2004: 87-88).
} 
europeas y japonesa, y luego por el ascenso de los nuevos «tigres» asiáticos (Corea del Sur, Hong Kong, Singapur y Taiwán), con la resultante expansión del comercio intraindustrial de esas economías con los Estados Unidos. A ese comercio se ha agregado, durante la segunda etapa, el creciente comercio manufacturero Norte-Sur y Sur-Sur, debido al auge industrial de varios países del sureste asiático, a la recuperación económica de otras regiones en desarrollo y de las economías en transición y, sobre todo, al gran ascenso de China y a la emergencia de la India. Por añadidura, gran parte de todo ese comercio generador de carga para contenedores está siendo incentivado por acuerdos de libre comercio en veloz proliferación por prácticamente todo el planeta.

Reflejando lo anterior, entre una y otra etapa ha variado la composición tanto de la élite de LN globales como la del siguiente tramo, conformado por LN emergentes (es decir, que están en vías de convertirse de regionales en globales) y por destacadas LN regionales. Así, la primera etapa fue liderada por LN que dominaban las rutas con los Estados Unidos, como Sealand, Maersk, $\mathrm{APL}^{17}$ y P\&O Containers; seguidas por (en aquel entonces) emergentes LN japonesas como MOL y K-Line (Olivier et al. 2007: 3, 7). Mientras que la segunda etapa ha traído, en lo que va de su desarrollo y según el ranking que Alphaliner mantiene actualizado ${ }^{18}$, a una nueva élite de LN globales donde, entre las diez más grandes, están cuatro de origen europeo y esta vez cinco de origen asiático. Sobresalen Maersk (con matriz en Dinamarca), MSC (Suiza) y CMA CGM (Francia) como las tres mega-LN (con el 37,7\% de la capacidad en TEU de la flota mundial); seguidas por Evergreen (Taiwán), Coscon (China), Hapag-Lloyd (Alemania), CSCL (China), Hanjin (Corea), MOL (Japón) y APL (Singapur). En la decena siguiente, aparecen algunas destacadas LN regionales en vías de convertirse en (globalmente) emergentes, como la chilena CSAV y la UASC (Emiratos Árabes Unidos).

Esas son las LN que van teniendo más éxito en el objetivo de ganar o mantener cuota en el transporte marítimo de carga contenedorizada, en

17. Las siglas en este párrafo (que se usarán en adelante) corresponden a: American President Line (APL), Peninsular \& Oriental (P\&O), Mitsui-OSK Lines (MOL), Kawasaki (K) Line, Mediterranean Shipping Co. (MSC), Compagnie Maritime d'Affrètement Compagnie Générale Maritime (CMA CMG), Cosco Container Line (Coscon), China Shipping Container Line (CSCL), United Arab Shipping Co. (UASC) y Compañia Sudamericana de Vapores (CSAV).

18. Véase "Alphaliner - Top 100: Operated Fleets as per 03 December 2014». En: <http://www.alphaliner. com/top 100/>. Consultado el 3/12/2014. 
un contexto de exigentes desafíos competitivos planteados por fuerzas del mercado acompañadas por medidas de política acomodaticias. De hecho, la ya mencionada liberalización de fletes marítimos se acopló a las fuerzas económicas que presionan a la baja los costos en el segmento mar de la cadena logística para contenedores. Dada la lógica de acumulación de EE (sección 1.1), la fuerte competencia entre LN por captar aquella carga las conduce a aumentar su capacidad de transporte para así reducir costos medios, no obstante la asociada elevación de la intensidad de capital y de los costos totales de sus operaciones, con los consiguientes riesgos de rentabilidad baja o negativa en períodos de poca demanda al vaivén del ciclo económico (Notteboom 2004: 88).

El aumento de la capacidad de transporte marítimo se ha dado a través de dos ejes de acción interrelacionados, que las LN más destacadas han implementado por cuenta propia y/o con otras empresas del SMP, dando lugar a la conformación de REMP, lideradas sea por un grupo de LN (como es el caso usual en las REMP globales, con las notables excepciones de las forjadas individualmente por Maersk [Frémont 2007: 432] y por $\mathrm{MSC}^{19}$ ), sea por una sola LN (como suele ser el caso en las REMP regionales). Un eje de acción, mantenido a lo largo de las dos etapas, es el agrandamiento del tamaño de las naves para contenedores, a lo que durante la segunda etapa se sumó la diversificación de la gama de tamaños de las naves que integran la flota marítima. Ello es insostenible económicamente sin el otro eje de acción, consistente en optimizar el rendimiento de la flota, en términos tanto de acceso seguro a la carga y a las rutas e itinerarios para transportarla, como de uso de la capacidad de transporte de la nave en cada trayecto. La ejecución de este eje ha comprendido acciones por parte de las LN entre sí y respecto a OP, que han cambiado en modalidad o énfasis entre una y otra etapa, como se verá párrafos adelante.

Acerca del tamaño de la capacidad de carga de las naves para contenedores, este creció bastante durante la primera etapa y más aún en lo que va de la segunda etapa. De un rango de 1.000-2.500 TEU a principios de la década de 1970 a 3.000-4.000 TEU en la de 1980, a 4.000-8.000 TEU en la de 1990

19. La sección 3.1 (capitulo III) del presente documento incluye una breve reseña de Maersk y allí también se menciona a MSC, debido a la importante presencia de los OP empresarialmente ligados a estas $L N$-es decir A. P. Møller-Maersk Terminals (APMT) y Terminal Investment Limited (TIL) respectivamente- en el Muelle Norte del puerto del Callao. 
y a más de 10.000 TEU desde la década de 2000 (Banco Mundial 2007: 38, Rodrigue 2010: 8). Pero, si bien la participación en la flota mundial de las naves con capacidad mayor de 5.000 TEU alcanzó un 30\% a mediados de la década de 2000 (versus 0\% al inicio de la década de 1990), seguían siendo significativas las participaciones de aquellas con capacidades en los rangos de 3.000-5.000 TEU y 1.500-3.000 TEU: 28,5\% y 26,9\%, respectivamente (Notteboom 2004: 89 [tabla 1]). Esta (relativamente reciente) diversificación de la flota en cuanto a tamaños de naves, permite atender los distintos volúmenes de carga y recorridos resultantes de la multiplicación de orígenes y destinos del comercio transportable en contenedores, con una adecuada combinación de naves de dimensiones Panamax y post-Panamax ${ }^{20}$ entrelazando las diversas rutas (transoceánicas, pendulares, circunferenciales, entre otras) requeridas por ese comercio. Así se optimiza el desempeño de la flota en su conjunto, teniendo además en cuenta las diferentes capacidades operativas de los puertos y el tamaño de naves que pueden atender sus grúas (Cullinane y Khanna 1999: 204).

En lo relativo a la optimización del acceso a carga y rutas marítimas, el mecanismo utilizado por las LN durante la primera etapa, cuando en muchos países la operación portuaria estaba solamente en manos de entidades o empresas públicas, fue establecer contratos con esos OP que les garantizaran la disponibilidad de amarraderos en los tiempos requeridos por sus itinerarios de transporte, lo que a su vez les aseguraba rutas con los puertos deseados (Notteboom 2004: 88). Conforme las barreras de ingreso a la operación portuaria han ido reduciéndose en la segunda etapa, aquel mecanismo sigue en pie pero ha dejado de ser la única opción para LN destacadas. Ahora estas tienen ante sí la posibilidad, según su envergadura y la importancia del puerto en la mira, de disponer de todas las instalaciones para contenedores del puerto por interpósita vía de un OP empresarialmente ligado a la LN, o de recurrir al mecanismo de terminales dedicados. Ambas opciones, especialmente la primera, han sido abiertas por el otro gran proceso en

\footnotetext{
20. La dimensión que marca la diferencia entre una nave Panamax y una post-Panamax es el ancho de la nave. Si este no excede los 32,2 metros, el máximo permitido por el canal de Panamá (antes de su ampliación en curso), la nave es denominada Panamax porque puede pasar por dicho canal. Mientras que las naves post-Panamax, construidas a partir de la década de 1980, lo han sido con anchos en un rango promedio de 44-46 metros. Otras diferencias de dimensión hacen que en estas últimas puedan caber más de 20 filas de contenedores superpuestas (versus 13 filas en una nave Panamax típica), por lo que solo pueden ser atendidas por puertos dotados de grúas con gran alcance (Banco Mundial 2007: 41).
} 
curso, de internacionalización portuaria, el cual será abordado en el acápite inmediatamente siguiente al actual.

Entretanto, conviene señalar que el significado conceptual de los terminales portuarios para contenedores, de ser "facilidades esenciales" con la misión de funcionar como «inputs compartibles» (sección 1.1), no ha sido contradicho por la privatización de la operación portuaria. Cuando esta es limitada e incipiente, da pie a terminales dedicados, entendidos como aquellos cuya gestión es adjudicada por la autoridad portuaria o el OP público a la(s) LN que invierte(n) en la construcción o mejora o mantenimiento del terminal, la(s) cual(es) logra(n) así no solo un acceso seguro a rutas y carga sino también el control necesario para optimizar la gestión de la cadena logística, minimizando tiempos de espera y demoras en el puerto (Haralambides, Cariou y Benacchio 2002: 22-24; Ferrari y Benacchio 2002: 155-156). Pero con la liberalización del ingreso de LN internacionales a la gestión del segmento-puerto (a través de un OP del mismo grupo empresarial), se observa una tendencia al uso no exclusivo de terminales (de algunos dedicados, incluso) conforme la LN inversora constata que le es más rentable rentar espacios de los mismos a otras LN (Álvarez-San Jaime et al. 2013: 52). Ello permite que se establezcan compatibilidades parciales entre LN y OP de distintas REMP.

En lo concerniente a la optimización del uso de la capacidad de la flota, esta involucra la utilización de la "facilidad esencial" por excelencia en el transporte marítimo -la nave- como un «input compartible» a disposición de varias LN, dando así lugar al establecimiento de compatibilidades entre estas, que pueden ser plenas o parciales dependiendo de si son o no miembros de una misma REMP. Los mecanismos básicos empleados con tal fin desde la primera etapa, son acuerdos operacionales consistentes en alquilar espacios para una travesía de la nave (slot chartering) y/o compartir el acondicionamiento de naves (vessel sharing), no solo ocasionalmente sino para ciertas frecuencias regulares también. En este último caso, dándoles una denominación común al servicio marítimo en cuestión e incluso al consorcio o alianza de LN participantes (D’Arcy 2001: 11-12) ${ }^{21}$. Ambos son acuerdos gana-gana

21. Según este autor, la cooperación operacional entre $L N$, como el slot chartering o el vessel sharing $u$ otras modalidades implementadas en forma ad hoc o mediante alianzas o consorcios navieros, reemplazó a la fijación conjunta de fletes (y tarifas relacionadas) que fuera practicada por las Conferencias Navieras hasta la década de 1980 (D'Arcy 2001: 9-10). 
porque, al mismo tiempo que permiten que las LN globales optimicen el uso de la capacidad de transporte instalada en sus grandes flotas, también sirven para que las LN emergentes y regionales amplíen el alcance geográfico de la carga que manejan más allá de lo permitido por sus propias flotas. Son, por ello, acuerdos muy frecuentes hasta nuestros días.

Sin mengua de los cuales, conforme las presiones competitivas se fueron intensificando en la segunda etapa, algunas de las LN globales han impulsado un mecanismo más ambicioso y complejo de interacción entre sí y/o con LN emergentes y regionales. Se trata de alianzas estratégicas, que denotan compromisos de más aliento entre dos o más LN para interconectar parte de sus respectivas rutas y para colaborar en otras áreas clave del negocio marítimo, tales como la planeación conjunta o coordinación de las capacidades de sus flotas y de las relacionadas inversiones o compras compartiendo los riesgos de estas; para juntas beneficiarse de la consiguiente acumulación de EE en un espacio geográfico más amplio y de la concomitante capacidad de atender sus rutas con mayor frecuencia y calidad (D’Arcy 2001: 45, Bergantino y Veenstra 2002: 237-238). Pero es difícil lograr todo ello con cada LN manteniendo su identidad empresarial propia, de modo que tales alianzas pueden no durar mucho o, de sostenerse en el tiempo, pueden consolidar la existencia de una REMP encabezada por un grupo de LN o bien pueden ser la antesala de la formación de la REMP de una LN; todo ello dependiendo de la periódica evaluación costo-beneficio por parte de cada integrante de la alianza estratégica.

En efecto, la evidencia encontrada por estudios de alianzas estratégicas indica que sus beneficios potenciales no se concretan todos, ya que, si bien mejoran la frecuencia y calidad de los servicios brindados, el ahorro en costos suele ser menor del esperado, especialmente por la dificultad de compatibilizar las rutas (Bergantino y Veenstra 2002: 243-245), y también porque no se reduce la competencia con otras alianzas (D’Arcy 2001: 60) ni los integrantes de la alianza dejan de competir entre sí (Notteboom 2004: 92) ni tampoco se abstienen siempre de incurrir en parasitismo (free-riding) u otros oportunismos. Lo cual implica (sección 1.1) que las externalidades por interconexión y el ahorro en costos medios pueden no compensar los costos de coordinación y por desalineación de integrantes, cabiendo así la posibilidad de defecciones o de recurrir a otras opciones que mejor aseguren el control necesario para maximizar beneficios y racionalizar costos. 
Una opción predilecta para conseguir ese control son las fusiones (mergers) y adquisiciones. La racionalidad económica de las M\&A (por sus siglas en inglés) está siempre guiada, cualquiera sea el sector donde ocurran, por objetivos de tamaño, crecimiento, EE, cuota de mercado y poder económico. En el caso del SMP y las LN en particular, también buscan el objetivo específico de lograr acceso instantáneo a mercados, capacidades instaladas y redes de transporte y distribución. Dadas las altas barreras de entrada al negocio naviero, erigidas por los montos de inversión y el desarrollo de bases de clientes que requiere, las M\&A suelen ser una opción preferible a la apuesta por incursiones nuevas (o proyectos greenfield), pese a no estar exentas de verse complicadas por expectativas erróneas u otros contratiempos (Notteboom 2004: 90). De ahí las M\&A entre LN registradas durante la segunda etapa, sea como mecanismo complementario a las alianzas estratégicas que ha reforzado a unas y recompuesto a otras, sea como palanca para potenciar el liderazgo de LN no integrantes de esas alianzas ${ }^{22}$. En uno u otro caso, las M\&A y las alianzas estratégicas entre LN, al incrementar su capacidad de negociación y con ello el poder del segmento mar frente al resto del SMP, han espoleado el proceso de internacionalización portuaria.

\section{Internacionalización portuaria: de operadores portuarios y con líneas navieras}

El proceso en curso de internacionalización del segmento puerto del SMP, que en lo esencial está guiado por los mismos factores (económicos, técnicos y organizacionales) que impulsan el proceso análogo a nivel del segmento mar, ha sido muy facilitado por las políticas públicas de modernización de puertos y especialmente de liberalización de la función de operación portuaria. Dadas esas políticas y el derivado rol facilitador de la autoridad portuaria, la identificación de los actores empresariales protagónicos del proceso permite distinguir en su evolución dos fases que ahora transcurren

\footnotetext{
22. En lo atinente a $L N$ globales, dos ejemplos de $M \& A$ entre $L N$ integrantes de alianzas son los ocurridos a mediados de la década de 1990, entre APL que era integrante de la Global Alliance y NOL (Neptune Oriental Lines) que integraba la Grand Alliance, y de $P \& O$, integrante de la Grand Alliance, con Nedloyd, que integraba la Global Alliance. A consecuencia de ello, la Global Alliance fue recompuesta y renombrada como New World Alliance bajo el liderazgo de APL/NOL, mientras que la Grand Alliance, liderada por Hapag-Lloyd, resultó reforzada por la fortalecida P\&O Nedloyd (Notteboom 2004: 91 [figura 1]). Mientras que un par de ejemplos de $M \& A$ lideradas por $L N$ no integrantes de esas alianzas son las realizadas por Maersk, cuando hizo dos grandes adquisiciones de un par de LN que estaban entre las cuatro primeras del mundo: de Sealand en 1999 y luego de P\&O Nedloyd el año 2005 (Frémont 2007: 432).
} 
superpuestas. La primera fase se caracteriza por la expansión internacional de OP mediante su «integración» horizontal con alcance global o regional, como reflejo de la expansión internacional de LN bajo los distintos mecanismos de «integración» horizontal vistos en el acápite anterior. La segunda fase está marcada por el ingreso de LN al manejo de puertos a través de OP ligados empresarialmente; es decir, por la expansión internacional de LN «integrando" verticalmente el segmento puerto con el segmento mar a escala global o regional. Se da así la formación de REMP encabezadas por OP o, al alimón, por OP y LN del mismo conglomerado empresarial.

La condición habilitadora de ambas fases fue el declive del monopolio nacional (público o mixto) de la función de operación portuaria y su remplazo por políticas que liberalizaron el ingreso de empresas extranjeras a esa función, usualmente mediante concesiones otorgadas al cabo de licitaciones internacionales (Olivier et al. 2007: 3). La principal razón explicativa de tales reformas es la modernización de una actividad clave para la competitividad nacional como es la portuaria, hecha indispensable ante los altos niveles de productividad en puerto requeridos por naves para contenedores de mayor tamaño (Cullinane y Khanna 1999: 205) y demandantes de montos de inversión portuaria ${ }^{23}$ que, en muchos países, ni el Estado ni las empresas privadas nacionales del SMP pueden financiar por sí solos. Como tampoco pueden garantizar por sí solos los accesos privilegiados a redes externas (de LN y puertos) que aseguren el movimiento de carga necesario para un uso eficiente de instalaciones portuarias muy intensivas en capital. Pero varios países han realizado sus reformas portuarias sin abandonar el tradicional apoyo gubernamental a las empresas nacionales de un sector que consideran estratégico, incluyendo la mantención de subsidios para las actividades en puertos de provincias (Banco Mundial 2007: 26) así como la ejecución de procesos de concesión portuaria dando preferencia a joint ventures con empresas locales, que OP extranjeros suelen aceptar para no perder la concesión y porque necesitan socios locales para el aseguramiento de la base de clientes en el hinterland del puerto (Olivier et al. 2007: 16, 24).

\footnotetext{
23. Según estimaciones para mediados de la década de 2000, a más de US\$150 millones ascendía en ese entonces la inversión en infraestructura y equipamiento (de grúas, en particular) necesaria para habilitar un terminal moderno de contenedores con dos muelles; en nitido contraste con la (comparativamente) ínfima suma de US\$ 1 millón (a precios actuales) que en la década de 1950 costaba la habilitación de un terminal para carga en general (Banco Mundial 2007: 41).
} 
Esas reformas portuarias fueron así muy útiles para que los OP más destacados y/o mejor apoyados por sus países de origen se proyecten internacionalmente y, al conformar sus propias REMP de alcance global o regional, puedan contrapesar, aunque sea parcialmente, el poder logrado por las REMP lideradas por LN, negociando con estas los términos en que obtendrían del puerto mejores servicios a menor costo (Notteboom y Rodrigue 2011: 243, 249). La expansión internacional de esos OP se ha dado mayormente bajo la modalidad de "integración" horizontal en el segmento puerto, tomando a su cargo la gestión de terminales para contenedores y de los relacionados servicios básicos a naves y carga. Esta expansión empezó en ámbitos regionales, teniendo como pioneros en la década de 1980 a OP europeos como Eurokai/Eurogate, aunque solo cobró intensidad a partir de la década de 1990 al calor de las reformas portuarias, cuando desplegaron sus bases transpacíficas OP como HPH, PSA y SSA ${ }^{24}$ (Olivier et al. 2007: 3-4, Notteboom y Rodrigue 2011: 247). De los cuales, los más destacados llegaron a la década de 2000 ubicados entre los cinco mayores OP globales (o mega-OP), como son los casos de HPH y PSA; categoría a la que en esa década se sumaron DPW, luego de exitosos M\&A de otros $\mathrm{OP}^{25}$, el ya mencionado APMT, que el conglomerado Møller-Maersk constituyó en el año 2001, y Cosco Pacific.

Ese ascenso de poderosos OP a lo largo de la primera fase gatilló el desarrollo de la segunda fase de internacionalización portuaria, durante la cual varios conglomerados empresariales liderados por las LN con mejores capacidades y recursos han incrementado fuertemente sus inversiones en terminales de contenedores, desplegando una estrategia de "integración" vertical desde el segmento mar hacia el segmento puerto, con el propósito de que el primero

24. Las siglas en este párrafo (que se usarán en adelante) corresponden a Hutchison Port Holdings (HPH), Port of Singapore Authority (PSA), Stevedoring Services of America (SSA) y Dubai Ports World (DPW). HPH tiene una presencia indirecta en el muelle de contenedores y multipropósito del puerto de Guayaquil, por lo que es mencionado en el acápite 2.3.1 (capitulo II) de este documento de trabajo. SSA forma parte del consorcio San Antonio Terminal Internacional (STI) que obtuvo la concesión del terminal de contenedores del puerto de San Antonio, por lo que es mencionado en el acápite 2.1.1 (capitulo II). En tanto que DPW es mencionado en los acápites 2.2.1 y 2.4.1 (capitulo II) y luego es reseñado en el acápite 3.1.3 (capitulo III), en razón de que está a cargo de la operación del Muelle Sur del puerto del Callao y del terminal de contenedores del puerto de Buenaventura. 25. Dos grandes adquisiciones de otros OP colocaron a DPW en la liga de mega-OP: I a de CSX World Terminals, hecha el año 2005, y la de P\&O Ports, en 2006. También PSA hizo en aquella década importantes MEtA de OP, incluyendo la compra del 20\% del accionariado de HPH el 2006 (Notteboom y Rodrigue 2011:249, 251 [tabla 3]), en virtud de la cual PSA se ubicó desde entonces como el primer OP del mundo en términos de participación accionarial, mientras que HPH ha mantenido su condición de primer OP del mundo en términos de las TEU manejadas por los terminales de contenedores a su cargo (Rodrigue y Notteboom 2011: 11 [tabla 1]). 
no pierda poder de negociación frente al segundo y pueda así asegurarse frecuencias en sus rutas y la carga respectiva (Soppé, Parola y Fémont 2009: 10). Con tal fin, esas LN reorganizaron sus estructuras empresariales desde la década de 1990, creando divisiones portuarias internas o empresas del conglomerado especializadas en la operación portuaria (Olivier et al. 2007: 18-19). Ejemplos de ello son los ya citados casos de Maersk/APMT y MSC/ TIL, junto con los de otras LN globales (tales como CMA CGM, Evergreen y Coscon) cuyos OP empresarialmente ligados operan un gran número de terminales para contenedores a nivel mundial (Notteboom y Rodrigue 2011: 250). Similar estrategia de «integración» vertical ha sido protagonizada por LN y OP regionales en sus respectivos ámbitos geográficos, también a partir de la década de 1990 en el caso de la COAS, como se verá en los capítulos II y III de este documento.

Si bien la pugna entre OP y LN de distintas REMP por controlar el segmento puerto explica el ingrediente defensivo presente en cada fase (de OP reaccionando ante LN en la primera y ambos iterativamente en la segunda), la internacionalización portuaria se da ahora de un modo y en un contexto que generan complementariedades -e incluso convergencias parciales- entre esos OP y LN. No solo porque son finitas las oportunidades de obtener la concesión de un terminal de contenedores importante o de construir uno nuevo. También porque los intercambios y contratos específicos siguen siendo la forma más usual de interacción empresarial en el puerto; $\mathrm{y}$, cuando de por medio hay inversión en el terminal por parte del OP de la LN global, los joint ventures con $\mathrm{OP}$ locales o regionales son más frecuentes que las subsidiarias al 100\% (Soppé et al. 2009: 10, 15). Así, en torno al puerto, se establecen diversas interacciones e interdependencias ${ }^{26}$ entre OP y LN (y los respectivos $\mathrm{PL}$ ) pertenecientes a distintas REMP con diferentes alcances geográficos.

Todos ellos encaran el desafío de funcionar como eslabones eficientes en un contexto de cadenas de valor (CV) o de supply chains (SC) internacionales cada vez más exigentes en cuanto a soporte logístico (Banco Mundial 2007:

26. Al investigar, con base en información para seis mega-OP al año 2003, la variopinta gama de relaciones que estos establecen para los terminales de contenedores que operan (desde simple transacciones de mercado hasta joint ventures), Vanelslander se ve en la necesidad de utilizar catorce criterios (propuestos por Notteboom y otros reconocidos autores) para clasificarlas y analizarlas según su forma legal, duración, actividades y ámbito geográfico cubiertos, número y nacionalidad de participantes, distribución de decisiones y riesgos, entre otros criterios (Vanelslander 2005: 20 y ss.). 
37). Estas requieren de las LN más frecuencias, puntualidad, seguridad y alcance geográfico (Notteboom 2004: 92-93); así como de los OP una amplia cartera de LN que recalen en el puerto y un manejo fluido, puntual y seguro de carga y contenedores (Frémont 2009: 22-23); poniendo a ambos (y a los PL también) en la necesidad de cooperar y complementarse, aunque sin dejar de competir por cierto. Ello significa, a la luz de los conceptos básicos (sección 1.1), la puesta en relieve de la función de interfaz que cumple el puerto o terminal de contenedores, en su condición de "facilidad esencial" e "input compartible» por excelencia en tierra; función que permite el entramado de CV/SC y la coexistencia de distintas REMP con variados niveles de compatibilidad/incompatibilidad entre sí.

\section{Conglomerados, holdings y redes empresariales}

Varias de las expansiones internacionales exitosas corresponden a LN y/u OP miembros de conglomerados empresariales (Olivier et al. 2007: 7), tanto globales como regionales ${ }^{27}$. Estos conglomerados, que abarcan una gran parte de las ramas del SMP e incluso algunas de otros sectores que les son funcionalmente necesarias, suelen tener en su cúspide una organización de holding y, desde la década de 2000, se advierte una mayor presencia de entidades financieras a nivel del holding o como accionistas de sus negocios portuarios (Rodrigue 2010: 3-4). Si bien esto último es considerado por algunos autores como el síntoma de una nueva etapa en la internacionalización del SMP (Pawlik et al. 2011: 321), por ahora hay consenso en que la organización como conglomerado y de su cúspide como holding responde tanto a necesidades financieras como al desafío de articular los segmentos mar-puerto-tierra y las ramas de apoyo, con el propósito de consolidar el desarrollo de REMP que lideren todo el soporte logístico y de transporte requerido por las $\mathrm{CV} / \mathrm{SC}^{28}$-globales o regionales- más dinámicas.

En efecto, entre las empresas pertenecientes a los conglomerados en cuestión, suele haber bancos, financieras y fondos previsionales del país de origen

27. De esos casos exitosos, en el capitulo III de este documento de trabajo se reseñan los ejemplos más relevantes para lo que atañe al ámbito de la COAS, como son los conglomerados globales A. P. Møller-Maersk y Dubai World (al que pertenece DPW) y conglomerados regionales de origen chileno como CSAV/SAAM y CCNI/Agunsa.

28. La anotación compacta CV/SC, que se hace aquí y en párrafos siguientes de este texto, se justifica no solo por la necesidad de abreviarlo sino sobre todo porque la literatura especializada en el SMP que le sirve de sustento suele referirse indistintamente a cadenas de valor o a supply chains. 
del OP y/o de la LN miembro del conglomerado, así como de algunos otros países de la región que les sirven de plataforma para sus operaciones internacionales. Estos miembros financieros son la primera instancia para acceder al financiamiento de los elevados montos de inversión requeridos por flotas marítimas e instalaciones portuarias capaces de movilizar grandes volúmenes de carga (Pawlik et al. 2011: 328). A ese contingente financiero de base se ha sumado el reciente ingreso -vía MctA- de bancos y fondos de inversión globales o de otras regiones, motivados por los ingresos relativamente estables (por comparación con otros sectores) que asegura un sector indispensable para el comercio como es el SMP (Pawlik et al. 2011: 327). Se refuerza así el circuito de apalancamiento entre el conglomerado con su holding de cúspide y el capital financiero global: el primero recurre al segundo para apalancar sus inversiones marítimo-portuarias crecientemente intensivas en capital y, a su vez, la participación en estas le sirven al segundo para apalancar su tasa de retorno y el valor en libros de su capital al sumarle activos con ingresos de largo plazo asegurados por la duración de las concesiones portuarias (Rodrigue y Notteboom 2011: 265).

Sin desconocer esa mutua necesidad de apalancamiento financiero, algunos autores alertan sobre los riesgos de la administración a manos del capital financiero (o "financialización») de activos clave del SMP (terminales o naves) que, por ser "facilidades esenciales" para el comercio y la competitividad de la economía en su conjunto, deben ser administrados con visión de largo plazo y una lógica no simplemente financiera (Rodrigue et al. 2011: 10-14). Según estos autores, la proclividad de esa lógica al lucro de corto plazo puede llevar a que contablemente se infle el valor de tales activos y se recorte su plazo de amortización sin debida cuenta de las variables reales propias del SMP y su ciclo de negocios, y/o a que esos activos sean tratados como un colateral más en situaciones de estrés financiero o crisis. Los mismos autores también alertan sobre los problemas que puede generar el ingreso de entidades financieras con poco arraigo local o regional a un sector como el SMP donde ese arraigo suele ser fuerte, no obstante la internacionalización de sus segmentos mar y puerto. Sin embargo, hay importantes ejemplos de que los activos del sector no han sido incluidos en restructuraciones patrimoniales forzadas por acreedores $^{29}$. Además, a juzgar por las M\&A del tipo aludido en el párrafo

29. Es el caso del conglomerado Dubai World, cuyo holding no se desprendió de su rama portuaria a cargo de DPW cuando enfrentó problemas de deuda en los años 2008-2009. Véase el acápite 3.1.3 (capitulo III) del presente documento. 
anterior, da la impresión de que esa forma de apalancamiento financiero estaría siendo más necesaria para algunas REMP emergentes o regionales ${ }^{30}$.

Al mismo tiempo, a los conglomerados activos en el SMP suelen pertenecer empresas inmobiliarias y del comercio al mayoreo o en retail (Bichou y Bell 2007: 41). Estos miembros resultan cada vez más importantes para esos conglomerados liderados por LN u OP, de cara a la meta de extender su liderazgo a todo el soporte logístico y de transporte que requieren las $\mathrm{CV} / \mathrm{SC}$ internacionales, con miras a la cual enfrentan el desafío de contar con sistemas para distribuir la carga tierra adentro capaces de circularla en volúmenes y tiempos compatibles con los de terminales portuarios capaces de atender eficientemente a naves de gran tamaño (Notteboom y Rodrigue 2008: 157). Este desafío implica articular mejor el segmento tierra con los segmentos puerto y mar.

De cara a tal desafío, los miembros inmobiliarios del conglomerado le sirven a este para disponer de la "bolsa de terrenos» con ubicaciones privilegiadas, alrededor del puerto y en su hinterland, para sus PL y para sus empresas de comercio mayorista o retail en todo el segmento tierra; estas últimas le son a su vez indispensables para el armado de clústeres de proveedores y clientes insertos en las CV/SC ligadas al conglomerado y por ende fidelizados a su LN u OP. Ambas tareas son menos complicadas para las REMP regionales o locales, por ser las más arraigadas en razón de su implantación temprana, y, por ello, también suelen tener mucha capacidad de influir en la economía y política domésticas (Olivier et al. 2007: 20). Es así probable que a esas redes les urja robustecerse financieramente para no perder cuota de mercado en el segmento tierra, ante la necesidad que tienen las REMP globales de completar su internacionalización extendiéndola a ese segmento en las distintas regiones que cubren sus naves y puertos a cargo.

30. Algunos ejemplos de ese tipo de MEtA realizadas entre los años 2006-2008 son: la compra por Goldman Sachs del $49 \%$ del capital de Carrix Inc. (Seattle), matriz de SSA, comprometido para el pago de un préstamo sindicado por Citigroup y otros ocho bancos; la compra por Morgan Stanley del $80 \%$ del capital accionario del Montreal Gateway Terminal; la compra por el Macquaire Bank (Australia) del 40\% del paquete de acciones de Hanjin Line en la operación portuaria de seis terminales (en Long Beach, Kaohsiung, Oakland, Osaka, Seattle y Tokio, respectivamente); la compra por el Ontario Teacher's Pension Fund de las acciones de OOCL (Orient Overseas Container Line) en dos terminales en Vancouvery en otros dos en Nueva Jersey y Nueva York respectivamente; y la compra por RREEF Infrastructure (subsidiaria del Deutsche Bank) de Maher Terminals, OP en British Columbia y Nueva Jersey (Pawlik et al. 2011: 323-324). 
Está aún por verse si el proceso en el segmento tierra, donde hasta ahora prima la dimensión regionalización de la globalización, evolucionará parecidamente o no a lo observado en los segmentos mar y puerto. En estos, lo visto en esta sección confirma lo aprendido de los conceptos explicados en la sección 1.1: la necesidad económica de acumular EE a través de toda la cadena marítimo-portuaria para maximizar las externalidades de su funcionamiento en red, posibilitada técnicamente por la potencial complementariedad entre los segmentos de la cadena, ha hecho que los procesos de expansión internacional de LN y OP combinen «integraciones» (horizontales y verticales) de empresas individuales con una amplia gama de asociaciones y contratos entre empresas, estableciendo así compatibilidades (plenas) de red o (parciales) entre redes. De modo que, en los segmentos mar y puerto, la conformación de REMP globales lideradas por LN u OP de esa categoria, ha procedido dando espacio no solo para la permanencia de REMP regionales, sino incluso para la consolidación de algunas y su salto a la categoría de (globalmente) emergentes.

En tal sentido, respecto al segmento mar es ilustrativo un estudio que, con base en data al año 2010, identifica las redes operacionales entre las 25 primeras LN (los nodos, en este caso) delineadas por los vínculos establecidos entre pares de las mismas mediante acuerdos de vessel sharing y slot chartering, detectados en 287 casos sobre un total de 604 servicios de transporte marítimo (Caschili et al. 2011: 4-5). Estos autores analizan la topología de ese tipo de redes y, al cotejarla con las capacidades de transporte de las LN involucradas, encuentran que: (1) las de menor capacidad (inferior a 350.000 TEU) tienden a cooperar (mediante dichos acuerdos) restringidamente, en el interior de grupos pequeños que forman entre sí y con pocas otras LN (de la misma región y solo de algunas otras regiones); (2) las de capacidad intermedia (entre 350.000 y 700.000 TEU) son las que usan esos acuerdos más intensamente y con LN de más regiones y distintas capacidades; (3) en tanto que las LN más grandes (capacidad superior a 1 millón de TEU) no los usan proporcionalmente tanto como las medianas debido al mayor tamaño de su flota propia ${ }^{31}$, pero también lo hacen en forma abierta e indistinta con LN de varias regiones y redes (Caschili et al. 2011: 9-11).

31. Sin embargo, mega-LN como Maersk, MSC y CMA-CGM (incluidas en el tramo superior analizado por Caschili et al.) ya están iniciando un proceso de cooperación más intensa. Maersk y MSC han confirmado la implementación, a partir de enero de 2015, de su comprehensivo Vessel Sharing Agreement (VSA), luego 
Esos resultados estarian indicando que el propósito específico de dichos acuerdos, consistente en optimizar el rendimiento de las naves, sería más claro en los casos de las LN globales y emergentes (respectivamente situadas en los tramos superior e intermedio de aquel estudio), con las LN globales actuando más a menudo como ofertantes y las LN emergentes como demandantes debido al desigual tamaño de sus respectivas flotas propias. Mientras que algunas LN regionales (situadas en el tramo de menor capacidad) parecían valerse de tales acuerdos más con el propósito de proteger sus bases regionales de carga, compartiendo el uso de sus propias flotas y, cuando necesitadas de recurrir a grandes naves ajenas, usando preferentemente las de ciertas LN globales que posteriormente han profundizado su rol de aliadas estratégicas con miras a dicho fin ${ }^{32}$. Lo cual corrobora que las redes son «intensivas en relaciones» (sección 1.1), pero también invita a reflexionar sobre las afinidades estratégicas de carácter más amplio que a lo mejor motivan algunas de esas relaciones.

Análogamente, en lo que atañe al segmento puerto, un estudio reciente no solo proporciona una idea concreta del avance en la conformación de redes portuarias con distintos alcances geográficos, sino que también devela sutiles patrones de relaciones entre las mismas. Con data al 2010, Parola, Sata y Caschili (2014: 17 [tabla 5]) procesan una muestra compuesta por 427 terminales para contenedores alrededor del mundo, operados por los primeros 40 OP internacionales (ninguno originario de América Latina)

de que la P3, una más ambiciosa alianza entre las dos y CMA CGM, fuera objetada por el Gobierno chino (pais de origen de grandes LN competidoras). Véase: $<$ http://www.reuters.com/article/2014/10/09/maerskalliance-idUSL3NOS35A820141009>. Consultado el 29/12/2014.

Por su parte, CMA CGM anunció, en septiembre de 2014, el lanzamiento de "Ocean Three", resultante de la suscripción de tres amplios acuerdos con las navieras CSCN y UASC: un VSA, un Slot Charter Agreement y un Slot Exchange Agreement. Véase: <http://www.cma-cgm.com/news/565>. Consultado el 29/12/2014.

32. En las "small-world networks" de las LN chilenas CSAV y CCNI, analizadas por Caschili et al., al año 2010 figuraban destacadamente las $L N$ alemanas Hapag-Lloyd y Hamburg-Süd. Estas relaciones especiales están profundizándose mediante un par de MEtA recientes. Una es la fusión en curso de CSAV con Hapag-Lloyd para lo relativo al negocio del transporte marítimo en contenedores, que el director ejecutivo de Hapag-Lloyd, Rolf Habben Jansen, explica asi: "Con la fuerza de Hapag-Lloyd en el tráfico asiático y el Atlántico Norte, combinada con la fuerte posición de CSAV en América Latina, nos convertiremos en la compañía naviera líder en esta regiónn. La otra es la adquisición, por parte de Hamburg-Süd, del negocio de transporte marítimo en contenedores de CCNI. Véanse las sendas notas de prensa del 2/12/2014 y del 31/3/2015, respectivamente,

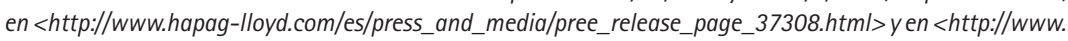
hamburg-sued.com/group/en/corporatehome/pressmedia/pressreleases/pressreleasedetails_614712.html>. 
mayormente en joint ventures entre sí y/o con OP locales. Esta muestra permite distinguir cuando menos tres categorías en esos OP: los 4 mega-OP globales, encabezados (de lejos) por PSA con 86 terminales en su haber, seguido por APMT (con 54 terminales), DPW (52) y HPH (49); por lo que los 4 mega-OP están presentes, en conjunto, en el 56\% de los terminales de la muestra. Luego están 8 OP que podrían calificarse como emergentes, por estar presentes en un rango de entre 15 terminales (la media de la muestra) y 33 terminales en distintas regiones. La mayoría de los otros 28 OP están presentes solo en una región y con menos de 10 terminales. A lo que puede agregarse una cuarta categoria, la más numerosa por cierto: los 210 OP locales, socios en al menos uno de los terminales operados en joint venture de la muestra (Parola et al. 2014: 5).

Dichos autores analizan la topología de las redes entre aquellos OP internacionales (los nodos, en este caso) reveladas por los vínculos de joint venture establecidos entre pares de los mismos para operar terminales de la muestra. La metodología que aplican para tal efecto les permite distinguir si esos vínculos son puntuales, respondiendo al aprovechamiento de alguna ocasión propicia (como la concesión de un terminal, por ejemplo), o si muestran continuidades en el tiempo y coberturas geográficas amplias que reflejarían convergencias estratégicas en el seno de "familias ocultas» (o "hidden families") de OP internacionales (Parola et al. 2014: 3-4). Estos autores, luego de detectar la existencia de 16 "hidden families» cuyo tamaño guarda relación con el tamaño del OP líder en tanto que las "familias" más numerosas son las lideradas por los mega-OP globales, plantean la necesidad de estudios similares enfocados en OP locales que permitan evaluar la medida en que sus estrategias difieren de las de OP internacionales (Parola et al. 2014: 11, 16 [tabla 4]).

Esa contrastación de estrategias empresariales sería muy esclarecedora si se realiza a nivel de REMP (dado lo examinado hasta el momento sobre los conceptos articulados por la network economics y su aplicación a la realidad contemporánea del SMP para contenedores) y poniendo especial énfasis en la comparación entre REMP globales y REMP regionales, con sus respectivos socios locales. Esto último, en razón de que los hallazgos de los estudios antes citados se enlazan bien con lo que se verá a continuación, respecto a la forma en que el poder de mercado y los costos de la logística marítimo-portuaria están distribuidos según segmentos del SMP (acápite 
siguiente), así como respecto a la intensa competencia por el control de la carga y las distintas estrategias portuarias según el segmento del SMP donde está basado el poder de mercado (sección 1.3). Ante ello, la COAS representa un interesante caso de estudio, porque allí concurren una creciente presencia de OP y LN globales con una fuerte implantación de REMP regionales (capítulo II).

\section{Concentración de mercado y costos en la cadena marítimo-portuaria}

A resultas de los dos procesos de expansión internacional antes examinados, el mercado mundial de transporte maritimo en contenedores se ha concentrado en manos de las LN globales, y también se ha incrementado la concentración del mercado portuario mundial para contenedores a manos de los OP globales. Pero ello es cierto solo cuando ambas concentraciones de mercado son estimadas de manera simple y agregada, en términos de participaciones en los respectivos totales para el mundo en general. Así, la participación de las 10 primeras LN en la capacidad (en TEU) de la flota mundial de naves para contenedores, que era un 18\% en 1980 (enero) y 28\% en 1995 (enero), saltó a un 53\% en 2006 (junio) y llegó a un 63\% en diciembre de 2012 (Notteboom 2004: 90 [tabla 2] [recuadro 19]; Banco Mundial 2007: 48; Alphaliner 2012: 4). Respecto a los 10 primeros OP, su participación en el movimiento de carga (en TEU) en todos los terminales para contenedores del mundo tomados en conjunto, pasó de un 41,5\% en el año 2001 a un 52,9\% en el 2006 (junio) y a un 64,6\% en el año 2009 (Rodrigue y Notteboom 2011: 11 [tabla 1]; Frémont 2009: 15 [tabla 4]).

Sin embargo, el poder efectivo de mercado está más repartido que lo sugerido por aquellas participaciones agregadas. En efecto, también es alta la concentración del mercado para contenedores en ámbitos regionales (Notteboom 2004: 100), pero en varios de estos la posición de dominio en el mercado no está en manos de REMP lideradas por LN u OP globales sino de REMP regionales o locales nativas de esos ámbitos, incluso en terminales de contenedores principales de una costa o región marítima y más aún en los de menor rango a lo largo de la misma. Esta posición de dominio en mercados regionales, uno de cuyos pilares clave es la fuerte presencia de los PL de REMP locales o regionales en el segmento tierra de sus ámbitos nativos (como se verá algunos párrafos más adelante), constituye otra importante razón explicativa del intenso recurso a joint ventures y otros contratos o acuerdos para 
el tráfico de carga contenedorizada en terminales ${ }^{33}$ y naves, adicional a las razones anteriormente mencionadas acerca del rol de estas colaboraciones en la lógica económica que orienta las expansiones internacionales de LN y OP.

De modo que cuando la participación en el movimiento de carga en contenedores (medido en TEU) de los 10 primeros OP es ponderada por su participación accionaria en los terminales donde operan, la participación efectiva de los mismos al año 2009 resulta ser de un 38,7\% (en vez del no ponderado 64,6\% arriba indicado) e incluso bajó a un 36\% al año 2012 (Rodrigue y Notteboom 2011: 11 [tabla 1], Drewry Maritime Research 2013). En sentido similar, al analizar cómo se distribuyó la provisión de toda la carga contenedorizada transportada por LN a nivel mundial en el año 2006, un estudio encontró que el 44\% fue provista por OP locales versus un 28\% por los cinco primeros OP globales y un 15\% por otros OP internacionales (Soppé et al. 2009: 10, 14 [figura 4]). Puesto que, en los términos de ese estudio, entre aquellos "otros» OP hay tanto globales como regionales y de estos últimos también hay entre los «locales», al mismo tiempo que bajo la denominación "OP» están incluidos los empresarialmente ligados a LN; se infiere entonces que lo hallado por tal estudio, junto con lo precisado por el método ponderado de Drewry, permite percibir el considerable poder de mercado que REMP regionales y locales detentan en sus ámbitos geográficos de origen, con base en los cuales buscan convertir a sus LN u OP en globalmente emergentes ${ }^{34}$.

Lo anterior revela los límites que aún confronta la expansión internacional de los OP globales y su desfase con la lograda por las LN globales, al mismo

33. Esto se entiende mejor cuando se tiene en cuenta que la presencia de un conglomerado empresarial a lo largo de una costa puede darse simultáneamente como OP en algunos terminales de contenedores de la costa y como PL en otros terminales de la misma donde no tiene a su cargo la función de operación portuaria. Por ejemplo, así sucede en la COAS con SAAM (Sudamericana Agencias Aéreas y Maritimas) del conglomerado chileno controlado por la familia Luksic y al que también pertenece la CSAV. SAAM está presente como OP en el puerto de San Antonio, como PL en el puerto de Guayaquil y también como PL en el puerto del Callao a través de un joint venture; tal como se mostrará en el capitulo Il de este documento.

34. Entre los ejemplos recientemente mencionados por expertos de Drewry (Davidson 2010: 9, Drewry Maritime Research 2013), de OP de REMP regionales fuertemente implantadas en sus ámbitos geográficos de origen y en vías de concretar sus aspiraciones de expandirse hacia otras regiones, están, además de China Merchants, Ports America y Gulftainer (Emiratos Árabes Unidos), dos empresas-SAAM y Ultramar-de sendos conglomerados chilenos cuya amplia presencia en la COAS y otras costas de Latinoamérica es examinada en los capitulos II y III del presente documento. 
tiempo que da indicios útiles para detectar la todavía limitada expansión de ambos (LN y OP globales) hacia el campo de acción de los PL: el segmento tierra (Merckx y Notteboom 2006: 14). En efecto, los procesos de «integración» vertical de LN globales y OP globales hasta el segmento tierra han avanzado poco y disparejamente según ámbitos geográficos. Así, en lo relativo a las 10 primeras LN, si bien todas cuentan en sus conglomerados con empresas o divisiones logísticas encargadas de armar sus redes de PL a escala global, al año 2007 este negocio logístico seguía representando una porción minoritaria de la facturación total de los mismos: a lo sumo de un 15,1\% para NOL-APL (a través de APL Logistics) y de un 11,2\% para AP Møller (a través de Maersk Logistics), por citar solo los dos porcentajes menos bajos entre los relacionados con dichas LN (Frémont 2009: 17 [tabla 6]). Similarmente, si bien varios de los OP globales tienen divisiones o empresas separadas enfocadas en la cadena logística tierra adentro, tampoco suelen controlarla fuera de sus ámbitos geográficos de origen (Bichou y Gray 2004: 52, Notteboom 2004: 102), en especial en aquellos donde han obtenido terminales portuarios recientemente y donde PL de REMP regionales o locales dominan el segmento tierra; tal como es el caso en la COAS, según se mostrará en este documento.

No obstante los grandes recursos con que cuentan las REMP globales, les puede resultar complicada la tarea de agenciarse canales de distribución en el segmento tierra de los ámbitos geográficos que les son nuevos (Banco Mundial 2007: 29). Dado que, en su condición de "recién llegados» (o late-comers), enfrentan el desafío de superar las significativas ventajas que, por haber «llegado primero" (o first-mover advantages), tienen los PL de REMP regionales o locales tempranamente instalados (o incumbents) en dicho segmento, con sus ya establecidas redes de distribución, bases de clientes fidelizados (Shy 2001: 1, 4) y su mayor capacidad de influir en la economía política doméstica (Olivier et al. 2007: 20). Esto último puede reflejarse en políticas sesgadas o tratos preferentes, con efectos equivalentes a barreras al ingreso que cabría analizar en términos análogos a los usuales para instalaciones portuarias, puesto que hay PL que también poseen "facilidades esenciales" (tales como almacenes, terminales "secos» y plataformas logísticas) que son "inputs compartibles» de utilidad pública (porque su uso debe contribuir al flujo eficiente de la carga generada por el comercio de una economía), especialmente cuando están instaladas en zonas poco reproducibles en otros lugares (Eilts y 0xley 2011: 48). Por ello, a esos PL también se les debiera aplicar lo exigido a los OP: atender eficientemente -en calidad y costos- al entramado de CV/SC y 
REMP que necesitan acceder a tal tipo de instalaciones (Langen y Pallis 2007: 2), no obstante su pertenencia a una REMP en particular.

En efecto, los PL (de REMP regionales o locales) que se instalaron primero pueden estar protegidos por barreras (económicas, regulatorias y de localización) al ingreso de nuevos PL (de REMP globales), análogas a las que esos dos autores analizan para el caso de los OP, ya que aquellos PL incumbents pueden haberse beneficiado de diversos apoyos gubernamentales dictados a la medida para facilitarles su instalación en zonas privilegiadamente ubicadas, a las que los "recién llegados» o ya no pueden acceder por saturación de la zona o podrían pero costosamente por encarecimiento de la misma (Langen y Pallis 2007: 5). Esta ventaja económica puede ser de largo plazo o permanente, dependiendo de si la regulación previó que esas zonas sean adjudicadas vía concesiones o permitió su entrega en propiedad privada (Raimbault, Douet y Frémont 2013: 31). En ambos casos, se habría "fabricado" ventajas de localización a favor de los PL locales o regionales tempranamente instalados (incumbents) y, simultáneamente, se les habría encarecido a PL locales y dueños de la carga los "costos de cambiarse" (switching costs) hacia los "recién llegados" por estar instalados estos en zonas menos favorecidas. Ello, por encima de los switching costs impuestos por los propios incumbents para retener clientes, fidelizándolos con prácticas de discriminación de precios y/o ventas atadas empaquetando servicios, y/o desalentándolos de migrar insinuando riesgos de represalias posibilitadas por su influencia en círculos empresariales y políticos locales (Langen y Pallis 2007: 6-9, Banco Mundial 2007: 29).

Lo anterior significa, en términos conceptuales (sección 1.1), que los PL incumbents obtienen la posesión de activos (tangibles e intangibles) especiales, con base en los cuales el dominio de los estándares de REMP regionales o locales en el segmento tierra puede mantenerse pese al arribo de REMP globales con estándares superiores (Economides 1996: 677, 696; Gottinger 2003: 8-9). Esa situación, resultante de la posesión de activos especiales conseguidos merced no solo a méritos empresariales sino al apoyo gubernamental también, puede durar mucho tiempo, ya que la función de interfaz propia del puerto implica que este actúa como adaptador o convertidor entre estándares regionales o locales en el segmento tierra y estándares globales en los segmentos puerto y mar, permitiendo así la coexistencia entre REMP regionales o locales y REMP globales. 
Todo ello, junto con la relativamente reciente incorporación de varios ámbitos regionales al comercio generador de carga para contenedores, explica que la internacionalización en el segmento tierra tiene -por ahora, al menosmás de regionalización que de globalización (Rodrigue y Notteboom 2010b: 2-3, 10). También explica la distribución del poder de mercado entre REMP globales y REMP regionales o locales según segmentos del SMP: muy fuerte el de las primeras en el segmento mar y el de las segundas en el segmento tierra; con el segmento puerto en una situación intermedia, de creciente poder de las primeras en principales terminales de contenedores pero a menudo compartiéndolo (vía joint ventures) con las segundas (Vanelslander 2005: 26), además de que las segundas suelen dominar los otros puertos en la misma costa o región.

Ante ello, no todas las REMP globales sino aquellas cuyo OP ha logrado implantarse en un terminal de contenedores importante de un ámbito geográfico con atractivo potencial y que, debido a ello, están decididas a cubrir allí todo el soporte logístico requerido por las CV/SC internacionales, ponen en marcha un proceso de incursión en el respectivo segmento tierra, recurriendo a dos mecanismos. Uno es la incursión compitiendo con las REMP regionales o locales allí existentes. Este involucra tanto una paulatina inserción en la economía política doméstica para que los PL propios se puedan instalar en zonas bien ubicadas y rentables, como la paciente construcción de una base de clientes sólidos sucesivamente atraídos por los mejores estándares de servicios demostrados en varias maneras que incluyen su captación vía contratos o acuerdos operacionales con PL incumbents ${ }^{35}$. El otro mecanismo, siempre contemplado a todo lo largo de la implementación del anterior en razón de que aquel es lento y de resultados inciertos, consiste en agilizar la incursión en el segmento tierra, heredándola mediante una operación de M\&A con alguna REMP regional o local bien posicionada en aquel segmento ${ }^{36}$.

35. La investigación de Vanelslander (2005: 73-75) encuentra que los contratos o acuerdos operacionales de $O P$ globales con $O P$ regionales y locales (que involucran a los respectivos $P L$ ), sirven al propósito de lograr un posicionamiento de largo plazo y por ello se enfocan no solo en adquirir insumos sino en brindar servicios adicionales y captar clientes.

36. Ejemplos de ello podrian ser la fusión en curso de CSAV con Hapag-Lloyd para lo relativo al negocio de transporte marítimo en contenedores, así como la compra de dicho negocio de CCNI por parte de Hamburg-Süd, según lo que cada MEtA comporte para los negocios en puerto y tierra adentro del conglomerado chileno asociado a CSAV y al de CCNI. 
En tal contexto, son muy reveladores los indicios que se obtienen de la literatura especializada acerca de la participación de cada segmento en los costos a lo largo de la cadena logística para contenedores. Respecto al segmento mar, que es el más internacionalizado, los fletes marítimos para carga en contenedores ya no representan en promedio sino un 6\% de esos costos (Vanelslander 2005: 2). Cuando es medida respecto al costo total del transporte en servicios puerta a puerta, la participación del flete marítimo solo bordea un 23\% (Frémont 2009: 16), correspondiéndole así un 77\% al costo en tierra de dichos servicios. Esto encaja con otro estimado, según el cual la participación de los costos logísticos en tierra en el costo total por transporte y manejo de contenedores, se ubica en un rango del 80\% al 40\% (Notteboom 2004: 92). Mientras que respecto al segmento puerto, debido a las tarifas reguladas en valores competitivos asociadas a su reforma y licitaciones internacionales, la participación de tales tarifas en el valor de la carga movilizada ha caído a un rango de 15\% para productos de bajo valor a 1\% para los de alto valor (Banco Mundial 2007: 30). Se infiere así que en el segmento tierra adentro está la mayor parte de los costos en la cadena logística para contenedores relacionada con el SMP (Notteboom 2004: 92, Merckx y Notteboom 2006: 13), y es por ello el segmento más costoso para los dueños de la carga que hacen uso de dicha cadena ${ }^{37}$.

Parece haber entonces la siguiente relación inversa: a mayor grado de internacionalización del segmento, menor su participación en el costo total, y viceversa. Es cierto que no es lo mismo correlación que causalidad. Es seguro que en el alto costo relativo del segmento tierra inciden grandemente otros factores, como por ejemplo las brechas de infraestructura y la complicidad gubernamental -a nivel central y/o regional y/o local- con intereses privados muy influyentes en todos o algunos de esos niveles. Pero estas dos fallas están interrelacionadas, en tanto que ambas frenan la competencia. No es aconsejable, por ello, ver como mera coincidencia el hecho de que el segmento costoso sea aquel donde no suelen regir tarifas reguladas, pese a que allí también hay (análogamente al segmento puerto) «facilidades esenciales» e «inputs compartibles» de utilidad pública y difícilmente reproducibles en

37. En línea con las estimaciones citadas en este párrafo, un estudio sobre el puerto del Callao prolijamente elaborado por Martín Sgut con data al año 2004, encontró que el 71\% de los costos para los dueños de la carga (exportadores e importadores) correspondía a las tarifas (no reguladas) cobradas por PL localizados fuera del perímetro portuario (Sgut 2005: 33). 
condiciones similares. Resulta así razonable afırmar que la competitividad del comercio de un país y la eficiencia conjunta de su SMP se beneficiarian mucho con una mayor presencia en el segmento tierra de REMP con mejores estándares de calidad y fijación de precios; así como con una regulación actualizada y neutra, que promueva la competencia transversalmente en todo el SMP, aplicando criterios similares a situaciones análogas sin distingos con dudoso sustento entre los segmentos del mismo.

\subsection{Estrategias empresariales: tendencias globales y espacios regionales}

El análisis realizado en la sección 1.2 (con la ayuda de los conceptos explicados en la sección 1.1) ha tenido en cuenta las dos dimensiones -globalización y regionalización- del proceso de internacionalización del SMP para contenedores y, por ello, ha permitido identificar sus siguientes rasgos interrelacionados: (1) el segmento del SMP más internacionalizado es el segmento mar, el menos internacionalizado es el segmento tierra y el segmento puerto está en una situación intermedia al respecto; (2) el proceso tiene como sus representantes empresariales más avanzados a LN globales y OP globales, que respectivamente lideran el segmento mar y el segmento puerto cuando el mundo es visto como un todo; pero, al mismo tiempo, hay LN y OP regionales que, en sus espacios regionales nativos, lideran los respectivos segmentos mar y puerto y, a través de sus PL, dominan el segmento tierra; (3) el poder de mercado (medido en TEU) es grande pero está distribuido entre REMP globales y REMP regionales: el de las globales es fuerte a nivel agregado mundial, especialmente en el segmento mar; el de las regionales es fuerte en sus respectivas regiones de origen, especialmente en el segmento tierra; mientras que está más repartido entre ambas en el segmento puerto; (4) correlacionado con todo lo anterior, en el segmento tierra está la mayor parte de los costos para los dueños de la carga, en el segmento mar está la menor parte de esos costos, y los correspondientes al segmento puerto se sitúan en un rango intermedio.

Esos rasgos brindan valiosos elementos de juicio para el análisis objeto de la presente sección, acerca de las estrategias que REMP globales o regionales pueden implementar para ganar o mantener cuota de mercado, robusteciendo las fortalezas y reduciendo las debilidades relativas que cada cual tiene en los distintos segmentos del SMP. Con tal fin, en esta sección se agregan otros elementos de juicio indispensables. A saber: los cambios que tipifican la dinámica contemporánea del SMP, sus implicancias en las ventajas competitivas propias 
a cada tipo de empresas que lo conforman (LN, OP y PL) y en la competencia que estas entablan entre sí a nivel de REMP; así como las diversas concreciones regionales que adoptan las tendencias globales resultantes de aquella dinámica, especialmente en materia de configuraciones de rutas marítimas y jerarquías portuarias. El análisis que sigue al respecto está centrado en la dinámica portuaria, porque en el segmento puerto se distinguen con mayor nitidez las opciones estratégicas debido a que alli confluyen los tres tipos de empresas del sector y debido a que, según los rasgos arriba sintetizados, allí es menos dispareja la competencia entre REMP globales y regionales.

\section{Competencia por la carga para liderar cadenas de valor o cadenas de suministro internacionales}

Según el Banco Mundial (2007: 36 y ss.), cinco son las tendencias globales que están marcando la dinámica de los terminales portuarios para contenedores. (1) Los cambios que a todos los integrantes de la cadena logística (puertos incluidos) les exige realizar la intensificada competencia resultante de la globalización de la producción y el comercio. Ducruet y Notteboom (2012: 2) reconocen a la regionalización como parte de esta tendencia, por lo que pueden percibir la economía política de la misma y dar cuenta de sus diversas estructuras espaciales. (2) Los exigentes requisitos de infraestructura portuaria y especialización de los servicios brindados por $0 P$, que plantean cambios tecnológicos de impacto transversal sobre la cadena logística, como son la contenedorización y la informática. (3) El cambiante poder de negociación entre los integrantes de la cadena logística, conforme la consolidación de poderosas LN se ve confrontada no solo por el surgimiento de poderosos OP sino también por el ascenso de PL globales. (4) Las jerarquías de puertos y modificaciones en operaciones portuarias resultantes de cambios en los patrones de distribución de la carga contenedorizada, manifiestos en las configuraciones $h u b \&$ spoke que adopta su transporte marítimo, así como en el traslado hacia tierra adentro de servicios tradicionalmente portuarios. (5) Las inversiones y regulaciones necesarias para cumplir con altos estándares medioambientales y de seguridad en el transporte y manejo de la carga a lo largo de toda la cadena logística.

El impacto combinado de estas interrelacionadas tendencias, al dirigir la competencia entre REMP hacia el objetivo estratégico de liderar el soporte logístico requerido por CV/SC internacionales, transforma los determinantes 
de las ventajas competitivas de LN y OP haciendo que se yuxtapongan en parte con la ventaja competitiva de los PL. En efecto, las LN se ven impelidas a no limitarse al transporte marítimo sino a cubrir los tres segmentos del SMP, con el propósito de contar con la base de carga que les asegure el liderazgo de dicho soporte logístico (Panayides y Cullinane 2002: 192-193). Con similar fin, los OP se ven urgidos a no ser simples gestores de nodos geográficos sino a brindar servicios (a la nave y a la carga) que agreguen valor, para así poder convertirse en articuladores de entramados de CV/SC y REMP con sus respectivos clústeres institucionales (Ducruet 2009: 2, 7; Banco Mundial 2007: 37, 59). Lo uno y lo otro revaloriza el atractivo de la ventaja competitiva propia a los PL, reflejada en el control de la parte moderna del transporte y manipuleo de la carga en el segmento tierra (Frémont 2009: 22-23), al añadirle a tal control un valor estratégico por añadidura a la (comparativamente) alta rentabilidad que reditúa el segmento tierra (a juzgar por lo ya visto sobre la distribución de los costos para los dueños de la carga).

Lo anterior significa que la pugna entre REMP, para liderar el soporte de transporte y distribución requerido por CV/SC internacionales, se manifiesta críticamente en la competencia por (cuota en el mercado de) la carga contenedorizada, que se da a lo largo de toda la cadena logística (Bichou y Bell 2007: 36) y no se entabla en un mercado abstracto sino en mercados concretos, palmo a palmo en cada mercado local y regional (Parola et al. 2014: 1-2). De ahí la existencia simultánea de mucha cooperación y de fuerte competencia entre las empresas que conforman el SMP para contenedores (Vanelslander 2008: 193). Lo primero alude a la amplia gama de contactos o acuerdos, consorcios o alianzas que, a la vez que dan testimonio del carácter muy intensivo en relaciones que tiene un sector organizado en red (sección 1.1), facilitan el acceso a la carga (sección 1.2). En tanto que la competencia intensa (pero siempre imperfecta, porque está orientada a ganar cuota de mercado y a concentrarlo por ende) tiene coordenadas geográficas y ocurre por toda la respectiva cadena logística, entre sus segmentos y en el interior de cada uno, dando lugar a varias situaciones de conflicto ${ }^{38}$ cuyos diferentes argumentos (metas o roles incompatibles, expectativas o percepciones divergentes, etc.) suelen evidenciar al control de la carga como principal disputa específica y, por ello, la competencia imperfecta conduce a que se busque

38. Desde una perspectiva de cadena logistica, el conflicto ocurre cuando un miembro de la cadena interfiere en los objetivos de otro miembro para obtener beneficios a su costa o para perjudicarlo (Bichou y Bell 2007:39). 
aumentar tal control pese a que el $\operatorname{poder}^{39}$ (de mercado) que implica pueda ser un causante del conflicto (Bichou y Bell 2007: 39-41).

La explicitación de la competencia por la carga y sus asociados escenarios de poder y conflicto, inyecta realismo a la interpretación de las expansiones internacionales de LN y OP combinando modalidades de «integración» horizontal y vertical, así como de las desiguales y por lo general incipientes penetraciones de las REMP globales en el segmento tierra (sección 1.2). A lo que ahora cabe agregar la complicación adicional que, para la aspiración de LN y OP de liderar toda la cadena logística marítimo-portuaria requerida por CV/SC internacionales, representa la creciente participación de algunos retailers globales en cadenas logísticas internacionales (Bichou y Gray 2004: 51). Esta complicación no es tan amenazante para aquellas REMP regionales cuyos conglomerados empresariales cuentan con retailers y PL bien implantados en sus regiones de origen (sección 1.2). Pero sí puede afectar severamente a los OP, a los OP globales sobre todo, en la medida en que representa la emergencia de nuevos competidores en un contexto donde la competencia entre terminales de contenedores tiende a desplazarse -y quizá a definirse- fuera del perímetro portuario, en el segmento tierra donde operan los PL y transportistas intermodales con los cuales el OP debe coordinar enfoques para facilitar el desarrollo del terminal a su cargo (Notteboom 2008: 37); lo cual implica compatibilidades estratégicas que a un OP global le es difícil lograr con un segmento usualmente dominado por REMP regionales.

Así de complejo es el escenario de competencia que experimenta el SMP para contenedores y su segmento puerto en particular. Un escenario que comprende no solo a la (tradicional) rivalidad interportuaria sino también a los recientes cambios en el balance de poderes de negociación entre LN, OP y PL (Banco Mundial 2007: 21 y ss.), conforme las REMP de que son parte y empresas de otros sectores económicos buscan articular toda la cadena de servicios logísticos en función de los requerimientos de CV/SC. Las consecuencias de la resultante pugna por el control de la carga son más visibles en torno del nodo de heterogéneas empresas y redes involucradas que es el puerto (Meersman et al. 2010: 211); ya que esa pugna, dada la transversalidad de la competencia imperfecta y acumulación de EE y ES (sección

39. Desde la misma perspectiva, el poder de un miembro de la cadena logística se expresa en su capacidad de controlar o modificar el desempeño en el mercado de otro miembro (Bichou y Bell 2007: 40). 
1.1), desemboca en mercados concentrados ("integraciones» empresariales) a lo largo de cada segmento ("horizontales") así como entre segmentos y submercados en el interior de cada segmento ("verticales»).

De modo que en torno del nodo portuario confluye y se pulsea el resultante poder de mercado, en proporción del cual no solo el OP y las LN sino también los PL pueden apropiarse de rentas monopolistas (Langen y Pallis 2006: 6) y pueden abusar de su posición de dominio, con mayor motivo si tienen la posesión de "facilidades esenciales" difícilmente replicables (Eilts y Oxley 2011: 53). También pueden discriminar precios y atar ventas ofreciendo en paquete los servicios asociados a los submercados eslabonados que han logrado «integrar» empresarialmente ${ }^{40}$ (Gottinger 2003: 6, 9), para fidelizar o retener clientes y competir por diferenciación de servicios. Esta forma de competir ha cobrado mayor importancia conforme la aspiración de controlar la cadena logística trae consigo que a la incursión de PL en servicios básicos o estandarizados portuarios (a la nave y a la carga) vía subcontrataciones encomendadas por OP o LN, se superponga la incursión (en sentido contrario) de OP y LN hacia servicios (en tierra) especializados o a la medida del cliente parecidos a los brindados por PL (Ferrari y Benacchio 2002: 166, Merckx y Notteboom 2006: 3).

Sin embargo, la competencia diferenciando servicios no reemplaza sino complementa a la competencia por costos. Pero el margen para que LN y OP practiquen esta última se limita a lo que les permite su nivel acumulado de EE y las tarifas reguladas en el caso de los OP, mientras que tal margen es mayor para los PL que trabajan con tarifas libres en un segmento tierra, que pueden tenerlo como hinterland cautivo (Langen y Pallis 2006: 6-7), especialmente cuando son PL regionales o locales mejor implantados allí que PL de REMP globales. Ello, habida cuenta de que en la dinámica de EA la competencia por diferenciación refuerza las fuerzas centrípetas mientras que la competencia por costos provoca fuerzas centrífugas (sección 1.1), implica que a los PL de REMP regionales les es posible erosionar la cantidad de carga para un terminal de contenedores que no está a cargo de un OP de su misma red, a favor de otro terminal que sí lo esté en la misma costa

40. Para un análisis de las posibilidades de discriminación de precios y de ventas atadas por parte de PL "integrados" verticalmente que están localizados cerca del puerto del Callao pero fuera de su perímetro, véase Nadramija (2013: 30-31). 
o región. Esa posibilidad ayudará a entender mejor lo que sigue en esta sección acerca de las estrategias competitivas de REMP globales y de REMP regionales, así como las implicancias de la presencia de ambas redes en la COAS que se describe en el capítulo II.

\section{Patrones de transporte hub \& spoke y jerarquías de puertos}

Una tendencia global muy importante es la configuración, por parte de las REMP, de sus sistemas para el transporte de la carga en contenedores siguiendo patrones tipo hub and spoke (H\&S) -tanto en mar como en tierra- y sus asociadas jerarquías de puertos. Las diversas materializaciones geográficas de esos patrones son de singular relevancia para identificar las dimensiones espaciales de la competencia entre REMP, tanto de las REMP globales con las REMP regionales, como en el seno de cada uno de esos dos tipos de REMP, según sus distintos anclajes regionales o subregionales. Más aún, dada la gravitante función de los puertos en los inicios del proceso de acumulación de EA (sección 1.1), las diferentes jerarquías de terminales para contenedores que resultan de esos patrones inciden significativamente en el patrón de concentración de actividades económicas -y en la correspondiente formación de centros económicos y sus respectivas periferias- a lo largo de una costa o región, con el derivado impacto desigual sobre la competitividad de los países involucrados.

Conviene explicar aquello empezando por lo particular: a una LN, el organizar su sistema de transporte marítimo siguiendo un patrón H\&S, le sirve para optimizar el uso tanto de su flota de naves como del conjunto de puertos conectados por dicho sistema (Panayides y Cullinane 2002: 199, Banco Mundial 2007: 52). Para ello, las principales LN configuran sus respectivos patrones H\&S con un alcance global pero organizándolos por regiones. Si bien las configuraciones varían en la práctica según la LN concernida, por lo general están organizadas como sigue: las naves más grandes recalan en puertos que funcionan como hubs de transbordo (o PHT en adelante, para abreviar) localizados en cada región, con base en los cuales la carga en contenedores es llevada/traida por naves medianas a/desde algunos puertos principales de la región que funcionan como centros de carga (o load centers) ${ }^{41}$ subre-

41. Para un análisis comparativo de los conceptos de centro de carga y de hub portuario, con miras a su aplicación al caso de la COAS, véase Belaúnde y Bryce (2006: 8-10). 
gionales y por ello se les denomina puertos gateway (PGW en adelante), los que a su vez sirven de base para llevar/traer la carga con naves pequeñas a/desde otros puertos en la misma costa o subregión (Rodrigue 2010: 9-12).

Resulta así una jerarquía de puertos en tres niveles, en el interior del patrón H\&S propio de una gran LN: el o los PHT regionales (como el puerto de Singapur, por ejemplo), el o los PGW subregionales (como son los puertos de Shanghái y de Santos, por ejemplo), y los puertos periféricos en una región o costa (Ducruet y Notteboom 2012: 16-18). En términos de la network economics (sección 1.1), los dos primeros tipos de puertos cumplen por excelencia la función de nodos convertidores o adaptadores entre los sistemas de distribución/aglomeración de carga de las distintas REMP. La ganancia especifica que ambos obtienen -aunque el PHT en mayor medidaes el ingreso adicional generado por el doble manejo y reestiba de la carga (Banco Mundial 2007: 54); además de los varios beneficios que, a los países donde se ubican esos puertos, les reporta la mejor conectividad marítima y la mayor generación de EA que cada uno de esos estatus portuarios implica, especialmente en el caso de un PGW y también en el caso de un PHT cuando su ubicación no es off shore o aislada de los respectivos centros económicos nacionales.

Pero un puerto que aspire a obtener esos réditos debe reunir ciertos atributos y exigentes requisitos. En línea con las enseñanzas de la economía geográfica o del espacio (sección 1.1), el atributo más importante que un puerto debe tener, para que una gran LN lo escoja como PHT regional o PGW subregional, es su localización estratégica (Banco Mundial 2007: 52). Una localización estratégica respecto, en el caso de un PHT, a los principales corredores de navegación transoceánica -la mayoría de los cuales circundan el planeta por su cinturón ecuatorial en dirección Este-Oeste y viceversa-, por donde se transportan los grandes volúmenes de carga procedente de o destinada a los distintos mercados conectados mediante la ya mencionada combinación de naves y puertos de diferente tamaño y función; y respecto, en el caso de un PGW, a los orígenes y destinos primarios de la carga en la subregión, que delinean el tamaño (actual y potencial) de su base de carga y la correspondiente cuota del hinterland subregional (Banco Mundial 2007 [recuadro 23]).

A lo que se suman, en ambos casos, los requisitos de infraestructura de calidad y eficiencia en costos necesarios para brindar una atención competi- 
tiva a la nave y a la carga. Requisitos que, si bien varían para un PHT o un PGW, son de todos modos exigentes en los dos $\operatorname{casos}^{42}$. La necesidad de que los grandes montos de inversión requeridos para satisfacer esos requisitos se hagan efectivos en los puertos con atributos para lograr o mantener la posición de PHT o de PGW ${ }^{43}$, explica en parte las reformas pro modernización de puertos y concesión a privados de terminales para contenedores, que han facilitado el proceso de internacionalización portuaria (sección 1.2). A su vez, dicha necesidad refleja la competencia interportuaria por esos destacados posicionamientos, cuya intensidad y complejidad van en aumento debido tanto a rivales estrategias empresariales y gubernamentales, como al cambiante mapa del comercio internacional movilizado en contenedores.

En efecto, no hay en la práctica una sola sino varias manifestaciones concretas de configuraciones H\&S y asociadas jerarquías de puertos (Notteboom y Rodrigue 2008: 160). Las diversas configuraciones H\&S y jerarquías de puertos existentes revelan las distintas decisiones empresariales que responden a objetivos estratégicos, comerciales y operacionales propios de cada REMP y de su LN en particular (Robinson 2005: 253), y también reflejan la diferente calidad y eficacidad de las políticas públicas nacionales y de sus regulaciones marítimo-portuarias (Ducruet et al. 2009: 11-12). No podría ser de otro modo, a la luz de lo aprendido (en las secciones previas) acerca de la

42. Según el Banco Mundial (2007: 52-54), los principales de esos requisitos para ser un PHT o PGW, adicionales al atributo de localización estratégica, son los siguientes: (1) Buen frente marítimo, con un calado de 15-16 m como mínimo para permitir el acceso de grandes naves. (2) Instalaciones y equipos adecuados para manejar grandes volúmenes de carga con servicios operativos eficientes, provistos con sistemas computarizados y a tarifas competitivas. Lo crucial al respecto son las dotaciones de grúas con gran alcance y de longitud de muelles y de áreas suficientes para atender varias naves grandes y para apilary almacenar muchos contenedores, para minimizar el tiempo de permanencia de grandes naves en el puerto y que así pueda el puerto estar regularmente conectado con las rutas maritimas de larga distancia servidas por grandes naves (Cullinane y Khanna 1999: 203-204). (3) Alta capacidad de distribución/aglomeración de carga, facilitada por la red de puertos secundarios/feeder y por la conexión con el hinterland (Meersman et al. 2010:212-213). 43. Entre los ejemplos relevantes para el presente documento referido al caso de la COAS, cabe mencionar aqui el relativo a la inversión de DPW en el Muelle Sur del puerto del Callao: a US\$ 404 millones ascendió el compromiso (o monto mínimo) de inversión asumido por DPW el año 2006 para la etapa de ejecución inmediata -o Etapa I- de construcción de dicho muelle. Agregándose un monto mínimo adicional de US\$220 millones para la Etapa II, que serán ejecutados según los requerimientos de demanda expresados en la tasa de utilización del muelle construido en la Etapa I (González Vigil, Yong y Hurtado 2012: 36). Habiéndose verificado la existencia de tales requerimientos, en febrero de 2015 DPW anunció que ejecutará la Etapa II, destinando US\$190 millones para las primeras obras de la nueva etapa. 
vinculación entre estrategia competitiva de la empresa y ventaja competitiva de su país de origen, así como sobre el carácter estratégico que la mayoría de países asignan al desarrollo de su SMP y la consiguiente combinación de alta intensidad regulatoria con sostenido apoyo gubernamental a las empresas líderes del sector. Por lo que no debe sorprender que esa simbiosis empresa-país en materia de estrategia marítimo-portuaria sea, en términos comparativos, más necesaria para una REMP regional que para una REMP global, porque para la primera su subsistencia y posibilidades de emerger y convertirse en global dependen relativamente más de su mercado (nacional y regional) de base o home market (Olivier et al. 2007: 16). Como tampoco debe sorprender que tal simbiosis sea más necesaria para un país en desarrollo que para uno desarrollado, ya que para el primero su capacidad de acumulación de EA y de aprovechamiento de EF dependen relativamente más de un sector de infraestructura clave para la formación inicial de concentraciones económicas como es el SMP (Fujita y Mori 1996: 96).

De ahí que las principales LN diseñan, cada una en función de su alcance (global o regional) y singular fusión de objetivos estratégicos empresariales y nacionales, su propia configuración H\&S de servicios regulares de transporte marítimo en contenedores, aplicando la combinación que mejor les acomode de rutas directas (end-to-end) y/o con transbordos intermedios, al surcar grandes corredores transoceánicos (Este-Oeste) y/o rutas Norte-Sur o con diversos trazos pendulares, triangulares y circunferenciales (Notteboom y Rodrigue 2008: 159-164). Dada la gran importancia que para la estrategia competitiva de cada LN tiene su configuración de rutas y servicios marítimos, no sorprende que las alianzas navieras hayan avanzado poco en materia de diseño conjunto de las configuraciones de sus miembros y más en optimizar el uso de las existentes mediante acuerdos operacionales estilo vessel sharing y slot chartering (sección 1.2).

La dificultad del diseño conjunto se entiende aún más al tener en cuenta que esas distintas configuraciones comportan diversas jerarquías de puertos, que se superponen y mutan en el tiempo. Es inherente a la configuración H\&S de servicios marítimos propia de cada LN el que esta intercale sus recaladas en los puertos conectados por las rutas que cubre, de la manera más conveniente para su singular fusión de objetivos estratégicos. Por lo cual un mismo puerto puede cumplir, al mismo tiempo, el rol de PHT o de PGW para una LN y un rol secundario para otra LN, como también puede, 
con el transcurrir del tiempo, ganar estatus para una LN y perderlo para otra LN (Notteboom y Rodrigue 2008: 160). Algo similar se aplica a los OP, cuyas respectivas jerarquías de puertos dependen no solo del alcance de la red de terminales de contenedores que han logrado poner a su cargo (vía concesiones y/o M\&A), sino también del peso relativo de su anclaje en el respectivo mercado de base o home market (Notteboom y Rodrigue 2011: 254) y de la concomitante alineación con la estrategia del país de origen. Este último factor es comparativamente más gravitante en las decisiones de $\mathrm{OP}$ regionales que en las de $\mathrm{OP}$ globales, en razón de lo explicado antes.

Por tanto, los mencionados atributos y requisitos para PHT o PGW son condiciones necesarias pero no suficientes para que un puerto vea realizada su aspiración de ascender a uno o ambos de esos destacados estatus. Una indispensable condición adicional consiste en que esa aspiración encaje con la estrategia de una REMP. Además, debido a lo que se verá acto seguido y sobre desarrollo portuario al final de esta sección, también se requiere una acertada estrategia comercial -como parte integral de una comprehensiva estrategia económica y política- respecto a los mercados que alimentarían la función de transbordo por el lado del foreland, así como respecto a los orígenes y destinos primarios de la carga en la subregión que representarían la cuota del hinterland.

De hecho, la emergencia de un nuevo mapa del comercio mundial contribuye grandemente a los cambios en las jerarquías de puertos asociadas a las diversas configuraciones HetS. El incremento de los origenes y destinos primarios del comercio generador de carga en contenedores, junto con la proliferación de acuerdos comerciales entre los países involucrados, conducen a que en cada región, y sobre todo en las de mayor dinamismo económico, surjan más centros de carga y servicios marítimos de corta distancia o con recaladas de ida y venida en más puertos de una misma costa o región marítima (Ducruet y Notteboom 2012: 14, 16). En el interior de esta, puede entonces modificarse la jerarquía de puertos, si sucede que el rol de PGW subregional emerge en un puerto distinto al otrora dominante o se distribuye entre más puertos de la costa, los cuales se hacen así atractivos para recibir grandes naves e incluso para eventualmente convertirse algunos en nodos de rutas marítimas directas, con el consiguiente aumento de su función de transbordo y la concomitante posibilidad de que también cambie su rol de PHT regional para algunas LN. Escenario que, en términos de la dinámica 
de EA, correspondería a un proceso de reversión del centro existente y su reemplazo por un nuevo centro o por un sistema multipolar (sección 1.1).

Ante esa posibilidad de multiplicación de PGW en subregiones extensas y dinámicas, unida a la vulnerabilidad del rol de PHT regional, para que un puerto pueda ejercer un liderazgo sostenido su objetivo debe ser alcanzar una combinación apropiada de funciones de transbordo y de GW subregional (Banco Mundial 2007 [recuadro 23]). Tal objetivo implica que, en virtud de los ya mencionados factores comerciales y empresariales, un mayor número de puertos podrían asumir el rol de centralidad, respecto a mercados de origen/ destino, y el rol de mediación (o intermediacy), respecto a configuraciones de rutas o servicios marítimos (Fleming y Hayuth 1994: 3). Estos autores agregan que ambos roles analíticos pueden darse juntos en la práctica, debido a que los avances en materia de transportes y comunicaciones permiten que surjan nuevos patrones y percepciones de localización estratégica, a la medida de distintos intereses comerciales y empresariales (Hayuth y Fleming 1994: 187). Ello también implica que dicho objetivo es alcanzable incluso para puertos localizados en lugares remotos de una costa o subregión, cuya desventaja geográfica puede ser revertida por la acción de fuertes intereses empresa-país que los doten de mejor infraestructura y acceso al foreland y al hinterland en comparación con otros puertos menos distantes en la costa o subregión relevante.

De ahí que, con miras a la consecución del objetivo de combinar ambos roles, los puertos en una misma subregión o costa enfrentan desafíos distintos según el alcance de la REMP a la que pertenece el OP de su terminal para contenedores. En el caso de que sea un OP global, este podrá contribuir grandemente al mencionado objetivo por el lado del foreland y más aún si tiene una LN global socia, al integrar al puerto a un entramado de rutas marítimas y puertos de gran alcance y densidad y al mejorar así su eficiencia en virtud de los menores costos fijos medios y costos operativos asociados a niveles superiores de EE (Vanelslander 2006: 16). También se benefician los dueños de la carga, que tendrian más opciones de rutas (directas e indirectas o feeder) para escoger según sus recursos y necesidades (Notteboom y Rodrigue 2008: 159).

Pero la reducción de costos operativos puede verse frenada por el lado del hinterland, si la REMP del OP global no cuenta con una bien establecida 
malla de PL afines alrededor del puerto y tierra adentro (sección 1.2). De ser así, el puerto quedaría expuesto no solo a que el manejo de la carga sea entorpecido por "cuellos de botella» logísticos que protegen el negocio de PL incumbents, sino también a que aquellos de estos que pertenecen a una REMP competidora -probablemente regional (sección 1.2)- medren la aglomeración de carga del puerto, desviándola hacia otros puertos para que el rol de PGW -y eventualmente el de PHT también- quede en manos del puerto favorecido por su REMP (Banco Mundial 2007: 35, 56); el cual probablemente será el "puerto matriz" (o home port) de la respectiva REMP regional, en razón de lo visto párrafos arriba. En términos de la network economics (sección 1.1), esos obstáculos revelarian que desde el segmento tierra se erigen incompatibilidades inter-REMP, que bajan la sensibilidad de la demanda (de dueños de carga y PL) a la mayor variedad de amalgamas de ofertas de servicios y bienes (Economides 1996: 690) marítimo-portuarios que implica el ingreso de la REMP global, con el propósito de mantenerla fijada a la "oferta compuesta" (o composite supply) de la REMP (regional o local) a la que pertenecen los PL tempranamente establecidos (Gottinger 2003: 11).

Por otro lado, de darse el caso de que el terminal de contenedores del puerto aspirante a combinar las funciones de GW y HT esté a cargo del OP de una REMP regional bien establecida, la contribución de esta no sería en principio tan grande por el lado del foreland y en eficiencia por nivel de EE, aunque quizá sí podría ser superior por el lado del hinterland, debido a las ya mencionadas ventajas que tienen los primeros en llegar (first-mover advantages) en cuanto a base de clientes, canales de distribución tierra adentro e influencia en la economía política doméstica. Pero, de lo antes visto, se desprende que esas ventajas solo serán instrumentadas en pro de la mencionada aspiración del puerto si encaja con la estrategia de la REMP regional, y que esta probablemente estará muy sesgada a favor de que su "puerto matriz» asuma las funciones de GW y HT, en razón de la fuerte simbiosis empresa-país típica de las REMP de ese alcance. De ahí que los puertos competidores en la misma costa o subregión, donde la REMP regional tenga una presencia dominante, pueden ver su aspiración combatida, esta vez no solo desde el segmento tierra sino desde los segmentos puerto y mar también, mediante una serie de obstáculos que, o podrían ser ocasionados o exacerbados por integrantes de la REMP regional (OP, PL, LN) o, si son generados por otros factores, tales integrantes podrían no sentirse urgidos a valerse de su fuerte influencia en la economía política doméstica en pro de una pronta solución de los problemas. 
En tal sentido, la literatura especializada resalta la importancia crucial de que el puerto se dote de instalaciones y equipos de alta productividad, con el propósito de hacerse atractivo para grandes naves (Cullinane y Khanna 1999: 205) y desarrollar sus funciones de aglomeración y transbordo de carga, lo que puede frustrarse por inversiones limitadas o parsimoniosas de un OP regional interesado en que esas funciones recaigan en su "puerto matriz". También reconoce el impacto negativo de PL basados en sistemas ineficientes de transporte en tierra vía camiones, que congestionan el acceso al puerto y contaminan el medio ambiente (Raimbault, Douet y Frémont 2013: 31). No solo pueden amplificarse esas externalidades negativas cuando el sistema ineficiente de transporte está acoplado a zonas logísticas que refuerzan el poder de PL incumbents para hacerlo perdurar (Raimbault et al. 2012: 2), sino que el desarrollo de tales zonas o de almacenes y terminales de contenedores en tierra (o "puertos secos») solo beneficia la aspiración del puerto marítimo si le acumulan carga a su favor, mas no si le desvían carga sin que medien razones de saturación o sustitución interportuaria neutra frente al mismo hinterland (Notteboom y Rodrigue 2005: 1, 10). Este desvío de carga -y de su aglomeración y transbordo- puede ser facilitado por la LN regional socia, con rutas marítimas que dirijan la carga hacia el respectivo "puerto matriz", incluso cuando está ubicado en dirección opuesta a la de sus mercados de destino (González Vigil et al. 2012: 75).

Evidentemente, entre los dos casos estilizados que se acaba de analizar, hay en la práctica muchas situaciones mixtas posibilitadas por los diversos híbridos de competencia y cooperación de que se valen las REMP para implementar sus respectivas estrategias. De ello dan fe las alianzas entre LN, las «familias ocultas» entre OP, los M\&A no hostiles y las "redes de mundo pequeño» (o small-world networks) entre unos y otros, que involucran a miembros de REMP de distintos alcances geográficos. De todo ello ya se hizo mención (sección 1.2), incluyendo las recientes M\&A entre miembros de small-world networks, es decir de LN regionales de origen chileno con LN globales de origen alemán (CSAV con Hapag-Lloyd y CCNI con Hamburg-Süd), citadas allí por su relevancia para la COAS en particular.

Sin mengua de lo anterior, lo analizado hasta aquí permite afirmar que para los países con algún puerto poseedor de atributos para convertirse en PGW (y eventualmente en PHT) y que en la misma costa o subregión compite por esos estatus con el "puerto matriz» de la REMP regional allí dominante, la 
opción en buena cuenta menos riesgosa y lejana en el tiempo consiste en recurrir a REMP globales. Esta es precisamente la opción escogida en tres de los principales puertos para contenedores de la COAS que no son «puertos matrices» de la REMP regional dominante en esa costa, tal como se mostrará en el presente documento. Puesto que en muchas otras costas o subregiones también sucede que el número de puertos aspirantes a ser GW y/o HT es mayor que el número de "puertos matrices» de las respectivas REMP regionales, cabe desear, en aras de la formación de estructuras regionales multipolares (sección 1.1), que siga intensificándose el liderazgo de REMP globales en el proceso de internacionalización portuaria (cuyos límites actuales fueron mencionados en la sección 1.2). Por añadidura, tal liderazgo contribuiría a una mejor inserción de las economías de los países sedes de los puertos aspirantes a ser PGW y/o PHT en CV/SC globales y en las más benéficas de entre las CV/SC regionales.

\section{Desarrollo portuario: estrategias de regionalización}

Una implicancia clave de lo anterior tiene que ver con las perspectivas de desarrollo portuario, especialmente de un puerto con atributos para aspirar al estatus de PGW y/o PHT. De lo analizado se deduce que esas perspectivas no pueden ser aprehendidas a cabalidad tomando al puerto aisladamente sino, por el contrario, identificando correctamente las jerarquías de puertos en las que está inmerso y las estrategias -empresariales y gubernamentales- que le permitirían escalar posiciones jerárquicas. Si bien en principio puede haber tantas estrategias como REMP existentes, la identificación se simplifica no solo porque en la práctica es siempre limitado el número de REMP con cuyas estrategias puede encajar la aspiración de un determinado puerto, sino también porque los conceptos básicos (sección 1.1) ayudan a focalizar el análisis al desprenderse de estos que una acertada estrategia de regionalización es indispensable para el desarrollo portuario. Ello debido a que las jerarquías de puertos dan cuenta de una tendencia global pero con coordenadas geográficas, cuyas manifestaciones concretas de desarrollo desigual portuario ocurren en el seno de los espacios de gravedad económica que son los ámbitos regionales, donde tales jerarquías son configuradas por la acción simultánea de fuerzas del mercado y de políticas nacionales y regionales.

En tal sentido, la literatura especializada ofrece dos versiones estilizadas del proceso de regionalización portuaria: la de un proceso basado en el hinterland 
y la de un proceso basado en el foreland. Como cada una apela a VC distintas, algunas propias de REMP regionales y otras de REMP globales, el análisis que sigue servirá para identificar el tipo de proceso que resultaría más afín a cada cual, así como el que sería más conveniente para un puerto según sea o no el home port de la REMP regional dominante.

Notteboom y Rodrigue plantearon primero la regionalización portuaria como un proceso basado en el hinterland (o hinterland-based regionalization), requerido por la expansión de $\mathrm{CV} / \mathrm{SC}$ internacionales que exige no limitar la visión del desarrollo de un puerto a su perímetro y alrededores, sino formularla en términos de mejorar su competitividad incrementando su conectividad con el segmento tierra mediante un conjunto de políticas y acciones de mercado que lo conecten más estrechamente con los centros de distribución y transporte de carga tierra adentro (Notteboom y Rodrigue 2005: 1-2). Esta hinterland-based regionalization se caracteriza así no solo por una fuerte interdependencia funcional entre un específico centro de carga portuario y un número seleccionado de plataformas logísticas multimodales tierra adentro, sino incluso por un proceso de desarrollo conjunto entre ambos conducente a la formación de "la red de un centro de carga regional» o a regional load centre network (Notteboom y Rodrigue 2005: 4-5). Nótese el uso del singular en esa formulación, que la expone a ser confundida con una visión unipolar de la jerarquía portuaria en una región, a través de la formación de una red de plataformas tierra adentro al servicio de la conversión de «un específico» puerto en «el» PGW subregional.

El enfoque analítico al respecto fue enriquecido por Ducruet, quien plantea la "región portuaria" (o port region) como un concepto multifacético que comprende no solo al perímetro del puerto y a su hinterland, sino también al sistema de relaciones interportuarias resultante tanto de la proximidad geográfica como de las interdependencias funcionales que se establecen entre los puertos de una costa o costas marítimamente colindantes, sistema que configura la región o zona donde la influencia económica de un puerto es predominante (Ducruet 2009: 3-5). Esta noción sistémica de port region no se limita al hinterland e internaliza la dinámica centro-periferia (H\&S), pues la región en cuestión representa un mercado (marítimo y tierra adentro) relevante, en el interior del cual las fuerzas gravitacionales a favor de un puerto pueden convertir a los otros en su periferia, con las consiguientes posibilidades de desviación de comercio. De hecho, ese autor detecta la 
existencia de desbalances regionales entre tráfico de contenedores y PBI, con algunas regiones mostrando más tráfico que el predecible según su tamaño económico y lo inverso sucediendo en otras, aunque los atribuye solo a dispares calidades de los servicios portuarios (Ducruet 2009: 10-11, 14).

De ahí que Rodrigue y Notteboom, conscientes de la ausencia del ámbito marítimo en su versión inicial de la regionalización portuaria, la reformularon luego como un proceso basado en el foreland o foreland-based regionalization. Este proceso permite reconciliar las características operacionales de los forelands y hinterlands, en la medida en que considera la necesidad de las LN de configurar la red de puertos conectados por sus servicios marítimos de una manera que combine las funciones de HT con las de GW, con el propósito de hacer sostenible el rol de sus PHT respecto a las CV/SC y a los otros puertos de la red (Rodrigue y Notteboom 2010a: 19-24). Reconciliación que también sintoniza con la necesidad de los dueños de la carga, de contar en su región con sistemas de puertos y de distribución de la carga en tierra que refuercen sus estrategias de exportación e inserción en CV/SC generadoras de valor. Ambas necesidades serían reconciliadas mediante rutas marítimas con recaladas de ida y vuelta en más de un puerto de una costa o costas colindantes, lo que implica la formación de «una red regional de centros de carga" o a regional network of load centres (Rodrigue y Notteboom 2010a: 5-8). Se destaca el uso del plural esta vez, significante de una visión regional multipolar, mejor alineada con la tendencia a la multiplicación de orígenes y destinos de la carga, así como con la existencia yuxtapuesta de distintas jerarquías portuarias reveladoras de estrategias (empresa-país) propias de cada REMP.

En términos de la network economics, la regionalización portuaria involucra la tarea de establecer compatibilidades parciales entre estándares de distintas REMP (Gottinger 2003: 11) en los tres segmentos de la cadena logística del SMP. Se trata de una tarea indispensable para que un puerto vea realizada su aspiración de consolidarse como PGW y eventualmente convertirse en un PHT también. Esa tarea de compatibilización parcial sería impulsada a partir del hinterland en la primera versión arriba expuesta y desde el foreland en la segunda.

Dado que las VC de las REMP globales en el segmento mar son muy necesarias para cumplir tal tarea en la versión foreland-based regionalization, 
esta probablemente sería la estrategia de desarrollo portuario que una REMP global aplicará a favor del puerto con atributos para ser PGW (y eventualmente PHT también), que haya logrado poner a su cargo -vía concesión o M\&A- en una región donde la incursión de su OP es reciente. Mientras que, dado que las VC de las REMP regionales en el segmento tierra son muy necesarias para cumplir dicha tarea en la versión hinterland-based regionalization, esta probablemente sería la estrategia de desarrollo portuario que una REMP regional aplicará en su región de origen, con un fuerte sesgo a favor de su "puerto matriz".

Evidentemente, aquí también corresponde aclarar que, entre aquellas dos opciones estilizadas de estrategia deducibles de las sendas versiones estilizadas de desarrollo portuario regionalizado, caben varias estrategias mixtas en la práctica. Ello debido, entre otras razones, a que la prevalencia de externalidades intrarred por sobre las interred (Birke 2009: 13) da margen para la coexistencia competitiva de los «servicios compuestos" ofrecidos por REMP de distinto tamaño o alcance geográfico, al mismo tiempo que hace potencialmente atractiva la posibilidad de M\&A entre estas.

Sin embargo, los mencionados aportes de Notteboom y Rodrigue en materia de regionalización portuaria proporcionan valiosos criterios adicionales para identificar el tipo de estrategia portuaria a la que REMP regionales pueden recurrir, especialmente cuando en su región ingresan OP de REMP globales, con el propósito de no perder cuota de mercado ni capacidad de competir por la carga y para liderar el soporte logístico a CV/SC en la región que les sirve de base. Esta identificación puede ser mejor calibrada con ayuda de la literatura especializada que aborda casos regionales desde la perspectiva de las respectivas REMP regionales dominantes. De entre esta literatura, para una investigación enfocada en la COAS como es la que genera el presente documento, resultan particularmente reveladores algunos estudios referidos al espacio de fuerzas de gravedad económica relevante para dicha costa (sección 1.1), que han sido elaborados después del ingreso de dos mega-OP globales (DPW y APMT) al puerto del Callao.

Por ejemplo, Wilmsmeier, Monios y Pérez constatan la reciente concentración del tráfico de contenedores en pocos PGW de América Latina y el Caribe $\mathrm{y}$, ante ello, reflexionan acerca de los factores impulsores necesarios para que puertos secundarios contribuyan a que esa concentración sea contra- 
rrestada (Wilmsmeier et al. 2013: 2). Sin embargo, si bien aquellos autores reconocen que la elección del rol de un puerto por parte de una REMP toma en consideración la ubicación geográfica y características físicas del puerto, optan por enfatizar otros factores como la estrategia de la LN, la eficiencia del puerto y su acceso al hinterland. Pero los analizan con un enfoque que los lleva a afirmar que dicha elección estaría determinada por la densidad de los flujos comerciales regionales atendidos por el puerto, por lo que sería un subproducto de la elección del "camino logístico" (logistic pathway) más conveniente para la REMP toda en términos de su desempeño y costos, cuyas asociadas EE solo darian cabida para un número muy limitado de centros de carga en la región (Wilmsmeier et al. 2013: 4).

En vista de lo anterior, dichos autores plantean que la descentralización portuaria insinuada por el reciente dinamismo de puertos secundarios -como los chilenos de San Vicente, Arica y Angamos, por ejemplo- podría contribuir al crecimiento de centros de carga y PGW de menor tamaño, lo que debiera ser impulsado mediante el desarrollo de un "camino logístico" conectado con el puerto principal (Wilmsmeier et al. 2013: 19). Dan así la impresión de que se trata de un enfoque analítico sesgado hacia la hinterland-based port regionalization, que concibe la descentralización portuaria, en el interior de un país y en las regiones de sus países vecinos que quiere hacer parte de su hinterland, como un mecanismo de apoyo a su PGW de mayor tamaño, el cual es probablemente el "puerto matriz" de la REMP regional originaria de tal país.

El contexto específico que explicaría la opción por ese enfoque analítico y las implicancias prácticas del mismo son más perceptibles en otro estudio coetáneo, donde Wilmsmeier pasa revista a los cambios marítimo-portuarios que están ocurriendo en la COAS, a resultas del ingreso de mega-OP globales a los terminales para contenedores de principales puertos no chilenos en dicha costa (como se detallará en el capítulo II del presente documento). Estos cambios se manifiestan, por ejemplo, en un arribo más frecuente de naves de mayor tamaño, un gran incremento de capacidad de transporte de carga en las principales rutas marítimas que conectan a la COAS y un mayor número de LN cubriendo las rutas transpacíficas entre la COAS y Asia (Wilmsmeier 2013: 15-17). Todo ello posibilitado en gran medida por las significativas mejoras en infraestructura portuaria y conectividad marítima de los puertos en la COAS que ahora están a cargo de mega-OP globales. 
Frente a ese nuevo contexto, anunciador de probables cambios en las jerarquías de puertos en el seno de la COAS, dicho autor reconoce que el sistema portuario de Chile está en una encrucijada (Wilmsmeier 2013: 18). Por esta razón plantea, teniendo como premisa que el carácter estratégico de la ubicación de un puerto (en una determinada jerarquía portuaria, se entiende) puede ser "fabricado" (o manufactured), la necesidad de una acción público-privada (para llevar a cabo tal "fabricación») guiada por una visión integrada y moderna de desarrollo portuario extendido al hinterland (Wilmsmeier 2013: 7, 18). Hinterland que, habida cuenta del peculiar trazo del territorio chileno, forzosamente incluye a territorios de países vecinos.

Aquella premisa de "fabricación" asimila la enseñanza de la literatura especializada, acerca de que los patrones y percepciones de localización estratégica se configuran a la medida de distintos intereses comerciales y empresariales (Hayuth y Fleming 1994: 187). Asimismo, aquel llamado a la acción público-privada refleja la convicción -compartida por muchos especialistas- de que el SMP es un sector estratégico (sección 1.1) y que, por ende, todo desarrollo portuario es un proyecto no solo empresarial sino político también, más aún cuando es concebido como una regionalización.

De hecho, la regionalización portuaria pensada por Notteboom y Rodrigue no es obra de empresas solamente. Comporta varias acciones público-privadas coherentes, de cara tanto al foreland como al hinterland, guiadas por políticas marítimo-portuarias de nuevo cuño y bien articuladas con otras políticas públicas que orienten la provisión de infraestructura, la formación de clústeres logísticos e industriales tierra adentro y la gobernanza de los mismos (Notteboom y Rodrigue 2005: 12, 18; Rodrigue 2010: 21). Es una labor muy compleja de por sí, ya que involucra a todos los niveles de gobierno y exige un gran esfuerzo de concertación con variopintos intereses privados. Su complejidad se acrecienta aún más por el hecho de que la regionalización significa que tal labor no se limita al ámbito nacional ni puede ser impuesta por un país, sino que debe ser resultante de negociaciones gana-gana con países vecinos y entre los respectivos sectores privados.

$\mathrm{Al}$ respecto, teniendo en cuenta que la proximidad geográfica y los acuerdos comerciales inciden grandemente en la configuración de nodos portuarios dominantes y subordinados (Ducruet y Notteboom 2012: 20-23), tiene alta prioridad el asegurar que los procesos de integración regional no favorezcan 
estrategias de "a regional load centre network» sino las estrategias que vayan en el sentido de "a regional network of load centres", porque estas últimas sí promoverían la estructuración de espacios económicos regionales multipolares y, por ende, menos desbalanceados o desequilibrados.

\subsection{Hipótesis de investigación}

Los conceptos básicos y los análisis especializados en el SMP que han sido explicados e interpretados en este capítulo, proporcionan un sólido sustento para formular ahora la hipótesis de investigación y las premisas que le dan lugar. Las premisas son: las estrategias de REMP globales y las de REMP regionales se asemejan en tanto que ambas reflejan las mismas tendencias que enmarcan la dinámica mundial del tráfico de carga en contenedores, pero se diferencian a nivel regional porque a este nivel son menos asimétricas sus respectivas VC de cara a la competencia por la carga y para el liderazgo de $\mathrm{CV} / \mathrm{SC}$ internacionales. De estas premisas se desprende la siguiente hipótesis sobre la materia específica de estudio que motiva el presente documento:

En materia de jerarquías de puertos y desarrollo portuario en una región, la estrategia que usualmente adopta una REMP global y la estrategia típica de una REMP regional se diferencian entre sí en dos aspectos clave: el criterio de localización estratégica con que seleccionan a los principales puertos subregionales que serían pilares de su jerarquía regional de puertos, y al tipo de proceso de regionalización portuaria que impulsan para desarrollar a esos puertos pilares. Es decir, el OP de una REMP global busca ingresar a los principales puertos subregionales que estén mejor ubicados con respecto al conjunto de rutas marítimas y puertos integrantes de la red, y tiende a desarrollarlos como pilares mediante una regionalización portuaria basada en el foreland, en razón de la fuerte VC de la REMP global en el segmento mar. Mientras que una REMP regional tiende, en su región de origen, a estructurar su jerarquía portuaria en torno de su "puerto matriz" como pilar central, y a desarrollarlo mediante una regionalización portuaria basada en el hinterland, debido a la fuerte VC que tiene en el segmento tierra de su base regional. 
Si bien la realidad es siempre más rica en variantes y mixturas de estrategias empresariales que el contraste estilizado al que convoca esa hipótesis, esta tiene la virtud de orientar con claridad la identificación de los probables efectos de cada estrategia en la jerarquía entre puertos de una misma región o costa, en términos de sus respectivas infraestructuras, eficiencias y conectividades. El análisis de estos efectos - para el caso de los principales puertos de la COAS- y de su impacto sobre la competitividad del comercio de los países involucrados, que necesariamente debe incorporar el rol de las respectivas políticas gubernamentales relevantes, será materia de las etapas subsiguientes de la investigación y sus correspondientes publicaciones. Entretanto, los otros dos capítulos del presente documento contienen el mapeo detallado de las REMP presentes en dicha costa, cuya identificación es un paso previo indispensable para poder elaborar con propiedad el análisis de efectos como los arriba mencionados, con miras a la verificación de la hipótesis. 


\section{Operadores portuarios y proveedores logísticos}

En este capitulo, se identifica a los operadores portuarios presentes -al año 2013- en cada uno de los cuatro principales puertos de la COAS, con énfasis en aquellos a cargo de los respectivos terminales para contenedores, así como a los proveedores logísticos que en dicho año brindaban servicios a la nave y/o la carga en tales terminales. Cada sección del capítulo está dedicada a un puerto y sus terminales para contenedores en particular, sobre cuyos operadores portuarios versan los primeros acápites (o subsecciones), y el último trata sobre los respectivos proveedores logísticos principales.

\subsection{Puerto de San Antonio, Chile}

El puerto chileno de San Antonio experimentó un gran cambio en su estructura organizacional y accionariado una vez decretada la reforma del régimen portuario chileno en 1997 mediante la Ley de Modernización Portuaria, que dio lugar a la creación de la Empresa Portuaria San Antonio (EPSA). Esta empresa estatal inició sus actividades en 1998 y se encargó de fiscalizar los procesos de concesión de los terminales norte y sur del puerto, ambos adjudicados en 1999. El Terminal Sur fue adjudicado al consorcio San Antonio Terminal Internacional (STI) S. A., conformado por Sudamericana Agencias Aéreas y Marítimas (SAAM) S. A. y S. S. A. Holdings International Chile, ambas con una participación de 50\% cada una. La concesión del Terminal Norte la obtuvo el consorcio Puertos Panul S. A., del cual formaron parte Graneles de Chile (40\%), SAAM (14,4\%), Inversiones Portuarias $(34,6 \%)$ e Inversiones Feld (11\%), empresas todas de capitales chilenos. Además, el puerto de San Antonio tiene otro muelle o terminal llamado Puerto Central, el cual está en manos de Puerto de Lirquén $(99,9 \%)$ y de Portuaria Lirquén (0,01\%), así como también cuenta con un Muelle 9 denominado Policarpo Toro, el cual es administrado al 100\% por la propia EPSA. 


\subsubsection{Terminal Sur: San Antonio Terminal Internacional (STI)}

\section{Sudamericana Agencias Aéreas y Marítimas S. A. (SAAM)}

SAAM es una empresa chilena fundada en Valparaíso en 1961, constituida actualmente como un conglomerado regional que presta servicios en tres áreas principales: logística, remolcadores y operación de puertos. SAAM forma parte del grupo empresarial de la Compañía Sudamericana de Vapores $(\mathrm{CSAV})^{44}$, sociedad en la cual CSAV representa la rama naviera y de servicios especiales en tanto que SAAM (propiedad en un 99,9995\% de la Sociedad Matriz SAAM, accionista de CSAV) presta tanto servicios portuarios y logísticos en tierra como servicios navieros que incluyen atraque, desatraque, salvataje de naves y asistencia en operaciones off shore, esto último con alcance regional y a veces incluso global ${ }^{45}$.

Esa relación accionarial entre CSAV y SAAM denota la existencia de una integración vertical entre los servicios de mar (naviera) y los servicios en tierra (operaciones portuarias y logísticas), que permite aglomerar carga para aumentar la cuota o participación en el movimiento de la misma, tanto en tierra como por mar, utilizando las rutas marítimas definidas por la naviera principal del grupo (CSAV, en este caso). Tal integración vertical explica a su vez el patrón de expansión regional llevado a cabo por SAAM, el cual ha seguido la trayectoria de crecimiento de CSAV y de sus rutas marítimas.

En efecto, la expansión de SAAM a nivel regional se inició en 1991 con la creación de Trabajos Marítimos S. A. (Tramarsa) en el Perú; luego, en 1995, de Ecuaestibas S. A. en Ecuador, y con la adquisición del 50\% de las acciones de Elequip S. A. y de Equimac S. A. en Colombia; posteriormente, accedió a Uruguay, Brasil, Guatemala, Costa Rica, México y los Estados

\footnotetext{
44. Vale aclarar, con validez para todas las veces que CSAV y SAAM sean mencionadas en el presente documento, que la información trabajada para elaborarlo cubre el período hasta el año 2013, anterior a la fusión en curso de CSAV con Hapag-Lloyd para lo relativo al transporte marítimo de carga en contenedores. Al cierre de este documento, todavía no se dispone de información precisa sobre lo que tal fusión conllevará respecto a las actividades de SAAM ni respecto a lo que más adelante se explica acerca de la pertenencia de CSAV y SAAM al conglomerado empresarial chileno de la familia Luksic. Sobre dicha fusión, véanse las respectivas notas a pie de página insertas en el acápite 3.2.1 del capitulo III.

45. En:<http://www.saam.cl>. Consultado el 22/10/2013.
} 
Unidos (Florida International Terminal) entre los años 2005 y 2006. La mayor parte de empresas filiales de SAAM a nivel regional prestan servicios de remolque naviero y estiba ${ }^{46}$.

En febrero de 2012, se constituyó la Sociedad Matriz (SM) SAAM como empresa aparte pero ligada a CSAV. En la imagen mostrada en el cuadro 1 , se observa la estructura del capital accionario de SM SAAM al 30 de septiembre de 2013, la cual pone de manifiesto el carácter nacional (chileno) de la empresa, puesto que solo el 5,7\% de las acciones se encuentran en poder de inversores extranjeros. Ahora bien, a primera vista aparece como si fuese muy diversificada la composición de los accionistas chilenos, dada la presencia de empresas en rubros tan diversos como retail, banca, AFP, corredores de bolsa e inmobiliarios, y otros de vinculación poco evidente con el giro principal de negocios de SM SAAM ${ }^{47}$.

\section{Cuadro 1}

Composición accionaria de SM SAAM, al 30 de septiembre de 2013

\begin{tabular}{|l|r|r|}
\hline \multicolumn{1}{|c|}{ Nombre } & Acciones & Porcentaje \\
\hline Inversiones Río Bravo S. A. & 3.237 .543 .274 & $33,25 \%$ \\
Marítima de Inversiones S. A. & 716.016 .838 & $7,35 \%$ \\
Quiñenco S. A. & 713.481 .340 & $7,33 \%$ \\
Banco de Chile por Cuenta de Tercero no Residentes & 397.141 .323 & $4,08 \%$ \\
Philtra Limitada & 353.702 .288 & $3,63 \%$ \\
BTG Pactual Chile S. A. Corredores de Bolsa & 332.769 .265 & $3,42 \%$ \\
Banco Itaú por Cuenta de Inversionistas & 315.650 .533 & $3,24 \%$ \\
Banco Santander por Cuenta de Inversionistas Extranjeros & 283.552 .444 & $2,91 \%$ \\
Inmobiliaria Norte Verde S. A. & 181.313 .939 & $1,86 \%$ \\
Cía. de Seguros de Vida Consorcio Nacional de Seguros S. A. & 179.632 .850 & $1,84 \%$ \\
Banchile Corredores de Bolsa S. A. & 152.785 .968 & $1,57 \%$ \\
Larrain Vial S. A. Corredora de Bolsa & 145.473 .772 & $1,49 \%$ \\
Otros & 2.727 .728 .149 & $28,01 \%$ \\
\hline Total & 9.736 .791 .983 & \\
\hline
\end{tabular}

Fuente: página web de SAAM: Accionistas (16/1/2014).

46. Véase: <http://www.saam.cl/prontus_saam/site/artic/20120502/asocfile/20120502170311/bitacora_34. pdf>. Consultado el 6/1/2014.

47. Véase: <http://www.smsaam.cl/prontus_smsaam/site/artic/20120404/asocfile/20120404184816/ santander_presentation_2012_09_24.pdf>.Consultado el 16/1/2014. 
Sin embargo, lo real es que más de la mitad del accionariado de SM SAAM se encuentra en posesión de tres grupos económicos chilenos (Luksic, Claro y Schiess), lo cual significa que la estrategia de la empresa responde fundamentalmente a los intereses empresariales marítimo-portuarios de Chile. De entre esos tres grupos chilenos, sobresale la participación accionaria del Grupo Luksic, vía Quiñenco S. A. ${ }^{48}$ y su filial Inversiones Río Bravo S. A. (formada el año 2009 como transadora y administradora de sociedades anónimas y sus derechos) y su subsidiaria Inmobiliaria Norte Verde S. A. ${ }^{49}$, a través de las cuales concentra el 42,44\% de las acciones en SM SAAM y ha obtenido 6 de los 11 asientos en el directorio de la misma.

Quiñenco fue creada en 1957 como la matriz de inversiones financieras e industriales del Grupo Luksic, el cual desde mediados de la década de 1980 emprendió un proceso de diversificación a partir del cual Quiñenco supervisa los negocios del grupo en varios sectores: servicios financieros (Banco de Chile), bebidas y alimentos (Compañía Cervecerías Unidas S. A.), manufacturas (Invexans y Madeco), energía (Empresa Nacional de Energía - Enex S. A., que opera con Shell), transporte (CSAV) y puertos (SM SAAM). Por otro lado, entre los accionistas de Quiñenco se encuentran empresas que también son accionistas de SM SAAM: Banchile Corredores de Bolsa; Larraín Vial, que promueve el MILA a raíz de sus operaciones en Chile, Perú y Colombia; Banco Santander; Banco de Chile; y Banco Itaú ${ }^{50}$. Esta integración a nivel accionario entre las empresas chilenas refleja lo examinado en el capitulo I sobre la tendencia global a la formación de holdings financieros crecientemente vinculados a los rubros de servicios de transporte, incluyendo los marítimos y sus multimodales conexiones tierra adentro.

A lo anterior cabe añadir que los tres grupos económicos chilenos dominantes en SM SAAM (Luksic, Claro y Schiess) son también accionistas de CSAV, lo cual indica que la conexión entre CSAV y SAAM, aparentemente separadas desde el año 2012, se lleva a cabo a través de dichos grupos y especialmente

\footnotetext{
48. Desde 1996, año de reorganización de la estructura de propiedad del Grupo Luksic, todas las inversiones financieras e industriales quedaron bajo la administración de Quiñenco. El $81 \%$ de las acciones de la empresa son de propiedad del Grupo Luksic, mientras la participación restante se divide entre accionistas minoritarios. Véase: <http://www.quinenco.cl/esp/grupo_luksic.html>. Consultado el 16/1/2014.

49. Véase:<http://www.quinenco.cl/archivos/memorias_anuales/memoria_rio_bravo_2012.pdf>.Consultado el 10/1/2014.

50. En:<http://www.quinenco.cl>. Consultado el 9/1/2014.
} 
del Grupo Luksic, principal controlador de SM SAAM y por tanto el vínculo más relevante entre la rama naviera y la rama portuaria. Asimismo, el Grupo Luksic ha ido incrementando su participación directamente en Quiñenco e indirectamente en SM SAAM ${ }^{51}$ (cuadro 2), lo cual refleja su interés por consolidar aún más el control que ya ejerce sobre CSAV y SAAM.

En el rubro de logística, SAAM ofrece casi todos los servicios para carga de contenedores (agenciamiento marítimo, depósito y maestranza, operaciones marítimas y de terminales incluyendo frigoríficos, almacenamiento, incluyendo el ex portuario y transporte en tierra), así como para cargas a granel y masivas (agente embarcador, transferencia y movilización). SAAM no solo se ha posicionado como uno de los principales operadores logísticos en Chile a través de la empresa SAAM Logística, sino que también ha logrado éxito en sus operaciones en otros países de la región. En el Perú posee Tramarsa, la cual opera como agencia naviera y de estiba en los puertos de Callao, Ilo, Matarani, Pisco, Chimbote, Salaverry, Chicama y Paita; también posee Construcciones Modulares, dedicada a la venta y arriendo de contenedores. En Uruguay, cuenta con la subsidiaria Gertil S. A., la cual presta servicios de transporte de carga y operaciones marítimas, así como con Riluc S. A., empresa con participación de capitales uruguayos y que presta servicios de transporte. En Colombia ${ }^{52}$, además de su presencia en el puerto de Barranquilla y de su proyectada incursión en el puerto de Cartagena (véase II.2.4, más adelante), opera con Transaéreo Ltd., empresa dedicada a la atención de aeronaves y la provisión de servicios para el embarque/descarga de pasajeros y mercancías. En Brasil, realizó la apertura de SAAM do Brasil, colocada estratégicamente en la ciudad sureña de Itajaí, cuyo puerto es el segundo más importante de ese país.

En el rubro de remolcadores, ofrece los servicios de atraque y desatraque de naves, remolques, salvataje y asistencia en operaciones off shore, todos

\footnotetext{
51. Véase:<http://www.smsaam.cl/informe-a-inversionistas/prontus_smsaam/2012-04-04/185034.html>. Consultado el 16/1/2014.

52. Tal como se mencionará en la sección sobre el puerto de Buenaventura, SAAM poseía hasta julio de 2013 el $50 \%$ de las acciones de Equimac S. A., a través de la cual participaba indirectamente de la SPRB, así como el 49,8\% de acciones en Elequip S. A. con lo cual integraba el Terminal Especializado de Contenedores de Buenaventura S. A. (Tecsa). Ambas participaciones accionarias las vendió a PAC de Hong Kong, predecesor de NWS Holdings y que actualmente tiene una importante participación accionaria (del $25 \%$ ) en el puerto colombiano de Buenaventura.
} 
provistos en o desde los puertos en que está presente. En Chile, SAAM realiza estos servicios en y desde los puertos de Arica, Iquique, Mejillones, Antofagasta, Coquimbo, Quintero, Valparaíso, Talcahuano y San Antonio. Las remolcadoras subsidiarias de SAAM están presentes en Perú (incluyendo Callao), México, Guatemala, Honduras, Ecuador (incluyendo Guayaquil), Uruguay, Brasil, Colombia (Santa Marta) y Costa Rica.

\section{Cuadro 2}

Distribución de inversiones del Grupo Luksic por empresa y sector

\begin{tabular}{|c|c|c|c|c|c|}
\hline Sector & Empresa & $\%$ de control & $\begin{array}{l}\text { Capitalización } \\
\text { de mercado }\end{array}$ & Productos & $\begin{array}{c}\text { Posición en } \\
\text { la industria } \\
\text { (2012) }\end{array}$ \\
\hline \multirow[t]{2}{*}{ Financiero } & \multirow{2}{*}{$\begin{array}{c}\text { Banco de } \\
\text { Chile }\end{array}$} & \multirow{2}{*}{$\begin{array}{c}58,5 \% \text { (en alianza } \\
\text { con Citigroup) }\end{array}$} & \multirow[t]{2}{*}{ US\$ 14.020 millones } & Colocaciones & 2 \\
\hline & & & & Depósitos & 1 \\
\hline \multirow{10}{*}{$\begin{array}{l}\text { Bebidas y } \\
\text { alimentos }\end{array}$} & \multirow{10}{*}{$\mathrm{CCU}$} & \multirow{10}{*}{$\begin{array}{c}\text { 61,6\% (en alianza } \\
\text { con Heineken) }\end{array}$} & \multirow[t]{10}{*}{ US\$ 4.390 millones } & Cervezas en Chile & 1 \\
\hline & & & & Cervezas en Argentina & 1 \\
\hline & & & & Bebidas gaseosas & 2 \\
\hline & & & & Néctares & 1 \\
\hline & & & & Agua mineral & 1 \\
\hline & & & & Vinos & 2 \\
\hline & & & & (exportación) & 3 \\
\hline & & & & (mercado local) & 1 \\
\hline & & & & Pisco & \\
\hline & & & & Ron & \\
\hline \multirow{6}{*}{$\begin{array}{c}\text { Manufactu- } \\
\text { rero }\end{array}$} & \multirow{6}{*}{$\begin{array}{l}\text { Madeco } \\
\text { Nexans }\end{array}$} & \multirow{6}{*}{$\begin{array}{l}65,9 \% \\
22,5 \%\end{array}$} & \multirow[t]{6}{*}{ US\$2 260 millones } & Envases flexibles & \\
\hline & & & & (en Chile) & 1 \\
\hline & & & & (en Perú) & 1 \\
\hline & & & & Tubos y planchas & 2 \\
\hline & & & & Perfiles de aluminio & \\
\hline & & & & Sistemas de cables & \\
\hline \multirow[t]{2}{*}{ Energía } & \multirow[t]{2}{*}{ ENEX } & \multirow[t]{2}{*}{$100 \%$} & \multirow[t]{2}{*}{ US\$ 920 millones } & Combustible & 2 \\
\hline & & & & Estaciones de servicio & 2 \\
\hline \multirow[t]{2}{*}{ Transporte } & \multirow[t]{2}{*}{ CSAV } & \multirow[t]{2}{*}{$46,0 \%$} & \multirow[t]{2}{*}{ US\$ 800 millones } & Contenedores & \\
\hline & & & & (Latinoamérica) & 1 \\
\hline \multirow{3}{*}{$\begin{array}{c}\text { Servicios } \\
\text { portuarios y } \\
\text { navieros }\end{array}$} & \multirow{3}{*}{$\begin{array}{c}\text { SM } \\
\text { SAAM }\end{array}$} & \multirow[t]{3}{*}{$42,4 \%$} & \multirow[t]{3}{*}{ US\$ 940 millones } & Operador portuario & \\
\hline & & & & (Latinoamérica) & 2 \\
\hline & & & & $\begin{array}{l}\text { Remolcadores } \\
\text { (Mundo) }\end{array}$ & 4 \\
\hline
\end{tabular}

Fuente: página web de Quiñenco (10/1/2014). 
La rama de terminales portuarios se destaca por el posicionamiento que ha alcanzado SAAM en Chile y a nivel regional, dado que tiene el manejo de los terminales en los puertos más importantes de Chile y posiciones estratégicas en Mazatlán (México), Guayaquil (Ecuador) y Florida (Estados Unidos), donde presta servicios a toda clase de cargas entre contenedores (rama principal vinculada a CSAV), cargas a granel, carga suelta y carga proyecto. Estos servicios incluyen la transferencia de carga a la nave, almacenaje, servicios a contenedores (almacenamiento, mantenimiento, acondicionamiento y refrigeración) y servicios logísticos complementarios como: consolidación y desconsolidación de contenedores, aforo e inspección de carga, pesaje, trinca y destrinca, y porteo de carga. En Chile, SAAM tiene concesiones para proveer servicios portuarios y logísticos en terminales de los puertos de Arica, Iquique, San Vicente, Antofagasta y San Antonio (Terminal Sur - STI y Terminal Norte - Puerto Panul).

\section{SSA Holdings International Chile Ltd..$^{53}$}

SSA Holdings International Chile es la subdivisión local de SSA Holdings International, una subsidiaria de propiedad de FRS Service Companies Inc. ubicada en los Estados Unidos. FRS Service Companies es un grupo empresarial norteamericano que provee procesos de control realizados por especialistas en sistemas de migración, en los sectores institucional, industrial, farmacéutico y marino, y de sistemas integrados de soluciones y servicio. FRS cuenta también con una división de control de productos para los cuales ofrece consultoría y sistemas de diseño de servicios, supervisión in situ, gestión de proyectos y contrataciones. FRS Service Companies opera desde 1987 y tiene entre sus clientes a universidades, hospitales y navieras. Su pertenencia al consorcio STI se explica entonces por su vasta experiencia en procesos de control marítimo y de operaciones como las realizadas en la logística de un puerto.

\subsubsection{Puerto Panul ${ }^{54}$}

Puerto Panul es el mayor operador chileno de granel sólido en el puerto de San Antonio, concentrado en los servicios de muellaje, transferencia de

53. En:<http://www.frscontrols.com/link.php?link=Products_Solutions:main>. Consultado el 24/10/2013.

54. En:<http://www.panul.cl/>. Consultado el 25/10/2013. 
carga y demás servicios en el frente de atraque. Los productos que circulan a través de Puerto Panul son productos agrícolas como trigo, maíz y soya, en su mayor parte importados desde países del Mercosur y eventualmente reexportados en parte a países de la COAS y otras regiones del mundo. Puerto Panul tiene como hinterland nacional las zonas centro y sur de Chile correspondientes a las regiones quinta, sexta y metropolitana de ese país; mientras que los principales destinos nacionales de las cargas que se transfieren desde el puerto son las regiones séptima y metropolitana. Puerto Panul está ubicado en el Terminal Norte del puerto de San Antonio, terminal que está especializado en carga a granel sólido pero que no se limita a esta. La empresa que lo agencia es Puerto Panul S. A., que opera en el sitio N. ${ }^{\circ} 8$ del frente de atraque.

Puerto Panul S. A. fue fundada el 14 de octubre de 1999 al adjudicarse la concesión por un período de 30 años del frente de atraque del Terminal Norte del puerto de San Antonio, específicamente del sitio N. ${ }^{\circ}$ 8. Desde entonces, Puerto Panul atiende el 80\% de la demanda de servicios portuarios del puerto de San Antonio, lo que le ha permitido situar a este puerto como el que más carga a granel moviliza en Chile y a la empresa como el mayor operador de carga a granel sólido en San Antonio.

\section{Gráfico 1}

Estructura accionaria de Puerto Panul, al 25 de octubre de 2013

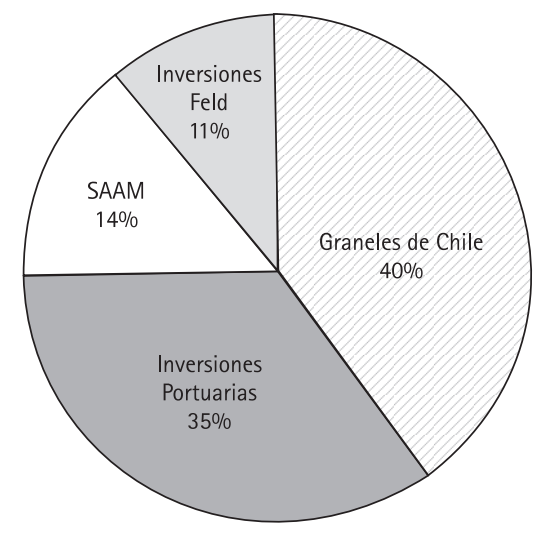

Fuente: página web de Puerto Panul: Accionistas. 
El 28 de octubre de 2013, ocurrió un cambio importante en la estructura accionaria de Puerto Panul S. A. cuando SAAM e Inversiones Portuarias Ltd. vendieron la totalidad de sus acciones (tenian respectivamente el 14,4\% y el 34,6\% del capital accionario de Puerto Panul, según lo mostrado en el gráfico 1) a Marítima Valparaíso Chile, con lo cual esta empresa controla ahora el 49\% de las acciones y es el socio mayoritario de Puerto Panul 55 .

\section{Graneles de Chile Ch $^{56}$}

Graneles de Chile S. A. es una empresa de ese país que provee servicios de logística para el abastecimiento de carga a granel coordinando sus operaciones desde la oficina central en Rancagua y con el apoyo de las oficinas situadas en Argentina, Brasil y los Estados Unidos (Minneapolis), lo que le permite operar directa e indirectamente 2 millones de toneladas de carga anuales. Actualmente, Graneles de Chile moviliza cereales (maíz, trigo y sorgo), subproductos de cereal (gluten de maiz, gluten feed y afrecho de trigo), concentrados de proteína vegetal y premezclas, aunque la empresa vislumbra una expansión hacia más productos y materias primas provenientes del agro.

\section{Inversiones Portuarias Ltda. (Familia Skalweit Wachsmann) ${ }^{57}$}

La Sociedad de Inversiones Portuarias Ltda. es una empresa de capitales chilenos que posee una cartera de proyectos que comprende los rubros de operaciones portuarias, transporte, muebles e inmobiliaria, gestionada mediante las siguientes empresas: Empresa de Servicios Marítimos Hualpén Limitada, Servicios Portuarios Reloncaví Limitada, Inmobiliaria Carriel Limitada, Transportes Fluviales Corral S. A., La Oriental Chile Limitada, Muebles CC Limitada (antes Muebles Canelos y Campos Limitada), Inversiones Naguilán Limitada y Portuaria Corral S. A.

55. Véase: <http://www.maritimoportuario.cl/?contenido=detallesNoticiątid_not=282>. Consultado el $31 / 10 / 2013$.

56. En: <http://www.granelesdechile.cl/>. Consultado el 25/10/2013.

57. Véase: <http://www.panul.cl/archivos/5884memoria_anual_2010.pdf>. Consultado el 26/10/2013. 
El 99,9\% del capital social de la Sociedad de Inversiones Portuarias Ltd. está en manos de Castor Inversiones Ltd., empresa chilena constituida el 19 de diciembre de 1989 en la ciudad de Talcahuano con el objetivo de ejecutar operaciones mercantiles de toda naturaleza: de inversión y para adquirir derechos y acciones en sociedades ya formadas, en valores mobiliarios e inmobiliarios, y en otros activos financieros.

\section{Inversiones Feld ${ }^{58}$}

Empresa chilena perteneciente a la familia Santa María, propietaria de Agrícola Manuel Santa María S. A., fundada en 1999 en la VII Región, y que también tiene participación accionaria en Comercial AMS Family S. A. (50\%) y Comercial AMS Traders S. A. $(84,86 \%)^{59}$, así como en Agrícola Vima Ltd. (90\%). La participación accionaria de la familia en Puerto Panul es un reflejo de una estrategia por consolidar cadenas de valor entre la rama productiva y la comercial de alimentos especialmente.

\section{Marítima Valparaíso Chile ${ }^{60}$}

Marval S. A. es el nuevo socio de Puerto Panul con 49\% del accionariado. Es una empresa chilena que inició operaciones en 1989 en el rubro de chartering internacional y posteriormente en servicios de agenciamiento liner, a los cuales ha añadido varios otros servicios portuarios, marítimos y logísticos, con base en los cuales ha compuesto una red que cubre los principales puertos de Chile y otros puertos importantes de la región. Para sus operaciones con líneas marítimas regulares, Marítima Valparaíso tiene una división comercial en Santiago y una presencia generalizada en puertos de Chile: Arica, Iquique, Antofagasta, Valparaíso (oficina central), San Antonio (ahora en Puerto Panul) y Talcahuano. Asimismo, cuenta con oficinas en Lima, La Paz, Río de Janeiro y Miami, con lo que asegura la eficiencia y control logístico de sus operaciones. En virtud de esa amplia cobertura y sus operaciones de líneas marítimas regulares, Marval se ha ubicado entre las más importantes empresas marítimas de Chile.

58. Véase: <http://www.panul.cl/archivos/5884memoria_anual_2010.pdf>. Consultado el 14/1/2014.

59. Cuyos productos incluyen arándanos, ciruelas, cerezas, kiwis, manzanas, peras y vinos. Véase: $<$ http:// www.amsfamily.com/>. Consultado el 14/1/2014.

60. En: <http://www.marval.cl/>. Consultado el 27/10/2013. 
En lo referido a transporte marítimo, Marval S. A. ofrece servicios a través de su subsidiaria Compañía Naviera Valparaíso (Conaval), establecida en 1998. Conaval está especializada en el manejo de carga a granel, carga general y cargas especiales. Desde 1995, Conaval ha añadido a sus servicios regulares los de rutas entre la costa oeste y este de Sudamérica que conectan con Brasil, con el propósito de aprovechar intensivamente las oportunidades abiertas por el convenio bilateral Chile-Brasil. La oficina de Marval S. A. en Río de Janeiro facilita el control de esas rutas, frecuentemente dedicadas a cargas en granel y productos derivados del acero.

En cuanto al agenciamiento de naves, la compañía atiende tráficos regulares entre Norteamérica y las costas este y oeste de Sudamérica, con clientes como Seaboard Marine Ltd. y de la propia Conaval, a los que Marval ofrece servicios de estiba y desestiba para carga general, contenedores y cargas de proyecto con servicios integrales: agenciamiento general y portuario, estiba y desestiba, manejo de cargas extrapeso/extradimensión, operación de naves, equipo portuario e intermodal.

En el rubro de terminales, Marval S. A. y sus filiales ubicadas en dos terminales de carga ubicados en Valparaíso (con acceso directo a Santiago) y San Antonio, proveen los servicios de: terminal extraportuario, operaciones de importación, exportación y tránsito, estación de transferencia de fruta (cross dock), consolidado y desconsolidado de contenedores, almacenaje de contenedores llenos (dry \& reefer), servicio a contenedores reefer, disponibilidad de power packs (para terminales y para naves), manejo de cargas de proyecto, manejo de cargas extradimensión y extrapeso, almacenaje cubierto y descubierto, control de inventario, distribución interior de cargas, picking y preparación de órdenes, paletizado, etiquetado y enzunchado, transporte terrestre internacional, disponibilidad de equipo intermodal, documentación de importación, exportación y tránsito, depósito y maestranza de contenedores y Tank Containers ISO 20.

Finalmente, para el rubro de servicios logísticos, Marval S. A. cuenta con la División Logística de Marítima Valparaíso (Margloval), empresa que ofrece servicios de: terminales de carga y contenedores, estación de transferencia de fruta y perecibles (cross dock), almacenaje de contenedores reefer, almacenaje cubierto y descubierto, transporte terrestre nacional e internacional, operaciones de transporte intermodal, manejo de cargas de 
proyecto, manejo de cargas extrapeso y extradimensión, documentación de importación, exportación y tránsito, acuerdos de operación logística, y estudios de factibilidad.

\subsubsection{Puerto Central}

\section{Puerto de Lirquén S. $A^{61}$}

Puerto Central o Puerto Lirquén, como indistintamente se le conoce, es un importante puerto privado de servicio público en Chile. El accionariado de esta zona del puerto de San Antonio está controlado en un 99,9\% por Puerto de Lirquén S. A., cuyos principales accionistas son los grupos económicos Matte (70\%) y Angelini (24\%). Portuaria Sur, de Puerto de Lirquén S. A., es un terminal multipropósito que se inició hacia 1953 como prolongación de las instalaciones portuarias de la Carbonífera Lirquén para el transporte de los productos de sus plantas.

Puerto Lirquén mantiene como áreas de negocios independientes aquellas referidas a contenedores y carga de tipo break bulk para importadores, exportadores y armadores, a los cuales ofrece servicios de sitio (almacenaje) y eficiencia (logística en puerto). Cuenta con un muelle propio que ha ampliado con zonas de calado, almacenamiento, bodegas y secciones de manejo de carga, así como infraestructura suficiente para garantizar la conectividad del puerto, esto último gracias a carreteras y ramales ferroviarios.

Recientemente, Puerto de Lirquén S. A. ha expandido su presencia en San Antonio. En efecto: «En mayo de 2011, Puerto de Lirquén S. A. se adjudicó la concesión a 20 años del Frente de Atraque Costanera - Espigón del Puerto de San Antonio, llevada a cabo por la Empresa Portuaria San Antonio (EPSA), y en julio del mismo año formó Puerto Central S. A. con el objeto de construir, desarrollar, mantener, reparar y explotar» dicho frente de atraque ${ }^{62}$. 


\subsubsection{Policarpo Toro (Muelle 9)}

\section{Empresa Portuaria San Antonio (EPSA) ${ }^{63}$}

"La Empresa Portuaria San Antonio (EPSA) es una empresa autónoma del Estado, creada por ley en diciembre de 1997, cuyo objeto es la administración, conservación y desarrollo de la actividad marítimo-portuaria del Puerto San Antonio. La propiedad de la empresa es 100\% estatal y no participa en la propiedad de otras empresas filiales ni coligadas. Su política de financiamiento se sustenta con recursos propios» ${ }^{64}$.

La empresa administra el puerto de San Antonio, el cual es el principal de Chile y cuyo hinterland más cercano es el centro del país y la provincia de Mendoza de Argentina. En 2011, terminó el proceso de concesión de la totalidad de la infraestructura portuaria en dicho puerto y ahora lleva a cabo un nuevo proceso de consolidación de su sistema portuario.

\subsubsection{Proveedores logísticos ${ }^{65}$}

A continuación, se pasa revista a los principales proveedores logísticos que, al año 2013, brindaban sus servicios a las naves portacontenedores y/o a los dueños de la carga respectiva, que en dicho año utilizaban el Terminal Internacional (STI) del puerto de San Antonio. La cantidad de servicios suministrados por cada proveedor es mostrada en el cuadro 3, como primer dato básico con miras a la estimación de su cobertura de la cadena logística y cuota en el mercado de la carga.

63. En:<http://www.sanantonioport.cc.cl>. Consultado el 28/10/2013.

64. Cita de <http://www.sanantonioport.cc.cl/index1.html>. Consultado el 28/10/2013.

65. En: <http://www.sanantonioport.cc.cl/html/sist_portuario/Servicios_navieros.pdf>. Consultado el 28/10/2013. 


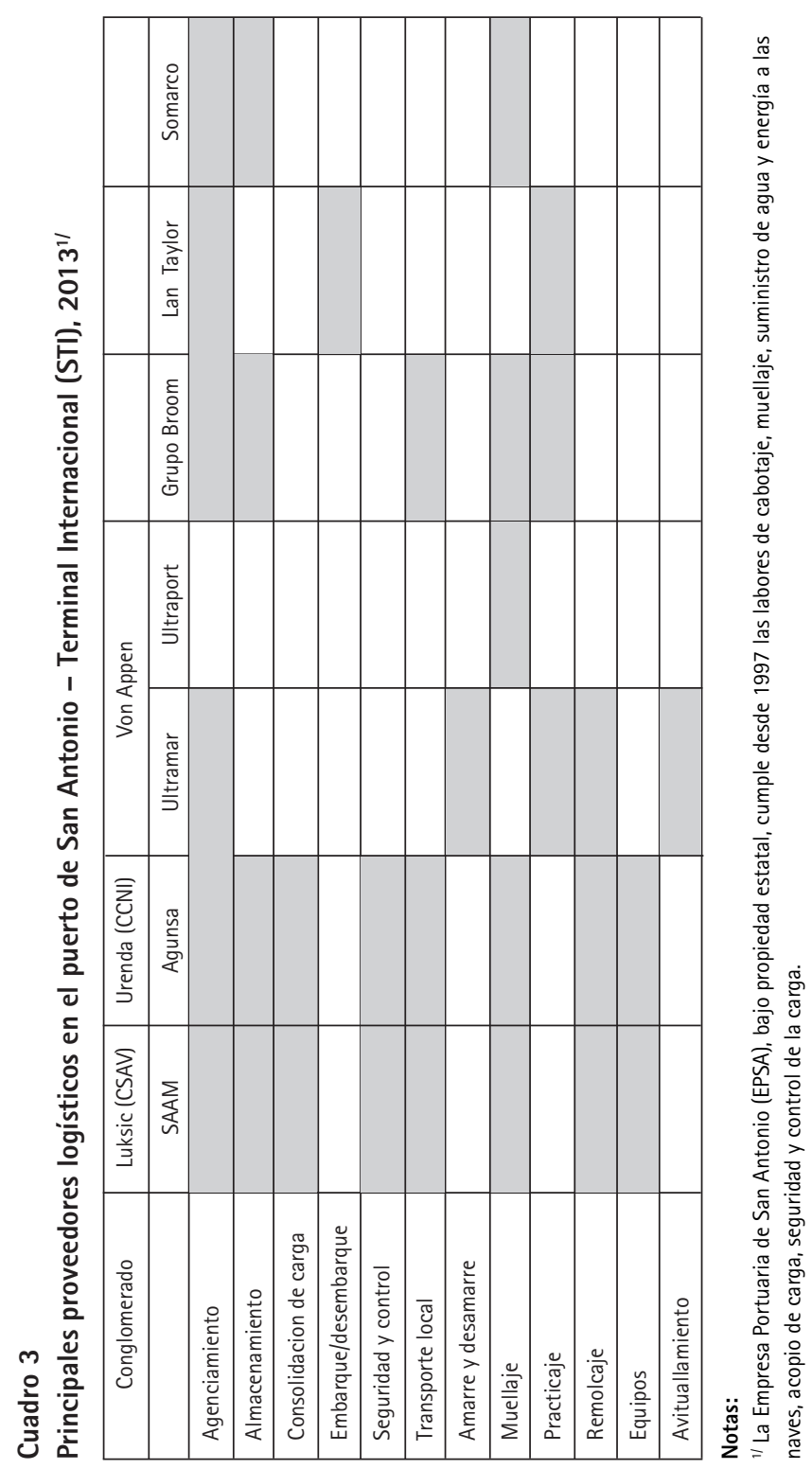




\section{Agencias Universales S. A. (Agunsa Chile)}

Agencias Universales S. A. es una agencia naviera chilena adquirida en 1961 por la Compañía Chilena de Navegación Interoceánica S. A. (CCNI) para ejercer casi en su totalidad actividades logísticas en el rubro marítimo y su brazo tierra. El 99,95\% de las acciones de la empresa pertenecían a Inversiones Cabo Froward S. A., la cual se fusionó con CCNI, constituyéndose Agencias Universales S. A. (Agunsa), y así esta empresa pasó a ser controlada, al igual que CCNI, por el conglomerado empresarial chileno de la familia Urenda (tal como se verá en el capítulo III) ${ }^{66}$.

Como estrategia de posicionamiento a nivel regional, Agunsa inició en 1992 procesos de adquisición de empresas de agenciamiento marítimo en Guayaquil, Mendoza, Panamá y Colombia (en Bogotá y Cali en 1995) y llegó al Callao a través de su subsidiaria Imupesa, con la cual formó un terminal extraportuario. Entre finales de la década de 1990 y mediados de la de 2000, Agunsa compró y formó empresas en Paraguay, Venezuela y Jamaica, y amplió su área de influencia hacia los Estados Unidos mediante la formación del consorcio Florida International Terminal en conjunto con SAAM y la constitución de Agunsa Europa S. A. ${ }^{67}$.

Agunsa ha desarrollado una estructura de cadenas de valor para los servicios que presta en vías aéreas, marítimas y terrestres. Estas cadenas incluyen servicios como los siguientes: almacenaje, embalaje, distribución y control de inventarios; agenciamiento aéreo, marítimo y portuario, documentación y administración de contenedores; devanning (desconsolidación), surveys (informes) y control de contenedores.

66. Vale aclarar, con validez para todas las veces que CCNI y Agunsa sean mencionadas en el presente documento, que la información trabajada para elaborarlo cubre el período hasta el año 2013, anterior a la adquisición del negocio de transporte en contenedores de CCNI por parte de Hamburg-Süd, compra que incluye las relacionadas funciones de agenciamiento de Agunsa. Al cierre de este documento, se sabe que CCNI continuará realizando a nombre propio el transporte marítimo de vehículos automotores, así como que Agunsa continuará haciendo lo propio en cuanto a la representación de otras líneas navieras y a sus actividades portuarias y logísticas en Sudamérica, pero todavía no se dispone de información precisa sobre lo que tal compra conllevará respecto a la pertenencia de CCNI y Agunsa al conglomerado empresarial chileno de la familia Urenda. Sobre dicha adquisición, véanse las respectivas notas al pie de página insertas en el acápite 3.2.2 del capítulo III.

67. En: <http://www.agunsa.com>. Consultado el 28/10/2013. 
En el puerto de San Antonio, Agunsa presta servicios de agenciamiento marítimo y aéreo, transporte, logística y distribución, operación de terminales (trabaja en consorcios con la Compañía Minera Doña Inés de Collahuasi, la Central Termoeléctrica Tarapacá y la Compañía Siderúrgica Huachipato en Chile), servicios de estiba, depósito de contenedores, embarcación y bunkering. En el año 2013, los servicios regulares de Agunsa en ese puerto los ofreció solo en STI y en asociación con CCNI: Condor Express y Americas.

\section{Agencias Maritimas Broom S. A. ${ }^{68}$}

La rama de Agencias Marítimas constituye el eje central y de mayor antigüedad del Broom Group ${ }^{69}$, el cual es una compañía chilena formada en 1920 y que a lo largo de su existencia ha consolidado una red empresarial que comprende toda la COAS (Chile, Perú, Ecuador y Colombia) y territorios interiores de Argentina, Bolivia y Venezuela que representan el hinterland regional, con extensiones en Panamá y Costa Rica así como presencia logística en Estados Unidos, Sudáfrica y Países Bajos, importantes destinos para la carga manejada por esta empresa.

Broom Group muestra un alto grado de diversificación y se encuentra subdividido en cuatro áreas, cada una de las cuales desarrolla actividades diferentes pero vinculadas de manera integral al sector marítimo:

- Broom Agency ofrece servicios de agenciamiento general, portuario y coordinación de pilotaje a importantes empresas navieras, contando con Portuaria Andes S. A. y Shipping Maritime International Agency como sus principales compañías, aunque también cuenta con representaciones en Maruba, PIL, CSCL, ZIM, CLAN S. A., Westcoast S. A. C. y Wallenius Wilhelmsem Logistics.

- Broom Logistics tiene 15 años de existencia cumpliendo labores de integración de las cadenas de abastecimiento, servicios logísticos (en

68. En:<http://www.broomgroup.com>. Consultado el 13/12/2013.

69. Broom Group fue fundado en 1920 bajo propiedad de las familias inmigrantes Wells y Sorensen, las cuales poseen las acciones del grupo y forman parte del directorio. Desde su concepción, Broom emprendió la expansión de su red a lo largo de la COAS. 
zonas francas y restringidas), transporte (marítimo-terrestre), fletes marítimos, aduanas, almacenaje (bodegaje y estación de carga de contenedores) y servicios de distribución. Para esta rama, el grupo cuenta con las compañías BG Logistics (BGL), Transportadora Austral Broom S. A. (Tabsa) y Aerodomo, así como con representaciones vía LCL, BGL Zona de Actividad Logística (ZAL), Contenedores y Servicios Ltda. y MaxTend.

- Broom Tourism está centrada especialmente en la rama de cruceros y está relacionada con empresas de la envergadura de Royal Caribbean International en las zonas de Ushuaia y Tierra del Fuego.

- Broom Innovation está enfocada especialmente en el desarrollo de tecnología ambiental, rubro en el cual Broom cuenta con Aerodomo, Exportadora Escorial y Polaris AGM.

En el STI del puerto de San Antonio, Broom Agency ofrece servicios regulares WSA (West Coast South America) en vinculación con las navieras PIL y Maruba, lo cual refleja el interés del grupo por valerse de carga desde/ hacia el hinterland argentino/Mercosur para consolidar su posición como un importante operador de carga en la COAS, además de su enganche con importantes cruceros de pasajeros.

\section{Ian \& Taylor Co. ${ }^{70}$}

Ian \& Taylor Co. ${ }^{71}$ es una empresa chilena de agenciamiento de naves y estibas fundada en 1965 en Valparaíso, la cual ha desarrollado una estrategia de expansión por la COAS que le ha permitido colocarse a lo largo de las costas chilena, peruana y ecuatoriana. En Chile, Ian \& Taylor Co. realiza operaciones en 13 puertos, incluyendo San Antonio, Valparaíso e Iquique, en los que ofrece servicios en línea de full container y de agenciamiento portuario en general, pilotaje por el estrecho de Magallanes, remolcadores, provisión de combustibles, estibas, atención a tripulantes

\footnotetext{
70. En: <http://www.iantaylor.com>. Consultado el 14/12/2013.

71. Ian \& Taylor Co. fue fundada en 1965 en Valparaíso, ofreciendo servicios de agenciamiento de naves y estibas. El fundador, Ian B. Taylor, descendiente de una familia escocesa que llegó a Coquimbo en 1909, estuvo vinculado a la industria de transporte marino desde antes de iniciar su empresa, puesto que su abuelo, John J. Mac Auliffe, adquirió en 1924 una fragata con la cual prestó servicios de cabotaje en Chile.
} 
y tramitación de cartas náuticas. En el Perú, la empresa tiene oficinas y operadores logísticos en siete puertos, entre ellos Callao, Paita y Chimbote; mientras que en Ecuador está presente en cuatro puertos: Puerto Bolívar, Guayaquil, Manta y Esmeraldas.

Así como la empresa presta servicios para carga contenedorizada, también atiende regularmente naves de carga a granel y refrigerada, cargas de proyecto con necesidades especiales, tanqueros, naves de transporte de automóviles y pasajeros y carga general. En el puerto de San Antonio ofreció en el año 2013 el servicio regular 699/AC3 a la naviera Maersk.

\section{Sudamericana Agencias Aéreas y Marítimas S. A. (SAAM Chile)}

En STI, SAAM es el principal proveedor logístico de cuatro tipos de servicios regulares ofrecidos por CSAV como naviera, lo cual refleja la integración vertical entre ambas empresas para articular labores logísticas en puerto con la labor de transporte maritimo. Los servicios regulares en STI son: Americas; Andex, cuya ruta se dirige hacia el sudeste asiático y pasa en la COAS solamente por Chile y Buenaventura en Colombia ${ }^{72}$; Conosur, que conecta la COAS con la CEAS; y Mediterráneo.

\section{Somarco $^{73}$}

Somarco es una agencia naviera chilena fundada en 1953 que opera como empresa independiente sin subsidiarias nacionales o extranjeras. Sus operaciones abarcan los rubros de: agenciamiento naviero, logística y almacenamiento de cargas masivas, administración y operación de terminales portuarios, chartering y corretaje de fletes, operación, mantención y explotación de transbordadores. En el rubro de agenciamiento general, Somarco tiene como clientes a STX Pan Ocean (Corea del Sur) y China Ocean Shipping Co. (China) y a Cosco Chile en agenciamiento general y portuario. Somarco se especializa en el corretaje de cargas proyecto, aunque moviliza productos como carbón, minerales, derivados forestales

72. La ruta de invierno para el servicio Andex se da bajo el contexto de una asociación temporal entre CSAV, MSC, CMA CGM, Hamburg Süd (HS) y CCNI para combinar el servicio Andex Sling 2 con el servicio de HS. Véase: <http://www.csav.com/es/news/paginas/andex-services-winter-program.aspx>.

73. En: <http://www.somarco.cl/>. Consultado el 16/12/2013. 
y minerales y productos agrícolas de Chile, Perú y Bolivia. Somarco es adjudicatario de contratos de servicio integral con el Ministerio de Obras Públicas de Chile para el transporte fluvial, lacustre y marítimo, por los cuales opera cuatro unidades de distintos tonelajes como parte del Plan de Conectividad Austral. La primera oficina de la empresa se ubicó en San Antonio, donde actualmente cumple los servicios señalados arriba.

\section{Ultramar $^{74}$}

La agencia marítima Ultramar fue fundada en Santiago de Chile en 1952 por el capitán Albert von Appen, como agente de naves y representante de las alemanas Hamburg-Amerika Line y Norddeutscher Lloyd, y en 1956 fue designada como agente general de Lufthansa. Ultramar no solo tiene operaciones en los principales puertos chilenos, sino también en aeropuertos como el de Santiago, en el cual cuenta con un terminal de exportaciones. La empresa tiene oficinas en 34 puertos chilenos (grandes y pequeños) entre los que figuran Arica, Valparaíso, San Antonio y Punta Arenas, además de una red empresarial compuesta por subsidiarias y empresas relacionadas ${ }^{75}$ con las cuales llega a Argentina, Paraguay, Uruguay, Brasil, Panamá, Colombia, Ecuador y Perú.

Ultramar cuenta con cuatro divisiones operacionales: servicios marítimos, representaciones marítimas, servicios aeroportuarios y servicios logísticos. En lo que corresponde a servicios marítimos, Ultramar cumple labores de agenciamiento integral, lanchas y remolcadores y pilotaje. En cuanto a representaciones marítimas, tiene como clientes importantes a las siguientes líneas navieras: Stolt Parcel Tankers Inc. (Noruega, químicos y productos agrícolas), Höegh Autoliners AS (Noruega, maquinaria y automóviles), Mitsui O. S. K. Lines Ltd. (Japón) y Transmares (Chile). Respecto a servicios aeroportuarios, Ultramar representa a líneas aéreas en pasajes y carga, entre ellas Lufthansa, Swiss, Qatar Airways, Avianca Cargo y Air Canada, además de operar el Terminal de Exportación Internacional S. A. (Teisa) en el aeropuerto de Santiago y la empresa de almacenamiento

74. En:<http://www.ultramar.cl/>. Consultado el 16/12/2013.

75. En el rubro de empresas navieras, el grupo Ultramar de la familia Von Appen cuenta con Ultragas, Sonap, Ultrbulk y Transmares, mientras que para servicios logísticos existen Ultrachart (División de Navieras Ultragas) y Humboldt. 
Depocargo. Finalmente, para el rubro de servicios logísticos, el grupo abrió Ultramar Logistics International en 1999, presente en más de 100 países en el mundo, 6 de ellos en Sudamérica; empresa mediante la cual ofrece servicios de transporte y logística para cargas proyecto, transporte aéreo, transporte marítimo, soluciones de almacenaje y distribución, cabotaje nacional, administración y costeo de órdenes de compra. En el puerto de San Antonio, en el año 2013 atendió las rutas New Andes, WSA (West South America), PWS y Americas en asociación con las navieras Allianca, Evergreen y Hamburg Süd.

\subsection{Puerto del Callao, Perú}

El puerto del Callao es el principal puerto marítimo del Perú. La totalidad de sus operaciones estuvieron bajo la administración de la Empresa Nacional de Puertos (Enapu) hasta que, producto del nuevo proceso de modernización impulsado por la Autoridad Portuaria Nacional (APN) desde su creación en el año 2003, se puso en marcha un proceso de privatización de la función de operación portuaria que tuvo su primer hito el año 2006 con la concesión del Muelle Sur a DP World.

A efectos de tal proceso, el puerto del Callao fue dividido en tres partes, según el principal tipo de carga que sería atendida en cada una: Muelle Sur, especializado en carga contenedorizada; Muelle Norte, multipropósito aunque con énfasis en contenedores; y Muelle Centro, especializado en minerales. Para los Muelles Sur y Norte, el proceso de concesión se orientó a atraer operadores portuarios de primer nivel mundial, capaces de lograr que el puerto sea muy competitivo en contenedores y que recupere su histórico sitial como primer puerto de la COAS. Mientras que para el Muelle Centro sí se contaba con empresas locales capaces de operar eficientemente un terminal para minerales.

Fue así que la concesión del Muelle Sur fue adjudicada a DP World Callao, subsidiaria de DP World, cuarto operador portuario del mundo (en términos del movimiento de TEU en los terminales de contenedores a su cargo) y conformante de un conglomerado -con manejo cúpula de holding- de propiedad estatal de Emiratos Árabes Unidos (EAU). El Muelle Norte fue luego concesionado a APM Terminals, segundo operador portuario de contenedores a nivel global (en los términos arriba mencionados) e integrante del grupo 
A.P. Møller-Maesrk liderado por Maersk Line, la primera naviera del mundo en transporte de contenedores. En tanto que la concesión del Muelle Centro fue otorgada al Consorcio Transportadora Callao, conformado por: Cormin Callao S. A. C. con el 30\% de participación, Perubar S. A. también con el 30\%, Santa Sofía Puertos S. A. con 25\%, Sociedad Minera El Brocal S. A. con 8\% y Minera Chinalco Perú S. A. con 7\%.

\subsubsection{Muelle Sur}

\section{DP World Callao ${ }^{76}$}

En julio de 2006, el Ministerio de Transportes y Comunicaciones suscribió el contrato de concesión para el diseño, construcción, financiamiento, conservación y explotación del Terminal de Contenedores del Terminal Portuario del Callao - Zona Sur con Dubai Ports (DP) World Callao, el cual inició operaciones el año 2010. La casa matriz de esta empresa es DP World, conglomerado de los EAU formado en 2005 luego de la integración de Dubai Ports Authority (DPA) con Dubai Ports International (DPI).

DP World cuenta con un portafolio de 65 terminales alrededor del mundo, en los cuales lleva a cabo principalmente el manejo de carga contenedorizada, el cual es el core business de la empresa. En puertos sudamericanos está presente como operador de terminales de contenedores, además de en el Callao y Buenaventura (Colombia), en Surinam (Paramaribo), Argentina (Buenos Aires) y Brasil (Santos), tal como se aprecia en el gráfico 2. A diferencia de conglomerados regionales como CSAV/SAAM y CCNI/Agunsa o globales como Maersk/APM, DP World no cuenta aún con una naviera subsidiaria de categoría global y concentra sus servicios en el segmento puerto del sector marítimo-portuario ${ }^{77}$. De hecho, el Muelle Sur del Callao ha sido expresamente diseñado para el tráfico de contenedores, lo cual refleja una estrategia en Sudamérica centrada en este tipo de carga, para lo cual el Callao, puerto con mayor cantidad de TEU movilizadas en la COAS, representa una posición estratégica.

76. En:<http://www.dpworldcallao.com.pe>. Consultado el 17/1/2014.

77. Véase: <http://www.dubaiworld.ae/>. Consultado el 17/1/2014. 


\section{Gráfico 2}

Ubicación geográfica de las operaciones de DP World en América del Norte, América Latina y el Caribe

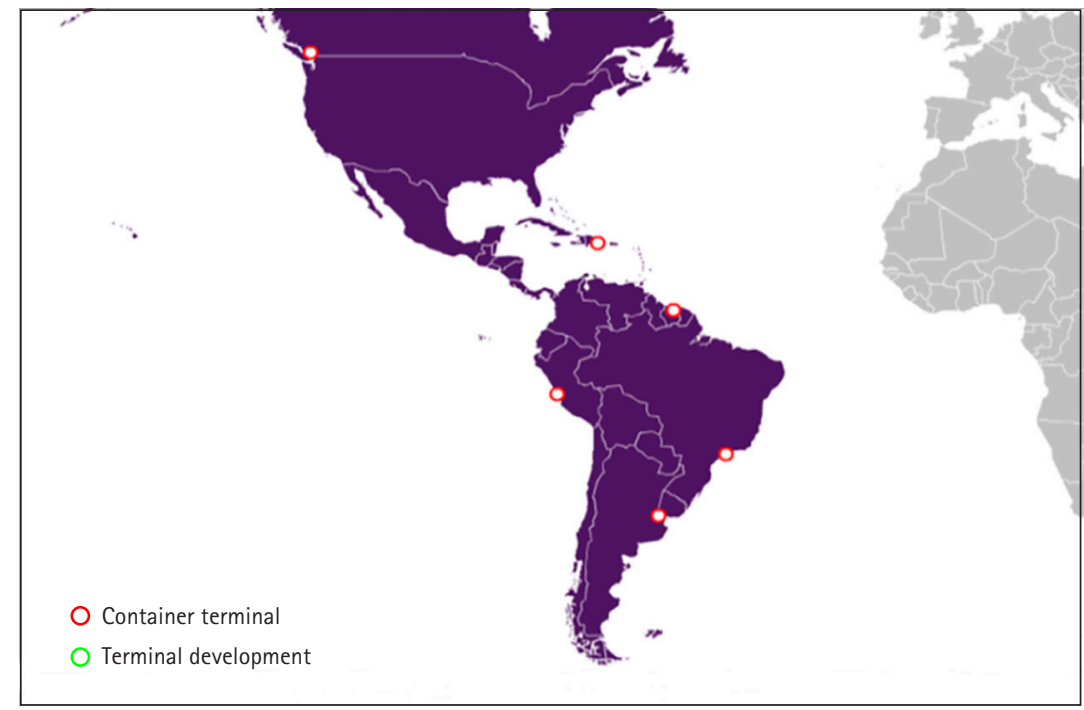

Fuente: página web de DP World (18/1/2014).

La principal actividad de DP World Callao es el embarque y descarga de contenedores así como la movilización de transbordo; estos representan los servicios estándar del operador portuario en el Muelle Sur. Asimismo, presta servicios especiales de reestiba de contenedores, prestación del área operativa de contenedores para carga de exportación, importación y vacíos; también los servicios de manejo de carga sobredimensionada y de contenedores con carga peligrosa y energía, y de monitoreo y manejo de contenedores reefer. Asimismo, a partir de septiembre de 2010, DP World Callao cuenta con licencia para operar como punto de llegada y depósito temporal de mercancías ${ }^{78}$. Este hecho está facilitando la aglomeración de carga en la zona del muelle a través de una reducción en los sobrecostos por transporte a y desde almacenes extraportuarios. 


\subsubsection{Muelle Norte}

El Consorcio APM Terminals (APMT) Callao, liderado por APM Terminals B. V. e inicialmente integrado también por las empresas Callao Port Holding B. V. y Central Portuaria S. A. C., se adjudicó en el año 2011 la concesión por 30 años del Muelle Norte del puerto del Callao. Posteriormente, en marzo de 2014, Callao Port Holding fue adquirido por TIL (Terminal Investment Limited), empresa de MSC (Mediterranean Shipping Co.), con lo cual la participación accionaria en el Muelle Norte ha quedado distribuida así: 51\%, APMT; 29\%, TIL; y 20\%, Unimar (véase III.3.1, más adelante). También cabe señalar que el consorcio liderado por APMT compitió en la licitación con el Consorcio Terminal Internacional Multipropósito del Callao, liderado por Hutchison Port Investments Ltd. (empresa perteneciente a Hutchison Port Holdings, primer operador portuario del mundo, en términos de TEU movilizadas en los terminales de contenedores a su cargo) y también compuesto por Sinoinvest S. A. C. ${ }^{79}$.

Que la elección final se diera entre los consorcios liderados por el primer operador portuario del mundo (HPH) y por el segundo en ese ranking (APMT), este último a su vez ligado empresarialmente a la primera naviera del mundo (Maersk), así como el posterior ingreso del operador portuario que el año 2012 se ubicó en el sexto lugar del ranking mundial (TIL) y que pertenece a la segunda naviera del mundo (MSC), son muestras por demás elocuentes del gran atractivo y potencialidad del Muelle Norte en particular y del puerto del Callao en su conjunto. Esto último, habida cuenta de que el cuarto operador portuario del mundo (DP World) ya estaba en el Muelle Sur. La concesión del Muelle Norte, que la APN encargó a la Agencia de Promoción de la Inversión Privada (Proinversión), siguió el principio de promover la competencia en el interior del puerto del Callao, para lo cual se buscó que el operador del Muelle Norte sea distinto pero de envergadura similar a la del operador del Muelle Sur.

79. Véase: <http://www.apn.gob.pe/web/apn/noticia/-/asset_publisher/7qFk/content/consorcio-apmterminals-callao-es-el-nuevo-operador-del-muelle-norte-del-puerto-del-callao?redirect=\%2Fweb2Fapn>. Consultado el 21/1/2014. 


\section{APM Terminals ${ }^{80}$}

APM Terminals fue creado el año 2001 como una división independiente del holding danés AP Møller-Maersk Group y concebido como el brazo tierra, especializado en operación de terminales para contenedores, de la naviera Maersk Line, la más grande del mundo. APM Terminals tiene presencia en 74 terminales portuarios a escala global, incluyendo, en América: Itajaí (sur de Brasil), Pecem (norte de Brasil), Buenos Aires (Argentina) y Callao (Muelle Norte), así como el proyecto de modernización y desarrollo de los puertos Lázaro Cárdenas (Pacífico mexicano) y Moin (terminal de contenedores de Costa Rica) (gráfico 3). La estrategia corporativa de esta empresa incluye el empleo de asociaciones con otras empresas en los rubros naviero (CMA-CGM, MSC) y de operaciones portuarias (DP World, Hutchison Port Holdings, PSA International, Transportation Investments Holding Ltd.).

\section{Gráfico 3}

Ubicación geográfica de las operaciones de APM Terminals en las Américas

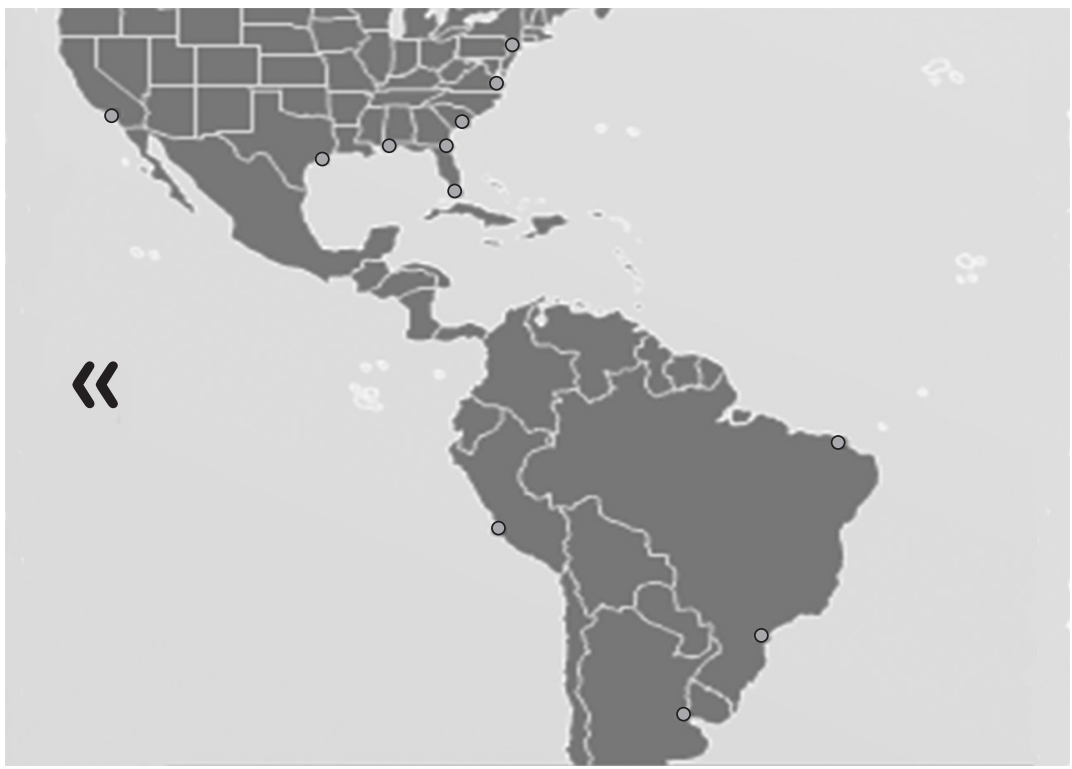

Fuente: página web de APM Terminals (26/1/2014).

80. En: <http://www.apmterminals.com/>. Consultado el 18/1/2014. 
Como ya se dijo, APM Terminals lidera el consorcio ganador de la concesión por 30 años del Muelle Norte del puerto del Callao, por lo cual conduce la ejecución del plan para su modernización en cinco etapas, cuyo objetivo es llegar a manipular 3 millones de TEU y 15 millones de carga en general. Ello implica un gran esfuerzo inversor por parte de esa empresa, cuyas razones explica de la manera siguiente: «El Puerto Multipropósito del Callao es la puerta de entrada al Perú -la cuarta economía más grande de América del Sur-. Ubicado a 15 kilómetros de la capital de Lima, el puerto del Callao, además de ser el puerto más grande del Perú, es el más importante de la costa del Pacífico sudamericano" ${ }^{81}$. Esto último, ligado con la ubicación en la zona media de la COAS que promete elevados niveles de carga, sería la característica del puerto del Callao más valorada por la empresa. De ahí que APM Terminals presta todos sus principales servicios en este puerto, entre ellos: manejo de contenedores, carga fraccionada, carga a granel y cruceros.

\subsubsection{Muelle Centro}

La concesión del Muelle Centro, que comprende el diseño, financiamiento, construcción y operación por 20 años del muelle, se otorgó al Consorcio Transportador Callao para que establezca y opere el Terminal de Embarque de Minerales del Callao. De ahí que las empresas componentes del mencionado consorcio sean del sector minero, interesadas en modernizar el manejo portuario de sus exportaciones. El proyecto considera la construcción de un nuevo muelle de 200 metros y la instalación de fajas transportadoras herméticamente cerradas y de equipamiento especializado para operaciones de carga y descarga de minerales, con lo cual el muelle verá reducidas las emisiones de contaminantes y se podrán atender mayores embarques de carga minera procedente del centro del país: «implicará para el Callao la eliminación de 130 mil viajes de camiones entre depósitos y el puerto, cifra a la que se llegaría con [...] [la producción] [...] de la minera Chinalco, lo que ayudará a liberar al Callao de contaminantes ${ }^{82}$. La finalización de las obras está prevista para el segundo trimestre de 2014, año de inicio de la producción de la mina Toromocho en manos de Chinalco ${ }^{83}$.

81. Cita de <http://www.apmterminals.com/americas/callao_es-pe/>. Consultado el 20/1/2014.

82. Cita de <http://gestion.pe/noticia/705489/obras-muelle-minerales-comenzaran-primer-semestre>. Consultado el 23/1/2014.

83. Véase: <http://www.iirsa.org/proyectos/detalle_proyecto.aspx?h=1333>. Consultado el 23/1/2014. 


\section{Cormin Callao S. A. C.}

"Cormin Callao S. A. C. es una empresa miembro del Grupo Trafigura, de servicios logísticos para la minería, creada en mayo de 2003, cuya historia se inicia conjuntamente con la de su casa matriz Consorcio Minero S. A. - Cormin, empresa comercializadora de concentrados y minerales fundada en 1982 por accionistas nacionales, que se orientó básicamente a brindar servicios a la pequeña minería y a comprar sus producciones» ${ }^{84}$.

Por su parte, el Grupo Trafigura es una importante empresa creada en 1993 que provee, almacena, mezcla y entrega petróleo y demás materias primas, actividades que inició con sus oficinas en Ámsterdam, Lucerna, Buenos Aires y Londres, y que se han expandido exponencialmente desde 2003 en los rubros comercial, industrial y de administración de derechos accionarios ${ }^{85}$.

\section{Perubar S. A.}

Compañía dedicada a la exploración y explotación de concesiones mineras y a la producción y comercialización de concentrados de zinc y plomo. Fue fundada en 1957 e inició operaciones en 1959. Perubar S. A. también realiza actividades de almacenamiento y embarque de concentrados minerales con base en un depósito alquilado a Logística Integral Callao S. A. (Licsa - Almacén Perubar) ${ }^{86}$.

Perubar S. A. forma parte del grupo Glencore Perú S. A. C., subsidiaria de Glencore International PLC, dedicada a la extracción y comercialización de carbón y metales, así como a la comercialización de petróleo y productos agrícolas.

\section{Minera Chinalco Perú S. A. ${ }^{87}$}

Minera Chinalco Perú S. A. es una subsidiaria de Aluminum Corporation of China (Chinalco), creada en 2007 cuando Chinalco adquirió Perú Copper

84. Cita de <http://intranet2.minem.gob.pe/web/archivos/dgaam/inicio/resumen/RE_1626739.PDF>. Consultado el 23/1/2014.

85. En:<http://www.trafigura.com/about-us/the-group/\#CorporateStructure>. Consultado el 23/1/2014. 86. Véase: <http://www.securities.com/Public/company-profile/PE/Perubar_SA_es_1240443.html>. Consultado el 25/1/2014.

87. En: <http://www.chinalco.com.pe/>. Consultado el 25/1/2014. 
Inc. (ahora Minera Chinalco Perú) y obtuvo la concesión del proyecto cuprífero Toromocho. Razón por la que pone sus intereses en el puerto de Callao como vía de salida para sus exportaciones. Chinalco es actualmente el segundo mayor productor de aluminio del mundo.

\section{Sociedad Minera El Brocal S. A. A. ${ }^{88}$}

La Sociedad Minera El Brocal S. A. A. es una empresa fundada en 1956 y que opera en el departamento de Pasco, dedicada a la extracción, concentración y comercialización de minerales polimetálicos: plata, plomo, zinc y cobre.

\section{Santa Sofía Puertos S. A. ${ }^{89}$}

Santa Sofía Puertos S. A. es una empresa peruana perteneciente al Grupo Romero, fundada en 1996 para el rubro de alquiler de maquinaria y equipos que constituye parte de su aporte a las operaciones de manejo de carga en el Muelle Centro. Entre sus principales operaciones portuarias se encuentra el puerto de Matarani, en el departamento de Arequipa, especializado en el transporte de minerales y donde el Grupo Romero está presente a través de la empresa Terminal Internacional del Sur (Tisur).

\subsubsection{Proveedores logísticos}

Hasta el momento, la reorganización estructural del puerto del Callao, resultante de las reformas impulsadas por la APN, solamente se ha dado a nivel de operadores portuarios y los accionistas respectivos, mas no todavía a nivel de los proveedores logísticos, donde aún están presentes casi 40 proveedores que intervienen en el manejo de carga contenedorizada, así como un número incluso mayor de proveedores extraportuarios, en su mayoría dedicados a actividades de almacenamiento en el distrito de Ventanilla al norte del puerto. De ahí que una primera mirada, superficial y cegada por esa numerosa cantidad de empresas aparentemente distintas y no ligadas entre sí, pueda dar la falsa impresión de poca concentración del manejo de la carga en el Callao.

88. En:<http://www.elbrocal.pe/>. Consultado el 25/1/2014.

89. En:<http://www.datosperu.org/ee-santa-sofia-puertos-sa-20302888231.php>. Consultado el 25/1/2014. 
Sin embargo, la realidad del primer puerto peruano indica que los servicios logísticos son manejados principalmente por unos pocos conglomerados que agrupan empresas mediante mecanismos de integración vertical o de vínculos contractuales que aseguran un alto grado de control del manejo de la carga. Tal es el caso de los conglomerados formados por las chilenas SAAM y Agunsa, o por el Andino Investment Holding registrado como peruano. De hecho, se ha afırmado que más del 50\% de la carga contenedorizada del Callao pasaba por empresas con capital chileno en los años previos al inicio de las operaciones de DPW Callao en el Muelle Sur ${ }^{90}$.

En tal sentido, la estructura del mercado de proveedores logísticos en el Callao se diferencia de las existentes en Buenaventura y San Antonio, donde los respectivos marcos regulatorios promovieron sostenidamente el fortalecimiento de sus proveedores logísticos nacionales y así una cantidad relativamente pequeña de estos dominan el manejo de la carga en los puertos de sus respectivos países. Por el contrario, dicha estructura de mercado se parece más a la de Guayaquil, donde los grupos chilenos también tienen una fuerte presencia que devela su claro interés por controlar el manejo de carga a lo largo de la COAS y así poder dirigir buena parte de la misma hacia rutas maritimas southbound que favorecen la aglomeración de carga de la COAS en puertos de Chile.

A continuación, se pasa revista a los principales proveedores logísticos que, al año 2013, brindaban sus servicios a las naves portacontenedores y/o a los dueños de la carga respectiva, que en dicho año utilizaban el Muelle Sur o el Muelle Norte del puerto del Callao. La cantidad de servicios suministrados por cada proveedor es mostrada en el cuadro 4, como primer dato básico con miras a la estimación de su cobertura de la cadena logística y cuota en el mercado de la carga. 


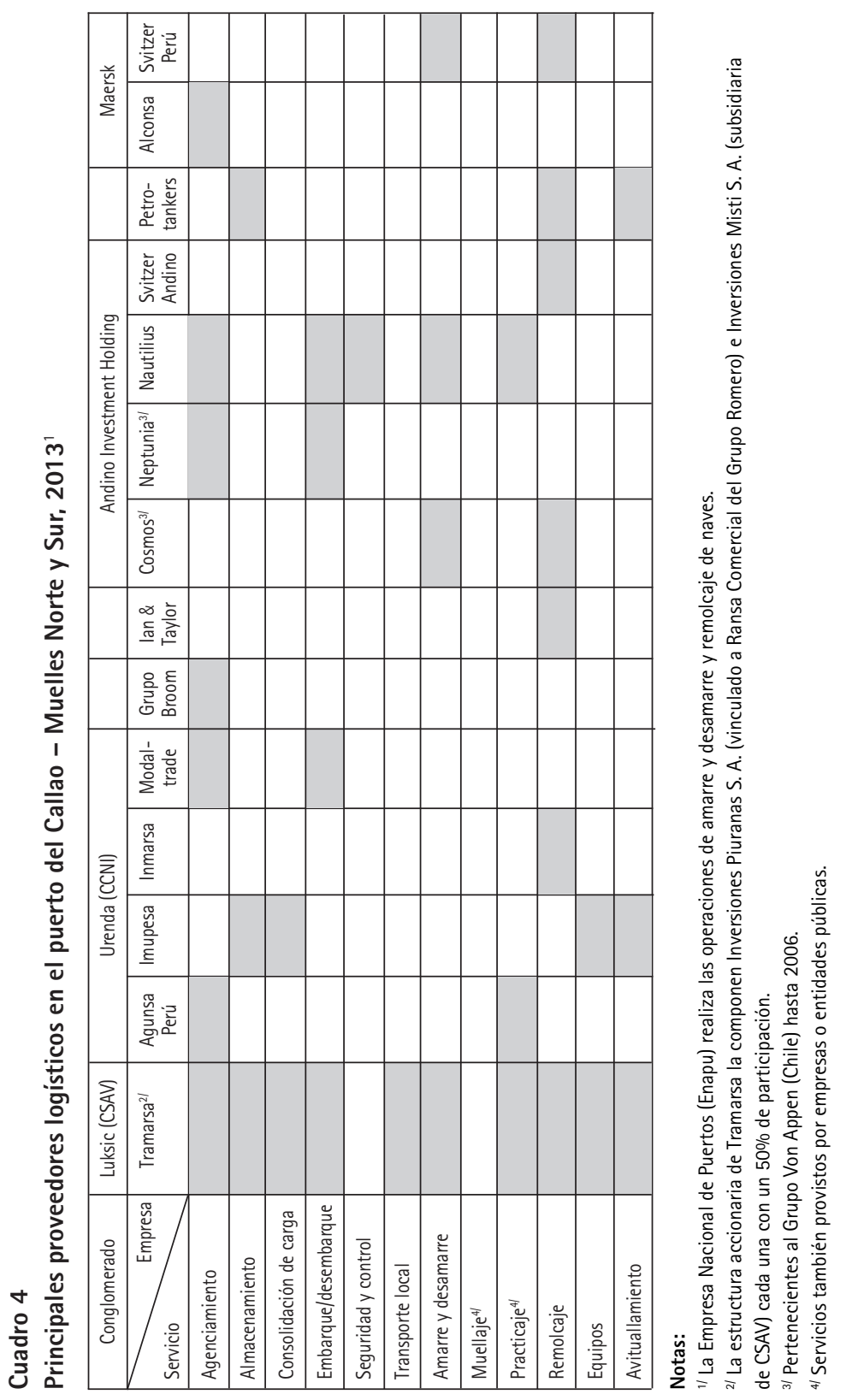




\section{Agencias Universales Perú S. A. (Agunsa Perú) ${ }^{91}$}

Agencias Universales (Agunsa) Perú S. A. es una empresa subsidiaria de la compañía chilena Agunsa que funciona cual brazo tierra de la naviera chilena CCNI a la cual pertenece, dedicada a la provisión de servicios portuarios y aeroportuarios y con una cobertura que en la COAS incluye también a Colombia (Agunsa Colombia) y Ecuador (Marglobal). Agunsa Perú fue fundada en 1995 para desarrollar operaciones de servicios logísticos a importadores y exportadores vía marítima, aérea y terrestre, que en promedio anual ascienden a más de 30.000 y representan cerca de 50.000 toneladas de carga general.

Agunsa Perú presta por sí misma los servicios de agenciamiento marítimo, portuario, general y de bunkering, aunque su estrategia incluye el uso de subsidiarias para labores intermedias. Este es el caso de Imupesa en los rubros de agenciamiento aéreo, logística y distribución (transporte, almacenaje, distribución y servicios adicionales), administración y operación de terminales. También cuenta con Modaltrade para el transporte directo desde la filial y labores de estiba/desestiba; Imudesa (Inversiones Marítimas Universales Depósitos S. A.) en logística e Inmarsa (Inversiones Marítimas Perú S. A.) para remolque.

\section{Inversiones Marítimas Universales Perú S. A. (Imupesa) ${ }^{92}$}

Inversiones Marítimas Universales Perú (Imupesa) S. A. es una empresa subsidiaria del grupo chileno Agunsa (operadora en tierra de la naviera CCNI) que inició sus operaciones en 1995 en las actividades de almacenamiento extraportuario y otros servicios logísticos a importadores, exportadores y operadores de comercio internacional. Actualmente, «Imupesa cuenta con un área total de $98,000 \mathrm{~m}^{2}$, instalaciones especiales para el tratamiento de las cargas según su naturaleza y régimen aduanero y 26,000 $\mathrm{m}^{2}$ de almacenes techados con asistencia de maquinaria y equipos de última generación $n^{93}$.

91. En:<http://www.agunsa.com.pe/>. Consultado el 27/1/14.

92. En:<http://www.imupesa.com.pe/>. Consultado el 26/1/2014.

93. Cita de <http://www.imupesa.com.pe/index.php?option=com_content\&task=view\&id=115\&/temid=156>.

Consultado el 26/1/2014. 


\section{Petrotankers S. A. C. ${ }^{94}$}

Petrotankers S. A. C. es una empresa fundada el año 2007 y ubicada en el Callao, en las inmediaciones del puerto. A exportadores e importadores, presta los servicios de almacenamiento extraportuario, avituallamiento y remolque de naves.

\section{Sudamericana Agencias Aéreas y Marítimas S. A. (SAAM Perú) ${ }^{95}$ - Trabajos Marítimos S. A. (Tramarsa) ${ }^{96}$}

En el Perú, la presencia de SAAM se da principalmente a través de Trabajos Marítimos S. A. (Tramarsa), uno de los importantes agentes de servicios logísticos y portuarios integrados con la naviera CSAV, así como con Construcciones Modulares S. A., dedicada a la venta, alquiler, transporte y mantenimiento de contenedores en el Callao. "SAAM estableció la subsidiaria peruana Trabajos Marítimos S. A. (Tramarsa), que opera como agencia naviera y de estiba en los puertos de Callao, Ilo, Matarani, Pisco, Chimbote, Salaverry, Chicama y Paita ${ }^{97}$. Tramarsa cuenta con oficinas en doce puertos del territorio peruano (Talara, Paita, Bayóvar, Salaverry, Chimbote, Huarmey, Supe, Callao, Pisco, Matarani, Ilo y Pucallpa).

Además de ser una subsidiaria de SAAM (e indirectamente de CSAV, por ende), Tramarsa forma parte del Holding Central Puertos, fundado en 1990 en el puerto del Callao para articular compañías del sector portuario de propiedad del peruano Grupo Romero.

Apalancada así por su pertenencia al conglomerado SAAM-CSAV y por sus vínculos con el Grupo Romero, Tramarsa ha logrado una posición determinante en el mercado peruano de servicios logísticos marítimo-portuarios, donde es la única que ofrece la gama completa de estos servicios y es la líder en logística marítima y la segunda en la relacionada logística en tierra. La amplia gama de sus servicios comprende: amarre/desamarre de naves, agenciamiento maritimo, remoque, practicaje, lanchaje, estiba/

94. En: <http://www.datosperu.org/peru-petrotankers-sac.php>. Consultado el 26/1/2014.

95. En:<http://www.saam.cl/peru/prontus_saam/2012-05-03/111215.html>. Consultado el 28/1/2014.

96. En:<http://www1.tramarsa.com.pe/>. Consultado el 26/1/2014.

97. Cita de <http://www.saam.cl/tramarsa/prontus_saam/2012-09-11/100412.html>. Consultado el 26/1/2014. 
desestiba de contenedores y carga a granel, servicio integral a terminales de contenedores y a terminales de líquidos, apoyo en descarga de hidrocarburos, trabajos submarinos y off shore.

\section{Andino Investment Holding ${ }^{98}$}

Andino Investment Holding (AIH) es un conglomerado empresarial creado el año 2005 para dedicarse a la prestación de servicios marítimos, aéreos y logísticos integrados a través de sus subsidiarias, así como a la comercialización, importación, exportación, intermediación, distribución, compra y/o venta de cualquier tipo de bienes.

Aunque legalmente registrado como conglomerado peruano, AIH surgió de una sofisticada combinación de transacciones financieras y accionariales que involucraron préstamos (con las probables garantias de por medio) facilitadores de compras y canje de acciones de las que era titular el Grupo Von Appen, el cual es nada menos que uno de los más importantes grupos empresariales marítimo-portuarios de Chile. Lo sucedido fue resumido en una entrevista por el propio presidente de AIH, Carlos Vargas Loret de Mola: "Andino pidió el préstamo y compró la participación de Ultramar, empresa del Grupo Von Appen, en Neptunia, y de otra persona en Cosmos. Von Appen tenía 20\% de Cosmos hasta el 2006, y con la creación de Andino se hizo un canje de acciones y se quedaron con el 1,96\%, el cual fue adquirido antes de entrar a Paita. Además de estas compras, se reestructuraron las deudas y nos hemos quedado casi con un solo préstamo" (Corvera 2011: 36).

El gran entendimiento y trabajo de equipo con el poderoso Grupo Von Appen que lo anterior revela debe ser tenido muy en cuenta al calibrar la información pública listada, según la cual, al 31 de diciembre de 2013, el accionariado de AIH es en su mayoría familiar y de capitales peruanos: «El accionariado de AIH está controlado (74,12\%) por un grupo de inversionistas que ha trabajado junto desde la creación de la primera empresa del Grupo, Cosmos, en 1972. El grupo de inversionistas incluye a la familia Vargas Loret de Mola, Jan Carsten Matthies Estenssoro, Wolf Dieter Krefft Berthold y Claus Krumdiek Majewski. El porcentaje de accionistas restante 
(25,88\%) se negocia en la BVL y está en manos de inversionistas nacionales y extranjeros, institucionales y personas naturales» ${ }^{99}$.

De hecho, AIH ya tiene el 20\% de participación en el mercado peruano de servicios marítimos (gráfico 4). Ello gracias a que, además de Cosmos Agencia Marítima, AIH agrupa a Triton Maritime Services, Svitzer Andino, Nautilius y Andino Shipping Agency. Así, este conglomerado puede ofrecer casi la totalidad de servicios logísticos en el puerto del Callao, con excepción del almacenamiento extraportuario de la carga contenedorizada. En el rubro de servicios logísticos, AIH tiene en Neptunia S. A. a la empresa con mayor participación de mercado en el grupo, además de Triton Transports, Multitainer y Almafin, con las cuales maneja más de 300.000 contenedores entre embarque y descarga. AIH también ha incursionado en el desarrollo y operación de infraestructura portuaria y aeroportuaria a través de concesiones, siendo las más importantes la del puerto de Paita y la de una red de aeropuertos en el sur peruano.

\section{Gráfico 4}

Participación de mercado de empresas de Andino Investment Holding en servicios logísticos y marítimos, 2012

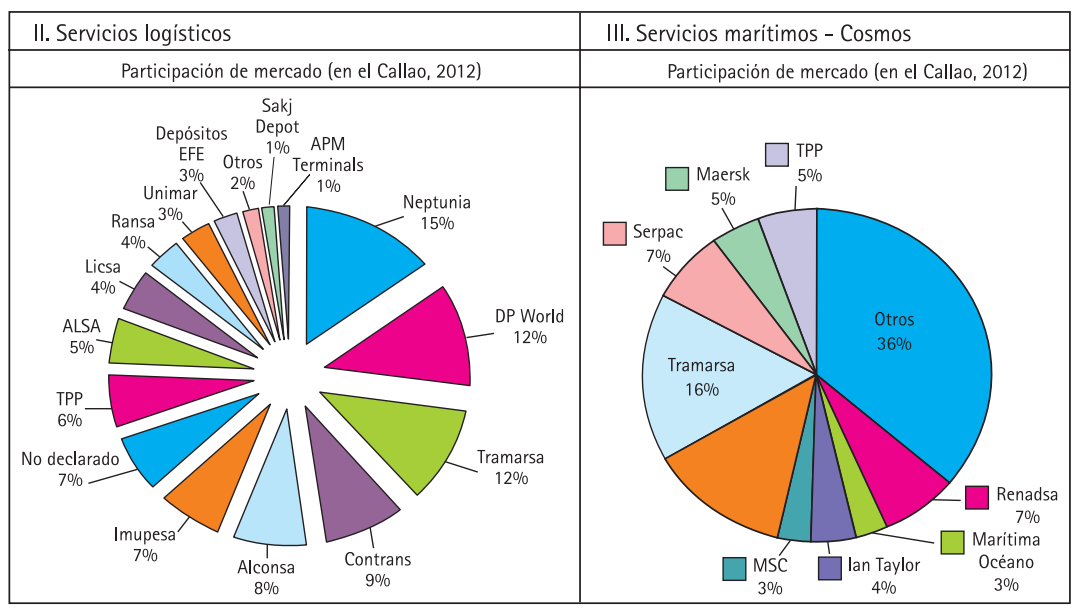

Fuente: página web de Andino Investment Holding: Presentación Corporativa (27/1/2014).

99. Cita de <http://www.bvl.com.pe/hhii/J40120/20130403173301/MEMORIA32ANDIN032INVESTMENT32 HOLDING322012.PDF>. Consultado el 27/1/2014. 


\section{Cosmos Agencia Marítima S. A. C. ${ }^{100}$}

Cosmos es una empresa fundada en 1972 con la familia Von Appen y capitales peruanos como accionistas ${ }^{101}$, para cubrir la malla de servicios marítimos, portuarios y fluviales. La empresa fue absorbida por el conglomerado AIH (desde la creación de este el año 2005) junto a sus acciones en Nautilius S. A. (50\%) y Neptunia S. A. (52,8\%). "Cosmos forma parte de Andino Investment Holding, grupo empresarial peruano que ofrece servicios en tres líneas principales: Infraestructura Portuaria y Aeroportuaria, Servicios Marítimos y Servicios Logísticos a nivel nacional. Una de las operaciones más importantes es la concesión del Terminal Portuario de Paita otorgada por el Estado peruano por un período de 30 años» ${ }^{102}$.

Además de en el Callao y Paita ${ }^{103}$, Cosmos está presente en los puertos de Zorritos, Talara, Salaverry, Chimbote, Pucallpa, Iquitos, Yurimaguas, Pisco, Mollendo e Ilo, en los cuales ofrece los servicios de agenciamiento naviero (actividad en la cual cuentan con una experiencia de alrededor de 40 años), remolque y practicaje naviero, estiba, transporte marítimo y fluvial, operación de terminales maritimos y fluviales, operaciones submarinas y servicios integrales para clientes en la industria de exploración y extracción de petróleo y gas en yacimientos de la selva peruana.

\section{Nautilius S. A.}

Nautilius Agentes Marítimos fue fundada en 1978 para cubrir la demanda de agenciamiento naviero en el puerto del Callao, actividad a la cual fue añadiendo paulatinamente los servicios de estiba/desestiba, amarre/desamarre y practicaje. La modificación accionaria de la empresa en 2006, tras la adquisición por Cosmos S. A. C. del 50\% de la participación accionaria en el año 2005, permitió la incorporación de la empresa a AIH.

100. En:<http://www.cosmos.com.pe>. Consultado el 26/1/2014.

101. Según el portal web de Cosmos y lo manifestado por Carlos Vargas Loret de Mola en la entrevista antes citada, "Von Appen tenía 20\% de Cosmos hasta el 2006 [...]" (Corvera 2011: 36). Sin embargo, según una investigación académica de aquellos años, "El grupo chileno Von Appen tiene el 100\% de las acciones de la empresa Cosmos [...]" (Fairlie y Queija 2007: 231).

102. Cita de <http://www.cosmos.com.pe/Content/Index.aspx?alD=15>. Consultado el 26/1/2014. 103. Sobre la controversia que generó la concesión del puerto de Paita y sus efectos inmediatos en los usuarios del mismo, véase García Marengo (2013). 
A partir de entonces, la empresa amplió sus servicios hacia el almacenamiento, custodia y manejo de carga a nivel extraportuario. De modo que, actualmente, "Entre sus principales unidades de negocio podemos mencionar el agenciamiento marítimo de naves mercantes y pesqueras, avituallamiento, custodia (almacenamiento) y distribución de materiales (rancho de naves) a nivel nacional, servicio de remolcadores, prácticos y el servicio de aperturas y reconocimiento físico de la carga ${ }^{104}$. Entre los principales clientes de Nautilius se encuentran DP World, operador del Muelle Sur, agencias marítimas, navieras (Transoceánica y Panoceánica) y empresas pesqueras.

\section{Neptunia S. A. ${ }^{105}$}

Neptunia es una empresa de operaciones portuarias y logísticas fundada en el Callao en 1980 con el Grupo Von Appen y capitales peruanos como accionistas $^{106}$. Por lo que también pasó a formar parte de AIH a resultas de las antes mencionadas transacciones de compra y canje de acciones habidas a partir del año 2005.

La gama de servicios de Neptunia abarca toda la cadena de movimiento de carga en el brazo tierra. Sus servicios en terminales portuarios y aeroportuarios incluyen: importación, exportación, servicio integral, forwarders y transporte; logística general, para la cual cuenta con centros especializados en depósitos, distribución de productos y metalurgia; así como un rubro específico de contenedores vacíos, a los cuales ofrece mantenimiento y movilización. Neptunia cuenta con uno de los principales centros de almacenamiento y servicios extraportuarios en el Callao, y con grandes instalaciones de almacenamiento en Paita y Matarani.

\section{Svitzer Andino S. A. C. ${ }^{107}$}

Svitzer Andino S. A. C. es una empresa que inició sus operaciones como una subsidiaria de Svitzer, empresa danesa fundada en 1833, especializada

104. Cita de <http://www.nautilius.com.pe/nautilius/nuestra-empresa.html>. Consultado el 27/1/2014.

105. En:<http://www.neptunia.com.pe/>. Consultado el 27/1/2014.

106. Von Appen poseía el 47\% de Neptunia según Fairlie y Queija (2007: 231).

107. En:<http://www.datosperu.org/ee-svitzer-andino-sa-20522581624.php>. Consultado el 27/1/2014. 
en labores de remolque naviero, y que en 1978 fue adquirida por A. P. Møller-Maersk. No obstante, Svitzer Andino S. A. C., sin abandonar el vínculo accionario con su matriz en Dinamarca, fue incorporada a Andino Investment Holding en el año 2009. Actualmente realiza labores de transporte marítimo y cabotaje, mientras que su empresa hermana, Svitzer Perú S. A., realiza labores de amarre/desamarre de naves.

\subsection{Puerto de Guayaquil, Ecuador}

El caso de Ecuador se asemeja a los casos de Chile y Colombia en el sentido de que los cambios del marco regulatorio en pro de la formación de empresas privadas nacionales especializadas en servicios portuarios precedieron a -y prepararon el camino hacia- la privatización de la función de operador portuario principal, del puerto de Guayaquil en este caso. La Ley de Modernización del Estado, Privatizaciones y Prestación de Servicios Públicos promulgada en 1983 eliminó el monopolio estatal (ejercido por la Autoridad Portuaria de Guayaquil - APG) e incentivó el desarrollo de empresas privadas nacionales, iniciando así un proceso gradual que finalmente desembocaría en privatizaciones diferenciadas según el principal tipo de carga por ser atendida en los muelles del puerto de Guayaquil. El muelle de granos y multipropósito fue adjudicado a la ecuatoriana Andipuerto S. A. el 27 de abril de 1999, mediante un contrato de concesión con APG por 20 años. Mientras que el muelle de contenedores y multipropósito fue adjudicado a una subsidiaria extranjera, Contecon Guayaquil S. A. (CGSA) el 31 de mayo de 2007, mediante un contrato de concesión también con APG y por 20 años en virtud del cual CGSA inició actividades el 1 de agosto de aquel año. Ambas empresas iniciaron sus operaciones en los sendos muelles actuando como accionistas únicos con participaciones al 100\%.

\subsubsection{Muelle de contenedores y multipropósito}

\section{Contecon Guayaquil S. A. (CGSA) ${ }^{108}$}

Contecon Guayaquil S. A. (CGSA) fue creada con ocasión de la concesión del muelle de contenedores y multipropósito (denominado como Terminal Libertador Simón Bolívar) del puerto de Guayaquil, por un período 
de 20 años, e inició la operación y prestación de servicios y actividades portuarias desde el 1 de agosto de 2007; "siendo que, en la actualidad, por este puerto se moviliza el 70\% del comercio exterior ecuatoriano que maneja el Sistema Portuario Nacional» de ese país ${ }^{109}$. Aquel muelle fue construido entre 1959 y 1963, y fue objeto de un proceso de ampliación entre 1978 y 1982; todo ello bajo la administración pública (de la APG) que lo operó hasta 2007, año en que la concesión fue adjudicada a la recién creada CGSA.

Esta empresa es subsidiaria de International Container Terminal Services Inc. (Ictsi), empresa filipina fundada en Manila en diciembre de 1987, especializada en la adquisición, desarrollo, manejo y operación de puertos de contenedores y terminales marítimos. Ictsi opera en todos los continentes ${ }^{110}$ salvo Oceanía, al cabo de un proceso de expansión global que fue impulsado a partir de que obtuvo la concesión por 25 años (y 25 años adicionales) del Manila International Container Terminal (MICT), un hecho significativo para Filipinas pues se trató de la primera privatización realizada por el gobierno de ese país. Cabe agregar que si bien la división de negocios internacionales de Ictsi fue adquirida por Hutchison Port Holdings en el año 2001, la operación del puerto de Guayaquil no formó parte de la cartera sujeta a esa adquisición.

CGSA provee una amplia gama de servicios, que divide sintéticamente entre servicios a importadores, exportadores, navieras y consolidadoras, siendo la razón de esta separación la diferenciación de tarifas y tipos de carga (contenedores, carga suelta, break bulk y vehículos), en tanto que los servicios para importadores y exportadores son prácticamente los mismos. Para importadores y exportadores con carga en contenedores, CGSA ofrece los servicios de: consolidación/desconsolidación de contenedores, almacenamiento, conexión y energía de contenedores refrigerados (cargas reefer), inspección, porteo (practicaje o pilotaje) y recepción/despacho. A las navieras, CGSA ofrece los servicios de: transferencia de contenedores llenos, reestiba, consolidación/desconsolidación, transferencia de

109. Véase: <http://www.cgsa.com.ec/quienes-somos/historia>. Consultado el 20/10/2013.

110. En Europa, cuenta con operaciones en Croacia, Polonia y Georgia; en África, en Nigeria y Madagascar; en Asia, en Filipinas, India, Pakistán, Japón, Brunéi, China e Indonesia; y en América, en Ecuador, México, Estados Unidos, Honduras, Colombia, Brasil y Argentina. 
contenedores vacíos y conexión y energía de contenedores refrigerados; en tanto que a las consolidadoras las ofrece lo siguiente: consolidación/ desconsolidación, conexión y energía de contenedores refrigerados, porteo y recepción/despacho.

Entre las obras que CGSA ha ejecutado recientemente o están en vías de ejecución, cabe mencionar las siguientes: reforzamiento y reparación de los muelles 2 y 3 del terminal, para facilitar el atraque de buques de contenedores de mayor envergadura (obra concluida en agosto de 2012); la construcción del patio del muelle 2, con el propósito de acondicionar el terreno con roderas de hormigón armado para la operación de grúas tipo RTG y con adocretos de alta resistencia en las vías para el tránsito y la operación de grúas portacontenedores tipo Reach Stacker, patio diseñado para permitir la conexión y monitoreo de contenedores reefer con 700 conexiones instaladas y una capacidad de almacenamiento de 6.000 TEU secas. Otros proyectos recientes incluyeron la instalación de un galpón, colocación de defensas en los muelles, electrificación y rehabilitación del pavimento; todas estas obras con fechas límite al año 2012 (por lo que se asume que ya fueron concluidas, aunque aún aparecen mencionadas como obras en ejecución). La inversión realizada por CGSA y sus resultados hasta ahora se resumen de la siguiente manera: «En los primeros cinco años de concesión, Contecon ha invertido más de 250 millones de dólares en equipos e infraestructura [...]. Los montos mayores han servido para adquirir cinco grúas pórtico post-panamax, tres grúas móviles de contenedores, 23 grúas de patio tipo RTG, construcción y reforzamiento de más de mil metros de muelles, reforzamiento de 20 hectáreas de patios, alrededor de 3.500 tomas reefer (para mantener la línea de frío), entre otros» ${ }^{111}$.

\subsubsection{Muelle de granos y multipropósito}

\section{Andipuerto S. A. ${ }^{112}$}

Andipuerto S. A. forma parte de un conglomerado empresarial ecuatoriano que abarca todas las actividades en mar y tierra, del cual Andipuerto es la división de operaciones portuarias, pero el conglomerado también 
comprende las divisiones de naviera, almacén y consolidación, teniendo a Andinave S. A. como cabeza de la organización. Andipuerto es así el operador portuario de Andinave. Apareció en 1998, con ocasión de la licitación del terminal de granos y multipropósito convocada por la APG y de la que obtuvo la concesión por 20 años (luego extendida hasta 2024). Andipuerto se ubica en el puerto principal de Guayaquil, Puerto Nuevo, donde dispone de un canal de acceso único para los buques que operan con esta empresa y a los cuales presta el servicio de pilotaje. Las instalaciones de Andipuerto facilitan el manejo de carga en muelle, transporte y bodegas, así como el almacenaje multipropósito, de carga líquida o sólida ${ }^{113}$.

Andinave S. A. es la agente naviera y proveedora de servicios logísticos del grupo. Fundada en 1983, tiene la autorización de operar en los puertos ecuatorianos de Guayaquil, Esmeraldas, Manta, Puerto Bolívar y La Libertad, ofreciendo los servicios de: manejo de carga especializada y logística, representación de compañías navieras, agente de puerto y navegación, protección de agentes, oficinas de ventas y seguro de cargas, carga, consultoría en marina y proyectos, estiba y logística y distribución de servicios.

Andigrain S. A. es otra empresa del grupo especializada en el manejo de la carga y su almacenamiento en depósitos temporales. Inició operaciones en 1996 como operador portuario exclusivo de Andinave en el puerto de Guayaquil, donde los depósitos fueron utilizados como almacenes de carga para esta y otras agencias navieras. Andigrain ofrece a navieras, comerciantes y propietarios de carga los siguientes servicios especializados: aseguramiento de la carga en su manejo y traslado entre el muelle y su almacenaje o entrega, y viceversa; separación de carga según embarcador/consignatario, color o marca; manejo de carga especializada; doble control total de la carga recibida/entregada; control de inventario diario; infraestructura y personal de seguridad. Andigrain también ofrece el servicio de Depósito Comercial Público, que es un servicio de internamiento temporal de carga requerido por comerciantes para permitir el paso de mercancía sin la necesidad de obtener el permiso de importación; así, la

113. Para información puntual sobre las instalaciones de Andipuerto, véase: <http://www.andinave.com/ pages/facilities>. 
carga se puede almacenar hasta por un año con la posibilidad de realizar entregas parciales ${ }^{114}$.

Pacific Link S. A. es la consolidadora de Andinave S. A. Fue establecida en Guayaquil en 1993 y actúa como operador de carga, promotor de carga y empresa de transporte y logística. Pacific Link ofrece servicios oceánicos, aéreos, de almacenaje, distribución y servicios de información. Cuenta con oficinas en Quito, Guayaquil y Esmeraldas, desde las que supervisa el transporte maritimo de cargas generales y pesadas, cargas proyecto, consolidadas, en contenedores completos (FCL) y contenedores medios (LCL) e incluye servicios door to door para recepción y entrega de la carga. En cuanto a servicios aéreos, Pacific Link mantiene vínculos con las aerolíneas comerciales más importantes, lo que le asegura la reserva de espacios para carga aérea, además de flexibilidad en la elección de vuelos y horarios según el usuario. Los servicios de almacén y distribución facilitan el control de la carga en las instalaciones propias situadas en el puerto de Guayaquil (con Andipuerto y Andigrain como agentes intermedios), garantizando el manejo seguro de cargas para exportaciones e importaciones. Finalmente, los servicios de información implican la provisión de sistemas de informática para supervisar la ejecución y coordinación de embarques, preparación de documentos y programación de procesos portuarios.

\subsubsection{Proveedores logísticos}

La privatización de la función de operación portuaria en Guayaquil aún no ha provocado un reordenamiento a nivel de los proveedores de los servicios logísticos relacionados. Actualmente están presentes ocho proveedores que realizan diversas labores logísticas en ese puerto, ninguno de los cuales tiene el monopolio de las distintas actividades que realizan. Sin embargo, sobresale la presencia de grandes holdings que realizan varias de esas labores (transporte terrestre, manejo en puerto, naviera) y las gestionan integradamente buscando el control de las respectivas cadenas de valor. Este es el caso de las chilenas SAAM y Agunsa para carga en contenedores sobre todo, así como de la ecuatoriana Andigrain para carga a granel. Esta última ya fue reseñada anteriormente, por lo que no es repetida aquí.

114. En:<http://www.andinave.com/andigrain.htm>. Consultado el 20/10/2013. 


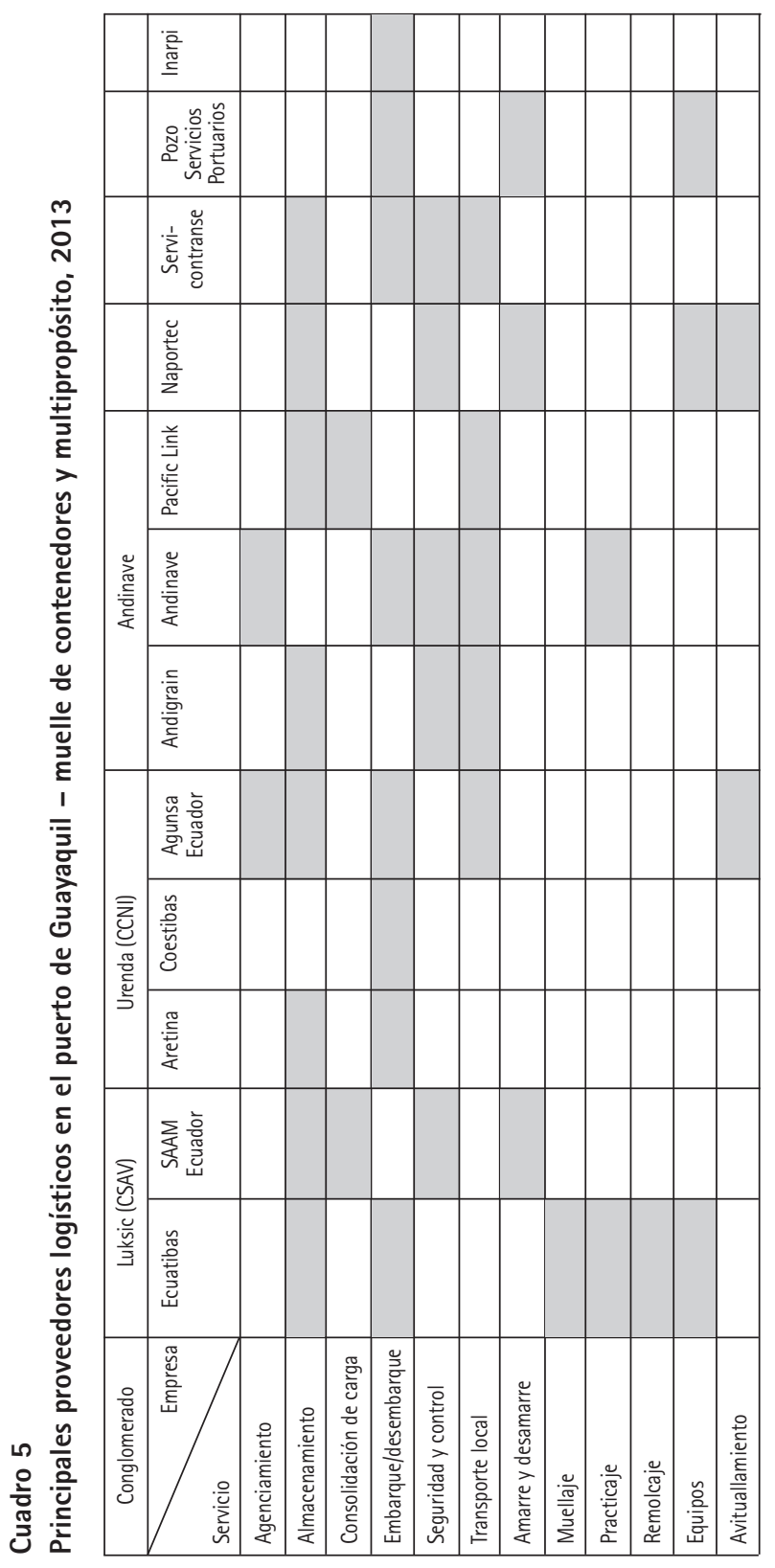


A continuación, se pasa revista a los principales proveedores logísticos que, al año 2013, brindaban sus servicios a las naves portacontenedores y/o a los dueños de la carga respectiva, que en dicho año utilizaban el muelle de contenedores y multipropósito del puerto de Guayaquil. La cantidad de servicios suministrados por cada proveedor es mostrada en el cuadro 5, como primer dato básico con miras a la estimación de su cobertura de la cadena logística y cuota en el mercado de la carga.

\section{Agencias Universales S. A. (Agunsa Ecuador) ${ }^{115}$}

En Ecuador, Agunsa cuenta con cinco subsidiarias: Marglobal realiza labores de agenciamiento marítimo, aéreo y bunkering; Portrans S. A. se encarga de logística y distribución; Modaltrade, de transporte y servicios adicionales; Aretina S. A., de los servicios de estiba y almacenaje; y Sagemar, de servicios de apoyo a naves a través del manejo de contenedores. En el puerto de Guayaquil, se encuentran Aretina y Coestibas.

\section{Aretina S. A. ${ }^{116}$}

Aretina S. A. es una empresa de logística portuaria y servicios integrales a carga y contenedores que inició operaciones en 1992, con lo cual se constituyó como el primer operador privado de carga en Ecuador, y en 1995 se convirtió en el primer operador portuario multipropósito del puerto de Guayaquil. Si bien Aretina figura como una empresa ecuatoriana que presta los servicios de estiba/desestiba y porteo, almacenamiento en terminal de contenedores y carga general y depósito de contenedores, su principal cliente es CCNI, naviera chilena a la que pertenece Agunsa. Para prestar servicios a contenedores y carga a granel en toda la gran área portuaria de Guayaquil, Aretina cuenta con una alianza estratégica con el Terminal Portuario de Banana Puerto; también cuenta con un depósito extraportuario llamado Depósito Guayaquil, así como con presencia en el Terminal Puerto Bolívar mediante un contrato de concesión para la administración del área de almacenamiento y control en este terminal.

115. En:<http://www.agunsa.com/index.php?option=com_content\&task=view\&id=69\&ltemid=70\&pais=>. Consultado el 30/1/2014.

116. En:<http://www.aretina.com>. Consultado el 30/1/2014. 


\section{Coestibas S. A. ${ }^{117}$}

Compañía registrada como ecuatoriana pero subsidiaria de Agunsa, dedicada al servicio de estiba y desestiba de contenedores en la ciudad de Guayaquil, el cual presta a CGSA, Naportec S. A. en Banana Puerto y Portrans S. A. Según el árbol organizacional, Coestibas se supedita a Modaltrade.

\section{Sudamericana Agencias Aéreas y Maritimas S. A. (SAAM Ecuador) ${ }^{118}$}

En Ecuador, esta gran empresa chilena opera en Puerto Bolívar y los terminales portuarios de Esmeraldas, Manta y Guayaquil. Para ello, cuenta con la subsidiaria Ecuaestibas. Su presencia más importante como proveedor logístico la tiene en el Terminal Puerto de Guayaquil (TPG), donde SAAM cubre los rubros de transferencia de carga para todo tipo de naves, almacenaje, servicio a contenedores vacíos y servicios logísticos complementarios: consolidación/desconsolidación de contenedores, aforo e inspección de carga, pesaje y/o romaneo de carga y contenedores, trinca/ destrinca y porteo de carga.

\section{Ecuaestibas S. A. ${ }^{119}$}

Ecuaestibas S. A. es una empresa filial de SAAM registrada como ecuatoriana que inició operaciones en 1995, formando parte del proceso de modernización portuaria en los siguientes rubros de servicios logísticos a carga y naves: remolque, estiba/desestiba, almacenaje de contenedores y carga general, depósito y talleres de contenedores, grúas móviles, equipos portuarios y logística de practicaje. Ecuaestibas presta sus servicios directamente a las líneas navieras que se trasladan en los cuatro puertos comerciales de Ecuador (gráfico 5); entre ellas, las principales son CSAV (matriz de SAAM), Dole Ocean Cargo Express de los Estados Unidos y Hamburg Süd de Alemania 


\section{Gráfico 5}

Ubicación geográfica de las operaciones de Ecuaestibas en Ecuador

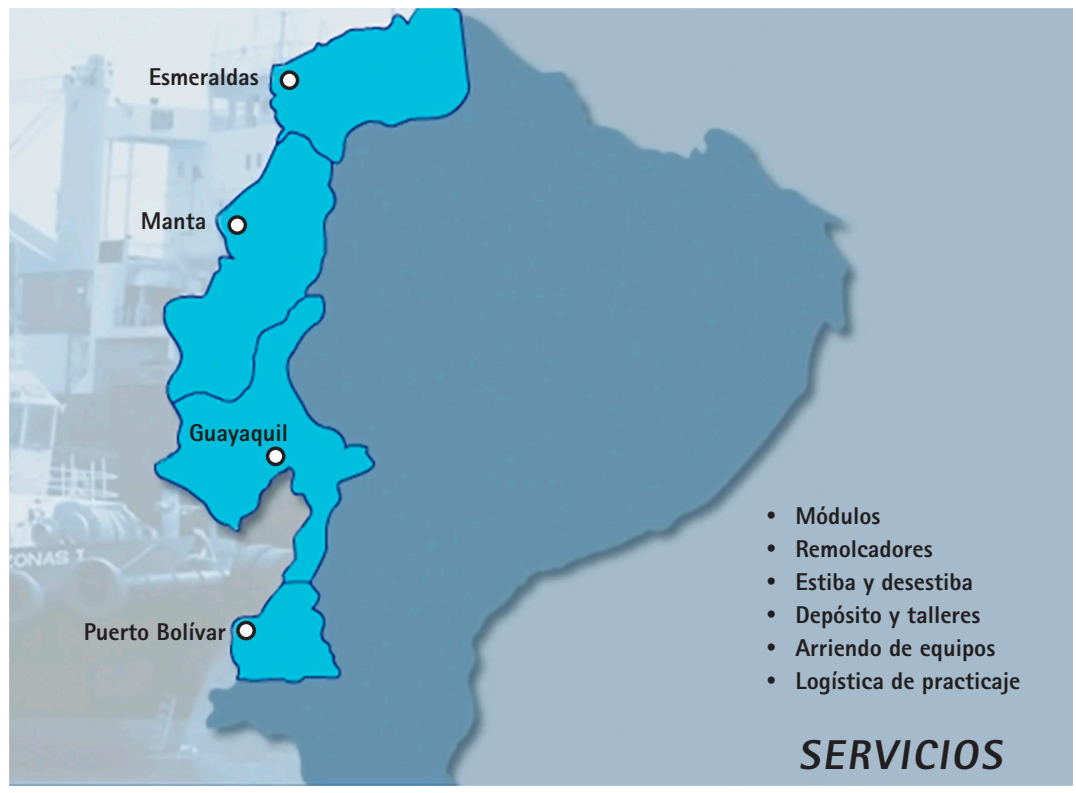

Fuente: página web de Ecuaestibas (4/2/2014).

\section{Terminal Portuario de Guayaquil (Inarpi) ${ }^{120}$}

El año 2006, inició operaciones la empresa del Terminal Portuario de Guayaquil, Inarpi S. A., ubicada a 2 millas náuticas de la APG. Inarpi presta los servicios de almacenamiento de contenedores, almacenamiento de carga suelta y estiba/desestiba, con una capacidad instalada que no solo se dedica a la movilización y despacho de carga de contenedores, sino también a procesos de control.

20. En:<http://www.tpg.com.ec/>. Consultado el 30/1/2014. 


\section{Naportec S. A. ${ }^{121}$}

Naportec S. A. es una subsidiaria ecuatoriana de la naviera norteamericana Dole Ocean Cargo Express, que surge el año 2002 a partir de Dole Ecuador, empresa que había iniciado operaciones en 1980 pero desde 1995 se concentraba en el sector de operación portuaria, como operador portuario autorizado que operaba en terrenos de la APG. Actualmente, presta en Banana Puerto los servicios de embarque/desembarque, de terminal (incluye el almacenaje, inspección de carga y consolidación) y de equipamiento. Otros servicios que presta Naportec son los de seguridad física de los contenedores, suministro de agua a barcos y de energía para las cargas reefer, vitales para el transporte de alimentos frescos como la banana.

\section{Pozo Servicios Portuarios Cía. Ltda.}

Pozo Servicios Portuarios Cía. Ltd. es un operador de carga que presta servicios técnicos especializados en el manipuleo de contenedores, carga general y buques Ro-Ro. "Actualmente nuestros servicios los brindamos en el Puerto Marítimo Simón Bolívar de Guayaquil» ${ }^{122}$. Esta empresa fue fundada en 1990 como agente de estiba/desestiba de carga, servicio que brinda en dicho puerto junto con los de trinca/destrinca, reparaciones navales, limpieza de bodegas, tanques, sentinas, maestranza y alquiler de equipos mecánicos, así como de planificación y gerenciamiento de infraestructura y equipos, siendo su principal cliente CGSA.

\subsection{Puerto de Buenaventura, Colombia}

El puerto de Buenaventura (localizado en el litoral del Valle del Cauca) fue privatizado el 21 de diciembre de 1993 en el marco de la ley portuaria de 1991, que impulsó la formación de empresas privadas para administrar y operar las instalaciones portuarias colombianas. Ello motivó la constitución de la Sociedad Portuaria Regional de Buenaventura S. A. (SPRB), empresa que desde marzo de 1994 se adjudicó la concesión por 20 años para la administración del Terminal Marítimo de Buenaventura, concesión que en 2008 fue renovada hasta 2034 bajo un nuevo programa de inversiones por el cual la empresa compromete un nuevo monto de US\$ 450 millones que,

121. En: <http://www.dole.com.ec/Portal/DolePortal/default_nodo3.asp>. Consultado el 30/1/2014.

122. Cita de <http://www.serviciosportuarios.com.ec/index.html>. Consultado el 4/2/2014. 
añadidos a los montos previos, supondrían una inversión total de alrededor de US\$ 700 millones al finalizar la concesión.

\subsubsection{Sociedad Portuaria Regional de Buenaventura S. A. (SPRB)}

La SPRB fue constituida como una empresa de accionariado mixto, donde la participación más importante estaba en manos del sector público pese a ser de solo un 17\% repartido entre la Alcaldía de Buenaventura (15\%) y el Ministerio de Transporte (2\%), ya que el 83\% restante estaba diseminado entre una gran cantidad de empresas privadas con participaciones pequeñas cada una. En efecto, los principales accionistas privados y sus respectivas participaciones eran: Consultoría de Inversiones S. A. (7,76\%), C. I. de Azúcares y Mieles S. A. (7,15\%), Harinera del Valle S. A. (6,35\%), Corporación Brisas del Pacífico S. A. (6,25\%) y Federación Nacional de Cafeteros (6,07\%); mientras que el restante 49,42\% estaba repartido entre accionistas aún más minoritarios que incluían a importadores, exportadores, operadores portuarios, líneas navieras, gremios y asociaciones de trabajadores portuarios.

La configuración accionaria del puerto de Buenaventura empezó a modificarse significativamente en el año 2012, cuando Dubai Ports (DP) World de EAU adquirió el 25\% de las acciones de la SPRB y así se convirtió en el accionista mayoritario de la empresa portuaria. Más recientemente, en julio de 2013, tanto el sector cafetalero como Gepsa (propietaria de Corporación Brisas del Pacífico) y la Compañía Transportadora Nautilus y la chilena SAAM ${ }^{123}$ vendieron sus acciones a PAC (Pacific Ports Company), compañía predecesora de NWS Holdings de Hong Kong, que forma parte de uno de los grupos económicos más poderosos de Hong Kong. Mediante esta operación, ingresaron nuevos capitales extranjeros, logrando un control mayoritario de la SPRB: DP World con el 25\% y NWS Holdings con el 19\%; aunque la participación de empresas colombianas sigue siendo

123. SAAM era propietaria del $50 \%$ de las acciones de Equimac S. A. y del $50 \%$ de las acciones de Elequip S. A., empresas colombianas ambas vinculadas al Terminal Especializado de Contenedores de Buenaventura (Tecsa). Esas participaciones representaban el $4,16 \%$ y 8,75\% de las acciones en la SPRB, las cuales adquirió PAC. Sumadas a las acciones de Gepsa y el sector cafetalero que entraron en esta subasta, el holding de Hong Kong acumuló el 19\%. Véanse: <http://www.mundomaritimo.cl> y <http://www.portafolio.co/>. Fecha de consulta: 8/1/2014. 
significativa y ha quedado distribuida de la siguiente manera: Harinera del Valle S. A. con el 24\%, el sector azucarero agremiado en Asocaña con el 10\%, la Alcaldía de Buenaventura con el 15\%, el Ministerio de Transporte con el $2 \%$ y accionistas minoritarios con el $6 \%{ }^{124}$.

Cabe señalar que la consiguiente salida de los accionistas chilenos de Buenaventura no implicaría su salida total del sector portuario colombiano, pues SAAM mantiene inversiones en el puerto de Barranquilla y planea una expansión hacia Cartagena: "[...] se asoció con dos firmas colombianas, Abonos Colombianos y Compás, para la explotación comercial del Puerto Buenavista y el desarrollo de un centro logístico integral de gran escala. Estas instalaciones están ubicadas en Cartagena de Indias, Colombia. Con esto SAAM -firma de servicios portuarios, remolcadores y logística- suma su puerto número once tras los siete terminales que tiene en Chile (siendo el más grande STI en San Antonio) y sus activos en Ecuador, Estados Unidos y México» ${ }^{125}$. De esta manera, los chilenos están redirigiendo su presencia accionarial hacia puertos colombianos en el Caribe, donde centran sus intereses en posicionarse como socios importantes en la prestación de servicios logísticos tanto a nivel marítimo como fluvial.

\section{Harinera del Valle S. A. ${ }^{126}$}

Harinera del Valle S. A. es una empresa colombiana cuyo origen se remonta a 1947 aunque su constitución como Organización Harinera del Valle data de 1956. Empezó como molinera de trigo atendiendo la demanda industrial del gremio panadero y, con el transcurso de los años, fue ampliando su portafolio productivo y llegó a poseer siete plantas distribuidas en Bogotá, Cali, Dagua, Palmira, Villarica y Pumbo, así como diez puntos de venta. Harinera del Valle S. A. concentra ahora sus procesos de producción en la preparación de harina de maiz, pastas alimenticias y harina de trigo. Para sus productos finales, ha desarrollado marcas en ocho mercados de consumo en la línea familiar (harinas de trigo, harinas de maíz, premez-

124. Véase:<http://www.mundomaritimo.cl/noticias/dubai-port-authority-adquiere-el-19-de-la-sociedadportuaria-de-buenaventura $>$. Fecha de consulta: 20/3/2014.

125. Cita de <http://www.saam.cl/saam-puertos-se-expande-a-colombia/prontus_saam/2013-01-17/ 134824.html>. Fecha de consulta: 5/1/2014.

126. En:<http://www.harineradelvalle.com/>. Fecha de consulta: 16/10/2013. 
clas, pastas alimenticias, margarina, aceites, productos listos y salsas y syrups) y cinco en la línea industrial (que se centra en costales de harinas y azúcar para la panadería comercial). Esta empresa ha desplegado una estrategia de inversión y expansión regional, mediante la compra de molinos locales de menor envergadura, a partir de la cual ha logrado una presencia comercial en casi toda Colombia que es reforzada por vínculos de su plana directiva con Consultoría de Inversiones S. A., integrante de un conglomerado empresarial con la rama alimentaria.

\section{NWS Holdings ${ }^{127}$}

NWS Holdings es un conglomerate flagship de Hong Kong fundado en el 2002 y sucesor de Pacific Ports Company (PAC) Ltd., también de Hong Kong. NWS Holdings pertenece al conglomerado New World Development (NWD), el cual aglomera a su vez la totalidad de acciones de New World Services Ltd. y los recursos de New World Infraestructure Ltd. NWD (conocido en esa región como "The Group"), fundado en Hong Kong en 1970, y es reconocido por la diversidad de actividades que realiza. Sus core businesses son: propiedades y bienes, los cuales negocia en Hong Kong y China continental; tiendas por departamento; inversión extranjera directa; e infraestructura y servicios. En este último rubro cumple su función NWS Holdings, el cual administra las inversiones del grupo en carreteras, generadores de energía, puertos y logística de transporte (movilizando un total anual de 4,9 millones de TEU en carga contenedorizada) y distribuye el procesamiento diario de 7,04 millones de metros cúbicos de agua.

La incursión de este holding de Hong Kong en el puerto de Buenaventura no es la única participación asiática en el sector. Actualmente se construye el puerto de Aguadulce al oeste de las instalaciones de la SPRB, cuyo principal socio es Ictsi, compañía filipina que también se encuentra en Guayaquil a través de Contecon Guayaquil S. A. (CGSA) ${ }^{128}$.

127. En: <http://www.nws.com.hk/>. Fecha de consulta: 8/1/2014.

128. Véase: <http://www.mundomaritimo.cl/noticias/dubai-port-authority-adquiere-el-19-de-la-sociedadportuaria-de-buenaventura>. Fecha de consulta: 8/1/2014. 


\section{Comercializadora Internacional de Azúcares y Mieles S. A. ${ }^{129}$}

El sector azucarero cumple un rol importante puesto que, al igual que para el café, el puerto de Buenaventura representa la principal salida para las exportaciones azucareras colombianas por el océano Pacífico. Representa a este sector la empresa C. I. de Azúcares y Mieles S. A. (Ciamsa), comercializadora internacional ubicada en el Valle del Cauca, en Cali, la cual agrupa a doce empresas azucareras de Colombia ${ }^{130}$. Ciamsa cuenta con una sucursal en el Perú e instalaciones portuarias en Buenaventura, con capacidad de almacenaje de 16.000 toneladas de azúcar a granel y 12.500 en sacos, con lo cual se encuentra en la capacidad de exportar cerca del $30 \%$ de la producción azucarera colombiana. La matriz productiva de Ciamsa la componen tres portafolios: el azucarero, de fertilizantes y de mezclas físicas, aunque la oferta exportable se centra en el azúcar crudo (a granel o en sacos) y en distintas calidades de azúcar blanco empacado. Ciamsa cuenta con equipos móviles por combustión, equipos de embarque y/o recibo y para la asistencia de la operación, con los cuales hace eficiente el manejo de carga azucarera en el puerto.

\section{Corporación Brisas del Pacífico S. A. ${ }^{131}$}

La Corporación Brisas del Pacífico S. A. es una empresa cuyo giro principal es la compraventa de combustibles y lubricantes derivados de petróleo, aunque incursiona también en otras inversiones temporales o permanentes y en el arrendamiento de bienes inmuebles. Esta empresa está ubicada en el mismo Buenaventura, a solo unas cuadras del puerto. Brisas del Pacífico es una de las divisiones en el sector de hidrocarburos que forma parte del Grupo Empresarial del Pacífico S. A. (Gepsa), el cual se dedica al desarrollo, ejecución y administración de infraestructuras portuarias y servicios logísticos, así como a la promoción de proyectos inmobiliarios y comercialización a gran escala de hidrocarburos. Gepsa está presente mediante asociaciones o empresas subsidiarias en los sectores de terminales marítimos (operación

129. Véase: <http://www.ciamsa.com/>. Fecha de consulta: 16/10/2013.

130. El conjunto de ingenios azucareros colombianos conglomerados en Ciamsa lo componen: Ingenio San Carlos, Ingenio Pichichi S. A., Incauca S. A., Mayagüez, Grupo Manuelita, Ingenio Risaralda, Ingenio Providencia S. A., Asocaña, Riopaila Castilla, La Cabaña, Ingenio Carmelita S. A. y Central Temuco S. A.

131. Véase: <http://www.gepsa.com.co>. Fecha de consulta: 17/10/2013. 
y logística), incluyendo la propiedad sobre Data Control Portuario S. A., y proyectos inmobiliarios, de entretenimiento y responsabilidad social, todo bajo una visión de expansión con miras a posicionarse como uno de los principales grupos empresariales del Pacífico colombiano.

En el rubro de terminales portuarios, Gepsa lleva a cabo actividades en Costa Rica, en el puerto de Caldera, primer puerto multipropósito del Pacífico costarricense, donde posee una concesión hasta 2036 con una participación del 9\% y cargas movilizadas por 150.000 TEU por las que factura US\$25.000 millones. En tanto que en Colombia opera desde el 24 de septiembre de 2012 como concesionario del puerto de Solo, el cual se ubicará al frente del actual puerto de Buenaventura y para el cual Gepsa tiene planificada la construcción de una planta de regasificación y terminales de minerales, granos e hidrocarburos para incrementar su tráfico por el Pacífico colombiano.

Aunque Gepsa ha dejado de pertenecer a la SPRB luego de la venta de sus acciones en julio de 2013, cumple aún un rol predominante en el puerto de Buenaventura pues tiene la posesión del Terminal de Contenedores de Buenaventura (TCBUEN), el cual es un terminal de servicio público especializado en el manejo de contenedores que Gepsa desarrolla en asociación con Grup Maritim TCB (operador del Terminal Marítimo de Barcelona) y que inició operaciones en 2011, con 260.875 TEU movilizadas anualmente, lo cual representa el 33,3\% de la carga contenedorizada de Buenaventura. El 73\% de la carga en el TCBUEN es transportada por Maersk Sealand; el $17 \%$, por Hamburg Süd; y un 10\%, por $\mathrm{CCNI}^{132}$.

Gepsa también administra el Terminal Logístico de Buenaventura (TLBUEN), el cual cuenta con áreas de bodega y la prestación de servicios comunes en espacios de logística portuaria: arrendamiento a TCBUEN para la consolidación y desconsolidación de carga, procesos de reexportación de carga, operaciones de valor agregado a la carga, y cargue y descargue de mercancía suelta, café y azúcar. Gracias a su vecindad y vínculos empresariales con TCBUEN, TLBUEN goza de los beneficios de contar con una zona franca portuaria y con una zona aduanera primaria (gráfico 6).

132. En:<http://www.gepsa.com.co/web/index.php?option=com_content\&view=article\&id=68\&/temid=81>. Consultado el 8/1/2014. 


\section{Gráfico 6}

\section{Ubicación geográfica de la SPRBUN, el TCBUEN y el TLBUEN}

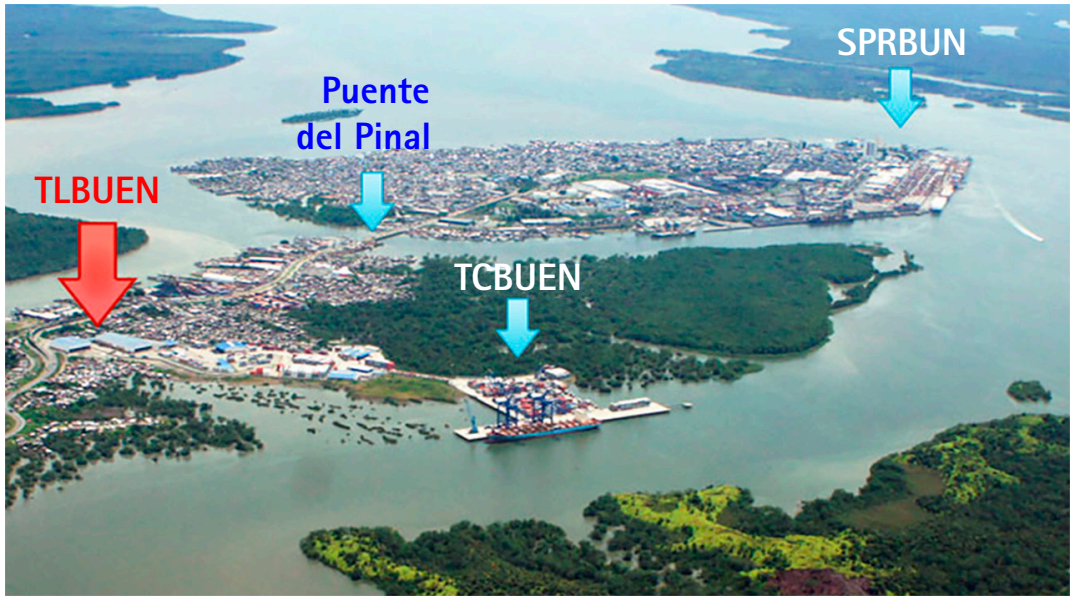

Fuente: página web de TCBUEN.

\subsubsection{Proveedores logísticos}

En los catorce muelles con los que cuenta el puerto de Buenaventura concurren 41 proveedores de servicios logísticos para contenedores, carga a granel sólido y líquido, carga general (fraccionada y multipropósito) y servicios para las naves. De este conjunto de proveedores, nueve centran sus servicios en carga contenedorizada: Asistencia Integrada y Cía. Ltda. OP, BGP Container and Logistics S. A., Data Control Portuario S. A., Elequip S. A., Galotrans Ltd., Granportuaria Buenaventura S. A., Nautiservicios S. A., Opermar Ltd., Serteport (Servicios Técnicos Portuarios) S. A. y Tecsa (Terminal Especializado de Contenedores de Buenaventura S. A.).

A continuación, se pasa revista a los principales proveedores logísticos que, al año 2013, brindaban sus servicios a las naves portacontenedores y/o a los dueños de la carga respectiva, que en dicho año utilizaban el terminal marítimo del puerto de Buenaventura. La cantidad de servicios suministrados por cada proveedor es mostrada en el cuadro 6, como primer dato básico con miras a la estimación de su cobertura de la cadena logística y cuota en el mercado de la carga. 


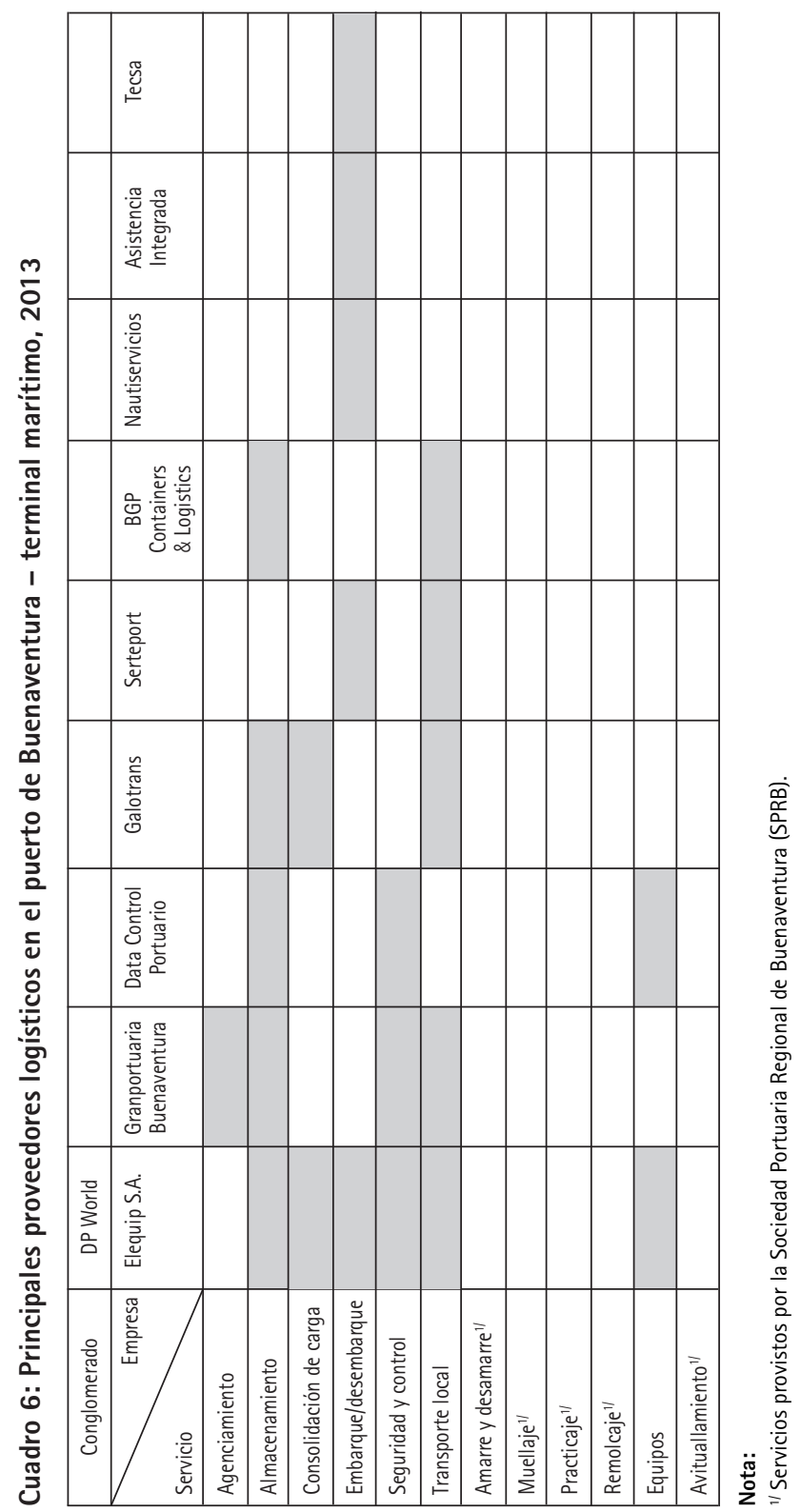


Asistencia Integrada y Cía. Ltda. OP ${ }^{133}$

Empresa colombiana ubicada en Buenaventura, especializada en manejo de contenedores, mantenimiento de instalaciones y servicios de correo aéreo.

\section{BGP Container and Logistics S. A. ${ }^{134}$}

Operadora logística de contenedores (llenos o vacíos) y transportados por carretera, adquirida en mayo de 2006 por un consorcio empresarial conformado por OPP Graneles, Grupo Portuario S. A. y Ferrocarril del Oeste S. A., empresas concentradas en los rubros de logística y transporte marítimo y férreo en el Valle del Cauca.

BGP maneja un portafolio de servicios con tres líneas principales: transporte terrestre, pues posee una flota propia de camiones para movilizar carga general, granel sólido y contenedores; almacenamiento, de contenedores o carga suelta; y urbaneo (o movimiento en zona urbana), para el cual cuenta con una flota propia de "minimulas» que transportan carga a granel, sacos y contenedores llenos o vacíos. En términos de infraestructura, BGP Container and Logistics S. A. cuenta con un muelle privado con posición de atraque, depósito habilitado y bodegas de almacenamiento, un patio de contenedores de $19.000 \mathrm{~m}^{2}$ y un patio de transferencia de carga de $9.000 \mathrm{~m}^{2}$.

\section{Data Control Portuario S. A. ${ }^{135}$}

Empresa colombiana perteneciente a Gepsa que presta servicios de operación portuaria y logística en el puerto de Buenaventura. Data Control Portuario S. A. tiene una oferta de servicios integrados y armados como "paquetes" según las preferencias del usuario: preinspecciones, inspecciones antinarcóticos, inspecciones DIAN (Dirección de Impuestos y Adua-

133. En: <http://www.iglobal.co/colombia/search/asistencia-integrada-amp-cia-Itda-op>. Consultado el 18/10/2013.

134. En:<http://bgp-cl.com/>. Consultado el 18/10/2013.

135. En:<http://www.datacontrolportuario.com/web2/index.php>. Consultado el 18/10/2013. 
nas Nacionales de Colombia), llenado y vaciado de contenedores, carga suelta, almacenaje, tarja y trazabilidad, y alquiler de equipo portuario. Data Control provee estos servicios tanto en el terminal de contenedores TCBUEN como en SPRB. Entre sus principales clientes se encuentran las estadounidenses Kraft Foods y Colgate-Palmolive Company.

\section{Elequip S. A. ${ }^{136}$}

Elequip S. A. es uno de los mayores operadores portuarios del Pacífico colombiano y operaba en el puerto de Buenaventura desde hace más de 30 años. En 2004, la chilena SAAM poseía cerca del 50\% del capital accionario tanto en Elequip (operador portuario) como en Equimac S. A. (servicio de remolcadores) y Equiyard S. A. (servicios de maestranza de contenedores), por lo que Elequip formaba parte de un conglomerado de servicios integrado en el puerto de Buenaventura. Sin embargo, desde julio de 2013 SAAM ha emprendido el retiro de parte de sus capitales de Buenaventura, con lo que sus participaciones en Elequip y Equimac han sido absorbidas por DP World, operador portuario de EAU que ahora incursiona en este puerto colombiano y aumenta así su presencia en la Costa Oeste de América del Sur (COAS) pues ya opera el Muelle Sur del puerto del Callao en el Perú.

\section{Galotrans Ltd. ${ }^{137}$}

La empresa Galotrans Ltd. fue fundada en 1993 como operador portuario en Colombia, pero ha ampliado la gama de servicios provistos a través del transporte terrestre de carga a nivel nacional, almacenamiento, distribución y alquiler de equipos, para cubrir los requerimientos de un creciente comercio internacional. Para asegurar el manejo integral de su carga, Galotrans opera a través de Centros de Apoyo Logístico (CAL), con lo que supervisa sus actividades en toda Colombia.

136. Véanse: <http://webmail.saam.cl/websaam/index.aspx?channel=2219> y <http://www.latercera. com/noticia/negocios/2013/07/655-531432-9-saam-acuerda-venta-de-su-participacion-minoritaria-enconcesionaria-de-puerto.shtml>. Consultados el 18/10/2013.

137. En:<http://www.galotrans.com/>. Consultado el 18/10/2013. 


\section{Granportuaria Buenaventura S. A. ${ }^{138}$}

Fundada como operadora portuaria en 1992, Granportuaria expandió sus negocios a raíz de que, primero, fue adquirida en 1997 por Transportación Marítima Mexicana (TMM México), formando así TMM Colombia, y luego capitales colombianos compraron el 90\% de las acciones de los mexicanos, con lo cual se dio un impulso a la empresa tras la inversión en infraestructura y tecnología en 2011. Así, Granportuaria ya no está limitada a la actividad portuaria, sino que ha ampliado sus servicios en transporte terrestre de carga, operaciones de transporte multimodal y operaciones integrales de logística ${ }^{139}$, bajo un modelo just in time.

\section{Nautiservicios S. A. ${ }^{140}$}

Nautiservicios S. A. forma parte del grupo empresarial de Transinternational Courier Ltd., presente en la gama de operadores logísticos del puerto de Buenaventura, mientras su par Nautiport S. A. opera en los puertos de la zona atlántica: Cartagena, Santa Marta y Barranquilla.

\section{Serteport - Servicios Técnicos Portuarios S. A. ${ }^{141}$}

Serteport es una empresa integrante de la Compañía Roldan Logística, que ofrece servicios de gerenciamiento de cadenas de abastecimiento en cada uno de sus eslabones. Serteport forma parte de un grupo de ocho empresas, siendo su giro principal el de movimiento de carga en los puertos, aeropuertos, zonas francas y plataformas logísticas de Colombia, a través de servicios a buques y terminales tanto públicos como privados.

138. En:<http://www.amg.com.co/>. Consultado el 18/10/2013.

139. Estos servicios incluyen: recolección de carga con bodegas en el exterior; transporte marítimo y aéreo de importación y exportación; transporte terrestre en OTM, DTA y nacionalizado; consolidación y desconsolidación de carga marítima y aérea; operaciones de vaciado simultáneo (ITR); venta de póliza de seguros; manejo de carga de proyecto, extradimensionada, peligrosa o equipos especiales; y logistica de generadores de energía (Genset) en puerto. Así como los siguientes servicios complementarios en Colombia: bodega y agenciamiento aduanero.

140. En: <http://www.transinternationalcourrier.com/GrupoEmpresas.aspx>. Consultado el 19/10/2013.

141. Véase: $<$ http://rlg.roldanlogistica.com:82/roldanweb/roldanweb/index.php?option=com_content\&view= article\&id=21\&/temid=90\&lang=es>. Consultado el 19/10/2013. 
Terminal Especializado de Contenedores de Buenaventura S. A. (Tecsa) ${ }^{142}$

Tecsa apareció en el contexto de la implementación del Plan Maestro de Desarrollo de la Sociedad Portuaria Regional de Buenaventura S. A., con el propósito de desarrollar actividades complementarias a los operadores logísticos en Buenaventura y de manipulación de contenedores de usuarios del puerto en mención. La visión hacia 2014 es tener la participación total de la manipulación de contenedores de importación y exportación en el puerto de Buenaventura. En Tecsa se ofrecen servicios terrestres (carga, descarga y localización de contenedores), marítimos (arrastre, carga y descarga de contenedores llenos y vacíos) y movimientos internos. 


\section{Conglomerados empresariales en la COAS}

La descripción detallada que se ha realizado en el capítulo II, de los operadores portuarios y principales proveedores logísticos presentes al año 2013 en los terminales para contenedores o multipropósito de los cuatro principales puertos de la Costa Oeste de América del Sur (COAS), junto con las menciones allí hechas a las líneas navieras empresarialmente ligadas a esos operadores portuarios y/o proveedores logísticos, proporciona información útil para encaminar la verificación de la hipótesis de nuestra investigación. Porque, de conformidad con lo que cabía esperar a la luz de lo enseñado por el marco analítico (capítulo I), acerca del puerto como nodo donde confluyen los integrantes de distintas redes empresariales marítimo-portuarias y donde estos pulsean su poder de mercado para competir entre sí por la carga y para proveer el soporte logístico a cadenas de valor/suministro internacionales, la detección de integrantes y sus respectivas redes provista por el capítulo II es un paso empírico indispensable hacia la identificación de sus probablemente diferentes estrategias de desarrollo portuario en la COAS.

En tal sentido, la información que se sintetiza en el cuadro 7 muestra una profunda transformación del "mapa» del manejo portuario de carga contenedorizada en la COAS, a raíz de la entrada de megaoperadores portuarios globales a tres de los cuatro principales puertos de dicha costa. Este cambio radical se inició el año 2006, con el ingreso al Muelle Sur del Callao de DPW (cuarto operador portuario del mundo) y se fue extendiendo luego: el año 2007 con el ingreso al puerto de Guayaquil de un operador extrarregional (Ictsi) vinculado al primer operador mundial según TEU a su cargo (HPH); el año 2011 con el ingreso al Muelle Norte del Callao de APMT (segundo operador portuario mundial, perteneciente al conglomerado de la primera línea naviera del mundo: Maersk); y el año 2013 con el ingreso de DPW al puerto de Buenaventura. 


\section{Cuadro 7}

\section{Operadores portuarios en los principales puertos de la COAS, 2013}

\begin{tabular}{|c|c|c|c|}
\hline $\begin{array}{l}\text { Terminal portuario de } \\
\text { contenedores y/o multipropósito } \\
\text { Puerto de San Antonio (Chile) }\end{array}$ & $\begin{array}{l}\text { Operadores } \\
\text { globales }^{1 /}\end{array}$ & $\begin{array}{l}\text { Operadores } \\
\text { regionales }\end{array}$ & $\begin{array}{c}\text { Operadores } \\
\text { locales }\end{array}$ \\
\hline San Antonio Terminal Internacional (STI) & & SAAM y $\mathrm{SSA}^{21}$ & \\
\hline Puerto Panul & & & Varios ${ }^{3 /}$ \\
\hline Puerto Central & & & Puerto de Lirquén S. A. \\
\hline Policarpo Toro (Muelle 9) & & & $\mathrm{EPSA}^{4 /}$ \\
\hline \multicolumn{4}{|l|}{ Puerto del Callao (Perú) } \\
\hline Muelle Sur & $\mathrm{DPW}^{5 /}$ & & \\
\hline Muelle Norte & APMT y TIL ${ }^{6 /}$ & & \\
\hline \multicolumn{4}{|l|}{ Puerto de Guayaquil (Ecuador) } \\
\hline Muelle de Contenedores & |ctsi/HPH ${ }^{7 /}$ & & \\
\hline Muelle Multipropósito & & & Andipuerto S. A. ${ }^{8 /}$ \\
\hline \multicolumn{4}{|l|}{ Puerto de Buenaventura (Colombia) } \\
\hline Sociedad Portuaria Regional de Buenaventura & $\mathrm{DPW}^{9 /}$ & & Varios $^{10 /}$ \\
\hline
\end{tabular}

\section{Notas:}

1/ En la introducción de este documento, se definen las categorias de operador portuario global y de operador portuario regional utilizadas en esta investigación.

2) SAAM y SSA componen el consorcio STI que en 1999 obtuvo la concesión de este terminal, pero la función de operación del mismo está básicamente a cargo de SAAM, por lo que se le ubica en la columna correspondiente a operadores regionales. SAAM forma parte del Grupo Quiñenco, controlado por la familia Luksic, y es la operadora principal en tierra, a nivel local y regional, de la naviera CSAV. SSA Holdings International Chile es la subdivisión local de SSA Holdings Internacional, subsidiaria de FRS Service Companies Inc. de los Estados Unidos.

${ }^{3 /}$ Incluye a las siguientes empresas chilenas: Maritima Valparaiso Chile (49\% de participación accionaria), Graneles de Chile (40\%) e Inversiones Feld (11\%).

${ }^{4 /}$ Empresa Portuaria San Antonio, de propiedad estatal, que supervisa todo el puerto de San Antonio, provee servicios logísticos a sus terminales y ejerce la función de operador del Muelle 9.

5/ Obtuvo la concesión del Muelle Sur el año 2006.

${ }^{6 /}$ APMT lideró el Consorcio APMT Callao que el año 2011 obtuvo la concesión del Muelle Norte. En marzo de 2014, al consorcio se integró TIL Group, perteneciente a la naviera MSC, que adquirió el 29\% de la participación que APMT tenía a través de Callao Port Holding B. V. Así, el consorcio está ahora conformado por APMT (con un 51\% de participación accionaria), TIL (29\%) y el Grupo Unimar como socio local (20\%).

${ }^{71}$ El operador que obtuvo la concesión el año 2007 es Contecon Guayaquil S. A., subsidiaria de la filipina Ictsi, cuya división de negocios internacionales fue comprada el año 2001 por HPH (con sede en Hong Kong).

${ }^{8 /}$ Pertenece al grupo ecuatoriano Andinave, el cual fue formado en 1998 y se hizo de la concesión del Terminal de Granos y Multipropósito de Guayaquil en 1999.

9/ DPW adquirió el 25\% de la participación accionaria de la SPRB el año 2012, convirtiéndose así en su accionista mayoritario y en el operador del Terminal Maritimo de Buenaventura. El segundo accionista es PAC (predecesora de NWS Holding de Hong Kong) con el 19\%, participación que acumuló el año 2013 al comprar las acciones de la chilena SAAM y de capitales colombianos del sector cafetalero, Gepsa y Nautilus.

${ }^{10 /}$ Incluye a un conjunto de empresas privadas y de entidades públicas colombianas. Los accionistas privados son las empresas Harinera del Valle (24\% de participación accionaria) y Asocaña (10\%), así como una serie de accionistas minoritarios (6\%). Los accionistas por el sector público son la Alcaldia de Buenaventura (15\%) y el Ministerio de Transporte (2\%). 
Además, el año 2014 se produjo el ingreso de TIL (un operador portuario que pertenece a la segunda línea naviera del mundo: MSC) al Muelle Norte del Callao en asociación con APMT. Muy sintomáticamente, a esta "ola" globalizante, que cual "Efecto Callao» ha modificado en pocos años los parámetros de la competencia interportuaria por la carga contenedorizada en el seno de la COAS, aún no se suman el puerto de San Antonio (que antes de aquella "ola» lideraba el manejo de dicha carga en la COAS) ni ningún otro puerto chileno a cargo de operadores pertenecientes a redes regionales originarias de ese país.

Sin embargo, en los cuadros 3 al 5 se mostró que los proveedores logísticos de redes regionales originarias de Chile mantienen hasta hoy una presencia muy importante en tres de los cuatro puertos examinados (San Antonio, Callao y Guayaquil) ${ }^{143}$. Este hecho, que para el caso de la COAS corrobora lo analizado en el capítulo I acerca de la fuerte implantación que las redes regionales suelen tener en el segmento tierra de sus respectivas regiones, unido a la tendencia (también analizada en dicho capítulo) a que las empresas insignia de redes marítimo-portuarias (línea navieras u operadores portuarios) sean parte de conglomerados que incluyen a proveedores logísticos y a empresas en otros sectores funcionales al propósito de cubrir los tres segmentos (mar, puerto, tierra adentro) de la cadena logística bajo el comando central del holding en la cúspide del conglomerado, hace necesario reseñar los conglomerados a que pertenecen los operadores portuarios y los proveedores logísticos identificados en el capítulo II.

Esa reseña, materia del presente capítulo, al mostrar las diferencias entre conglomerados globales y regionales en cuanto a cobertura del espacio marítimo-portuario conformado por la COAS y sus costas colindantes en el continente americano, agrega información sobre el posicionamiento (al año 2013) de cada conglomerado para disputar el manejo de la carga contenedorizada en dicho espacio, aportando así más elementos de juicio útiles para mejor detectar las estrategias de desarrollo portuario que cada cual podría aplicar a favor de los terminales de contenedores a su cargo en la COAS.

Respecto a los conglomerados globales presentes en la COAS, este capítulo mostrará que APMT y DPW operan grandes terminales para contenedores en

143. De hecho, también han estado presentes en el puerto de Buenaventura hasta julio de 2013, cuando la chilena SAAM vendió su participación accionaria en la Sociedad Portuaria Regional de Buenaventura, tal como se vio en el acápite 2.4.1 (capítulo II). 
la CEAS (Costa Este de América del Sur) -en cuyo mayor puerto (Santos) hay incluso un joint venture entre APMT y TIL como el que estos tienen ahora en el mayor puerto de la COAS (Callao)- así como en la Costa Oeste de América del Norte (DPW en Canadá, y APMT en Estados Unidos y México). También mostrará que DPW opera varios terminales sobre el Mar Caribe y que APMT hace lo propio en varios de la Costa Este de América del Norte. Sin embargo, se percibirá una diferencia clave entre esos conglomerados globales en cuanto a su capacidad para establecer, entre el segmento mar y los importantes posicionamientos que están logrando en el segmento puerto a lo largo de las Américas, las fuertes compatibilidades que requiere una estrategia de desarrollo portuario basada en el foreland. En efecto, mientras que el negocio marítimo-portuario de los sendos conglomerados globales que comandan a APMT y a TIL está encabezado por sus respectivas megalíneas navieras globales (Maersk y MSC), a las que APMT y TIL sirven como anclas portuarias del foreland y para una eventual incursión hacia el hinterland, el caso del conglomerado global de DPW difiere en que aún no cuenta con una línea naviera global (pues P\&0 Maritime Services ya no califica como tal).

En lo concerniente a los conglomerados regionales, según la identificación realizada en la sección 2.1 (capítulo II), en la carga contenedorizada destacan los siguientes tres conglomerados comandados por holdings empresariales chilenos: CSAV/SAAM, CCNI/Agunsa ${ }^{144}$ y Ultramar/Ultragas. Las reseñas de estos presentadas en este capítulo muestran que no solo sus respectivos operadores portuarios (de los dos conglomerados mencionados primero, especialmente) están a cargo de varios terminales o puertos en Chile, sino que sus respectivos proveedores logísticos están fuertemente implantados en el segmento tierra a lo largo de toda la COAS y gran parte del cono sur de la CEAS. Es probable que este fuerte posicionamiento en los hinterlands sudamericanos haya sido puesto al servicio de la acumulación de carga en puertos chilenos para tratar de erigirlos como centros de carga (o gateways) y/o hubs de transbordo subregionales, a

\footnotetext{
144. Debido a que la información recopilada para este capítulo corresponde al año 2013 y a que el capítulo versa sobre los conglomerados empresariales cuyos operadores portuarios estaban en dicho año a cargo de terminales para contenedores en los principales puertos de la COAS, aqui se menciona a CSAV/SAAM y a CCNI/ Agunsa como integrantes de sendos conglomerados regionales de origen chileno. Esta aclaración se hace en vista de dos MEtA posteriores: I fusión entre CSAV y Hapag-Lloyd para lo relativo al negocio del transporte marítimo de contenedores que está por completarse al cierre del presente documento, asi como la compra hecha por Hamburg Süd de CCNI en lo concerniente a dicho negocio y de las relacionadas funciones que desempeña Agunsa. Véanse las respectivas notas al pie de página en los acápites 3.2.1 y 3.2.2 de este capítulo.
} 
juzgar por los primeros resultados de nuestra investigación (González Vigil et al. 2012) que fueron comentados en la introducción del presente documento.

Adicionalmente, la presencia de proveedores logísticos de CSAV/SAAM y CCNI/ Agunsa se extiende -a través de subsidiarias o de joint ventures- no solo a la zona mesoamericana comprendida por América Central, el Caribe y México, donde se ha reforzado con el ingreso conjunto de SAAM y Agunsa como operadores de un terminal en Florida (Estados Unidos), sino que también se extiende a algunos países del este de Asia y del sur de Europa, aunque en estos lares se trata sobre todo de servicios relacionados con el transporte marítimo. Ello está sin duda asociado al hecho de que el negocio marítimo-portuario de esos dos conglomerados chilenos está encabezado por sus respectivas líneas navieras, CSAV y CCNI (de manera similar que en los casos de Maersk/APMT y MSC/TIL). Con el mismo rasgo empresarial estaría asociada la perceptible tendencia de esos dos conglomerados chilenos a mejorar su presencia por el norte de la CEAS y el Caribe, ejemplificada por el traslado de SAAM hacia los puertos caribeños de Colombia (visto en el acápite 2.4.1). Aparentemente, ante el riesgo de perder participación en la carga de la COAS resultante de la acrecentada presencia de conglomerados globales en dicha costa, aquellos dos conglomerados chilenos estarían en pos de aumentar su presencia por el lado de la CEAS, América Central y alrededor del Mar Caribe, con el propósito de ganar participación en la carga que las conecta entre sí y en parte de sus cargas transatlánticas y transpacíficas.

A primera vista, lo anterior parece anunciar la posibilidad de algunos cambios en las estrategias de esos dos conglomerados regionales en materia de sus respectivas jerarquías portuarias, quizá ya no tan centradas en sus respectivos "puertos matrices" (o home ports) en Chile. Sin embargo, también hay que tener en cuenta que aún es predominantemente sudamericana la implantación de las otras empresas de los conglomerados chilenos que les sirven a estos para hacerse de un hinterland bajo su control; es decir, de sus empresas financieras, de retail e inmobiliarias. Mientras ello siga siendo así, los hinterlands sudamericanos continuarán representando para tales conglomerados la parte esencial de su base regional de carga y, en lo que particularmente atañe a la carga por el cono sur de las dos costas de Sudamérica, es probable que continúe su propensión a dirigirla y manejarla en formas diseñadas con el doble propósito de que esa carga sea aglomerada en sus "puertos matrices" en Chile (es decir, el puerto de San Antonio para CSAV/SAAM y el de Valparaíso para 
CCNI/Agunsa) y de mantener su cuota de mercado en el comercio marítimo entre Sudamérica y la región Asia-Pacífico ${ }^{145}$.

Por lo demás, en línea con lo que generalmente sucede en el negocio marítimo-portuario contemporáneo, los tres conglomerados chilenos comparten un perfil familiar de propiedad y gobernanza empresarial: un control mayoritario de la familia Luksic en CSAV/SAAM, de la familia Urenda en el caso de CCNI/ Agunsa y de la familia Von Appen en el caso de Ultramar/Ultragas. Pero en este capítulo se verá que el negocio marítimo-portuario de este último es liderado por la agencia marítima del conglomerado y que su línea naviera cumple un rol secundario, por ahora al menos. Ello puede explicar en parte el alcance de la presencia del conglomerado Von Appen, casi exclusivamente sudamericana hasta el momento. También podría explicar en parte la mayor disposición del conglomerado Von Appen a trabajar en red con empresas locales establecidas en países sudamericanos como independientes de dicho conglomerado, e incluso a facilitarles la adquisición de empresas que le pertenecían. Tal como parece sugerir su relación con el grupo empresarial peruano Andino Investment Holding (véase 2.2.4, arriba).

\subsection{Conglomerados globales}

\subsubsection{A. P. Møller-Maersk ${ }^{146}$}

El Grupo A. P. Møller-Mærsk, también conocido simplemente como Maersk, es un conglomerado de transporte, logística y relacionados negocios internacionales, fundado en 1904 por familias danesas en su actual sede de Copenhague. El negocio principal del grupo radica en el rubro de transportes y energía, en los cuales, a la fecha, concentra el mayor volumen de inversiones, habiendo llegado a posicionarse en 2011 como la compañía de transporte marítimo más importante del mundo.

\section{Industrias}

En el rubro de transporte marítimo, el grupo cuenta desde 1928 con Maersk Line, la naviera número uno del mundo y división empresarial que genera 
los mayores beneficios al grupo. El año 2012, Maersk Line transportó 35 millones de contenedores, operando alrededor de 500 embarcaciones para mercancía refrigerada (reefer), seca y especial. El año 2001, creó APM Terminals (APMT), como una división independiente encargada de las operaciones portuarias y logísticas en tierra, que opera en 74 puertos y terminales en 40 países alrededor del mundo y presta 166 inland services en 47 países. En puertos del continente americano, APMT opera en Buenos Aires, en tres puertos de Brasil (Santos, Pecem e Itajaí) y en el Callao, y ha obtenido la concesión de Lázaro Cárdenas (México) ${ }^{147}$, así como también en varios puertos de los Estados Unidos entre los cuales destacan Miami y Los Ángeles. Todo ello ha llevado a APMT a posicionarse como el segundo operador del mundo, en términos de TEU movilizadas por los terminales para contenedores a su cargo.

En la rama energética, el grupo cuenta con Maersk Oil, una división independiente fundada en 1962 y dedicada a la extracción de petróleo y gas, cuyas operaciones se localizan en el Mar del Norte (secciones de Dinamarca y Gran Bretaña), Qatar, Argelia y Kazajistán; también realiza labores de exploración en las áreas antes mencionadas, además de en Brasil, Angola, el Golfo de México y los Estados Unidos. Asimismo, desde 1972 existe Maersk Storm Drilling Corporation, que presta servicios de perforación de yacimientos de combustibles fósiles para compañías como BP, Chevron o Statoil.

Entre sus empresas de relativamente menor envergadura, el grupo A. P. Møller-Mærsk cuenta con Maersk Supply Service (servicios de abastecimiento naviero off shore), Maersk Tankers (transporte de crudo y petróleo refinado), Damco (cadenas de abastecimiento para carga aérea y marítima), Svitzer (salvamento naviero), Maersk FPSO's (con flotas en Escocia y el Congo para producción, almacenaje y descarga de gas), Dansk Supermarked (retail en Dinamarca), Maersk Container Industry (sus productos incluyen contenedores secos, contenedores refrigerados y cargadores reefer), MCC Transport (con rutas de transporte marítimo intra-Asia), SeaGo Line (con rutas de transporte marítimo intra-Europa y en el Mediterráneo) y

147. Adicionalmente, APMT tenía en proyecto la construcción de un puerto en Moin (Costa Rica) y otro en Posorja (Ecuador). 
SafMarine (empresa de origen sudafricano-belga, que actualmente hace transporte marítimo entre África, Medio Oriente e India), y está volviendo a poner operativa a Sealand para con esta marca brindar transporte marítimo en rutas norte-sur y circunferenciales, como entre la CEAS y la COAS por ejemplo.

\section{Accionariado $^{148}$}

A. P. Møller-Maersk cuenta con aproximadamente 67.000 accionistas registrados pero los 4 más importantes, que son de origen danés, no solo tienen participación mayoritaria en el capital accionarial $(56,51 \%)$ sino que sobre todo controlan las decisiones pues sus votos pesan un 76,22\% en el directorio principal del grupo ${ }^{149}$. Estos son: A. P. Møller Holding, con 41,51\% de las acciones y 51,09\% de los votos; A. P. Møller og Hustru Chastine Mc-Kinney Møllers Familiefond, con 8,37\% de acciones y 12,84\% de votos; el patrimonio de M. Mc-Kinney Møller, con 3,69\% y 6,43\%, y el de Den A. P. Møllerske Stottefond, con 2,94\% y 5,86\% ${ }^{150}$.

\section{Perspectivas a futuro en el rubro marítimo ${ }^{151}$}

En lo que corresponde a Maersk Line, la compañía ha optado en los últimos cuatro años por mejorar la eficiencia en el manejo de la carga en contenedores y sus vínculos con los clientes y demás partes interesadas. En este sentido, desde el año 2011 la empresa puso en construcción los buques más grandes del mundo: los Triple $\mathrm{E}$ (acrónimo en inglés de economías de escala, eficiencia y medio ambiente), naves con las cuales el Grupo Maersk pretende establecer nuevos estándares de competitividad naviera, tamaño, ahorro de combustibles (emplea gas de escape con el cual produce energía extra para impulsar la nave) y eficiencia de costos, así como la reducción de emisiones de $\mathrm{CO}_{2}$. Estos buques tienen una capacidad de carga de 18.000

148. En: <http://investor.maersk.com/stockquote.cfm>. Consultado el 18/2/2014.

149. La participación accionaria solo da derecho a obtener utilidades por el rendimiento de la empresa, mientras que el derecho a voto en el directorio es para directamente participar en la toma de decisiones del grupo, donde el peso porcentual es una ponderación del valor del voto del socio.

150. Véase: <http://www.reuters.com/article/2013/12/17/us-maersk-owner-idUSBRE9BG12G20131217>. Consultado el 18/2/2014.

151. En: <http://www.maerskline.com/es-pe/about/milestones>. Consultado el 24/2/2014. 
TEU y 10 de ellos tienen un período de entrega a la naviera Maersk Line entre 2013 y 2015. El Triple E sigue la misma ruta Asia-Europa de clase Emma Maersk, ruta que dura 23 días entre Shanghái y Róterdam, pese a que la nave ha sido diseñada para ir a menor velocidad para ahorrar combustible y reducir efectos contaminantes ${ }^{152}$.

Otro aspecto importante en los planes de Maersk es el de sostenibilidad, el cual está ligado al anterior pero que inicialmente se concentró en el ahorro de combustibles y dinero en los procesos de transporte de carga desde el año 2012. Sin embargo, a consecuencia de los logros en políticas de sostenibilidad ambiental que otras navieras como Hapag-Lloyd y CMA CGM habían alcanzado desde 2010, Maersk introdujo los siguientes cambios operacionales: la navegación lenta, con la cual además de reducir el consumo de combustible y emisiones de $\mathrm{CO}_{2}$, absorbió la capacidad de carga de buques de repuesto (ahorro en naves y rutas en circulación) y ayudó a Maersk Line a otorgar un servicio más confiable pues la velocidad de la nave es ajustable y así, ante contratiempos, pueden asegurar con precisión la llegada de las cargas a su destino; operaciones optimizadas gracias a un sistema integrado de bases de datos sobre las naves en circulación simultánea; la reducción de emisiones de sulfuro; y la protección del ambiente marino. Los cambios técnicos se han concentrado en la adquisición de nuevos buques y combustibles y el mantenimiento de los antiguos. Maersk Line utiliza este proceso de mejora de sostenibilidad como una manera de diferenciarse de la competencia ${ }^{153}$.

El grupo Møller-Maersk también ha intensificado su actividad en el desarrollo portuario llevado a cabo a través de APM Terminals. Ejemplos de ello son los proyectos del puerto Lázaro Cárdenas en México y del puerto Moin en Costa Rica, que forman parte de un proceso de expansión acelerado y significa que el grupo pretende competir con mayor énfasis en el brazo tierra del negocio, con el propósito de consolidar economías de escala y cadenas de valor integradas que supongan ventajas comparativas sustanciales pues cuenta ya con la naviera líder.

152. Véase:<http://www.worlds/argestship.com/the-ship/\#page/efficiency/shape-of-change>. Consultado el $24 / 2 / 2014$.

153. Véase: https://wwz.unibas.ch/fileadmin/wwz/redaktion/Summer_School/2012/Maersk_2012_Reinhardt_HBS_712-449.pdf>. 


\subsubsection{TIL Group ${ }^{154}$}

Terminal Investmente Limited (TIL) S. A., fundada en el año 2000, es la empresa inversora, desarrolladora y operadora de terminales perteneciente a Mediterranean Shipping Company (MSC), la segunda naviera del mundo (con sede en Ginebra). TIL ha logrado convertirse en el sexto operador portuario del mundo ${ }^{155}$, como resultado de una estrategia empresarial que ha priorizado la formación de joint ventures con otros operadores portuarios globales especializados en el manejo de carga en contenedores. Así, la presencia de TIL en terminales de contenedores incluye actualmente 26 terminales en 19 países a nivel global en Norteamérica, Sudamérica, Europa, África, Medio Oriente, la India y el sudeste asiático. En el año 2013, TIL controló un total de 15,5 millones TEU en su portafolio de terminales.

Un ejemplo reciente de la estrategia de expansión del operador portuario de MSC es la toma de participación del 29\% de APM Terminals Callao a través de la adquisición de Callao Port Holding B. V. en marzo de 2014, a consecuencia de la cual la participación accionaria en el Muelle Norte del Callao ha quedado distribuida de la siguiente manera: 51\%, APMT; 29\%, TIL; y un 20\%, a manos de Unimar ${ }^{156}$. TIL se asegura así una asociación estrecha con el operador de Maersk en este puerto, asociación que ya mantienen en FOS 2XL en Francia y en el nuevo Brasil Terminal Portuario (BTP) en el puerto de Santos ${ }^{157}$.

Esta asociación entre operadores globales de primer nivel y ligados empresarialmente a las dos principales navieras del mundo, que son a su vez la principal en rutas transpacíficas (MSC) y la principal en rutas

154. En:<http://www.tilgroup.com/>. Consultado el 14/3/2014.

155. Véase: "Drewry's Top Ten Global Terminal Operators, 2012》. En: <http://www.drewry.co.uk/news. php?id=232>.

156. Véase: <http://www.apmterminals.com/uploadedFiles/corporate/Media_Center/Press_Releases/ 140302\%20APM\%20Terminals\%20Welcomes\%20TIL\%20to\%20Callao.pdf>. Consultado el 14/3/2014.

157. El acuerdo de joint venture en Santos se dio en noviembre de 2013, luego de la adquisición del 50\% de la participación accionaria en el BTP por parte de APMT y, de esta manera, formaliza la asociación con el ya presente TIL en el puerto por el que pasa el 25\% del comercio brasileño. El puerto de Santos se añade a la lista en la que están incluidos Itajaí y Pecem dentro de los proyectos portuarios desarrollados por APMT en Brasil. Véase: <http://www.apmterminals.com/uploadedFiles/corporate/Media_Center/Press_Releases/ 100818\%20_Santos_press_\%20release.pdf $>$. Consultado el 14/3/2014. 
transatlánticas (Maersk), con joint ventures en el mayor puerto de la CEAS (Santos) y en el mayor de la COAS (Callao), sugiere grandes posibilidades de conexión entre ambas costas sudamericanas y los servicios/rutas que enlazan, así como de aglomeración global de carga contenedorizada por parte de esas dos navieras actuando en consuno.

En el mismo sentido, cabe resaltar que el año 2013 se ha gestado el establecimiento de una alianza o red trascendental entre las tres compañias navieras más grandes en el mercado marítimo mundial: Maersk, con un 15\% de dicho mercado; MSC, con el 13\%; y la francesa CMA CGM, con el 9\%. Según información preliminar sobre esta alianza, denominada P3 por los medios especializados, "The Partners will commit all vessels deployed on the 3 trades into a joint vessel operating center (JVOC) that will operate the combined fleet independently. The Partners will continue to have fully independent sales, customer service and marketing functions. Vessels committed to the P3 Network will continue to be owned/chartered and funded by the Partners» ${ }^{158}$.

El fenómeno de asociación y formación de alianzas no es extraño al sector de transporte marítimo, pero la envergadura del P3 representa un cambio trascendental pues, de consolidarse, esta alianza acumularía el 43\% del mercado naviero entre Europa y Asia, 24\% del transpacífico, y del 40\% al 43\% del transatlántico, según la Federal Maritime Comission de los Estados Unidos: «The P3 Network will operate a capacity of 2.6 million TEU (initially 255 vessels on 29 loops) on three trade lanes: Asia - Europe, Trans-Pacific and Trans-Atlantic» ${ }^{159}$. De hecho, la alianza implica que se compartirán naves en rutas que pasen por los canales de Suez y de Panamá, conectando el Atlántico y el Pacífico y a ambos océanos con otros mares del mundo.

En términos de carga, Maersk contribuirá con el 42\% de la capacidad de carga del P3; MSC, con el 34\%; y CMA CGM, con el 24\%. Ello potenciado también por los joint ventures entre los operadores portuarios de Maersk y

158. Cita de <http://shippingwatch.com/carriers/article5632893.ece>. Consultado el 14/3/2014.

159. Cita de <https://www.cma-cgm.com/news/1/cma-cgm-maersk-line-and-msc-to-establish-anoperational-alliances. Consultado el 14/3/2014. 
MSC, además de compartir instalaciones portuarias en puertos de origen y destino. Así podrán modificar sus rutas con recaladas para optimizar servicios de transporte y control, y aumentar la frecuencia y la cobertura de los servicios ${ }^{160}$.

\subsubsection{Dubai World}

Dubai World es un holding empresarial multisectorial de propiedad del Estado de Dubái en los Emiratos Árabes Unidos, fundado el año 2006 por el jeque Mohammed bin Rashid Al Maktum, primer ministro de EAU y gobernador de Dubái, con el objetivo de promover este país como un hub comercial global. El holding se concentra en actividades estratégicas y dinámicas como transporte y logística marítimo-portuaria, diques secos, desarrollo urbano, inversiones y servicios financieros. A pesar de haber requerido un rescate fiscal por parte del emirato de Abu Dhabi luego de enfrentar problemas de deuda el año 2009, tras el mal desenvolvimiento del mercado de bienes raíces en $2008^{161}$, este holding preservó sus activos portuarios y cuenta hoy con operaciones estables en sus diferentes ramas empresariales.

\section{Industrias}

Desde 1968, Dubai World opera Drydocks World en el rubro de diques secos, empresa filial a través de la cual opera astilleros en los cuales se cumplen labores de construcción y reparación de naves ULCC (Ultra Large Crude Carriers) y VLCC (Very Large Crude Carriers). Su astillero principal es el ubicado en Dubái, en el cual hasta ahora se han trabajado alrededor de 7.500 buques internacionales. Drydocks World también posee cuatro astilleros menores de apoyo que se encuentran en Singapur y en las Islas Batam en Indonesia (Graha, Nanindah y Pertama), con los cuales la compañía se ha especializado en las labores de reparación, mantenimiento, construcción y transformación de buques y ha llegado a formar clústeres marítimos-comerciales y de yates ${ }^{162}$.

160. Véase: <http://www.cnbc.com/id/101162806>. Consultado el 14/3/2014.

161. En:<http://www.dubaiworld.ae/>. Consultado el 24/2/2014.

162. En:<http://www.drydocks.gov.ae/>. Consultado el 25/2/2014.

163. En:<http://www.dubaimaritimecity.com/>. Consultado el 25/2/2014. 
Estrechamente vinculado a las labores realizadas por Drydocks World se encuentra Dubai Maritime City, un proyecto de construcción de una isla conectada al puerto que contará con un recinto industrial que permitiría acceso sin restricciones desde mar abierto al Golfo Árabe, lo que facilitará tanto los servicios de mantenimiento de buques y yates provistos por DW, como las operaciones del puerto Rashid del Emirato de Abu Dhabi, e involucrará también la edificación de oficinas y viviendas de lujo ${ }^{163}$.

En cuanto al sector de inversión y servicios financieros, la punta de lanza en la estrategia de Dubai World por promover su emirato como centro de negocios globales y particularmente entre Europa y Asia, ha sido la promoción de zonas económicas (similar al plan de Zonas Económicas Especiales implementado desde la década de 1980 en Shenzhen y Hainan por el Gobierno de China) y de parques comerciales e industriales. Para ello está Economic Zones World (EZW) como operador y desarrollador de zonas económicas, tecnología, logística y parques industriales, creando plataformas de infraestructura con las que Dubái pueda formar una red integrada de negocios de diferente índole y facilitando a los EAU su participación en proyectos en Asia, África, Europa, América y Medio Oriente. El portafolio de EZW incluye tres zonas: la Jebel Ali Free Zone (Jafza), que busca consolidar su posición como $h u b$ de negocios internacionales en Medio Oriente; el Techno Park ubicado en Dubái como centro de colaboración para el desarrollo de ciencia y tecnología; y la Dubai Auto Zone (DAZ), cuyo objetivo es desarrollar el mercado automovilístico en Dubái como lugar para atraer compradores, productores, proveedores de servicios y agentes afines ${ }^{164}$.

Istithmar World es una empresa de inversiones que ofrece servicios de consumo, industriales y financieros a hoteles y propiedades / centros comerciales, con formas de inversión que incluyen apuestas mayoritarias y minoritarias, empresas conjuntas, acciones cotizadas e instrumentos de deuda. El portafolio de consumo incluye a Barneys New York (Estados Unidos) y Cirque du Soleil (Canadá); el de finanzas, a Pension Insurance Corporation (Reino Unido) y Gulf African Bank (Kenia); y el industrial, a Padaeng Industry (Tailandia) y Palm District Cooling (EAU). La empresa

163. En:<http://www.dubaimaritimecity.com/>. Consultado el 25/2/2014. 164. En:<http://www.ezw.ae/>. Consultado el 25/2/2014. 
tiene una división especial que controla hoteles en diversas ubicaciones a nivel global, entre los que resaltan el Fontainebleau en Miami, el Mandarin Oriental en Nueva York y el Atlantis The Palm en Dubái ${ }^{165}$.

\section{Dubai Ports World ${ }^{166}$}

En la rama marítima, el holding Dubai World cuenta con un operador portuario y logístico global de gran envergadura como es Dubai Ports (DP) World, formado en 2005 luego de la integración de Dubai Ports Authority (DPA) y Dubai Ports International. Dubai Ports Authority administraba las operaciones de los puertos de Rashid y Jebel Ali, mientras que Dubai Ports International estaba encargada de la promoción internacional de la empresa a través de sus operaciones en terminales portuarios alrededor del mundo con el propósito de ayudar a crear la imagen de los EAU como $h u b$ de negocios. La formación de esta empresa respondía al objetivo de realizar operaciones a nivel mundial con el fin último de promover al emirato como centro de comercio. Uno de los hitos principales para lograr este cometido es la expansión de las actividades de operación marítima más allá del hinterland natural de Medio Oriente, Europa o la India. Es en este contexto que se explica la presencia de DP World como operador portuario del Muelle Sur del puerto del Callao, concentrando sus actividades en el manejo de carga contenedorizada y en la construcción de terminales ${ }^{167}$.

DP World cuenta con un portafolio de instalaciones en operación de 65 terminales marítimos en los cinco continentes, con proyectos en desarrollo en la India, África, Europa, Sudamérica y el Medio Oriente. Su negocio principal, el manejo de contenedores, representa tres cuartos de los réditos de la compañía y abarcó el manejo de alrededor de 55 millones de TEU el año 2013, con una meta de 100 millones para 2020. Asimismo, DP ofrece servicios a otros tipos de carga, como carga general, naves Ro-Ro y pasajeros (en las Américas y Filipinas). Todo lo cual ha llevado a DP World a

165. En: <http://www.istithmarworld.com/>. Consultado el 25/2/2014.

166. En:<http://web.dpworld.com/>. Consultado el 26/2/2014.

167. Como reflejo de una estrategia de expansión global en el manejo de carga en contenedores, en su año de fundación, DP World firmó acuerdos de desarrollo y operación de los puertos de Vallarpadam (India), Fujairah (EAU), Yarimca (Turquía) y Qingdao (China). Al año 2014, tiene en desarrollo un terminal en Róterdam y el FOS en el sur de Francia. 
ubicarse como cuarto operador portuario a nivel mundial, en términos de TEU movilizadas por los terminales de contenedores a su cargo.

En el continente americano, DP World opera terminales de contenedores en Vancouver, Callao, Caucedo (República Dominicana), Puerto Cabello (Venezuela), Paramaribo (Surinam), Santos y Buenos Aires, y acaba de asegurarse una importante participación en la SPRB del puerto de Buenaventura. Llama la atención que, siendo un operador global, DP World no tenga aún instalaciones portuarias en los Estados Unidos, pese a ser el único operador portuario del mundo que cuenta con el Customs - Trade Partnership Against Terrorism (C-TPAT). Por esta razón, las actividades de DP World se han intensificado especialmente en Europa, la India, China, Australia y recientemente en América Latina, con el propósito de dotarse de una red integrada que impulse tanto sus negocios portuario-logísticos en tierra como sus servicios marítimos a través de la naviera Peninsular and Oriental Steam Navigation Company (P\&O).

P\&0 es una empresa originaria del Reino Unido que fue adquirida por DP el año 2006, mediante la cual DP opera P\&0 Maritime Services para prestar servicios a carga en ríos y mares, suscribir contratos y concesiones de largo plazo con gobiernos, y complementar las labores de operación y logística en puertos. En este sentido, DP World tiene la misma estrategia que Maersk, de creación de redes globales e integraciones verticales, aunque con el orden inverso (operador portuario y luego naviera) y una envergadura sustancialmente menor en el brazo agua del transporte marítimo de contenedores. Puede inferirse que la estrategia del emirato al lanzar DP World y adquirir con prontitud P\&O responde al plan emprendido por Maersk cuando creó APM Terminals.

P\&0 Maritime Services fue fundada en 1960 como filial de P\&0 para servicios off shore en Australia y el sudeste asiático, particularmente enfocados en la industria energética de gas y petróleo. A la fecha, ha expandido sus actividades y oficinas hacia Europa (destacan Reino Unido y Francia), África (Egipto, Mozambique), Medio Oriente (Dubái) y Sudamérica (Paraguay y Buenos Aires). P\&0 presta servicios de navegación para investigación y operaciones logísticas; también coloca instalaciones de energía eólica en altamar; presta todos los servicios portuarios en el puerto emblemático de Jebel Ali y en el puerto de Rashid para DP en EAU, en Egipto (Sokhna) 
y Mozambique (Maputo); y opera rutas rivereñas en el norte de Australia y Papúa Nueva Guinea, así como de chartering a través de su subsidiaria Anderson Hughes Group, especializada en minerales ${ }^{168}$.

\subsection{Conglomerados regionales}

\subsubsection{Compañía Sudamericana de Vapores ${ }^{169}$}

La chilena Compañía Sudamericana de Vapores (CSAV) fue fundada en 1872 en Valparaíso por los hermanos Lyon Santa María, Jorge Ross, Joaquín Dorado, Federico Matthei y el presidente del directorio Maximiliano Errázuriz Valdivieso ${ }^{170}$. A mediados del siglo XX, pasó a manos de la familia Claro, que condujo la expansión de CSAV a nivel regional durante las décadas de 1990 y 2000, teniendo a SAAM como el pivote en tierra de la cadena logística. A partir de agosto de 2012, luego de que la red empresarial CSAV-SAAM enfrentara una reestructuración financiera, esta quedó bajo la propiedad mayoritaria de la familia Luksic. Ello incluye las subsidiarias de la naviera CSAV, de la operadora portuaria SAAM y de la empresa Quiñenco S. A.; esto es, de un conjunto de empresas que abarcan los sectores de transporte marítimo y aéreo, logístico, inmobiliario, servicios financieros, inversión, alimentos, manufacturas, energía y minería.

\section{Red CSAV}

La red CSAV incluye al conjunto de subsidiarias de la naviera chilena que operan no solo en todos los países de la COAS, sino también en la CEAS

168. En:<http://www.pomaritime.com/>. Consultado el 26/2/2014.

169. Esta reseña cubre el periodo hasta el año 2013, anterior a la fusión en curso de CSAV con Hapag-Lloyd para lo relativo a contenedores, sobre la que aún no se conocen algunos detalles importantes. La nota de prensa que confirmó la fusión el 2/12/2014 informa que en ese mes se financiará un incremento de capital y el 51\% del resultante capital accionario de Hapag-Lloyd AG será gestionado conjuntamente, del cual CSAV tendrá el $50 \%$ y el otro $50 \%$ estará en manos de los dos principales accionistas alemanes de Hapag-Lloyd (HGVy Kühne Maritime) a razón de 25\% cada uno. Pero esa nota de prensa anuncia que el proceso de integración del negocio de contenedores de CSAV con el de Hapag-Lloyd estaría completado hacia mediados del año 2015. Por ello, el presente documento se cierra sin poder dar cuenta de los cambios que esa fusión eventualmente conllevará en la estructura del conglomerado chileno conducido por la familia Luksic, particularmente en la gestión de SAAM y los proveedores logisticos del conglomerado. Véase: "Hapag-Lloyd and CSAV complete the merger and become the 4th largest container liner shipping company in the world". <http://www.hapag-lloyd. com/es/press_and_media/pree_release_page_37308.html >. Consultado el 2/12/2014.

170. Véase:<http://www.economiaynegocios.cl/noticias/noticias.asp?id=55263>. Consultado el 10/3/2014. 
y en la región marítima mesoamericana que comprende a Centroamérica, el Caribe, México y el sur de los Estados Unidos, así como en Panamá para los transbordos o conexiones entre todas esas costas y las de Asia y Europa. Además, esta red abarca a empresas varias vinculadas principalmente a los rubros marítimo (agenciamiento, logística), inmobiliario y de inversión en varios tipos de activos relacionados directa e indirectamente con el core business de la empresa ${ }^{171}$.

En Panamá están presentes: Corvina Shipping Co. S. A. y Tollo Shipping Co. S. A., dedicadas a la compraventa, fletamento y administración de buques y operación de líneas de navegación, agenciamiento marítimo, compraventa de bienes mueble e inmuebles y transacción de acciones o cuotas/derechos de capital social; Inversiones Plan Futuro S. A., Inversiones Nuevo Tiempo S. A., Inversiones Alaria S. A. e Inversiones Habsburgo S. A., dedicadas a la compraventa e inversión en bienes muebles e inmuebles y operaciones en otras actividades económicas (comerciales, financieras y marítimas); y en el rubro de logística y operación portuaria cuenta con SAAM Remolcadores S. A., Dry Bulk Handy Holding Inc. y CSAV Ships S. A., entre otras armadoras de naves y agentes logísticos importantes por su funcionamiento en el $h u b$ del canal interoceánico.

En Colombia, la red CSAV ha estado concentrada en la rama de transporte y servicios complementarios. De ahí que CSAV Group Agency Ltd. desempeña funciones de agenciamiento de comercio para transporte marítimo y aéreo; y Transaéreo proporciona servicios aeroportuarios y de manejo de carga en tierra y facilidades en aeropuertos conexos. El servicio de remolque naviero fue provisto por SAAM en el puerto de Buenaventura a través de Equimac S. A. hasta julio de 2013, cuando vendió sus acciones en esa empresa y dejó así de participar en el capital accionario de la Sociedad

171. Véase: <http://www.csav.com/es/InvestorRelations/Documents/2012\%20-\%20Memoria\%20Anual. $p d f>$. De esta información, se rescata aquí la más directamente relacionada con la COAS. Pero la presencia de CSAV en la CEAS también es muy importante, especialmente a partir de que en 1999 adquiriera la naviera brasileña Libra y la compañía uruguaya Montemar Marítima S. A. Para sus operaciones desde la CEAS, CSAV/ Libra tiene ahora filiales en Argentina y Uruguay, además de la subsidiaria en Brasil. CSAV también está asociada con la LN argentina Maruba para ofrecer conjuntamente los servicios maritimos Conosur entre la CEASy la COAS; véase: $<$ http://www.tradewindsnews.com/weekly/w2006-08-11/217386/csav-and-marubamerging-services>. Contando con esta fuerte base regional y la adquisición de Norasia el año 2000, CSAV pudo reforzar desde entonces su participación en rutas marítimas Este-Oeste, transpacíficas sobre todo. 
Portuaria Regional de Buenaventura (SPRB). Esta salida respondería a una nueva estrategia de la red CSAV en Colombia, que pondría mayor énfasis en los puertos caribeños de ese país, donde dicha red ya está presente en el puerto de Barranquilla y apunta a incursionar en el puerto de Cartagena, para así incrementar su participación en el manejo de la carga movilizada no solo en esa costa colombiana sino en la contigua CEAS también, con el propósito de compensar la menor cuota de carga que eventualmente le pueda ocasionar el reciente ingreso a la COAS de operadores portuarios pertenecientes a conglomerados globales (DP World, APM Terminals).

En Ecuador, CSAV tiene Ecuaestibas S. A., como operadora portuaria y de servicios complementarios; CSAV Ecuador S. A., para el armado y administración de naves, así como para agenciamiento marítimo; y Geurim S. A., dedicada al soporte industrial, comercial y de servicios a la industria hidrobiológica. La presencia de la red CSAV-SAAM en Ecuador cubre tanto las operaciones del brazo tierra como del brazo mar del transporte marítimo, así como labores logísticas complementarias en puerto.

En Perú, CSAV posee el Consorcio Naviero Peruano S. A. y, a través de SAAM, controla Tramarsa, empresa que es al mismo tiempo parte del Holding Central Puertos, formado por el grupo empresarial peruano encabezado por la familia Romero. También bajo el control conjunto con SAAM se encuentran Construcciones Modulares S. A. en el rubro de instalación y operación de contenedores, así como Inversiones Misti S. A., Inversiones CNP S. A. e Inversiones Navieras S. A. C. en el rubro de armado de buques y otros negocios marítimos.

Teniendo en mente lo anterior y que Tramarsa lidera el mercado de servicios marítimos y ocupa el segundo lugar en el mercado de servicios logísticos en tierra, puede afirmarse que la estrategia de la red CSAV en el Perú no se ha limitado a lograr una alta cuota en el manejo de la carga con énfasis en la contenedorizada, sino que también se ha orientado a tener una posición dominante a lo largo de toda la cadena de servicios marítimos y sus relacionados servicios logísticos en tierra. Para ello, le ha sido muy útil la asociación con el Grupo Romero así como la dispersión y poca envergadura de las otras empresas nacionales presentes en el sector. Si bien este escenario se asemeja al de Ecuador, allá existe al menos el grupo empresarial ecuatoriano encabezado por Andinave, que por sí solo 
cubre los diferentes servicios de transporte marítimo y de operación portuaria y logística en tierra, algo inexistente en el Perú, donde no se registra presencia de navieras nacionales ni de empresas con capitales netamente peruanos que cubran todo o buena parte del espectro de servicios en la cadena del transporte marítimo.

Por tratarse de un conglomerado chileno, es natural que CSAV cuente con un amplio número de subsidiarias y joint ventures dentro de su territorio nacional. Este conglomerado cuenta en Chile con SAAM como su principal empresa para agenciamiento naviero y operación portuaria y, para servicios logísticos complementarios, también tiene a Odjfell \& Vapores S. A., Servicios Logísticos Ltd. y a la subdivisión SAAM Contenedores S. A., entre otros ${ }^{172}$. Asimismo, desarrolla proyectos de inversión en el sector marítimo y afines a través de CSAV Inversiones Navieras S. A. Además, la compañía tiene diez empresas dedicadas al negocio inmobiliario, más de cinco en funciones de muellaje y dos en servicios aeroportuarios. Sin embargo, destaca en el portafolio de CSAV su participación a través de SAAM en la operación del Terminal Internacional de San Antonio (y la que allí tuvo en Puerto Panul hasta octubre de 2013), además de administrar terminales y prestar servicios navieros en las sociedades anónimas de los terminales de Peñuelas, Barrancas, Chinchorro, El Colorado, El Caliche y Las Golondrinas.

\section{Red SAAM ${ }^{173}$}

El operador portuario exclusivo de CSAV tiene una estrategia de expansión a través de la adquisición de empresas y la apertura de filiales a nivel regional. A escala internacional, SAAM provee servicios de remolque y

172. El conjunto de filiales que forman parte de la red directa de CSAV en Chile incluye a Empresa de Transporte Sudamericana Austral Ltda. (transporte maritimo, aéreo, terrestre y servicios a naves), Odjfell y Vapores S. A. (actividades de comercio y adquisición de embarcaciones), CSAV Inversiones Navieras S. A. y Norgistics Holding S. A. (inversión y participación en empresas chilenas o extranjeras dedicadas al agenciamiento naviero y transporte). Véase: <http://www.csav.com/es/InvestorRelations/Documents/2012\%20\%20Memoria\%20 Anual.pdf>. Consultado el 10/3/2014.

173. Esta reseña cubre el periodo hasta el año 2013, anterior a la fusión en curso de CSAV con Hapag-Lloyd para lo relativo a contenedores. Sin embargo, la ya citada nota de prensa que confirmó la fusión el 2/12/2014 no hace alusión alguna a lo que esta conllevará respecto a SAAM, su red y pertenencia al conglomerado chileno conducido por la familia Luksic. 
salvamento naviero, pero sus inversiones en el continente americano cubren, además de remolcadores, servicios integrales de logística portuaria y participación en la operación de puertos ${ }^{174}$.

Los servicios de logística, muy vinculados a las rutas marítimas de CSAV pues las conectan con el manejo de carga en puerto (o en instalaciones extraportuarias), incluyen el agenciamiento naviero; depósito y maestranza de contenedores, almacenaje y traslado de carga en contenedores incluyendo la refrigerada y el manejo de frigorificos y enchufes reefer; agenciamiento de embarques/desembarques y manejo de carga a granel y de cargas masivas. En Brasil, cuenta con la empresa SAAM do Brasil, ubicada en el puerto de Itajaí, donde presta servicios de depósito, transporte de contenedores, logística integral e instalación de módulos ${ }^{175}$. En el Perú, SAAM también cumple funciones logísticas y de instalación de módulos para vivienda y oficinas, a través de Tramarsa (como agencia naviera y de estiba en los puertos de Callao, Ilo, Matarani, Pisco, Chimbote, Salaverry, Chicama y Paita) y de Construcciones Modulares S. A., ambas pertenecientes a la red directa de $\mathrm{CSAV}^{176}$. En Colombia, cuenta con Transaéreo S. A., ubicado en el aeropuerto El Dorado en Bogotá y que presta servicios de atención a aeronaves y de embarque/desembarque de mercancías y pasajeros ${ }^{177}$. En Uruguay, dispone de la transportista Riluc S. A. y de Gertil S. A., que presta servicios de cosecha forestal, espacio logístico, transporte de carga y operaciones marítimas. En Chile, a través de la división SAAM Logística, cubre la totalidad de servicios del grupo para diversas industrias (mercado naviero, minería, frutas, vinos, forestal, acuícola y retail); además de contar con empresas vinculadas como Aerosan (atención de aeronaves y embarque/descarga en el Aeropuerto Internacional Comodoro Arturo Merino de Santiago) y Reloncavi (estiba especializada en productos forestales, presente en Puerto Montt, Valdivia y Corral).

174. En:<http://www.saam.cl/prontus_saam/site/edic/base/port/inicio.html>. Consultado el 28/2/2014.

175. En: <http://www.saam.com.br/>. Consultado el 28/2/2014.

176. El año 2012, SAAM intentó comprar al Grupo Romero el 50\% de sus acciones en la empresa peruana de logística Ransa, lo que hubiese acrecentado aún más el dominio de Tramarsa sobre la cadena de servicios a la carga y de agenciamiento marítimo, pero este intento no prosperó: <http://elcomercio.pe/economia/peru/ grupo-romero-no-vendio-parte-ransa-porque-precio-no-convencio-noticia-1492319>. Ransa inició su plan de expansión el año 2003 y está presente en el Perú y Bolivia, con planes de expansión hacia Colombia y Centroamérica (en El Salvador, Guatemala y Honduras). Véase: <http://www.ransa.biz/>.

177. En: <http://www.transaereo.com/>. Consultado el 28/2/2014. 
En el rubro de remolcadores, negocio principal de SAAM a nivel internacional, la empresa cuenta con filiales en Chile (9 puertos), Brasil (7), Perú (6), México (6), Ecuador (4), Uruguay (3), Costa Rica (3), Colombia (1), Honduras (1) y Guatemala (1), las cuales cubren las funciones de atraque/ desatraque de naves, remolque y salvamento naviero así como de asistencia en operaciones off shore.

Finalmente, como operador portuario, SAAM ha obtenido las concesiones de administración y/o funcionamiento de varios terminales en los que desarrolla las labores propias de un puerto respecto a todo tipo de naves y cargas, incluyendo los servicios respecto a contenedores vacíos así como los servicios logísticos complementarios a los portuarios. SAAM se encuentra como operador portuario en los terminales chilenos de Iquique, Antofagasta, San Antonio y San Vicente, y en los terminales de Arica y Corral; en Ecuador, es el operador portuario del Terminal Puerto de Guayaquil (TPG); en México, del Terminal Marítimo de Mazatlán, licitación que se adjudicó en noviembre de 2011; y en los Estados Unidos, del Florida International Terminal, cuya concesión se adjudicó conjuntamente con Agunsa.

\section{Red Quiñenco ${ }^{178}$}

La familia Luksic, propietaria de Quiñenco S. A. y su red afiliada, se convirtió en la controladora de CSAV y de SAAM desde agosto de 2012, al acumular el 37,44\% del capital accionario en CSAV mediante una operación combinada de compra de acciones del Grupo Claro que dejó a este último con el 12,35\% de dicho capital, así como de disolución de un pacto entre accionistas de SAAM vinculados a Quiñenco y al Grupo Claro. Ello permitió la constitución de la Sociedad Matriz (SM) SAAM como propietaria del 99,95\% de SAAM y con Luksic como accionista mayoritario de la misma a través de Quiñenco $S$. A.

Cabe señalar que el cruce mutuo de acciones entre Quiñenco, CSAV y SAAM, implica que esta red empresarial está muy integrada pero de un modo poco claro, que dificulta la distinción de una filial como parte de una u otra empresa, a diferencia de los conglomerados globales donde las jerarquías empresariales son más definidas y transparentes.

178 En: <http://www.quinenco.cl/>. Consultado el 28/2/2014. 
Al mismo tiempo, la red Quiñenco abarca mercados aparentemente no relacionados o poco relacionados entre sí, pero en realidad su estructura muestra un perfil empresarial que facilita al holding Luksic cubrir financiamiento, producción y comercio; ello porque comprende empresas que en conjunto permiten evitar la tercerización de labores a lo largo de las etapas de producción y comercialización de la cadena de valor en su integridad. Por esta razón, la red Quiñenco abarca empresas en los siguientes mercados: financiero, retail, bebidas y alimentos, manufacturas, energía, transportes y servicios navieros y portuarios.

En el sector financiero, tiene el 58,5\% de los derechos de voto y 40\% de los derechos económicos del Banco de Chile, a través de LQ Inversiones Financieras S. A., fundada el 2000 y gestionada en asociación con el Citigroup desde el año 2008. Banco de Chile es una de las instituciones financieras más rentables del país gracias a la variedad de productos que ofrece a diferentes segmentos de mercado, entre banca comercial, mayoristas, minoristas, créditos corporativos e inversiones.

En el sector manufacturero, Quiñenco posee el 65,9\% de las acciones de Invexans (empresa donde la francesa Nexans tiene una participación accionaria del 22,6\%), dedicada a la producción y comercialización de cables utilizados en construcción, energía, minería y telecomunicaciones. También tiene el 65,9\% de Madeco, empresa fundada el año 2013 y centrada en la producción de envases flexibles, perfiles y tubos de cobre, con presencia latinoamericana en el rubro de envases flexibles a través de sus filiales Alusa en Argentina (Aluflex), Peruplast en el Perú y Empaques Flexa en Colombia; así como a través de Madeco Mills en tubos de cobre, con presencia en Argentina.

En el mercado energético, Quiñenco está presente a través de la Empresa Nacional de Energía (ENEX), constituida el año 2011 con el 100\% de sus acciones en manos del holding Luksic luego de que este adquiriera los activos de Shell en Chile. ENEX participa en la industria del petróleo mediante la comercialización de combustibles (es el segundo mayor distribuidor minorista de combustibles en Chile, con una participación de mercado del $17,7 \%$ ), lubricantes, asfaltos y productos químicos. Adicionalmente, ENEX posee un 50\% de Asfaltos Conosur, un 14,9\% de la Sociedad Nacional de Oleoductos (Sonacol), un 33\% de la Sociedad de Inversiones de Aviación (SIAV) y un 19,3\% de Sociedad Nacional Marítima S. A. (Sonamar). 


\subsubsection{Compañía Chilena de Navegación Interoceánica ${ }^{179}$}

La Compañía Chilena de Navegación Interoceánica (CCNI) es una empresa dedicada al transporte marítimo desde su fundación en 1930 con sede en Valparaíso. En 1961, adquirió Agencias Universales S. A. (Agunsa), la cual prestaba servicios de agenciamiento general y portuario a naves y labores en la cadena logística del manejo de carga en puerto. El perfil de expansión de CCNI se refleja en la diversificación de las rutas y frecuencia que ha establecido desde sus inicios, cuando solo operaba rutas hacia el Pacifico norteamericano, hasta ahora que también cubre rutas a Asia, el Caribe, el Mediterráneo Europa y África. La naviera CCNI es controlada por el holding Grupo Empresas Navieras (GEN), de accionariado mixto pero presidido por José Manuel Urenda Salamanca ${ }^{180}$. Ello, unido al hecho de que CCNI es presidida por Beltrán Felipe Urenda Salamanca, muestra la subordinación a la familia Urenda, en semejanza al rol dirigente que la familia Luksic tiene respecto a CSAV y SAAM (cuadros 8 y 9).

\section{Cuadro 8}

\section{Composición accionaria de CCNI, al 31 de diciembre de 2013}

\begin{tabular}{|l|c|c|}
\hline \multicolumn{1}{|c|}{ Nombres } & Acciones & Porcentaje \\
\hline Grupo Empresas Navieras S. A. & 679.118 .599 & $74,27 \%$ \\
Moneda S. A. AFI P/Pionero Fdo. de Inversión & 81.372 .000 & $8,90 \%$ \\
Fondo de Inversión Larrain Vial Beagle & 43.611 .957 & $4,77 \%$ \\
Chile Fondo de Inversión Small Cap & 25.139 .719 & $2,75 \%$ \\
BTG Pactual Chile S. A. Fondo de Inversión & 23.597 .683 & $2,58 \%$ \\
BTG Pactual Chile S. A. Corredores de Bolsa & 19.065 .793 & $2,09 \%$ \\
Siglo XXI Fondo de Inversión & 8.953 .699 & $0,98 \%$ \\
Compass Small Cap Chile Fondo de Inversión & $6,419.992$ & $0,70 \%$ \\
Moneda S. A. AFI para Moneda Chile Fund. Ltda & 4.380 .000 & $0,48 \%$ \\
Banchile Corredores de Bolsa S. A. & 3.283 .175 & $0,36 \%$ \\
Airmania Travel S. A. & 2.787 .449 & $0,30 \%$ \\
BCl Corredor de S. A. & 2.455 .796 & $0,27 \%$ \\
Otros accionistas & 14.233 .087 & $1,55 \%$ \\
\hline
\end{tabular}

179. En: <http://www.ccni.cl/>. Consultado el 3/3/2014.

180. Esta reseña cubre el período hasta el año 2013, anterior a la compra del negocio relativo a contenedores de CCNI por parte de Hamburg Süd. La nota de prensa del 17/2/2015 que confirmó esta compra informa que CCNI solo hará a su nombre el transporte marítimo de vehículos automotores, pero no alude a las implicancias de esta compra para la estructura del conglomerado chileno dirigido por la familia Urenda. Véase: "Hamburg-Süd and CCNI sign Sale and Purchase Agreement», <http://www.hamburgsud.com/group/ es/corporatehome/pressmedia/pressreleases/pressreleasedetails_592632.html> 


\section{Cuadro 9}

Composición accionaria de Grupo Empresas Navieras S. A. al 31 de diciembre de 2013

\begin{tabular}{|l|c|c|}
\hline \multicolumn{1}{|c|}{ Nombres } & Acciones & Porcentaje \\
\hline Inversiones Tongoy S. A. & 1.446 .813 .294 & $20,94 \%$ \\
Sociedad de Inversiones Paine S. A. & 1.446 .813 .294 & $20,94 \%$ \\
Axxion S. A. & 1.017 .449 .607 & $14,72 \%$ \\
Euro Inversiones S. A. & 530.731 .543 & $7,68 \%$ \\
BTG Pactual Small Cap Chile Fondo de Inversión & 458.590 .260 & $6,64 \%$ \\
Soc. Nacional de Valores S. A. & 408.140 .339 & $5,91 \%$ \\
BTG Pactual Chile S. A. Corredores de Bolsa & 379.614 .035 & $5,49 \%$ \\
Del Bene Inversiones S. A. & 318.673 .021 & $4,61 \%$ \\
Banchile Corredores de Bolsa S. A. & 194.913 .093 & $2,82 \%$ \\
A. F. P. Provida S. A. Fondo de Pensiones C & 160.986 .060 & $2,33 \%$ \\
A. F. P. Habitat S. A. Para Fondo de Pensiones C & 96.055 .891 & $1,39 \%$ \\
Chile Fondo de Inversión Small Cap & 93.564 .526 & $1,35 \%$ \\
Otros accionistas & 357.484 .940 & $5,18 \%$ \\
\hline
\end{tabular}

Fuente: cuadro 8 y 9: página web de CCNI (3/3/2014).

\section{Red $\mathrm{CCNI}^{181}$}

Coherentemente con la diversificación y extensión de rutas y servicios emprendida por CCNI, la compañía ha establecido una red de agencias y oficinas a lo largo de toda América, Europa, África, Medio Oriente, el sudeste asiático y el subcontinente indio. La presencia de subsidiarias en la COAS y Panamá, área de influencia inicial de CCNI, no es tan vasta como la de CSAV pero, igualmente, cubre los requerimientos de la cadena de transporte y manejo portuario de la carga contenedorizada así como también presenta una clara integración a nivel de subsidiarias con Agunsa, su operador pivote en tierra. "La gestión de la red Agunsa cobra, nuevamente, valor en términos del soporte de las actividades de CCNI en el mundo con procesos estandarizados y con altos niveles de desempeño» ${ }^{182}$.

En Panamá, CCNI ha centrado sus actividades en filiales/sociedades navieras (Naviera Arica S. A., Naviera Antofagasta S. A. y Key Biscayne Marine

181. En: <http://www.ccni.cl/>. Consultado el 3/3/2014.

182. Cita de <http://200.31.35.125/images/pdf_investor_relations/2013/memoria.pdf>. Consultado el $3 / 3 / 2014$. 
Inc.) y en operaciones logísticas con una única subsidiaria en South Cape Financial and Maritime Corp.

En Chile, la empresa ha formado subsidiarias especializadas en diferentes labores que complementan el servicio de transporte marítimo en el brazo tierra de la cadena: Interoceanbulk S. A., dedicada al transporte marítimo de carga a granel líquida y sólida; Recursos Portuarios y Estibas Ltd., para servicios de muellaje y estiba/desestiba; Modaltrade S. A. (grupo Agunsa), que cubre importaciones, exportaciones, comercialización y distribución de bienes, abarcando íntegramente la cadena de embarque hasta entrega; $\mathrm{y}$, finalmente, Terminal y Servicios de Contenedores S. A., que administra y opera depósitos de contenedores en el puerto de Valparaíso.

En el resto de los países de la COAS (Perú, Ecuador y Colombia), CCNI está presente indirectamente a través de las subsidiarias de Agunsa, especializada en cadenas de control logístico y almacenamiento de contenedores en Chile, Perú, Ecuador y Estados Unidos a través de una amplia red de almacenes propios y arrendados ${ }^{183}$. También cuenta con representación en Venezuela, a través de CCNI Venezuela Representaciones Marítimas S. A. y de una asociación con Agencia Marítima Selinger para ofrecer servicios de agenciamiento portuario, administración y operación de terminales y estiba.

\section{Red Agunsa ${ }^{184}$}

Como operador portuario y proveedor logístico de CCNI, Agunsa conforma también una red de apoyo a las operaciones globales de la naviera con oficinas a lo largo de América Latina, América del Norte, China, Hong Kong, Corea del Sur, Bahréin, Portugal, España e Italia ${ }^{185}$. Para cubrir las labores de agenciamiento naviero y operaciones logísticas, Agunsa tiene varias filiales y subsidiarias en la región (gráfico 7).

183. Véase: $<$ http://www.agunsa.com/?option=com_contentEtask=viewEtid=96ctltemid=103>. Consultado el 10/3/2014.

184. Esta reseña cubre el periodo hasta el año 2013, anterior a la compra de CCNI por parte de Hamburg Süd para lo relativo a contenedores, que incluye a las relacionadas funciones de Agunsa. La ya citada nota de prensa del 17/2/2015, que confirmó el acuerdo de compraventa, informa que Agunsa continuará representando a otras líneas navieras como agencia y desarrollando sus negocios portuarios y logísticos en Sudamérica, pero no hace alusión alguna a lo que dicha compra conllevará respecto a la gestión de Agunsa, su red y pertenencia al conglomerado chileno conducido por la familia Urenda.

185. En: <http://www.agunsa.com/>. Consultado el 3/3/2014. 


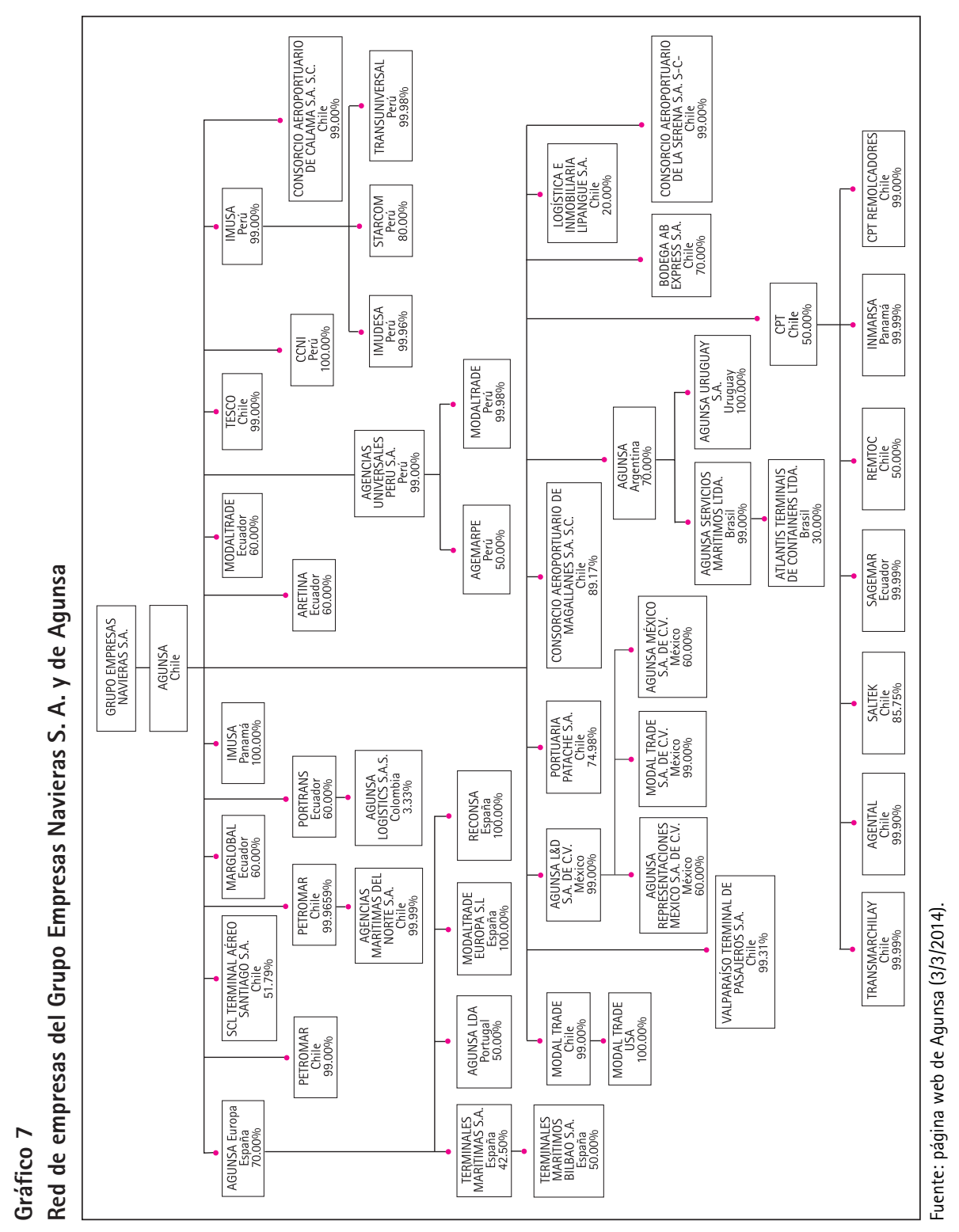


En Panamá y México, la empresa, a través de sus filiales locales, cubre los servicios de agenciamiento maritimo, bunkering, logística, distribución, venta y arriendo de contenedores. En países como Brasil, Costa Rica y Uruguay, así como en Hong Kong, Agunsa se ha centrado en las funciones de agenciamiento (marítimo y general) y transporte terrestre. Asimismo, destaca la presencia de Agunsa como operador en los Estados Unidos, lograda en el Florida International Terminal mediante una alianza con SAAM establecida el año 2004, donde además brinda servicios logísticos a través de Agunsa USA y Agunsa L\&D (L. A.).

Es en Ecuador y en el Perú donde destaca la formación varias subsidiarias con las que Agunsa terceriza labores para complementar los servicios navieros de CCNI, especialmente en el caso de labores de almacenaje, transporte, distribución, bunkering, apoyo de naves y estiba; espectro de servicios este que Agunsa cubre en ambos países. En Ecuador, Agunsa cuenta con: Marglobal, para labores de bunkering y agenciamiento marítimo y aéreo; Modaltrade, en el rubro de transporte y servicios logísticos complementarios; Aretina, en almacenaje y estiba; Portrans, en logística y distribución; y Sagemar, en remolcadores. En el Perú, aquellas labores que la filial de Agunsa no cumple directamente son realizadas por: Modaltrade, en transporte y estiba; Inmarsa, en remolcadores; e Imupesa (Inversiones Marítimas Universales Perú S. A.), ciertamente el más relevante porque actúa en agenciamiento aéreo, logística, distribución, administración y operación de terminales portuarios.

\section{Red Grupo Empresas Navieras ${ }^{186}$}

Grupo Empresas Navieras (GEN) es un holding chileno que controla directamente el 74,1\% de las acciones de CCNI, 69,83\% de Agunsa y 66\% de Portuaria Cabo Forward, Talcahuano Terminal Portuario S. A. (TIP) y Portuaria Mar Austral S. A.; a través de las cuales participa en un total de 116 empresas entre locales y extranjeras ${ }^{187}$, además de sus coligadas: Antofagasta Terminal Internacional S. A. (ATI), Terminal Puerto Arica S. A. (TPA) e Iquique Terminal Internacional S. A. (ITI).

186. En: <http://www.gen.cl/>. Consultado el 3/3/2014.

187. Para revisar la red de inversiones indirectas de Grupo Empresas Navieras al año 2012, véase: <http:// www.gen.cl/files/Holding_201212.pdf>. 
La participación accionaria en GEN se distribuye principalmente entre empresas del rubro financiero (de inversiones, banca y AFP) en su mayoría chilenas. Ello corrobora la tendencia de los conglomerados chilenos en el sector marítimo-portuario a diversificarse y ser corporativamente conducidos por holdings financieros, sin mengua del poder decisorio en manos de una familia. Otra conclusión que se extrae al revisar la lista de accionistas tanto en CCNI como en GEN, es que también en este caso (similarmente al caso del conglomerado CSAV-SAAM) existe mucha integración empresarial entre la naviera líder y las empresas dedicadas al brazo tierra del transporte marítimo; lo cual, unido al rol supervisor/planificador que tienen las empresas estatales chilenas del sector, denota una estrecha coordinación y sugiere que, no obstante la diaria competencia por los negocios, parecen existir estrategias que son comunes por ser nacionales, que probablemente incluyen el tejido de rutas marítimas (como las de tipo southbound) y de roles entre puertos que en conjunto puedan beneficiar más a los intereses marítimo-portuarios de Chile y su aspiración de ser el $h u b$ transpacífico de Sudamérica (gráfico 8).

\section{Gráfico 8}

Empresas parte del holding Grupo Empresas Navieras S. A.

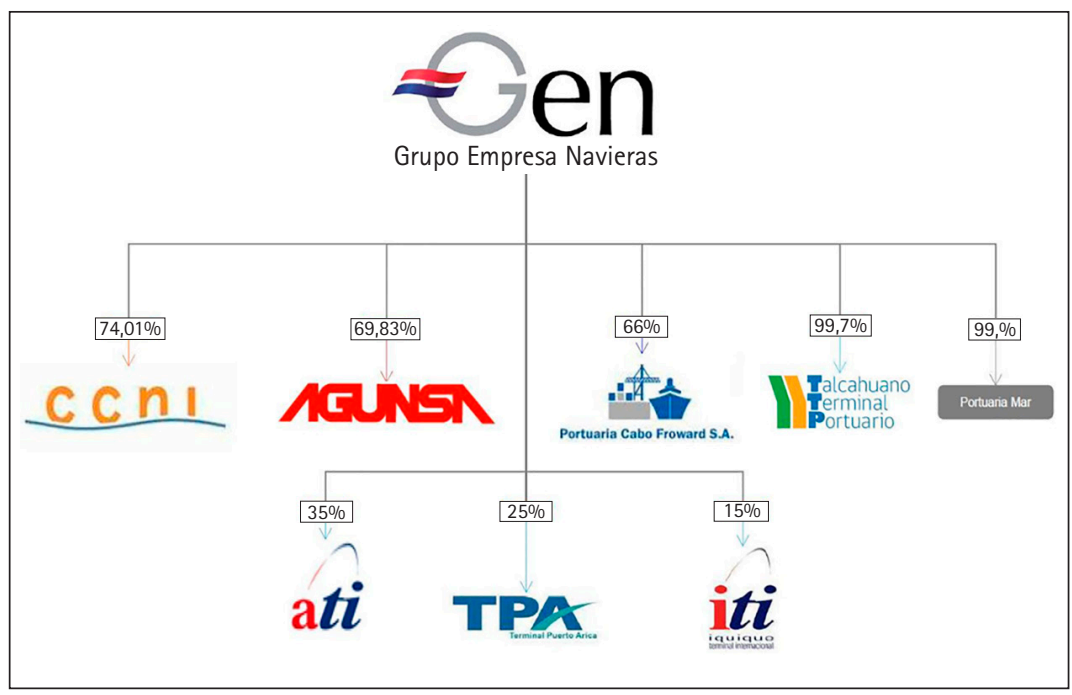

Fuente: página web de Grupo Empresas Navieras S. A.: Estructura del holding (3/3/2014). 


\subsubsection{Ultramar Agencia Marítima ${ }^{188}$}

Ultramar Agencia Marítima fue fundada en 1952 por el inmigrante alemán Albert von Appen, como matriz de los negocios del Grupo Von Appen, e inició sus actividades representando a las navieras alemanas Hapag y Norddeutscher Lloyd, y en 1956 también fue designada como agente general de Lufthansa para la apertura de sus vuelos directos a Chile. La primera subsidiaria de Ultramar, Ultragas, fue fundada en 1960 para transportar el gas encontrado en Tierra del Fuego, y en 1969 Von Appen estableció Transmares Naviera Chilena para así consolidar su holding de transporte marítimo con un brazo tierra y un brazo $\operatorname{mar}^{189}$. El conglomerado de la familia Von Appen y su funcionamiento en la actividad naviera se diferencia de los casos de Luksic y Urenda pues, en primer lugar, la matriz empresarial es la agencia marítima y no la naviera y, en segundo lugar, la estructura propietaria es distinta en tanto que la familia posee Ultramar directamente.

El conglomerado Von Appen cuenta, a través de Ultramar, con empresas subsidiarias en cuatro sectores: empresas navieras (Ultragas, Sonap, Ultrabulk y Transmares; Ultrachart y Humboldt en servicios); puertos, depósitos y servicios portuarios (destacan los terminales en los puertos de Arica, Valparaíso, Mejillones, Coquimbo así como en Montecon-Montevideo a través de Neltume); remolque y salvamento naviero (Ultratug); e inversiones inmobiliarias (Ultraterra). A nivel internacional, Ultramar opera en Argentina, Paraguay, Uruguay, Brasil, Panamá, Colombia, Ecuador y Perú, en los rubros de transporte, agenciamiento naviero, transporte transatlántico y servicios de gas y petróleo ${ }^{190}$ (gráfico 9).

\section{Ultragas $^{191}$}

Navieras Ultragas fue fundada en 1960 para que, dentro de la estructura del Grupo Ultramar, cubra los servicios de transporte marítimo y agrupe las subdivisiones empresariales especializadas en diferentes servicios y

188. En:<http://www.ultramar.cl/>. Consultado el 5/3/2014.

189. Véase: <http://www.mundomaritimo.cl/noticias/el-grupo-von-appen-y-su-tradicion-naviera> Consultado el 5/3/2014.

190. En:<http://www.ultramarnetwork.com/>. Consultado el 5/3/2014.

191. En:<http://www.ultramar.cl/ultragas.php>. Consultado el 6/3/2014. 
tipos de carga, mientras que Ultragas en sí se encarga del armado y operación de buques tanque para el transporte de productos químicos, GLP y productos limpios derivados de petróleo. Para este rubro, Ultragas cuenta con Sonap (productos sucios de petróleo), Ultrabulk (carga seca granel) y Transmares (armadores de buques de línea y de servicios break bulk). Además, en el rubro de servicios Ultragas controla Ultrachart (fletado de buques para transporte de carga seca a granel y carga de proyectos) y Humboldt (servicios de administración y arriendo de naves).

\section{Gráfico 9}

Empresas del grupo Ultramar y empresas asociadas

\section{ULTRAMAR GROUP \& ASSOCIATED COMPANIES}

\author{
Shipping and Towages \\ Navieras Ultragas Ltda. (Chile) \\ Ultragas Division \\ Ultrabulk Division \\ Sonap Division \\ Transmares Division \\ Antares Naviera S. A. (Argentina) \\ Petrolera Transoceanica S. A. (Perú) \\ Japina S. A. (Ecuador) \\ Pot Concesions \\ Port of Valparaíso (Chile) \\ Port of Angamos (Chile) \\ Port of Arica (Chile) \\ Terminal and Port Business \\ Port of Mejillones (Chile) \\ Port of Coronel (Chile)
}

Agencies

Ultramar Network (South America)

Ultramar Agencia Maritima Ltda. (Chile)

Agencia Marítima Internacional (Argentina)

Mercotrade (Brasil)

TransOceánica (Argentina)

Agencia Maritima Sudocean (Argentina)

Maritima Océano

Transtotal

Ship Management

Humboldt Shipmanagement Co. (Chile)

Humboldt Marine Training Ltda. (Chile)

Cargo and Container Services

Ultraport (Chile)

Servicios Integrados de Transporte S. A. (Chile)

Logistic

Ultramar Logistic

Fuente: página web de Ultratug: Grupo Ultramar (6/3/2014).

\section{Transmares}

Transmares fue fundada en 1969 como división de Ultragas encargada de las rutas navieras en la COAS, donde cubre servicios como nave de enlace o feeder, servicios de carga a granel, transporte multimodal, de contenedores y de productos forestales y metales, con rutas Chile-Perú-Ecuador, 
Chile-Perú y América Latina - América del Norte ${ }^{192}$. Transmares cumple un rol importante en la estructura de Ultramar pues es la única representante marítima de propiedad del grupo. Ultramar también trabaja con Mitsui 0. S. K. Lines Ltda. (MOL) de Japón para transportar carga general en rutas transpacíficas y hacia Norteamérica y Europa, así como con la noruega Stolt-Nielsen, que le presta servicios de tanktainer, flexibag y contenedores especiales para químicos y líquidos industriales, y con la noruega Höegh Autoliners para transportar vehículos y maquinarias en rutas hacia China, Japón y Corea del Sur.

\section{Ultratug ${ }^{193}$}

Ultratug contribuye al grupo con operaciones en Argentina (Antares Naviera S. A.), Brasil (Wilson Sons Ultratug Offshore), Chile (Remolcadores Ultratug Ltda.), Colombia (Coltugs), Ecuador (Japina S. A.), Perú (Petrolera Transoceánica S. A.) y Uruguay (Urutug), donde presta servicios de remolque y salvamento naviero en puerto y operaciones especiales de la costa o mar adentro, así como de transferencia de prácticos.

\section{Neltume $^{194}$}

Ultramar Inversiones Neltume Ltd. desarrolla proyectos en los sectores de minería, energía e industria, aunque su actividad principal es la operación portuaria, por la cual administra ocho terminales en Chile y Latinoamérica: Terminal Pacifico Sur en Valparaíso, Montecon Puerto de Montevideo, Terminal Puerto Arica, Terminal de Angamos (Compañía Portuaria Mejillones S. A.), Puerto de Coronel, Puerto de Mejillones (transferencia de carga a granel sólida), Terminal de Mejillones (comercio de ácido sulfúrico) y Terminal de Graneles del Norte (filial de puerto Angamos) en Mejillones. Las licitaciones adquiridas para la operación de estos terminales y puertos se han dado entre los años 2000 y 2010, indicador del reciente proceso de consolidación del Grupo Ultramar en la operación portuaria, más allá del agenciamiento general y marítimo.

192. En:<http://www.ultramar.cl/rm-transmares.php>. Consultado el 6/3/2014.

193. En:<http://www.ultratug.com/>. Consultado el 6/3/2014.

194. En:<http://www.ultramar.cl/neltume.php>. Consultado el 6/3/2014. 


\section{Ultraterra $^{195}$}

Ultraterra gestiona las inversiones del Grupo Ultramar en negocios complementarios al negocio principal marítimo, como son los sectores energético, de bienes raíces e inmobiliario y de servicios industriales.

\section{Ultramar Network ${ }^{196}$}

Ultramar Network es una división del Grupo Ultramar que provee servicios de agenciamiento naviero y operación con líneas navieras en labores relacionadas con la adición de valor a la industria de petróleo y gas en tierra y mar adentro. Los principales servicios que Ultramar Network ofrece, por medio de sus agentes y subagentes por toda Sudamérica, incluyen, en el rubro marítimo, el agenciamiento portuario, tránsito por el estrecho de Magallanes, suministros a naves, transporte de bunkers e investigación de mercado (preparación de reportes sobre política, sociedad y economía relevantes al sector marítimo). Ultramar Network también tiene una asociación con GAC Shipping de Dubái ${ }^{197}$, con el objetivo de compartir experiencias $\mathrm{y}$ la posibilidad de formar joint ventures para agenciamiento y servicios en puertos, así como eventualmente para formar un hub en Latinoamérica.

195. En:<http://www.ultramar.cl/ultraterra.php>. Consultado el 6/3/2014.

196. En: <http://www.ultramarnetwork.com/>. Consultado el 6/3/2014.

197. Gulf Agency Company (GAC) es un grupo empresarial fundado en 1956 originalmente como un joint venture de la agencia naviera sueca Nyman \& Schultz, pero estableció su sede en la zona económica libre de Jebel Ali luego de 1967. GAC presta servicios de agenciamiento naviero, servicios logísticos, transporte marítimo e inversión en industrias como: construcción de aeronaves y buques, inmobiliaria, entretenimiento, moda, etc. GAC está presente en puertos de América, Europa, África, Rusia, Medio Oriente, el subcontinente indio y la región Asia-Pacifico, donde funciona como operador portuario y/o proveedor de servicios logísticos. Véase: <http://www.gac.com/>. Consultado el 10/3/2014. 


\section{Conclusiones preliminares}

El mapa marítimo-portuario de la COAS está cambiando, al compás de un creciente protagonismo de redes empresariales globales en los segmentos puerto y mar de la cadena logística para contenedores. Este es el rasgo novedoso del panorama que proyecta el mapeo realizado en este documento (con información al año 2013), de los operadores portuarios y principales proveedores logísticos presentes en uno o más de los cinco mayores terminales para contenedores o multipropósito que en conjunto hay en los cuatro principales puertos en la COAS, así como de las líneas navieras y conglomerados con los que están empresarialmente vinculados esos operadores portuarios o proveedores logísticos.

En efecto, como resultado de un proceso iniciado a mediados de la década pasada, cuatro de esos cinco terminales están ahora a cargo o de un megaoperador portuario global (APMT o DPW) o de un importante operador portuario extrarregional (Ictsi). Por añadidura, la entrada de operadores portuarios de esa envergadura está trayendo consigo una presencia más activa de líneas navieras globales en la COAS; especialmente la entrada de APMT, dados sus fuertes vínculos con las dos mayores líneas navieras del mundo: Maersk y MSC.

Los elementos catalizadores de la serie de cambios significativos fueron un par de muy importantes concesiones en el puerto del Callao. La de su Muelle Sur trajo el ingreso, en el año 2006, de DPW (cuarto operador portuario del mundo y miembro del conglomerado Dubai World), rápidamente seguida el año 2007 por el ingreso al Terminal Simón Bolívar del puerto de Guayaquil de un operador portuario extrarregional (Ictsi) vinculado al primer operador portuario del mundo en términos de TEU movilizadas (HPH). 
Luego se realizó la concesión del Muelle Norte del Callao en el año 2011, que produjo el ingreso de APMT (segundo operador portuario mundial e integrante del conglomerado A. P. Møller, al que pertenece la primera línea naviera del mundo: Maersk), complementado pocos años después con una recomposición del consorcio encabezado por APMT que facilitó el ingreso a dicho muelle de TIL (operador portuario del conglomerado de la segunda línea naviera del mundo: MSC) en calidad de segundo accionista. En tanto que DPW extendió su presencia en la COAS, ingresando el año 2013 al Terminal Marítimo del puerto de Buenaventura mediante una compra de acciones.

Sintomáticamente, a esta «ola» globalizante a nivel de la función de operación portuaria en la mayoría de los principales terminales para contenedores de la COAS, que cual "efecto Callao" ha modificado en siete años los parámetros de la competencia interportuaria por la carga contenedorizada en el seno de esta costa, aún no se suman (al cierre del presente documento, al menos) el puerto de San Antonio -que antes de aquella "ola» lideraba el manejo de dicha carga en la COAS- ni ningún otro puerto chileno a cargo de operadores portuarios pertenecientes a redes regionales originarias de ese país. De hecho, si bien la concesión del Terminal Internacional de San Antonio fue adjudicada en 1999 al consorcio conformado por SAAM y una subsidiaria del holding norteamericano SSA, la operación de este terminal está básicamente a cargo de SAAM, que forma parte del mismo conglomerado chileno al que pertenece la línea naviera CSAV, para la cual dicho terminal ha funcionado desde entonces como su "puerto matriz".

Sin embargo, en lo concerniente a proveedores logísticos, el mapeo realizado en este documento muestra que los ligados a conglomerados regionales originarios de Chile mantienen una presencia muy importante en tres de los cuatro puertos examinados: San Antonio, el Callao y Guayaquil. Y también muestra que la presencia de proveedores logísticos nacionales (o locales) continúa siendo importante en todos los cuatro puertos examinados, Buenaventura incluido. Esta presencia local, cuando está referida solamente a proveedores logísticos locales no ligados empresarialmente a aquellas redes regionales dominantes, se muestra como comparativamente mayor en Buenaventura, menor en el Callao e intermedia entre estos extremos en Guayaquil. Estos hechos corroboran, para el caso de la COAS, lo analizado en el capítulo I acerca de la fuerte implantación que las redes marítimo-portuarias regionales o locales suelen tener en el segmento tierra de sus respectivas regiones o paises de origen. 
Cuando esa realidad por el lado del segmento tierra es contrastada con la otra realidad en curso, de creciente presencia de redes globales en los segmentos puerto y mar de la cadena logística para contenedores, se perciben las dimensiones globalización y regionalización del proceso actual en la COAS. Ello, muy especialmente, en los tres puertos principales de la COAS (Callao, Guayaquil y Buenaventura) donde se ubican los ya mencionados terminales para contenedores o multipropósito a cargo de operadores portuarios globales o extrarregionales vinculados con conglomerados globales. Las enseñanzas del marco analítico expuesto en el capítulo I son muy útiles para esbozar, a propósito de las implicancias de tal situación, algunas conjeturas como las siguientes.

En primer lugar, que los países involucrados (Perú, Ecuador y Colombia), al haber decidido recurrir a operadores portuarios globales o extrarregionales para que se encarguen de los mencionados terminales en sus respectivos puertos principales en la COAS, estarían señalizando tanto su aspiración a que tales puertos asciendan al estatus de centros de carga (o gateways) subregionales, como su preferencia por lograrla con la ayuda de redes globales (en lo atinente a sus principales puertos, al menos). Lo cual es probablemente una reacción ante la histórica propensión de las redes regionales dominantes en la COAS a que dicho estatus se centralice en sus respectivos "puertos matrices" (o home ports) en Chile y, al mismo tiempo, un indicador de la existencia de una opción, mayoritaria en la COAS, a favor de que en la misma haya una estructura marítimo-portuaria multipolar.

Segundo, que en virtud de esa decisión, aquellos tres puertos estarían cumpliendo ahora, más intensamente que antes, la función inherente a un nodo portuario de importante tamaño y potencial. Es decir, la función de interfaz que facilita el establecimiento de compatibilidades parciales entre redes marítimo-portuarias de distinto alcance (global, regional, local), al actuar como un adaptador de sus diferentes estándares. Función esta que, de desarrollarse, podría desembocar en la conversión de cuando menos algunos de esos puertos en centros de carga (o gateways) de sus respectivos ámbitos subregionales de influencia. Sin embargo, conforme la susodicha función se hace más intensa, también se intensifica la competencia entre las coexistentes redes marítimo-portuarias por la carga contenedorizada y para liderar el soporte logístico a las cadenas de valor/suministro presentes en los respectivos espacios subregionales. 
En tercer lugar entonces, cabe suponer que tal competencia es ahora más aguda que antes en aquellos tres puertos (Callao, Guayaquil y Buenaventura), donde habría un tenso pulseo de poderes de mercado. En este pulseo, dado el corto tiempo transcurrido desde la acrecentada presencia de redes globales en esos puertos, aún sería incierta la medida en que estas lograrán concretar su en principio clara ventaja en los segmentos mar y puerto, debido a que es probable que las líneas navieras regionales todavía tengan una alta participación en el tráfico marítimo que conecta a esos puertos, y debido también a la clara ventaja que los proveedores logísticos regionales o locales mantienen en el segmento tierra. Se destacan los proveedores locales en Buenaventura, los regionales en el Callao y ambos en Guayaquil. El Callao aparece así como un caso de estudio muy interesante, ya que allí, en comparación con Guayaquil y Buenaventura, podría llegar a ser mayor el poder de redes globales en los segmentos mar y puerto (habida cuenta de DPW, de APMT y lo que este implica respecto a Maersk y MSC), pero también es mayor el poder de las redes regionales originarias de Chile en el segmento tierra.

De lo anterior surge un corolario importante a la luz de la hipótesis de nuestra investigación. A saber: que en la COAS ya están instalados los diversos actores empresariales que hacen de esta costa un campo de observación pertinente para analizar posibles estrategias de desarrollo portuario, sea impulsándolo desde el foreland o basándolo en el hinterland, o reforzándolo mediante híbridos de ambas estrategias.

Con miras a ello, el mapeo de los principales conglomerados empresariales presentes en la COAS que se ha realizado en este documento, al mostrar las diferencias entre los conglomerados globales y regionales en cuanto a cobertura del espacio marítimo-portuario conformado por la COAS y sus costas colindantes en el continente americano, agrega información sobre el posicionamiento (al año 2013) de cada conglomerado para disputar el manejo de la carga contenedorizada en dicho espacio, aportando así más elementos de juicio útiles para detectar mejor las estrategias de desarrollo portuario que cada cual podría aplicar a favor de los terminales de contenedores a su cargo en la COAS.

En tal sentido, respecto a los conglomerados de los operadores portuarios globales presentes en la COAS, se ha mostrado que APMT y DPW operan los principales terminales para contenedores en la CEAS (Costa Este de América del Sur) -en cuyo mayor puerto (Santos) hay incluso un joint venture entre 
APMT y TIL, parecido al que ambos tienen ahora en el mayor puerto de la COAS (Callao)- así como grandes terminales en la Costa Oeste de América del Norte (DPW en Canadá, y APMT en los Estados Unidos y México). También se ha mostrado que DPW opera varios terminales sobre el Mar Caribe y que APMT hace lo propio en varios de la Costa Este de América del Norte. Sin duda, estas vastas redes de importantes terminales alrededor de las Américas dotan de sólidas y geográficamente bien distribuidas anclas portuarias para ensayar estrategias basadas en el foreland.

APMT luce como privilegiadamente dotado para implementar ese tipo de estrategia a favor de los terminales ahora a su cargo en puertos sudamericanos que tienen atributos para funcionar como centros de carga / gateways e incluso como hubs de transbordo subregionales, como son los puertos de Santos y de Buenos Aires en la CEAS y del Callao en la COAS. Tal dotación privilegiada le viene de que cuenta, además de con su vasta red de puertos, con las vastísimas redes marítimas no solo de Maersk, primera línea naviera del mundo y líder del conglomerado al que pertenece APMT, sino también de MSC, segunda línea naviera del mundo que con su operador portuario (TIL) están trabajando en estrecha alianza estratégica con Maersk y APMT en Sudamérica.

Sin embargo, según las enseñanzas del marco analítico (capítulo I), la implementación de una estrategia basada en el foreland por parte de una red global "recién llegada» (o late-comer) en puertos de un determinado ámbito regional o subregional, enfrenta serias dificultades en su inicio ante la posición de dominio que redes locales o regionales tempranamente instaladas (o incumbents) suelen tener en su ámbito de origen, en términos no solo de tráfico marítimo intrarregional y de carga movilizada en puertos secundarios (que pueden no avenirse a ser feeders del puerto principal a cargo de la red global), sino sobre todo de bases de clientes y canales de distribución tierra adentro.

Por esta razón, cabe suponer que Maersk/APMT y MSC/TIL, de apostar por dicha estrategia, tratarán de facilitarse su implementación mediante atajos provistos por medidas complementarias para acelerar ganancias de participación en el tráfico marítimo intrarregional (como podría ser -por ejemplo- que Maersk recurra a su naviera filial Sealand para que compita por dicho tráfico y quizá por el cabotaje nacional también) y/o vía M\&A de empresas regionales o locales. Con mayor motivo en vista de que ese tipo de MctA acaba de ser puesto en práctica por dos navieras competidoras de origen alemán, que están 
absorbiendo el transporte marítimo en contenedores de las navieras chilenas dominantes en Sudamérica: Hapag-Lloyd acogiendo a CSAV vía una fusión y Hamburg Süd comprando a CCNI.

Mientras que para DPW, el hecho de que su conglomerado todavía no cuente con una línea naviera global (pues P\&0 Maritime Services ya no califica como tal) podría significarle un matizado balance de desventajas y ventajas que quizá apunte hacia una opción híbrida en materia de desarrollo portuario. Puesto que, por un lado, esa carencia en el segmento mar puede complicarle aún más el éxito de una eventual estrategia basada en el foreland, que ya de por sí enfrentaría las serias dificultades antes mencionadas, especialmente en el segmento tierra.

Pero, por otro lado, esa misma carencia podría funcionar a favor de DPW, al no ser percibido como un competidor en el segmento mar por navieras globales y regionales, por lo que estas últimas quizá podrían tener una actitud menos reticente a que los proveedores logísticos en tierra ligados a sus conglomerados regionales hagan uso intensivo de terminales a cargo de DPW, los cuales tendrían así relativamente facilitado su acceso tanto al foreland como al hinterland. Es decir, aquella carencia le complicaría a DPW la tarea de cubrir toda la cadena logística bajo la égida de su propio conglomerado (o de "integrarla" verticalmente), pero quizá le facilitaría la tarea de articularla tejiendo una red plural con integrantes de distintos conglomerados congregados en torno del terminal a su cargo.

Respecto a los conglomerados regionales presentes en la COAS, este documento ha mostrado que, en lo relativo a carga contenedorizada, destacan tres que en el año 2013 estaban encabezados por holdings controlados por familias chilenas: los conglomerados CSAV/SAAM, CCNI/Agunsa y Ultramar/Ultragas, bajo control mayoritario de las familias Luksic, Urenda y Von Appen, respectivamente.

A este último, habida cuenta de que su negocio marítimo-portuario es liderado por la agencia marítima (Ultramar) del conglomerado y su línea naviera cumple un rol secundario en contenedores, quizá podría aplicársele una reflexión análoga a la arriba realizada acerca de las ventajas y desventajas relativas que ello puede conllevar de cara al foreland y al hinterland. En todo caso, dicho rol secundario puede explicar en parte el alcance de la presencia del conglomerado Von Appen, hasta el momento casi exclusivamente sudamericana. 
También podría explicar en parte la disposición del conglomerado Von Appen a trabajar en red con empresas locales establecidas en países sudamericanos como independientes de dicho conglomerado, e incluso a facilitarles la adquisición de empresas que le pertenecían; tal como parece sugerir su relación con el grupo empresarial peruano Andino Investment Holding, según lo visto en este documento.

En lo referente a los conglomerados CSAV/SAAM y CCNI/Agunsa, no solo sus respectivos operadores portuarios están a cargo de varios terminales o puertos en Chile, sino que sus respectivos proveedores logísticos están fuertemente implantados en el segmento tierra a lo largo de casi toda la COAS y gran parte del cono sur de la CEAS.

En esos ámbitos sudamericanos sobresale CSAV, sobre todo luego de su adquisición de la naviera brasileña Libra en 1999 y las consiguientes filiales que CSAV/ Libra estableció en Argentina y Uruguay además de la subsidiaria en Brasil. Todo ello complementado por las rutas marítimas entre la CEAS y la COAS que opera el consorcio Conosur conformado por CSAV con la naviera argentina Maruba y, con miras a la carga transpacífica de esas dos costas sudamericanas, mediante la compra de Norasia que CSAV hiciera el año 2000. A juzgar por los primeros resultados de nuestra investigación (que fueron comentados en la introducción de este documento), es probable que ese fuerte posicionamiento en varios hinterlands sudamericanos haya sido puesto al servicio de la acumulación de carga en los "puertos matrices» de CSAV y CCNI (San Antonio y Valparaíso, respectivamente), para tratar de erigirlos como gateways y/o hubs de transbordo subregionales, respecto a la carga transpacífica especialmente.

Adicionalmente, la presencia de proveedores logísticos de CSAV/SAAM y CCNI/ Agunsa se extiende -a través de subsidiarias o de joint ventures- no solo al ámbito mesoamericano comprendido por América Central, el Caribe y México, donde se ha reforzado con el ingreso conjunto de SAAM y Agunsa como operadores de un terminal en Florida (Estados Unidos). También se extiende a algunos países del este de Asia y del sur de Europa, aunque en estos lares se trata sobre todo de servicios marítimos en apoyo a los negocios de transporte de CSAV o CCNI. Asimismo, ya por el año 2013 era perceptible una tendencia de esos dos conglomerados chilenos a mejorar su presencia por el norte de la CEAS y el litoral caribeño de Sudamérica, ejemplificada por el traslado de SAAM hacia puertos caribeños de Colombia. 
Aparentemente, dado el riesgo de perder participación en la carga de la COAS ante la acrecentada presencia de conglomerados globales en dicha costa, aquellos dos conglomerados chilenos estaban en pos de aumentar su presencia por el lado de la CEAS y de costas centroamericanas y caribeñas, con el propósito de ganar participación en la carga que conecta a esas costas entre sí y en parte de las respectivas cargas transatlánticas y transpacíficas.

Ese reciente despliegue mesoamericano parecía estar indicando, a la luz de la hipótesis de nuestra investigación, que los conglomerados chilenos CSAV/SAAM y CCNI/Agunsa estarían preparándose para emprender estrategias diferenciadas en materia de sus respectivas jerarquías de puertos y opciones de desarrollo para los terminales a su alcance. $\mathrm{Al}$ respecto, cabe suponer que, en aquel ámbito mesoamericano, situado en los confines o afuera del espacio gravitacional más relevante para sus "puertos matrices" en Chile y donde su implantación en los segmentos tierra y puerto no era tan sólida como en Sudamérica, aquellos conglomerados podían estar contemplando estrategias tipo basadas en el foreland pivoteadas por sus respectivas navieras, especialmente CSAV, que ya por aquel entonces se ubicaba entre las veinte mayores navieras del mundo y era así una naviera emergente transitando de regional a global. Ahora, con la fusión Hapag-Lloyd / CSAV y la compra de CCNI por Hamburg Süd, queda por ver la orientación estratégica con la que esos conglomerados alemanes harán uso de los acervos mesoamericanos de las navieras chilenas absorbidas.

Pero, en lo que atañe al ámbito sudamericano, cabe suponer que, si bien el alcance global de las mencionadas navieras alemanas aportaría tintes basados en el foreland al uso de los robustos acervos en dicho ámbito de las navieras chilenas absorbidas, la opción estratégica para las empresas de los respectivos conglomerados chilenos no incluidas -o cuya inclusión aún no está definida (al cierre del presente documento)- en tales M\&tA, probablemente tendrá en dicho ámbito un sesgo basado en el hinterland. Así parece sugerir el hecho de que el acuerdo de compraventa entre Hamburg Süd y CCNI explicita que Agunsa continuará desarrollando sus actividades portuarias y logísticas a cuenta y nombre propios, así como el hecho de que SAAM no haya sido mencionado en los reportes (disponibles al cierre de este documento, al menos) acerca de la fusión de CSAV con Hapag-Lloyd.

Más aún, se debe tener en cuenta que todavía es predominantemente sudamericana la implantación de las otras empresas de los conglomerados chilenos 
que les sirven a estos para hacerse de un hinterland bajo su control; es decir, la de sus empresas financieras, de retail e inmobiliarias. Mientras así siga siendo, los hinterlands sudamericanos continuarán representando para tales conglomerados chilenos la parte esencial de su base regional de carga y, en lo que particularmente concierne a la carga por el sur de las dos costas de Sudamérica, es probable que continúe su propensión a manejarla y dirigirla de modo que sea aglomerada en sus respectivos "puertos matrices» en Chile.

Lo cual implicaría, a la luz de las enseñanzas provenientes del marco analítico (capítulo I), que la estrategia sudamericana de esos conglomerados empresariales chilenos probablemente tendría que seguir mostrando una fuerte simbiosis con la estrategia de su país de origen. Ello con el propósito de poder contar con el decidido apoyo gubernamental que es indispensable para implementar el tipo de acciones público-privadas que conllevan la "fabricación" de ventajas de localización, especialmente cuando son dirigidas a favor de puertos que están ubicados en lugares muy distantes de los mercados o rutas marítimas más grandes y que, por añadidura, tienen aspiraciones de convertirse en centros de carga (gateways) y/o hubs de transbordo que por el lado tierra dependen de hinterlands en su mayor parte ubicados en territorios de países vecinos.

En buena cuenta, puede afirmarse que la significativa transformación en curso del mapa marítimo-portuario de la COAS parece anunciar interesantes cambios en las jerarquías de puertos y sus relacionadas configuraciones $h u b$ \& spoke de rutas maritimas en el seno de esta costa. Sin embargo, hay no pocas opciones de desarrollo portuario a las que los conglomerados y redes empresariales marítimo-portuarias globales o regionales allí presentes pueden recurrir, según sus respectivas ventajas competitivas.

De ahí que, con miras a la verificación de la hipótesis de nuestra investigación, se requiere de información y análisis complementarios capaces de detectar cómo aquellas opciones se van revelando, en términos de calidad y eficiencia de la infraestructura portuaria, trazos de rutas marítimas y niveles de conectividad en cada uno de los puertos principales de la COAS estudiados, así como del consiguiente impacto sobre la competitividad del comercio de los países involucrados. Estos son, tal como se precisó en la introducción del presente documento, los temas de las siguientes publicaciones previstas por nuestra investigación, de la que este documento es simplemente un hito. 



\section{Bibliografía}

\section{Artículos y documentos técnicos}

ADLUNG, Rudolf y Aaditya MATTOO

2008 "The GATS». En: MATTO0, A.; R. M. STERN y G. ZIANINI (Eds.). A Handbook of International Trade in Services, pp. 48-83. Washington D. C.: World Bank / Oxford University Press.

\section{ALPHALINER}

2012 "Evolution of Main Carriers Operated Fleets 1996-2012». Disponible en: <http://www.alphaliner.com/liner2/research_files/liner_studies/misc/ AlphalinerTopCarriers-2012.pdf>.

ÁLVAREZ-SAN JAIME, Óscar; Pedro CANTOS-SÁNCHEZ, Rafael MONER-COLONQUES Y José SEMPERE-MONERRIS

2013 "Vertical Integration and Exclusivities in Maritime Freight Transport». En: Transportation Research - Part E, 51, pp. 50-61.

BANCO MUNDIAL

2007 Port Reform Tool Kit - Module 2: The Evolution of Ports in a Competitive World. 2. ed. Washington D. C.: World Bank - Public-Private Infrastructure Advisory Facility, pp. 21-67.

BELAÚNDE, Ignacio y Alfonso BRYCE

2006 «Evaluación de los requisitos para el desarrollo del puerto del Callao como un hub portuario subregional en la costa oeste de América del Surn. Seminario de Investigación Económica 2006-II, noviembre. Lima: Universidad del Pacífico - Departamento Académico de Economía. 
BERGANTINO, Angela S. y Albert W. VEENSTRA

2002 "Interconnection and Co-ordination: An Application of Network Theory to Liner Shippingn. En: International Journal of Maritime Economics, N. ${ }^{\circ} 4$, pp. 231-248.

BICHOU, Khalid y Michel G. H. BELL

2007 "Internationalisation and Consolidation of the Container Port Industry: Assessment of Channel Structure and Relationships». En: Maritime Economics and Logistics, vol. 9, N. ${ }^{\circ}$, pp. 35-51.

BICHOU, Khalid y Richard GRAY

2004 "A Logistics and Supply Chain Management Approach to Port Performance Measurement». En: Maritime Policy and Management, vol. 31, N. ${ }^{\circ}$ 1, pp. 47-67.

BIRKE, Daniel

2009 "The Economics of Networks - A Survey of the Empirical Literature». En: Journal of Economic Surveys, vol. 23, N. ${ }^{\circ}$ 4, pp. 762-793. [Las páginas citadas en este documento de trabajo corresponden a la versión en PDF disponible en: <http://www.nottingham.ac.uk/ lizecon/RePEc/pdf/22.pdf>].

CASCHILI, Simone; Francesca R. MEDDA, Francesco PAROLA y Claudio FERRARI 2011 Cooperation in Container Shipping: A Small World Network of Agreements. Centre for Advanced Spatial Analysis Working Papers Series, Paper 173, noviembre. Londres: University College of London.

CEPAL

2008 "La actividad portuaria en América Latina y el Caribe 2007». En: Boletín FAL, N. ${ }^{\circ} 264$, agosto. Santiago, Chile: Comisión Económica para América Latina y el Caribe.

COE, Neil; Martin HESS, Henry Wai-Chung YEUNG, Peter DICKEN y Jeffrey HENDERSON 2004 "'Globalizing' Regional Development: A Global Production Network Perspective». En: Transactions of the Institute of British Geographers, New Series, 29(4), pp. 468-484.

COPELAND, Brian y Aaditya MATTO0

2008 "The Basic Economics of Services Trade». En: MATT00, A.; R. M. STERN y G. ZIANINI (Eds.). A Handbook of International Trade in Services, pp. 84-129. Washington D. C.: World Bank / Oxford University Press. 
CORVERA, Luis

2011 "Carlos Vargas Loret de Mola: 'En tres años duplicaremos nuestro negocio'». En: Poder, N. ${ }^{\circ} 29$, julio, pp. 31-37. Lima. [Disponible en: <http://www.poder360. com/article_detail.php?id_article=5868>].

COX, Andrew

1997 Business Success: A Way of Thinking about Strategy, Critical Supply Chain Assets and Operational Best Practice. Reino Unido: Earlsgate Press.

CRAMPES, Claude

1999 "Network Industries and Network Goods». En: European Economy: Liberalisation of Network Industries: Economic Implications and Main Policy Issues - Introductory Chapter, Reports and Studies, vol. 4. Bruselas: Comisión Europea. [Las páginas citadas en este documento de trabajo corresponden a la versión en PDF disponible en: <http://idei.fr/doc/by/crampes/network.pdf>].

CULLINANE, Kevin y Mahim KHANNA

1999 "Economies of Scale in Large Container Ships». En: Journal of Transport Economics and Policy, vol. 33, N. ${ }^{\circ}$ 2, pp. 185-208.

D'ARCY, Ryan

2001 "Strategic Alliances and their Impacts on the Container Shipping Industry". Master Degree Thesis. Montreal: Concordia University-Department of Geography. [Las páginas citadas en este documento de trabajo son las de la versión en PDF disponible en: <http://spectrum.library.concordia.ca/1692/1/ M068388.pdf $>$ ].

DAVIDSON, Neil

2010 «Global Container Terminal Operators: Forecast». En: Port Technology International. [Las páginas citadas en este documento de trabajo corresponden a la versión en PDF disponible en: <http://www.porttechnology.org/images/ uploads/technical_papers/007-009.pdf>].

DREWRY Maritime Research

2013 «Drewry Top Ten Global Terminal Operators - 2012». En: <http://www.drewry. co.uk/news.php?id=232>. 
DUCRUET, César

2009 "Port Regions and Globalization». En: NOTTEBOOM, T.; C. DUCRUET y P. W. De LANGEN (Eds.). Ports in Proximity: Competition and Co-Ordination among Adjacent Seaports, pp. 41-53. Ashgate. [Las páginas citadas en este documento de trabajo corresponden a la versión en PDF disponible en: $<$ http://hal.archivesouvertes.fr/docs/00/45/80/71/PDF/P3_-_Ducruet_PIP_chapter2.pdf>].

DUCRUET, César y Theo NOTTEBOOM

2012 "The World Maritime Network of Container Shipping: Spatial Structure and Regional Dynamicsi. En: Global Networks, vol. 12, N. 3, pp. 395-423. [Las páginas citadas en este documento de trabajo corresponden a la versión en PDF disponible en: <http://hal.archives-ouvertes.fr/docs/00/53/80/51/PDF/ Global_Networks_CD_TN_edited.pdf>].

DUCRUET, César; Theo NOTTEBOOM y Peter W. DE LANGEN

2009 "Revisiting Inter-Port Relationships under the New Economic Geography Research Framework». En: NOTTEBOOM, T.; C. DUCRUET y P. W. DE LANGEN (Eds.). Ports in Proximity: Competition and Co-Ordination among Adjacent Seaports, pp. 11-27. Ashgate. [Las páginas citadas en este documento de trabajo corresponden a la versión en PDF disponible en: <http://www.vliz. be/imisdocs/publications/248324.pdf>].

DUNNING, John $\mathrm{H}$.

1992 Multinational Enterprises and the Global Economy. Gran Bretaña: Addison-Wesley.

ECONOMIDES, Nicholas

1996 "The Economics of Networks». En: International Journal of Industrial Organization, N. ${ }^{\circ} 14$, pp. 673-699.

EILTS, Enno y Paul OXLEY

2011 "Background Paper». En: "Competition in Ports and Port Services» DAF/COMP (2011) 14. Paris: Organization for Economic Co-operation and Development, pp. 21-62.

FAIRLIE, Alan y Sandra QUEIJA

2007 Relaciones económicas Perú-Chile: ¿integración o conflicto? Lima: Pontificia Universidad Católica del Perú - Centro de Investigaciones Sociológicas, Económicas, Políticas y Antropológicas. 
FERRARI, Claudio y Marco BENACCHIO

2002 "Recent Trends in the Market Structure of Container Terminal Services: Which Way to Integration?». En: Pomorski Zbornik, vol. 40, N.॰ 1, pp. 153-176.

FINDLAY, Christopher

2008 "Transport Services». En: MATT00, A.; Robert M. STERN y G. ZIANINI (Eds.). A Handbook of International Trade in Services, pp. 356-388. Washington D. C.: World Bank / Oxford University Press.

FLEMING, Douglas K. y Yehuda HAYUTH

1994 "Spatial Characteristics of Transportation Hubs: Centrality and Intermediacy". En: Journal of Transportation Geography, vol. 2, N.` 1, pp. 3-18.

FRÉMONT, Antoine

2009 Empirical Evidence for Integration and Disintegration of Maritime Shipping, Port and Logistics. Discussion Paper N. ${ }^{\circ}$ 2009-1, enero. Paris: International Transport Forum - Organization for Economic Co-operation and Development. 2007 "Global Maritime Networks: The Case of Maersk». En: Journal of Transport Geography, vol. 15, pp. 431-442.

FUJITA, Masahisa y Tomoya MORI

2005 Transport Development and the Evolution of Economic Geography. IDE Discussion Paper N. ${ }^{\circ} 21$, enero. Chiba: Institute of Developing Economies, Jetro.

1996 "The Role of Ports in the Making of Major Cities: Self-Agglomeration and Hub-Effect». En: Journal of Development Economics, vol. 49, pp. 93-120.

FUJITA, Masahisa y Jacques-François THISSE

2004 Globalization and the Evolution of the Supply Chain: Who Gains and Who Losses? IDE Discussion Paper N. ${ }^{\circ}$, agosto. Chiba: Institute of Developing Economies, Jetro.

1996 "Economies of Agglomeration». En: Journal of the Japanese and International Economies, N. ${ }^{\circ} 10$, pp. 339-378.

FUJITA, Masahisa; Paul KRUGMAN y Anthony VENABLES

1999 The Spatial Economy: Cities, Regions and International Trade. Cambridge: MIT Press. [Las páginas citadas en este documento de trabajo corresponden a la versión en PDF disponible en: <http://web.mit.edu/krugman/www/fkvintro. html>]. 
GARCÍA MARENGO, Sebastián

2013 "La concesión del Puerto de Paita como una muestra de la ausencia de planeamiento en conectividad marítima en el Perúw. Caso Práctico para obtener el Título de Diplomático de Carrera. Lima: Academia Diplomática del Perú.

GONZÁLEZ VIGIL, Fernando; Alexis YONG y Juan Manuel HURTADO

2012 Comercio y transporte marítimo: El caso del Pacífico suramericano. Documento de Discusión DD/12/08, noviembre. Lima: Centro de Investigación de la Universidad del Pacífico. Disponible en: <http://srvnetappseg.up.edu.pe/ siswebciup/Files/DD1208\%20-\%20Yong_Gonzalez-Vigil_Hurtado.pdf>.

GOTTINGER, Hans-Werner

2003 Economies of Network Industries. Nueva York: Routledge-Taylor \& Francis Group.

HARALAMBIDES, Hercules; Pierre CARIOU y Marco BENACCHIO

2002 "Costs, Benefits and Pricing of Dedicated Terminals». En: International Journal of Maritime Economics, vol. 4, pp. 21-34.

HAYUTH, Yehuda y Douglas K. FLEMING

1994 "Concepts of Strategic Commercial Location: The Case of Container Ports". En: Maritime Policy and Management, vol. 21, N. ${ }^{\circ} 3$, pp. 187-193.

HENDERSON, Jeffrey; Peter DICKEN, Martin HESS, Neil COE y Henry Wai-Chung YEUNG

2002 "Global Production Networks and the Analysis of Economic Development". En: Review of International Political Economy, vol. 9, N. ${ }^{\circ} 3$, pp. 436-464.

JONES, Ronald W. y Henryk KIERZKOWSKI

2005 "International Fragmentation and the New Economic Geography». En: North American Journal of Economics and Finance, vol. 16, N. 1, pp. 1-10. [Las páginas citadas corresponden a la versión en PDF disponible en: <http:// graduateinstitute.ch/files/live/sites/iheid/files/shared/iheid/800/kierzkowski/ international-fragmentation04.pdf $>$ ].

2001 "A Framework for Fragmentation». En: ARNDT, S. y H. KIERZKOWSKI (Eds.). Fragmentation: New Production Patterns in the World Economy. Oxford University Press, pp. 17-34. [Las páginas citadas corresponden a la versión en PDF disponible en: <http://papers.tinbergen.nl/00056.pdf>]. 
KATZ, Michael y Carl SHAPIRO

1985 "Network Externalities, Competition and Compatibility». En: American Economic Review, vol. 75(3), pp. 424-440.

KIMURA, Fukunari

2008 "The Mechanics of Production Networks in Southeast Asia: The Fragmentation Theory Approach». En: KUROIWA, I. y T. M. HENG (Eds.). Production Networks and Industrial Clusters: Integrating Economies in Southeast Asia. Chiba / Singapur: Institute of Developing Economies (IDE) - Jetro / Institute of Southeast Asian Studies (Iseas), pp. 33-53.

KRUGMAN, Paul

1991 Geography and Trade. Cambridge: MIT Press / Leuven University Press [1. ${ }^{\text {e ed. }}$ en rústica, 1993].

KRUGMAN, Paul y Maurice OBSTFELD

1995 Economía Internacional: teoría y política. Madrid: McGraw-Hill / Interamericana de España S.A [3.a ed. en castellano].

KUROIWA, Ikuo y Toh Mun HENG

2008 "Introduction». En: KUROIWA, I. y T. M. HENG (Eds.). Production Networks and Industrial Clusters: Integrating Economies in Southeast Asia. Chiba / Singapur: Institute of Developing Economies (IDE) - Jetro / Institute of Southeast Asian Studies (Iseas), pp. 1-29.

LANGEN DE, Peter W. y Athanasios A. PALLIS

2007 "Entry Barriers in Seaports». En: Maritime Policy and Management, vol. 34, N. ${ }^{\circ}$ 5, pp. 427-440 [Las páginas citadas corresponden a la versión en PDF disponible en: <http://www.porteconomics.eu/downloads-section/doc details/176-2007-mpm-de-langen-and-pallis.html>].

2006 "Analysis of the Benefits of Intra-Port Competition». En: International Journal of Transport Economics, vol. 33, N.` 1, pp. 69-85. [Las páginas citadas corresponden a la versión en PDF disponible en: <http://www.porteconomics.eu/ downloads-section/doc_details/173-2006-ijte-pallis-and-de-langen.html>]. 
LUGO, Eduardo

2013 "El comercio marítimo en la perspectiva global». Ponencia en representación de HDR Engineering Inc. XXXV Repica (Reunión Portuaria del Istmo Centroamericano), mayo. Honduras: Cocatram (Comisión Centroamericana de Transporte Marítimo). [Las páginas citadas corresponden a la versión en PPT/PDF disponible en: <http://www.cocatram.org.ni/repica/El_Comercio_ Maritimo_en_la_Perspectiva_Global_Eduardo_Lugo.pdf>.

MARSHALL, Alfred

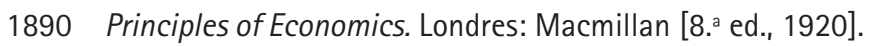

MATTO0, Aaditya y Pierre SAUVÉ

2003 "Domestic Regulation and Trade in Services: Key Issues". En: MATT00, A. y P. SAUVÉ (Eds.). Domestic Regulation and Services Trade Liberalization, pp. 1-6. Washington D. C.: World Bank.

MATTO0, Aaditya y Robert M. STERN

2008 "Overview». En: MATTOO, A.; R. M. STERN y G. ZIANINI (Eds.). A Handbook of International Trade in Services, pp. 3-47. Washington D. C.: World Bank / Oxford University Press.

MEERSMAN, Hilde; Eddy VAN DE VOORDE y Thierry VANELSLANDER 2010 "Port Competition Revisited». En: Review of Business and Economics, N. ${ }^{\circ} 2$, pp. 210-232.

MERCKX, Filip y Theo NOTTEBOOM

2006 "Freight Integration in Liner Shipping: A Strategy Serving Global Production Networks". En: Growth and Change: A Journal of Regional Development, vol. 37, N. 4, pp. 550-569 [Las páginas citadas corresponden a la versión en PDF disponible en: <http://www.porteconomics.eu/downloads-section/ doc_details/181-2006gcmerckx-a-notteboom.html>].

MESOUITA MOREIRA, Mauricio; Christian VOLPE y Juan S. BLYDE

2008 Destrabando las arterias - El impacto de los costos de transporte en el comercio de América Latina y el Caribe. Washington D. C.: Banco Interamericano de Desarrollo / David Rockefeller Center for Latin American Studies / Harvard University Press. 
NADRAMIJA, Nathan

2013 «Evaluación comparada del impacto económico como resultado de aplicar las Reglas de La Haya de 1924 y las Reglas de Hamburgo de 1978 en el flete marítimo". Informe final de consultoría. Lima: Ministerio de Transportes y Comunicaciones.

NATHAN Associates Inc.

2005 "Container Shipping Service Patterns and Transshipment Potential for Port of Callao». Technical Report, marzo. Lima: Proyecto Crecer Usaid Peru / Apoyo Consultoría.

NOTTEBOOM, Theo

2008 The Relationship between Seaports and the Intermodal Hinterland in Light of Global Supply Chains. Discussion Paper N. ${ }^{\circ}$ 2008-10, marzo. París: International Transport Forum - OECD Joint Research Transport Centre.

2004 "Container Shipping and Ports: An Overview». En: Review of Network Economics, vol. 3, N.², pp. 86-106.

NOTTEBOOM, Theo y Jean-Paul RODRIGUE

2011 "Emerging Global Networks in the Container Terminal Operating Industry". En: NOTTEBOOM, T. (Ed.). Current Issues in Shipping, Ports and Logistics, pp. 243-270. Amberes: Antwerp University Press.

2008 "Containerisation, Box Logistics and Global Supply Chains: The Integration of Ports and Linear Shipping Networks». En: Maritime Economics and Logistics, vol. 10, N. ${ }^{\circ} 1$, pp. 152-174.

2005 «Port Regionalization: Towards a New Phase in Port Development». En: Maritime Policy and Management, vol. 32, N.³, pp. 297-313. [Las páginas citadas corresponden a la versión en PDF disponible en: <http://www.porteconomics. eu/downloads-section/doc_details/191-2005mpmnotteboom-and-rodrigue. html>].

OLIVIER, Daniel; Francesco PAROLA, Brian SLACK y James J. WANG

2007 "The Time Scale of Internationalization: The Case of the Container Port Industry". En: Maritime Economics and Logistics, vol. 9, N. 1, pp. 1-34.

PANAYIDES, Photis y Kevin CULLINANE

2002 "Competitive Advantage in Liner Shipping: A Review and Research Agenda". En: International Journal of Maritime Economics, N. 4, pp. 189-209. 
PANZAR, John C. y Robert D. WILLIG

1981 "Economies of Scope». En: The American Economic Review, vol. 71, N.² 2. Papers and Proceedings of the Ninety-Third Annual Meeting of the American Economic Association, pp. 268-272.

PAROLA, Francesco; Giovanni SATTA y Simone CASCHILI

2014 "Unveiling Co-Operative Networks and 'Hidden Families' in the Container Port Industry". En: Maritime Policy and Management, vol. 41, N. ${ }^{\circ} 4$, pp. 384-404. [Las páginas citadas en este documento de trabajo corresponden a la versión en PDF disponible en: http://www.porteconomics.eu/downloads-section/ cat_view/21-journal-papers.html>].

PAWLIK, Thomas; Lars STEMMLER, Alfred J. BAIRD y Manfred HELCH

2011 "The Value of Container Terminal Investment to Ocean Carrier Strategy». En: Maritime Economics and Logistics, vol. 13, N. ${ }^{\circ} 3$, pp. 319-341.

PORTER, Michael E.

1990 The Competitive Advantage of Nations. Nueva York: The Free Press - Macmillan Inc.

1987 Ventaja competitiva: creación y sostenimiento de un desempeño superior. México D. F.: Compañia Editorial Continental [1. a ed. en español].

RAIMBAULT, Nicolas; Marie DOUET y Antoine FRÉMONT

2013 "Logistics Locations - The Joint Dependence between Networks and Territories». En: L'Espace Géographique, vol. 42, N.1, pp. 31-42.

2012 "Logistics Hubs: Between Fixity and Flow». En: Les 4 Pages de Fluide. Marzo. Paris: Université Paris Est y Agence Nationale de la Recherche - Programme de Recherche Fluide.

REINHARDT, Forest L.; Ramon CASADESUS-MASANELL y Frederik NELLEMANN 2012 "Maersk Line and the Future of Container Shipping". En: Harvard Business School Case, 712-449, mayo. Disponible en: <https://wwz.unibas.ch/ fileadmin/wwz/redaktion/Summer_School/2012/Maersk_2012_Reinhardt_ HBS_712-449.pdf>.

ROBINSON, Ross

2005 "Liner Shipping Strategy, Network Structuring and Competitive Advantage: A Chain Systems Perspectiven. En: Research in Transportation Economics, vol. 12, pp. 247-289. 
RODRIGUE, Jean-Paul

2010 "Maritime Transportation: Drivers for the Shipping and Port Industries». En: International Transport Forum 2010, enero. Paris: Organisation for Economic Cooperation and Development.

\section{RODRIGUE, Jean-Paul y Theo NOTTEBOOM}

2011 "Global Networks in the Container Terminal Operating Industry" Port Technology International. [Las páginas citadas en este documento de trabajo corresponden a la versión en PDF disponible en: <http://www.porttechnology. org/images/uploads/technical_papers/10-14.pdf>]>.

2010a «Foreland-Based Regionalization: Integrating Intermediate Hubs with Port Hinterlands». En: Research in Transportation Economics, vol. 27, N. ${ }^{\circ}$ 1, pp. 1-29. [Las páginas citadas en este documento de trabajo corresponden a la versión en PDF disponible en: <http://www.porteconomics.eu/downloads-section/ doc_details/320-2010rterodrigue-a-notteboom.html>].

$2010 b$ "Comparative North American and European Gateway Logistics: The Regionalism of Freight Distribution». En: Journal of Transport Geography, vol. 18, N. ${ }^{\circ}$ 4, pp. 497-507 [Las páginas citadas en este documento de trabajo corresponden a la versión en PDF disponible en: <http://www.researchgate. net/.../Theo_Notteboom/.../0c96052f1e867dc2bd000000.pdf >].

RODRIGUE, Jean-Paul; Theo NOTTEBOOM y Athanasios A. PALLIS

2011 "The Financialisation of the Port and Terminal Industry: Revisiting Risk and Embeddednessı. En: Maritime Policy and Management, vol. 38, N. 2, pp. 191-213 [Las páginas citadas en este documento de trabajo corresponden a la versión en PDF disponible en: <http://www.porteconomics.eu/downloadssection/doc_details/373-2011-mpm-rodrigue-notteboom-pallis.html>].

SÁNCHEZ, Ricardo J.

2012 «Transporte marítimo internacional 2012: ajustes, efectos y lecciones de la mitologían. En: Boletín Marítimo, N. 50, diciembre. Santiago: Comisión Económica para América Latina - Unidad de Servicios de Infraestructura, División de Recursos Naturales e Infraestructura.

SGUT, Martín

2005 "Estudio de los costos y sobrecostos portuarios del puerto del Callao». Enero. Lima: Proyecto Crecer, Apoyo/Usaid. 
$\mathrm{SHY}, \mathrm{Oz}$

2001 The Economics of Network Industries. Cambridge / Nueva York: Cambridge University Press.

SOPPÉ, Martin; Francesco PAROLA y Antoine FRÉMONT

2009 «Emerging Inter-Industry Partnerships between Shipping Line and Stevedores: From Rivalry to Cooperation?». En: Journal of Transport Geography, vol. 17, N. ${ }^{\circ} 1$, pp. 10-20.

TEECE, David. J.

1980 "Economies of Scope and the Scope of the Enterprise». En: Journal of Economic Behavior \& Organization, vol. 1, N. ${ }^{\circ} 3$, pp. 197-293.

UNCTAD

2013 Review of Maritime Transport 2013. Ginebra: United Nations Conference on Trade and Development.

UPV/CAF/IIRSA

2003 «Evaluación de los principales puertos de América del Sur: análisis institucional, técnico y económicon. Estudio conducido por un equipo de la Universidad Politécnica de Valencia (UPV) y financiado por la Corporación Andina de Fomento (CAF), junio. Buenos Aires: Iniciativa para la Integración de la Infraestructura Regional en Sudamérica (lirsa). Disponible en: <http:// www10.iadb.org/intal/intalcdi/PE/2008/01721.pdf>.

VANELSLANDER, Thierry

2008 "Expansion in Cargo Handling: Geographical and Functional Issues». En: Maritime Policy and Management, vol. 35, N. ${ }^{\circ}$ 2, pp. 193-214.

2006 "Co-Operation in Container Handling: What Are the Effects on Economies of Scale?». En: Proceedings of the European Transport Conference, 18-20 de septiembre, Estrasburgo. [Las páginas citadas en este documento de trabajo corresponden a la versión en PDF disponible en: <http://www.balticom.org/ download/reports/Deliverable_3_3.pdf>].

2005 "The Economics behind Co-Operation and Competition in Sea-Port Container Handling". PhD Thesis. Amberes: University of Antwerp-Faculty of Applied Economics. [Las páginas citadas en este documento de trabajo corresponden a la versión en PDF disponible en: <http://media.proquest.com/media/pq/ classic/doc/1158511361(...)>]. 
WERNERFELT, Birger

1984 "A Resource-Based View of the Firm». En: Strategic Management Journal, vol. 5, pp.171-180.

WILMSMEIER, Gordon W.

2013 Liner Shipping Markets, Networks and Strategies: The Implications for Port Development on the West Coast of South America - The Case of Chile. Discussion Paper 2013-22. París: International Transport Forum - Organisation for Economic Cooperation and Development.

WILMSMEIER, Gordon W.; Jason MONIOS y Gabriel PÉREZ

2013 "Port System evolution - The Case of Latin America and the Caribbean». En: IAME 2013 Conference, Paper 57, julio. Marsella, Francia.

\section{Información en portales web}

ALPHALINER

s. f. Portal. Fechas de consulta: varias. <http://www.alphaliner.com/>.

A. P. MØLLER-MAERSK GROUP

s. f. Portal. Fecha de consulta: 14/2/2014. <http://www.maersk.com/pages/default. aspx>.

2014 Share Information, 18 de marzo. Fecha de consulta: 10/3/2014. <http://investor. maersk.com/stockquote.cfm>.

2014 Maersk Line Milestones. Fecha de consulta:24/2/2014. <http://www.maerskline. com/es-pe/about/milestones>.

2013 Share Information, 23 de diciembre. Fecha de consulta: 18/2/2014. <http://investor. maersk.com/stockquote.cfm>.

AGUNSA (Agencias Universales S. A.)

s. f. Portal. Fecha de consulta: 3/3/2014. <http://www.agunsa.com/>.

2006 Agunsa Almacenaje. Fecha de consulta: 10/3/2014. <http://www.agunsa. com/?option=com_content\&task=view\&id=96\& Itemid=10>. 


\section{APM TERMINALS}

2014 "APM Terminals Welcomes New Partner to Callao». En: APM Terminals Media Center, 3 de marzo. Fecha de consulta: 14/3/2014. <http://www.apmterminals. com/uploadedFiles/corporate/Media_Center/Press_Releases/140302\%20 APM\%20Terminals\%20Welcomes\%20TIL\%20to\%20Callao.pdf>.

2010 "APM Terminals Acquires 50\% of New Terminal in Santos». En: APM Terminals Media Center, 18 de agosto. Fecha de consulta: 14/3/2014. <http://www. apmterminals.com/uploadedFiles/corporate/Media_Center/Press_Releases/ 100818\%20_Santos_press_\%20release.pdf>.

\section{CÁMARA CHILENO-ARGENTINA}

2013 Seminario "La vía chilena para las exportaciones argentinas a los mercados del Pacífico", 17 de octubre. Fecha de consulta: 10/3/2014. <http://www. camarco.cl/actividadesOK.php>.

CMA CGM (Compagnie Maritime d'Affrètemnent - Compagnie Générale Maritime) 2013 "CMA CGM, Maersk Line and MSC to Establish an Operational Alliance». En: CMA CGM News \& Media, 18 de junio. Fecha de consulta: 14/3/2014. <https://www.cma-cgm.com/news/1/cma-cgm-maersk-line-and-msc-toestablish-an-operational-alliance $>$.

CCNI (Compañía Chilena de Navegación Internacional)

s. f. Portal. Fecha de consulta: 3/3/2014. <http://www.ccni.cl/>.

2012 Memoria anual 2012. Fecha de consulta: 3/3/2014. <http://200.31.35.125/ images/pdf_investor_relations/2013/memoria.pdf >.

CSAV (Compañia Sudamericana de Vapores)

2012 Memoria y balance anual 2012. Fecha de consulta: 27/2/2014. <http://www. csav.com/es/InvestorRelations/Documents/2012\%20-\%20Memoria\%20 Anual.pdf>.

DREWRY SHIPPING CONSULTANTS LTD.

s. f. Portal. Fechas de consulta: varias. <http://www.drewry.co.uk>.

\section{DRY DOCKS}

s. f. Portal. Fecha de consulta: 25/2/2014. <http://www.drydocks.gov.ae/>. 


\section{DUBAI MARITIME CITY}

S. f. Portal. Fecha de consulta: 25/2/2014. <http://www.dubaimaritimecity.com/>.

\section{DUBAI PORTS WORLD}

S. f. Portal. Fecha de consulta: 26/2/2014. <http://web.dpworld.com/>.

\section{DUBAI WORLD}

S. f. Portal. Fecha de consulta: 24/2/2014. <http://www.dubaiworld.ae/>.

\section{ECONOMÍA Y NEGOCIOS ONLINE}

2008 "La historia de la Compañía Sudamericana de Vapores», 28 de octubre. Fecha de consulta: 10/3/2014. <http://www.economiaynegocios.cl/noticias/noticias. asp?id $=55263>$.

\section{EZW (Economic Zones World)}

s. f. Portal. Fecha de consulta: 25/2/2014. <http://www.ezw.ae/>.

\section{EL COMERCIO}

2012 "Grupo Romero no vendió parte de Ransa porque precio no los convenció», 11 de mayo. Fecha de consulta: 28/2/2014. <http://elcomercio.pe/economia/ peru/grupo-romero-no-vendio-parte-ransa-porque-precio-no-convencionoticia-1492319>.

EMOL

2006 "El Grupo Von Appen y su tradición naviera». Fecha de consulta: 5/3/2014. $<$ http://www.mundomaritimo.cl/noticias/el-grupo-von-appen-y-su-tradicionnaviera>.

GEN (Grupo Empresas Navieras)

s. f. Portal. Fecha de consulta: 3/3/2014. <http://www.gen.cl/>.

\section{ISTITHMAR WORLD}

s. f. Portal. Fecha de consulta: 25/2/2014. <http://www.istithmarworld.com/>.

\section{KRISTIANSEN, Tomas}

2013 "Maersk Line Launches New Alliance with MSC and CMA CGM», 18 de junio. Fecha de consulta: 14/3/2014. <http://shippingwatch.com/carriers/ article5632893.ece>. 


\section{MAERSK}

2013 "World's Largest Ship». Fecha de consulta: 24/2/2014. <http://www. worldslargestship.com/the-ship/\#page/efficiency/shape-of-change>.

MIKKELSEN, Ole

2013 "Denmark's Maersk Changes Ownership Structure to Boost Finances», 17 de diciembre. Fecha de consulta: 18/2/2014. <http://www.reuters.com/ article/2013/12/17/us-maersk-owner-idUSBRE9BG12G20131217>.

NOVOA, Sandra

2012 "Luksic se convierte en el nuevo controlador de CSAV, con el 37,44\%", 16 de febrero. Fecha de consulta: 10/3/2014. <http://diario.latercera. com/2012/02/16/01/contenido/negocios/10-100707-9-luksic-se-convierteen-el-nuevo-controlador-de-csav-con-el-3744.shtml>.

\section{P\&O MARITIME}

s. f. Portal. Fecha de consulta: 26/2/2014. <http://www.pomaritime.com/>.

\section{QUIÑENCO S. A.}

s. f. Portal. Fecha de consulta: 28/2/2014. <http://www.quinenco.cl/esp/>.

RANSA (Reprensa Algodonera y Almacén Nacional)

s. f. Portal. Fecha de consulta: 28/2/2014. <http://www.ransa.biz/ransa.biz/>.

SAAM (Sudamericana Agencias Aéreas y Marítimas)

s. f. Portal. Fecha de consulta: 28/2/2014. <http://www.saam.cl/prontus_saam/ site/edic/base/port/inicio.html>.

\section{SAAM DO BRASIL}

s. f. Portal. Fecha de consulta: 28/2/2014. <http://www.saam.com.br/>.

TIL (Terminal Investments Ltd.) Group

s. f. Portal. Fecha de consulta: 14/3/2014. <http://www.tilgroup.com/>.

\section{TRANSAÉREO S. A.}

s. f. Portal. Fecha de consulta: 28/2/2014. <http://www.transaereo.com/>. 


\section{ULTRAMAR AGENCIA MARITIMA}

s. f. Portal. Fecha de consulta: 5/3/2014. <http://www.ultramar.cl/>.

\section{ULTRAMAR NETWORK}

s. f. Portal. Fecha de consulta: 5/3/2014. <http://www.ultramarnetwork.com/>.

\section{ULTRATUG}

s. f. Portal. Fecha de consulta: 6/3/2014. <http://www.ultratug.com/>.

WASTLER, Allen

2013 "Businesses Eye a Giant Ocean Shipping Alliance», 11 de febrero. Fecha de consulta: 14/3/2014. <http://www.cnbc.com/id/101162806>. 



\section{Anexo: Glosario ${ }^{198}$}

- Acondicionamiento: adecuación de las condiciones de un contenedor. Lo cual incluye las condiciones de temperatura, humedad, etc. en el interior del mismo.

- Agenciamiento: representación de líneas navieras (o de cualquier otro medio de transporte comercial) ante autoridades maritimas, portuarias y aduaneras, para tramitar la documentación y obtener permisos de exportación o importación.

- Almacenamiento: servicio que facilita una instalación, dentro o fuera del puerto, para almacenar la carga; también llamado bodegaje.

- Amarre/desamarre: recoger/soltar las amarras de una nave en las instalaciones portuarias bajo la orden del capitán (y, usualmente, la supervisión del práctico).

- Avituallamiento: servicio de provisión de víveres y otros suministros básicos para la tripulación.

- Break bulk: carga transportada individualmente o en pequeñas cantidades, transportada ni en contenedores ni a granel, sino en bolsas, cajas o barriles.

- Bunkering: traducido al castellano como 'repostaje en alta mar', consiste en el suministro de combustible de barco a barco, mediante embarcaciones gasolineras que se acoplan al costado del barco receptor.

198. Véanse las principales fuentes al final de este glosario. 
- Cabotaje: transporte de carga entre puertos de un mismo país. En sentido amplio, comprende el transporte de personas, mercancías y equipajes a través del territorio de un país.

- Carga a granel: carga sólida o líquida puesta en el vehículo de transporte tal cual y en conjunto, sin separación en el interior del vehículo.

- Carga de proyecto: carga de gran tamaño y peso que implica procesos de planificación y gestión logística específicos a las características del proyecto demandante de la carga.

- Carga fraccionada: un tipo de carga general que consiste en bienes sueltos o individuales transportados en paquetes, sacos o cajas por separado.

- Carga general: denominación genérica que comprende a diversos tipos de carga, en estado sólido, líquido o gaseoso, que puede ser operada en forma fraccionada o embalada, en la medida en que cumpla con requisitos de no representar un riesgo para la salud, no atentar contra la seguridad de quienes la manejan y del medio ambiente, así como de no ser perecedera.

- Carga líquida: denominación usualmente referida al transporte de combustibles, productos químicos y alimentos en estado líquido.

- Chartering: fletar naves alquiladas.

- Conglomerado y holding: un holding es una sociedad o entidad financiera y de inversión conformada por los principales accionistas que controlan un conglomerado, el cual es un conjunto de empresas que operan en distintas actividades económicas.

- Consolidación y desconsolidación de carga: proceso que permite que cargas de diferentes procedencias o dueños puedan ser juntadas o aglomeradas para transportarlas en conjunto y luego separarlas y dirigirlas hacia sus destinatarios finales. Así se estandarizan los procesos por los que pasa la carga y se reducen tiempo y costos de transacción.

- Contenedor: recipiente rectangular de aluminio, acero o fibra de vidrio empleado para el transporte de carga terrestre, marítimo o multimodal. 
Sus dimensiones usuales son 20 pies de largo y 8 de ancho y alto, estándar denominado TEU (twenty-foot equivalent unit). Aunque existen con dimensiones mayores y también los modificados para tipos especiales de carga.

- Corretaje: contrato por el cual se acuerda una comisión por un servicio prestado.

- Cross-docking: preparación de una carga para que no tenga que ser almacenada o recolectada en el muelle, con lo cual su tránsito y consolidación se hace más rápido y menos costoso.

- DTA (declaración de tránsito aduanero): autorización de traslado de carga con suspensión de tributos aduaneros entre el punto de llegada y otro de salida en el interior de un mismo país.

- "Door-to-door»: servicio integral que comprende todas las etapas de la cadena logística, de transporte y distribución de la carga, desde su dueño hasta el cliente final, entre dos o más territorios nacionales o en el interior de uno solo.

- Estiba/desestiba: técnica para colocar/sacar la carga en/de la nave optimizando la seguridad y el uso del espacio. Protege tanto la carga como al buque.

- Extraportuario: se refiere al desempeño, en instalaciones ubicadas fuera del puerto, de operaciones típicas al puerto, tales como almacenaje, consolidación/desconsolidación de carga, etc.

- Flexi-bag: alternativa al tanktainer (véase más abajo); es una bolsa que aísla el líquido transportado para evitar el óxido en el interior del contenedor.

- Forwarder: intermediario que proporciona servicios complementarios al transporte de carga (freight) o a la representación (agenciamiento) de un agente que controla carga. Al freight forwarder también se le conoce como non-vessel operating common carrier (NVOCC) y opera como gestor de las cadenas de abastecimiento y de documentación. 
- Grúa móvil: máquina para levantar y depositar objetos pesados que cuenta con tracción propia para facilitar las operaciones de manipulación de carga en el muelle y con la nave.

- Grúa patio: estructura ubicada en el patio del muelle para operaciones de traslado de carga y objetos pesados. Incluye a las grúas RTG (Rubber Tyred Gantry), que se movilizan por neumáticos a través del muelle.

- Grúa pórtico: aparato de elevación mediante un montacargas instalado sobre una viga y sostenido por dos o más patas, con una estructura de aluminio o acero que permite el traslado de carga contenedorizada de varias toneladas. También se usan en construcción.

- Hinterland: zona geográfica tierra adentro, que constituye el área de influencia de un puerto y de las respectivas empresas marítimo-portuarias.

- Lanchaje: servicio de transporte en lanchas para pasajeros, tripulantes, pilotos, autoridades o en general cualquier usuario para abordarlo o regresarlo a tierra.

- Liner: se refiere a líneas navieras que ofrecen servicios regulares de transporte marítimo, de carga o pasajeros.

- Maestranza de contenedores: taller en el que se ensamblan o reparan las piezas y montajes de contenedores.

- OTM (operación de transporte multimodal): modalidad por la que el dueño de la carga o su representante firma un solo contrato que cubre toda la cadena logística entre el lugar de origen y el destino final de la carga.

- Operaciones de vaciado simultáneo (ITR): agrupación y transporte de carga mediante operaciones simultáneas de inspección, traslado y entrega.

- Operación off shore: en el rubro marítimo, se refiere a la prestación de servicios complementarios al transporte hechos en mar abierto o lejos de la costa. 
- Operador portuario: persona jurídica a cargo de la administración, operación y desarrollo de un puerto o terminal, que ejecuta las correspondientes inversiones en infraestructura o equipos y que realiza o supervisa las operaciones de atención a naves y manejo de carga en el interior de las instalaciones portuarias.

- Paletizado/paletización: disposición de la carga sobre un palé o armazón de madera empleado para su traslado o almacenaje. El proceso facilita la manipulación de la carga y agiliza su transporte al hacerlo estable y uniforme.

- Porteo: traslado de carga dentro de las instalaciones portuarias.

- Power pack (PP): batería de 6 a 9 voltios para equipos que requieren de ese voltaje.

- Practicaje: asesoramiento que hace el práctico del puerto al capitán de la nave para conducirla de forma segura en el espacio de maniobra portuario.

- Proveedor logístico: persona jurídica que provee servicios que componen la cadena de distribución de un producto o carga. En el rubro de transporte marítimo, los principales servicios se pueden dividir entre los provistos a la carga (por ejemplo almacenamiento) y los prestados a la nave (remolcaje, muellaje, etc.).

- Reefer (refrigerated container): contenedor refrigerado para transporte intermodal de carga sensible a la temperatura, alimentado por generadores eléctricos a base de diesel o sistemas de congelamiento con agua.

- Remolque: operación de arrastre que se realiza a una nave en el área del puerto o varada en mar abierto, así como a equipos que no pueden navegar por sí mismos.

- $\quad$ Romaneo: pesaje de carga antes/luego de su embarque/desembarque.

- Sentina: espacio en la parte más baja de la sala de máquinas de una embarcación, cuya función es la de recolectar los líquidos aceitosos y derrames vertidos en el interior de la nave. 
- Tanktainer (tank container): contenedor intermodal de acero cubierto por una estructura aislante de poliuretano y aluminio, utilizado para el transporte de carga a granel.

- Terminal portuario: unidad portuaria básica, compuesta por un muelle para la atención de naves complementado por instalaciones para almacenamiento y manipulación/traslado de la carga. Un puerto puede estar compuesto por uno o más terminales portuarios.

- TEU (twenty-foot equivalent unit): unidad de dimensión estándar de un contenedor, correspondiente a 20 pies de largo y 8 pies de ancho y de alto. Aunque hay contenedores de dimensiones mayores y también modificados para tipos especiales de carga.

- Transporte multimodal: articulación de diferentes modos y medios de transporte, pero bajo el régimen de un solo contrato de transporte.

- Trazabilidad: conjunto de procedimientos que permiten identificar el itinerario y ubicación de un producto en la cadena de suministro.

- Trinca: amarre con el que se sujeta un objeto. En el caso de la trinca de contenedores, hace referencia al servicio de amarre para mantener estable la carga. 


\section{Fuentes del glosario}

ALLIANCE OF THE PORTS OF CANADA, THE CARIBBEAN, LATIN AMERICA AND THE UNITED STATED (AAPA)

2013 Glossary of Maritime Terms. Consultado el 23/7/2014 del sitio web de American Association of Port Authorities: <http://www.aapa-ports.org/Industry/ content.cfm?ltemNumber $=1077>$.

AUTORIDAD PORTUARIA NACIONAL

2013 Navegacion: APN. Consultado el 5/6/2014 del sitio web de APN: <http:// www.apn.gob.pe>.

TRADE PORT

2010 Glossary of Trade \& Shipping Terms. Consultado el 23/7/2014 del sitio web de Trade Port Org: <http://www.tradeport.org/index.php/library/trade-unitsand-terms/127>.

\section{U.S. DEPARTMENT OF TRANSPORTATION}

2008 Glossary of Shipping Terms. Consultado el 23/7/2014 del sitio web de US Maritime Administration: <http://www.marad.dot.gov/documents/Glossary_final. $p d f>$.

\section{VANELSLANDER, T.}

2005 The Economics behind Co-Operation and Competition in Sea-Port Container Handling. Amberes: Universiteit Antwerpen.

WORLD BANK

2007 Port Reform Tool Kit - Glossary of Ports and Shipping Terms. Washington D. C. 